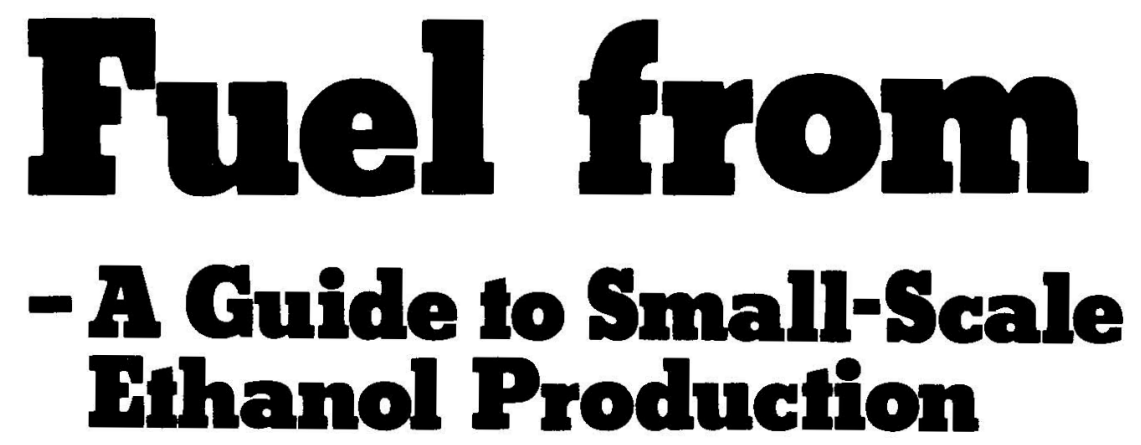

May, 1982
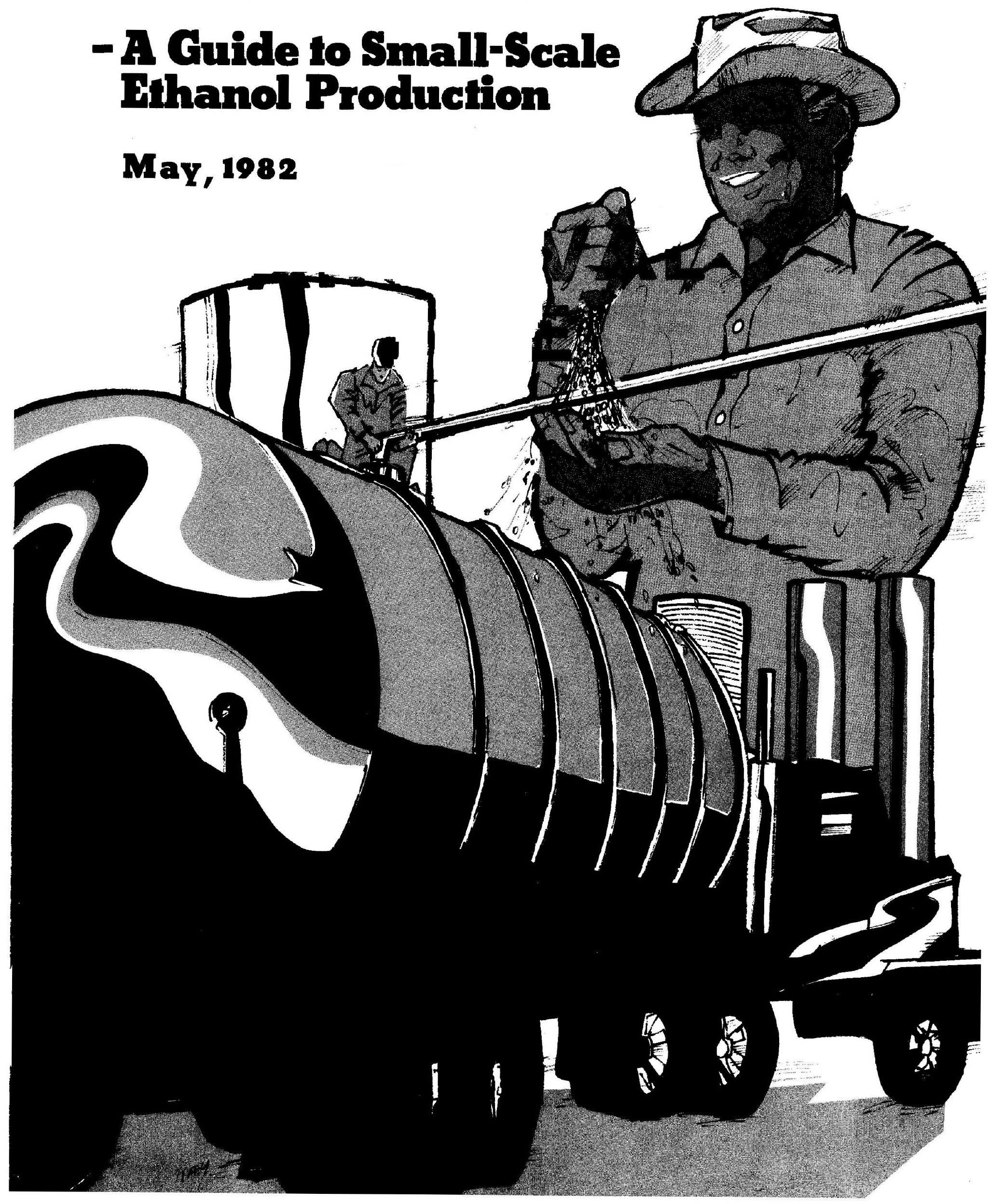


\section{NOTICE}

This guide was prepared as a result of work sponsored by the United States Government. Neither the United States nor the United States Department of Energy, nor any of their employees, nor any of their contractors, subcontractors, or their employees, makes any warranty, express or implied, or assumes any legal liability or responsibility for the accuracy, completeness or usefulness of any information, apparatus, product or process disclosed, or represents that its use would not infringe privately owned rights.

Copies may be purchased from the following sources:

The National Technical Information Service

U.S. Department of Commerce

5285 Port Royal Road

Springfield, Virginia 22161.

Please specify report number SERI/SP-451-519 when ordering.

The Superintendent of Government Documents

U.S. Government Printing Office

Washington, D.C. 20402 


\title{
FUEL FROM FARMS
}

\author{
A Guide to Small-Scale \\ Ethanol Production
}

Second Edition

Sponsored by

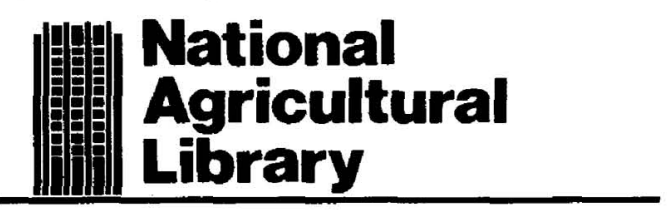

U.S. Department of Agriculture

and the Office of Alcohol Fuels, U.S. Department of Energy

Published by

Technical Information Office

Solar Energy Research Institute

1617 Cole Blvd., Golden, CO 80401

Operated for

U.S. Department of Energy

by the Midwest Research Institute

May 1982 


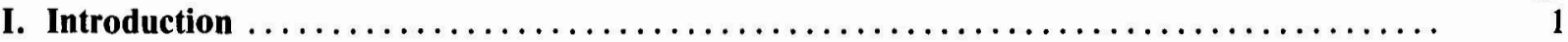

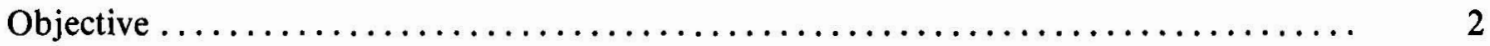

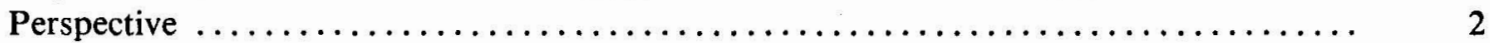

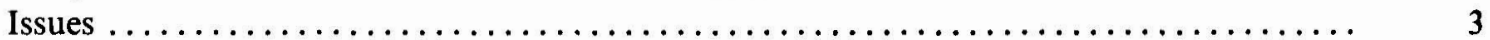

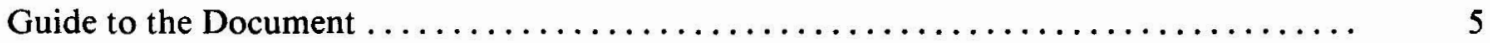

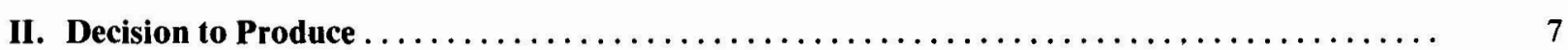

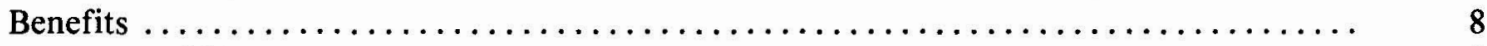

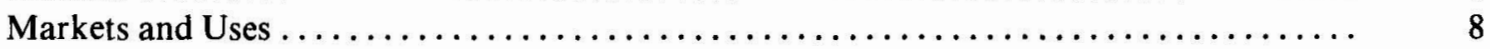

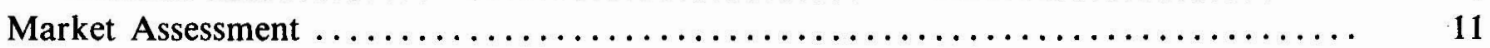

Production Potential ............................................. 11

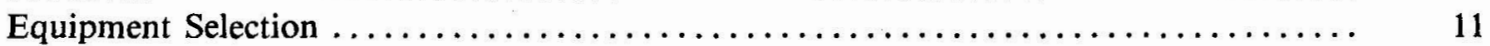

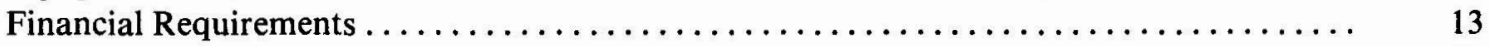

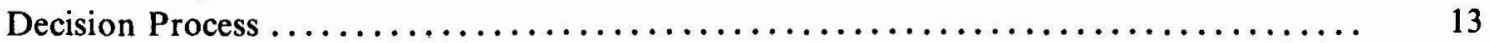

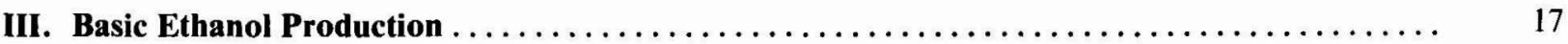

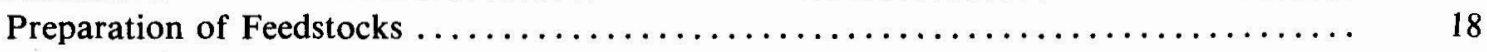

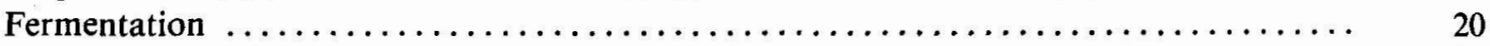

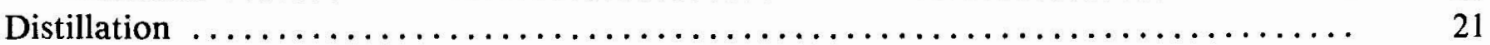

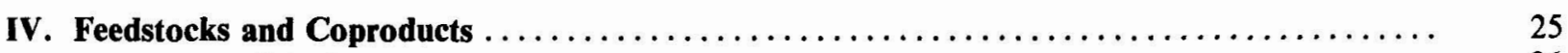

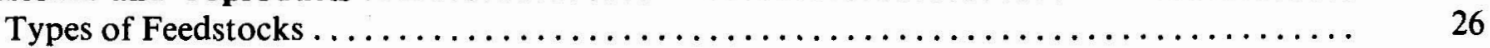

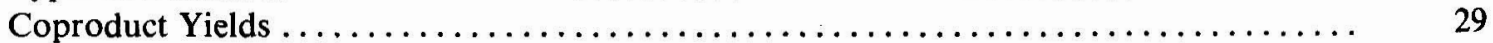

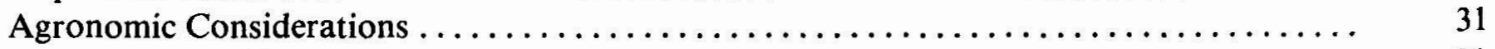

Feedstock Considerations . . . . . . . . 31

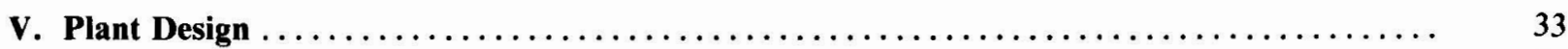

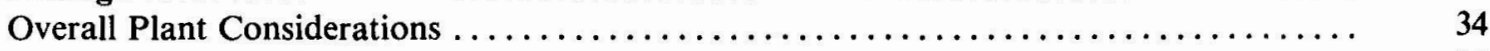

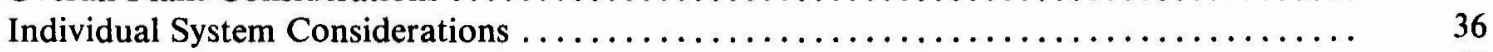

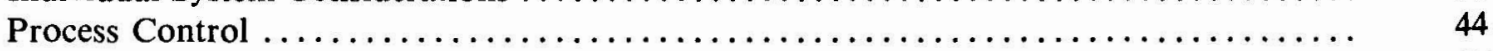

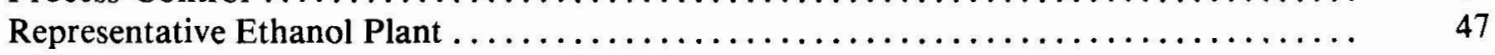

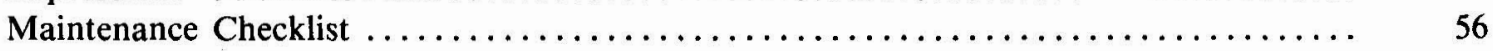

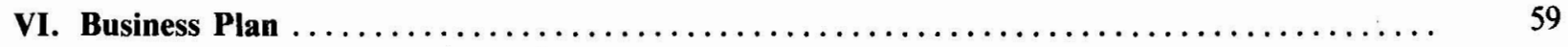

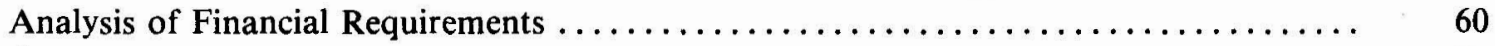

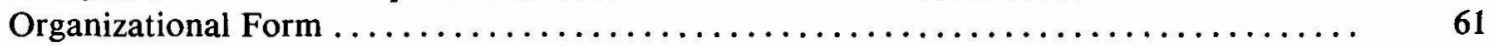

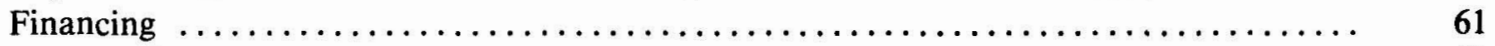

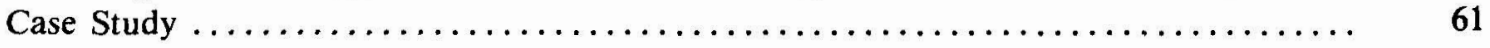

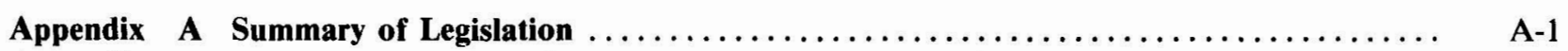

Appendix B Bureau of Alcohol, Tobacco, and Firearms Permit Information $\ldots \ldots \ldots \ldots \ldots \ldots \ldots$ B-1

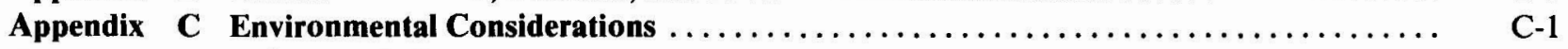

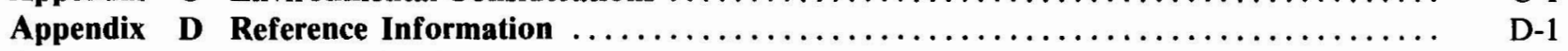

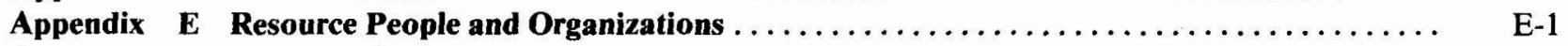

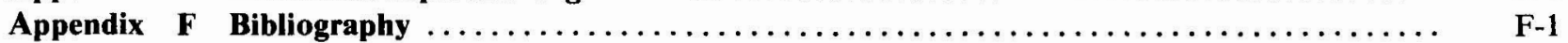

Appendix $G$ Glossary $\ldots \ldots \ldots \ldots \ldots \ldots \ldots \ldots \ldots \ldots \ldots \ldots \ldots \ldots \ldots \ldots \ldots \ldots \ldots \ldots \ldots, G \ldots \ldots \ldots \ldots, 1$ 


\section{LIST OF TABLES AND FIGURES}

Tables

Page

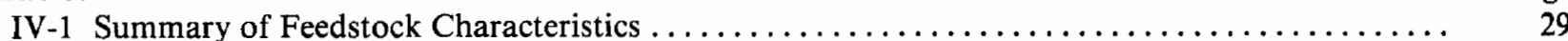

IV-2 Representative Yields of Some Major Domestic Feedstocks $\ldots \ldots \ldots \ldots \ldots \ldots \ldots \ldots \ldots \ldots, 31$

V-1 Heat Source Selection Considerations $\ldots \ldots \ldots \ldots \ldots \ldots \ldots \ldots \ldots \ldots \ldots \ldots \ldots \ldots \ldots \ldots, 36$

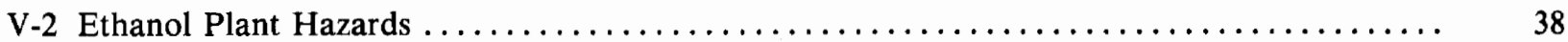

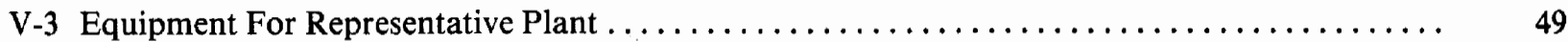

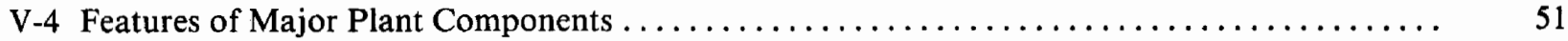

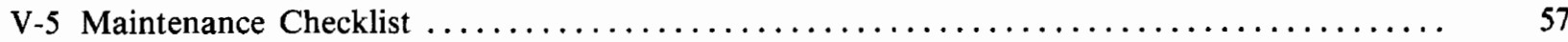

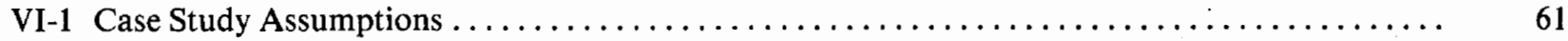

A-1 Summary of State Alcohol Fuel Exemptions . . . . . . . . . . . .

\section{Figures}

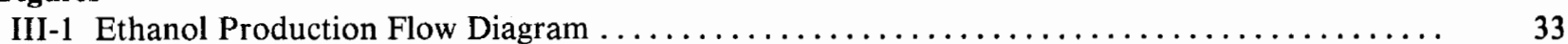

III-2 Basic Process of Successive Distillation to Increase Concentration of Ethanol . . . . . . . . . . . 36

III-3 Schematic Diagram of Sieve Tray Distillation of Ethanol . . . . . . . . . . . . . . . . . . . . 37

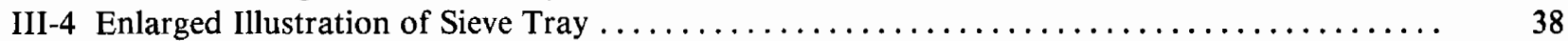

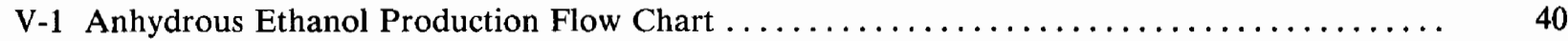

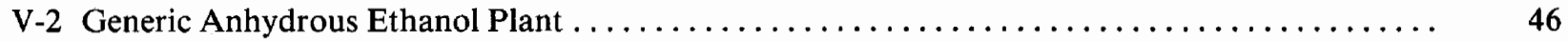

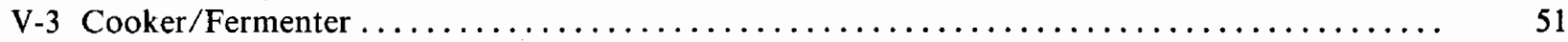

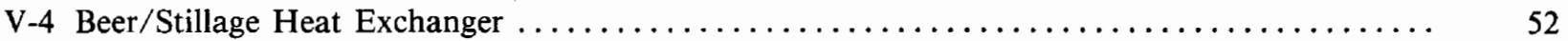

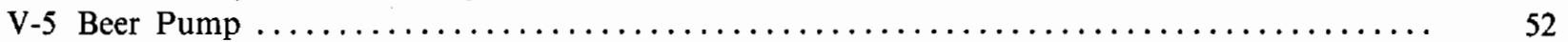

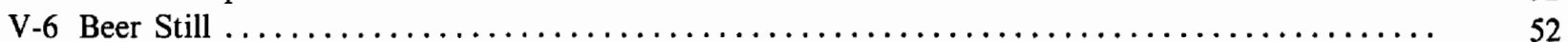

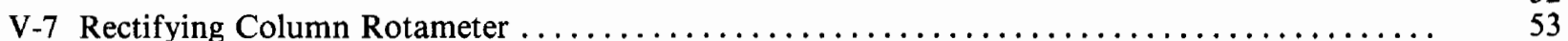

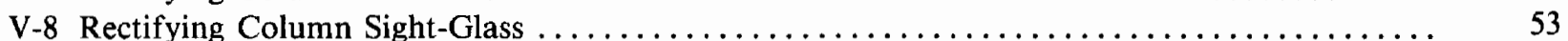

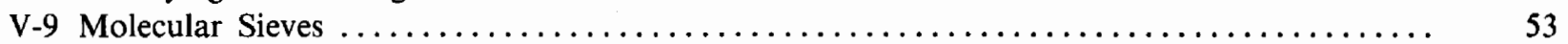

D-1 Ethanol Production System Block Diagram $\ldots \ldots \ldots \ldots \ldots \ldots \ldots \ldots \ldots \ldots \ldots \ldots \ldots \ldots \ldots \ldots \ldots \ldots$ 


\section{ACKNOWLEDGMENTS}

First Edition

The second edition was funded by the U.S. Department of Agriculture under the guidance of Wally Olsen, chief, Field and Special Programs Division. This edition was reviewed by W. C. Fairbank, Northern Agricultural Energy Center and Paul Hersch, SERI Technical Information Office. Publication of this edition was coordinated by Don Petty of the Technical Information Office.

\section{Second Edition}

Mr. Ted D. Tarr, of the U.S. Department of Energy's Division of Distributed Solar Technology, has provided overall policy guidance and direction in the development of Fuel from Farms - A Guide to Small-Scale Ethanol Production.

The Solar Energy Research Institute's Solar Energy Information Data Bank (SEIDB) staff was requested to prepare on a quick-return basis this guide on the small-scale production and use of fermentation ethanol. The effort at SEIDB was directed by Mr. Paul Notari and coordinated by Mr. Stephen Rubin of the Information Dissemination Branch.

The team created by SEIDB represented a cross-section of knowledgeable individuals and consultants familiar with small-scale fermentation ethanol techniques. The team consisted of the following individuals:

Project Manager
Mr. V. Daniel Hunt
TRW Energy Systems Group

\section{Project Editor}

Doann Houghton-Alico

Technical Information Services
Project Technical Director

Mr. Steven J. Winston

Energy Incorporated

\section{Consultants}

Dr. Billy R. Allen

Battelle Columbus Laboratories

Mr. Jerry Allsup

Bartlesville Energy Technology Center

Dr. Mani Balasubramaniam

TRW Energy Systems Group

Mr. William P. Corcoran

Solar Energy Research Institute

Mr. David Freedman

Center for the Biology of Natural Systems

Mr. William S. Hedrick

Consulting Engineer

Mr. Jack Hershey

Environmental Group
Mr. Pincas Jawetz

Consultant on Energy Policy

Mr. Donald M. LaRue

EG \& G Idaho, Inc.

Mr. Robert A. Meskunas

Environmental Group

Dr. Thomas Reed

Solar Energy Research Institute

Mr. Jim Smrcka

Galusha, Higgins and Galusha

Dr. Ruxton Villet

Solar Energy Research Institute

Dr. Harlan L. Watson

TRW Energy Systems Group

This document greatly benefited from the many previous efforts in alcohol fuels including working groups at universities and colleges (such as Colby Community College), private marketing efforts, private research and development projects, and individual efforts to collect and organize information pertinent to alcohol fuels. 


\section{Photographs}

The agricultural photographs are reprinted through the courtesy of Grant Heilman Photography. The photograph on page 9 appears courtesy of the Iowa Development Commission.

\section{Reviewers}

We acknowledge the following individuals for their helpful reviews of the draft of Fuel from Farms $-A$ Guide to Small-Scale Ethanol Production. These individuals do not necessarily approve, disapprove, or endorse the report for which SEIDB assumes responsibility.

Ms. Daryl Bladen

U.S. Department of Commerce

Mr. Ken Bogar

Montana Farmer

Mr. Robert E. Brown

Ohio Farm Bureau Federation

Mr. David L. Feasby

Solar Energy Research Institute

Mr. Charlie Garlow

Public Interest Research Group

Mr. Denis Hayes

Solar Energy Research Institute

Mr. Jack Hill

Ohio Farm Bureau Federation

Mr. William C. Holmberg

U.S. Department of Energy

Dr. T. Q. Hutchinson

U.S. Department of Agriculture

Mr. Edward A. Kirchner

Davy McKee Corp., Chicago

Dr. Michael R. Ladisch

Purdue University

Mr. Herbert Landau

Solar Energy Research Institute
Dr. Leslie S. Levine

U.S. Department of Energy

Dr. Edward S. Lipinsky

Battelle Columbus Laboratories

Mr. Irving Margeloff

Publicker Industries

Dr. Paul Middaugh

South Dakota State University

Mr. Strud Nash

E. F. Hutton \& Company

Mr. Michael H. Pete

Consultant

U.S. Department of Energy

Dr. Bruce L. Peterson

American Petroleum Institute

Mr. E. Stephen Potts

U.S. Department of Energy

Mr. Myron Reamon

National Gasohol Commission

Dr. Clayton Smith

Solar Energy Research Institute

Dr. Jon M. Veigel

Solar Energy Research Institute 


\section{CHAPTER I \\ Introduction}

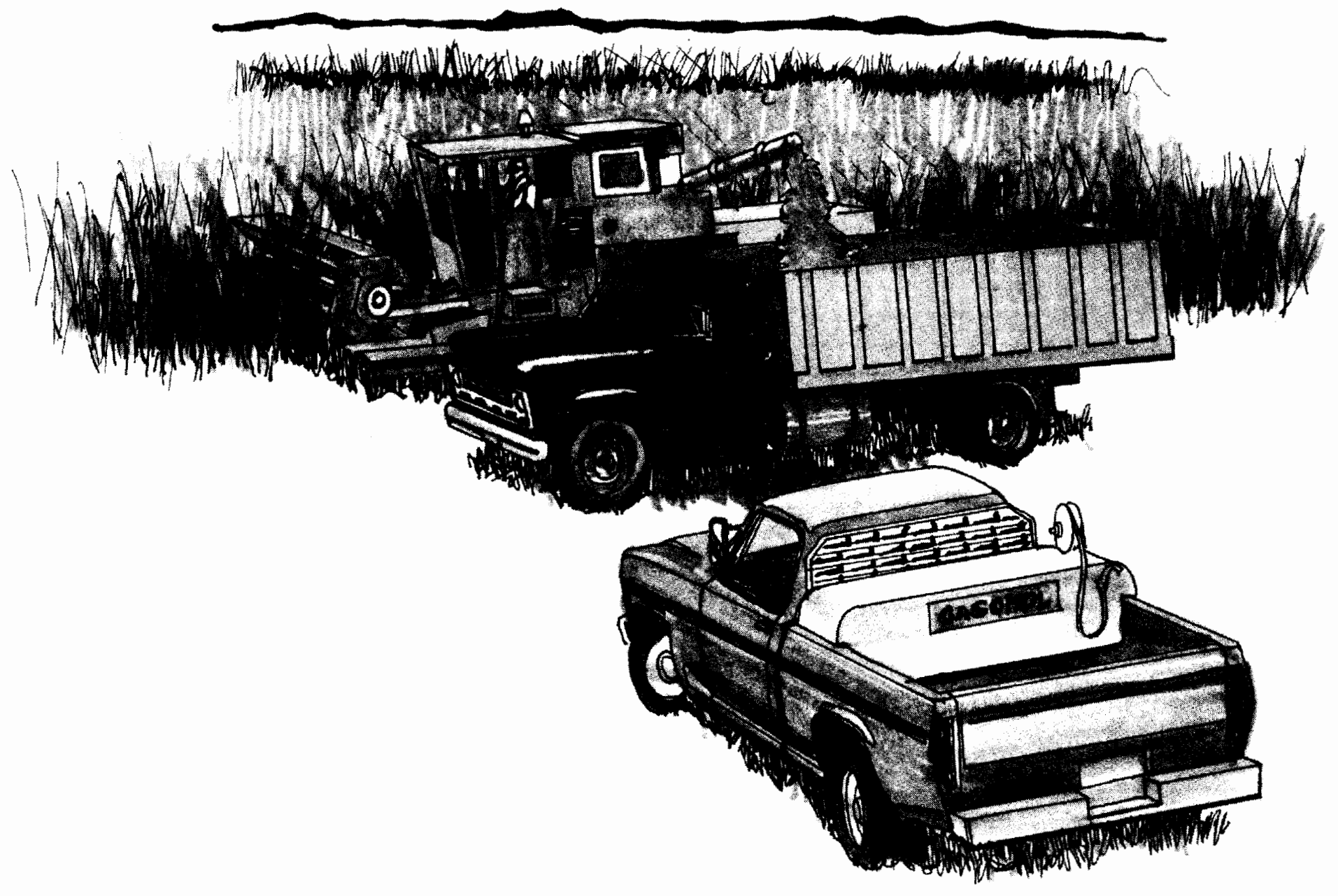




\section{OBJECTIVE}

The expanding support for gasohol in this country over the last several years provides an opportunity to directly reduce U.S. oil imports in the very near future. Interest is evident by the many requests for information about gasohol that are being received throughout the federal government daily. This guide has been prepared to meet the challenge of filling the information void on fermentation ethanol in a balanced, reasoned way, with emphasis on small-scale production of fermentation ethanol using farm crops as the source of raw materials. It is addressed not only to those in the U.S. farming community who may wish to consider the production of ethanol as part of their normal farming operations, but also to owners of small businesses, investors, and entrepreneurs.

This guide presents the current status of on-farm fermentation ethanol production as well as an overview of some of the technical and economic factors. Tools such as decision and planning worksheets and a sample business plan for use in exploring whether or not to go into ethanol production are given. Specifics in production including information on the raw materials, system components, and operational requirements are also provided. Recommendation of any particular process is deliberately avoided because the choice must be tailored to the needs and resources of each individual producer. The emphasis is on providing the facts necessary to make informed judgments.

\section{PERSPECTIVE}

Foreign crude oil imports currently provide the raw material for a considerable portion of the liquid fuels consumed in the United States and represent a cash outflow of millions of dollars per hour. Recent events have dramatically illustrated the substantial economic cost, instability, and economic vulnerability of such imports. Ethanol is a liquid fuel that can substitute domestic renewable resources for petroleum products now.

Fermentation ethanol as a nonpetroleum liquid fuel is attaining widespread use in the United States. This is apparent from the sale of ethanol/gasoline blends.
There has been a redirection in the marketing approach to selling ethanol as a blending agent for gasoline. Through 1980 ethanol primarily was used as a gasoline extender. Today several oil companies are incorporating ethanol into unleaded gasoline in amounts to $10 \%$ as a fuel additive, converting standard, low-octane, lead-free gasoline into a premium-grade fuel.

The use of ethanol in automotive applications has been proven technically and economically. Production of the alcohol in this capacity was 100 million gallons in 1981 . The major share of ethanol used in the automotive market is supplied by a handful of producers.

The petrochemical market for fermentation ethanol, while considerably smaller than the automotive fuel market, is also substantial. Thirty percent of the bulk of industrial-grade ethanol is produced from a petroleum derivative and hence is also a potential candidate for displacement by fermentation ethanol.

The production of ethanol from grain leaves behind a protein-rich stillage. This stillage, used in conjunction with straw, permits reduction in the use of hay and grain, and becomes an excellent, nutritive source of animal feed. Dried stillage, in turn, can also be exported as feed with practically no loss in commercial value.

Existing and proposed federal and state incentives for fermentation ethanol production and use have contributed to the rapid expansion of the gasohol market. In addition, a broad spectrum of options is currently being pursued at the federal level to help accelerate the commercialization of gasohol by stimulating both its production and uses. Maximizing ethanol production will require a mix of various sized ethanol plants. Because of the lag time involved in building and operating larger facilities, it is critical to provide basic information to individuals interested in constructing small-scale facilities-since they can be built most quickly.

The production of fermentation ethanol is based on established technology, and a variety of raw materials is available from the agricultural sector to more than meet projected demands. Fermentation ethanol can be produced from such crops as corn, wheat, sugarcane, 


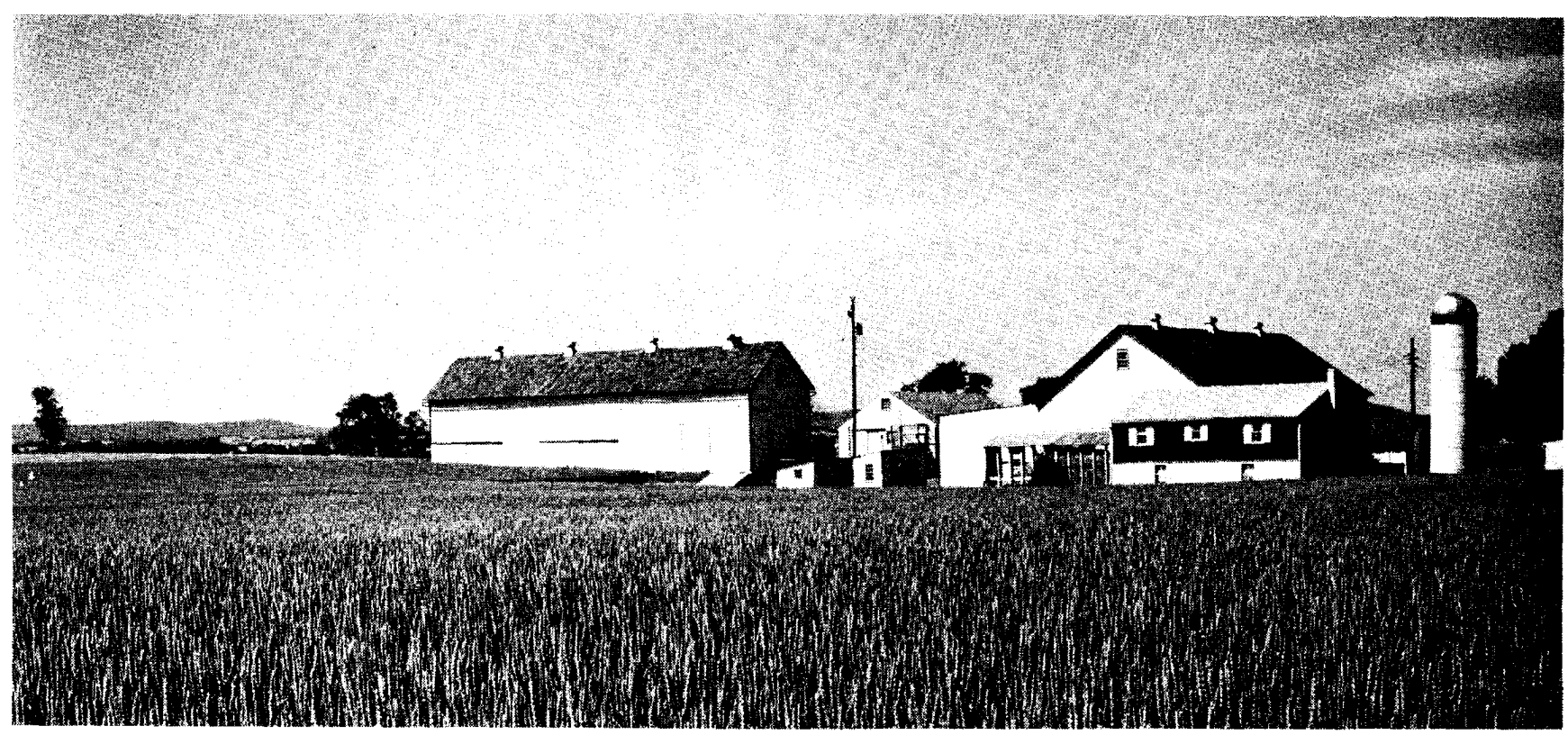

Small-Scale Ethanol Production can be Readily Incorporated into Farm Operations

potatoes, cassava, beets, and Jerusalem artichokes; from agricultural byproducts and wastes; and from cellulose. In short, whatever can be broken down to sugars can become a primary material for fermentation. Thus, the variety of raw materials is quite large. These crops as well as distressed grains are ideal for the production of fermentation ethanol and do not affect the availability of food supplies.

The United States has the potential for growing grains and other crops well in excess of the requirements for domestic and export markets. Economic factors have consequently played a major role in the institution of "set-aside land" and "land diversion" programs by the U.S. Department of Agriculture (USDA). However, growing grain or other crops on this land for fuel production would not detract from the production of food. Rather, if properly utilized, it would constitute a resource that would otherwise have been left idle. Furthermore, the crops grown on this fand can still be held in reserve for emergency food, should that become necessary. In 1978, for example, the USDA has certified that the amount of cropland left fallow was 13.4 million acres under the set-aside program and an additional 5.3 million acres under the diversion program. If this acreage had been cultivated with corn for ethanol production, nearly 3.03 billion gallons of ethanol and 10 million tons of distillers' dried grains (DDG) could have been produced. (This assumes a modest average yield of 65 bushels of corn per acre per year with an average production of 2.5 gallons of 200-proof ethanol and 17 pounds of DDG per bushel of corn.) This is only ethanol produced from land left idle through two specific farm programs. The production of fermentation ethanol is not limited by the extent of this land, and additional unused land as well as some land currently under cultivation can be used for crops for production of fermentation ethanol. All this makes the production of ethanol even more promising, and a conservative estimate for the potential displacement of petroleum is at least several billion gallons per year in the near term.

Belt tightening alone will not help the United States solve the present economic difficulties. Farmers, like everyone else, do not like austerity programs and would rather increase our national wealth. This can be achieved by increasing productivity-the production of more goods and services from every barrel of oil we use and development of new sources of energy.

Clearly, the agricultural sector has a role whose full potential is just beginning to be realized. A farm-based fermentation ethanol industry can provide a decentralized system of fuel production and a measure of energy self-sufficiency for the farm community. This can be accomplished as an integral part of normal farming operations following sound agricultural practices.

The technology for ethanol production has existed for centuries. In the early 1900's, Henry Ford and others in the U.S. auto industry used ethanol as the fuel for automobiles. Ultimately, it was replaced by gasoline, which was much cheaper. Today, the tables appear to be turning once again, this time in favor of fuel derived from renewable domestic resources. There are, however, several underlying issues related to fermentation ethanol production that must be examined.

\section{ISSUES}

In addition to the need to increase the number of ethanol production facilities, there is the concern about the impact of ethanol production on agriculture. The 
production of more ethanol than is obtainahle from surplus and distressed crops will require cultivation of land that is currently fallow or a shift to specialized high-yield crops. The switch to such crops may allow a decrease in use of fertilizers, pesticides, and herbicides, whose production and transport require petroleum fuels and natural gas. This diversification of crops itself offers specific advantages to the farmer, not least of which may be modifications of agricultural practice and new patterns of crop rotation to improve soil fertility. Nongrain forage crops need less fertilizer, herbicides, and pesticides than high-yield grain crops. As commercial processes become available for the small-scale conversion of these crops to ethanol, the opportunity will exist to decrease demands on the soil to achieve production of equivalent value to current crops.

The energy balance of ethanol production and use is a controversial subject. Whether one achieves a net energy gain or loss in ethanol production depends upon where the energy boundaries are drawn and the assumptions used. Examples of alternative means of determining the energy balance in ethanol production are given in Appendix D.

Conversion of crops with significant human food value to fuel is not desirable. Fortunately, production of fermentation ethanol does not make this an "either-or" consideration. Much of the cereal grain (including most of the corn) currently produced in the United States is used as animal feed. While fermentation of cereal grains to produce ethanol uses most of the carbohydrates, almost all of the protein is recovered in the stillage coproduct. This stillage, when dried, can be stored and is nutritionally on a par with such highprotein livestock feeds as soybean meal. This potential application of grain (alcohol/stillage) along with the use of spoiled perishable crops, distressed crops, and marginal crops, provides a feedstock base for ethanol production that requires no displacement of crops for human food.

Since stillage is considered an animal feed replacement for soybean meal (on a protein equivalence basis), there is legitimate concern about its impact on the soybean meal market. However, this concern has to be viewed in the proper perspective. First, the use of soybean meal and cotton seed meal for animal feed was developed after World War II. Their use changed the entire animal feed pattern in the United States and, in the process, displaced grains such as corn, oats, wheat, barley, and high-quality hay. Second, from the general viewpoint of the farm community, agricultural products must be able to compete for markets on an equal footing. Consequently, if stillage proves to be economically and nutritively more attractive than soybean meal, markets for it must be allowed to develop normally. One can thus predict a healthy readjustment of farm production to a new set of conditions that will develop with the introduction of fermentation ethanol.

Another issue is anhydrous ethanol versus hydrated ethanol production. Anhydrous ethanol is more costly and energy intensive to produce than lower proof ethanol. However, if the ethanol is to be sold to blenders for use in gasohol, the ability to produce

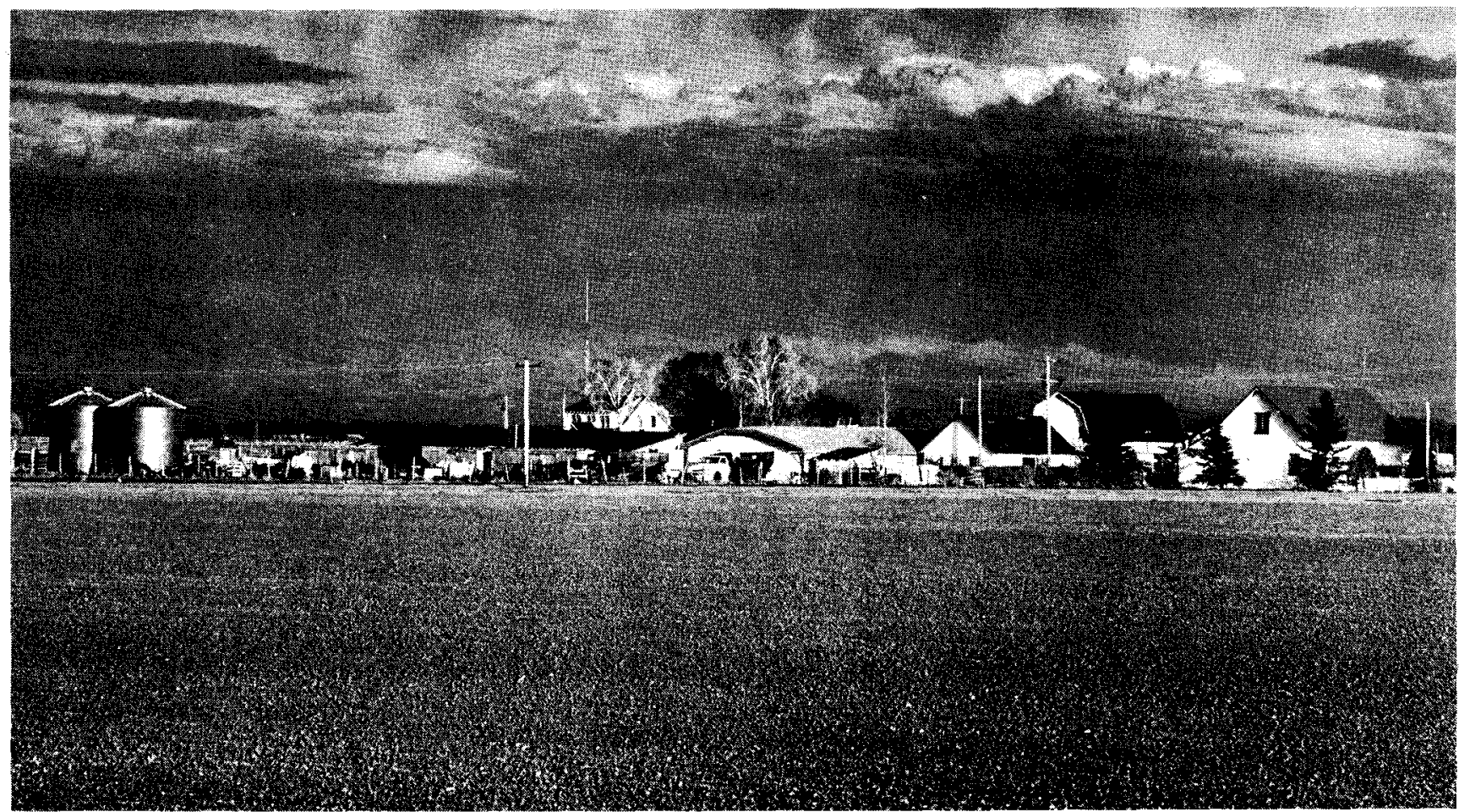

There is Sufficient Land Available to Produce the Quantity of Crops Needed to Achieve Ethanol Production Goals 


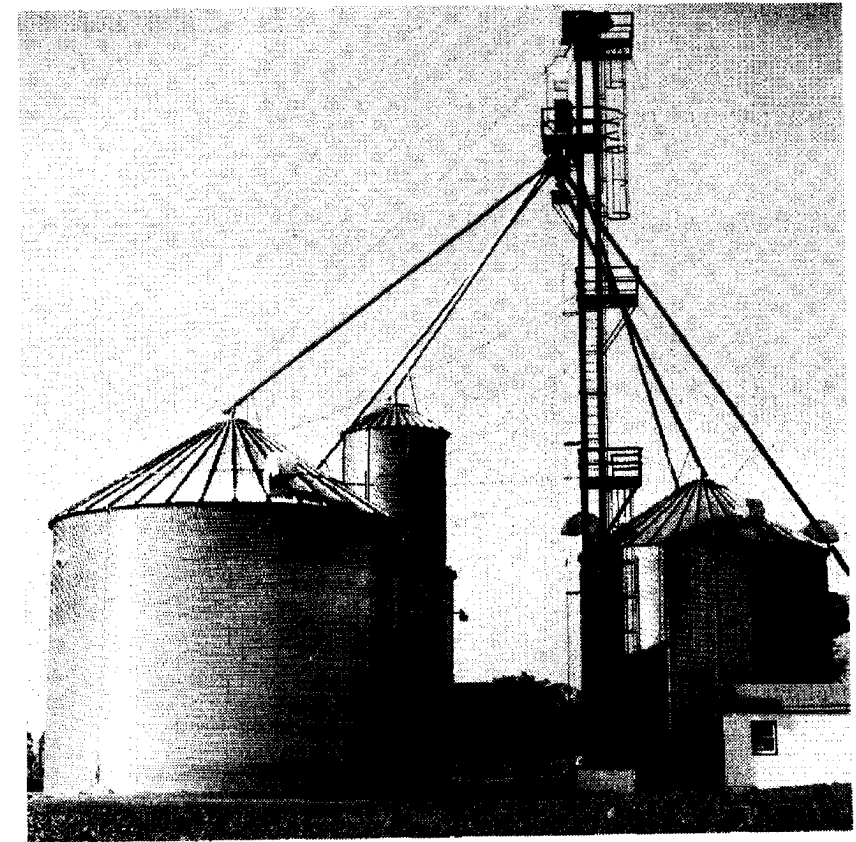

Small-Scale Ethanol Production can Take Advantage of the Types of Crop Storage and Handling Equipment Already in use on the Farm

anhydrous ethanol is mandatory. Hydrated ethanol may be produced for on-farm use or for use in topping cycles.

A final but important issue of concern is the economics of small- and large-scale production of fermentation ethanol. In most production processes, substantial economies-of-scale are realized with higher plant capacity. However, in the case of on-farm fermentation ethanol production, certain economies-of-scale are also present for small-scale production (e.g., lower transportation and capital costs) which may balance the economic advantages of large-scale plants. As a result, small-scale production of ethanol may possibly be achieved with product costs comparable to those from larger plants. Thus, there appears to be a future role for both small- and large-scale plants for the production of fermentation ethanol.

\section{GUIDE TO THE DOCUMENT}

A detailed consideration of the several factors briefly discussed above is presented in the six chapters and appendices that follow.

A decision process to determine the feasibility of onfarm production of ethanol is developed in Chapter II, with emphasis on the market for ethanol and what must be done to participate in it profitably. The sequential steps involved in this process are presented in planning and decision worksheets.

Ethanol production operations are described in Chapter III to indicate how the conversion of agricultural products proceeds through the various stages. Feedstock considerations are discussed in Chapter IV with particular attention to alternate crops, their ethanol yield potentials, and overall implications of their respective agricultural requirements. Ethanol plant design considerations are treated in detail in Chapter V. They include (1) farm-related objectives and integration of ethanol production with normal farming operations; (2) plant design criteria and functional specifications; and (3) energy, labor needs, process control, and safety aspects, and the inherent tradeoffs between them. The information developed is then applied to the design of a representative, small-scale fermentation ethanol production plant, with an output of 25 gallons of anhydrous ethanol per hour. All major operational features are addressed, including the requirements for system control, record keeping, and maintenance. This representative plant is intended to serve as a model from which an actual facility can be designed, built, and operated.

Chapter VI follows with a detailed preparation of a business plan for building the 25-gallon-per-hour facility. The business plan draws on information developed in Chapter V. Its purpose is to determine the financial obligations of the farm owner and the profitability of the enterprise, both of which are essential to obtain necessary financing for construction and operation. Alternative sources of financing available to the small-scale farmer are described and their special requirements are identified. As in Chapter $\mathrm{V}$, the material in Chapter VI is intended to serve as a basis from which an actual business plan can be prepared.

The appendices complete the handbook. They provide a description of current regulations and legislation at the federal and state levels concerning fermentation ethanol production; information on plant licensing and bonding requirements enforced by the Bureau of Alcohol, Tobacco, and Firearms; discussion of the environmental considerations that apply to on-farm production of ethanol; reference data and charts; lists of resources, both people and information; a bibliography; and a glossary. 


\section{CHAPTER II}

\section{Decision to Produce}

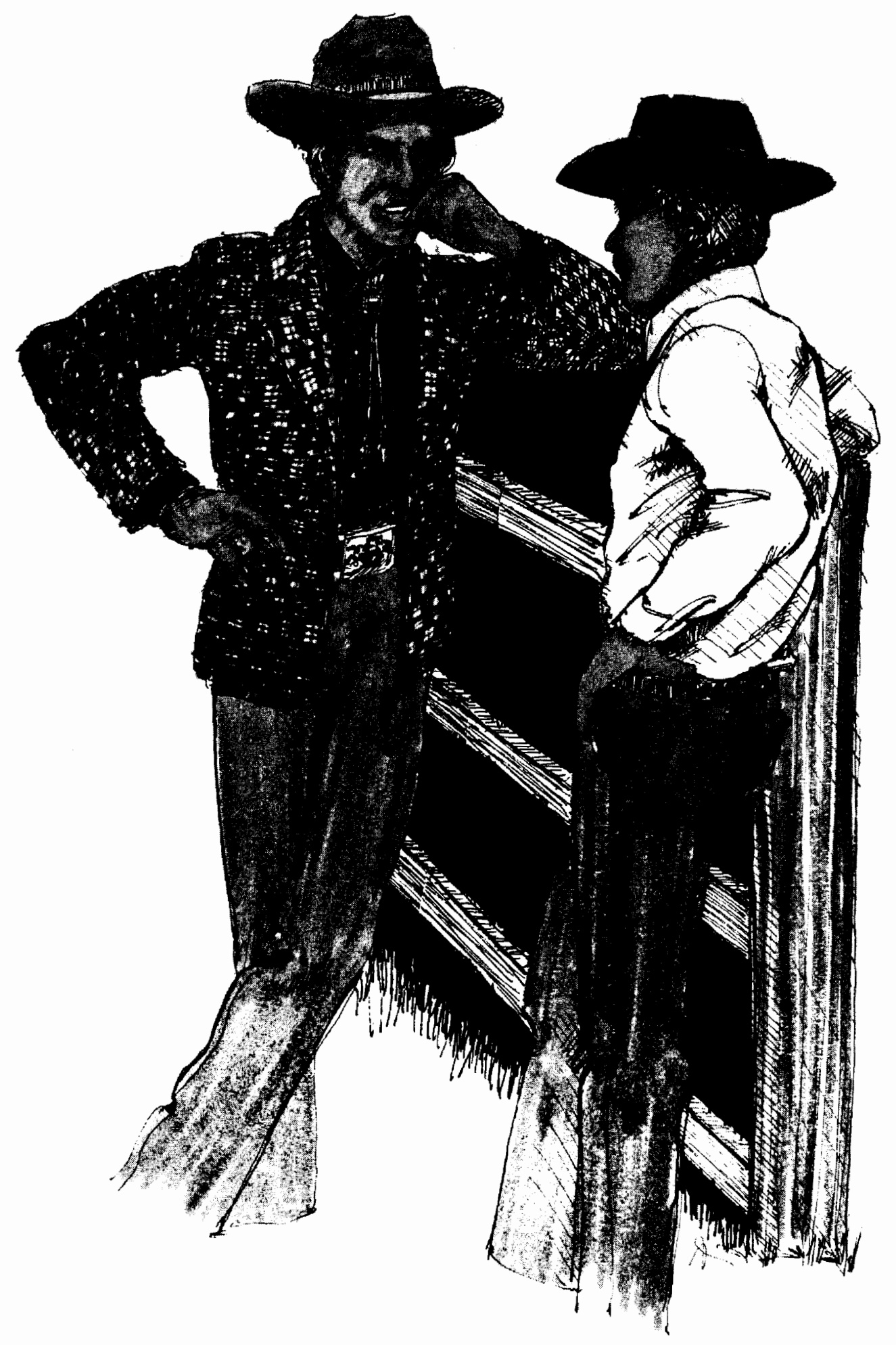




\section{CHAPTER II \\ Decision To Produce}

Expanding farm operations to include a fermentation ethanol plant is ultimately a personal decision. Information can be collected and planning tools used to provide a foundation for such a decision. Market uses and assessment for fuel ethanol and stillage as coproducts, production potential, equipment selection, and financial requirements are the four major areas to be considered in this chapter, which, with succeeding chapters as building blocks, is intended to set up the tools for the decision-making process.

Market values can be estimated for all the products and used as a basis for evaluating the profit potential, which can then be examined in relation to the complete farm operation. Direct considerations affecting production potential, such as how much feedstocks can be grown and how much ethanol can be produced, are also examined. The decision and planning worksheets at the end of this chapter can be used as a step-by-step tool for reaching a decision on whether or not to develop a small-scale, on-farm fermentation ethanol plant.

In addition to the direct factors examined in the worksheets there will be intangible considerations, such as a desire for on-farm fuel self-sufficiency.

\section{BENEFITS}

There are three areas in which there are benefits to the farm economy from small-scale, on-farm, ethanol production. These are direct sales, on-farm uses, and indirect farm benefits.

Farm-produced ethanol sold for profit provides an alternative market for farm commodities. It can provide a "shock absorber" for excess production and a "fall back position" if unforeseen events adversely affect crop or yields.

Farming, perhaps more than any other single occupation, offers the opportunity for self-reliance. The onfarm production of ethanol expands this opportunity. Ethanol can be used in farm equipment as a blend with gasoline in spark ignition engines, as anhydrous or hydrated ethanol fuels in modified spark ignition engines, as a blend with diesel fuel in diesel engines, and as a dual-carbureted mixture with water in diesel turbochargers to enhance efficiency. Protein coproducts, such as stillage, can be fed to farm animals as

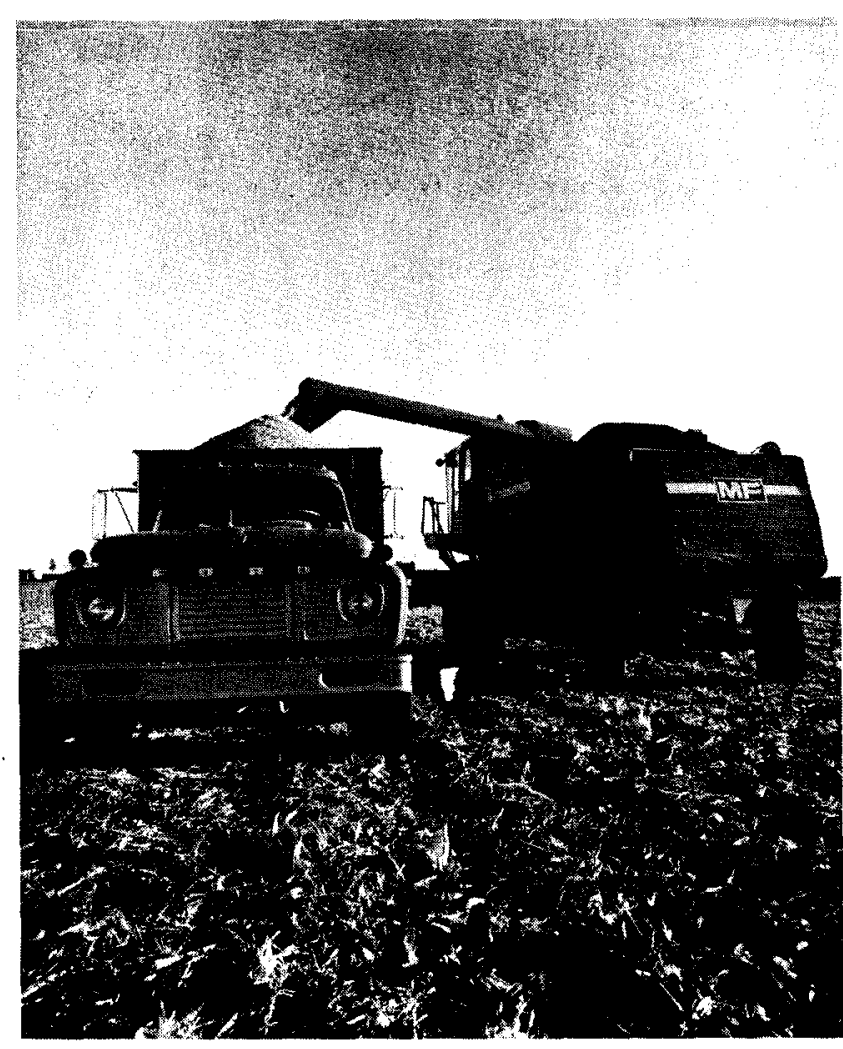

With Proper Modification, Straight Ethanol can be Used in Either Gasoline- or Diesel-Powered Farm Equipment

a replacement for other protein sources. Cellulosic coproducts, if sufficiently dry, can be burned as fuel.

Farm overproduction is generally planned to meet anticipated demand in the event of possible reductions in crop yield. However, the cumulative result of consistent overproduction in the absence of alternative markets is depressed commodity prices. Consequently, the financial health of many farms depends on the opening of new markets. Fermentation ethanol production provides several alternative markets for a broad variety of farm commodities.

\section{MARKETS AND USES}

\section{Ethanol}

The use of ethanol for fuel in internal combustion engines is not a new concept. Engines built around the turn of the century used ethanol for fuel. Henry Ford offered automobiles capable of operating on either ethanol or gasoline [1]. With the development of equip- 
ment capable of economically extracting and refining petroleum early in this century, gasoline became the more practical fuel and further development of fuelgrade ethanol was shelved. Now that the production from domestic petroleum reserves is becoming more costly and difficult to develop and foreign oil is at a premium, the nation is looking to displace some petroleum-based fuels and chemicals.

The forms in which ethanol can be used for fuel are as

- various ethanol-gasoline blends,

- hydrated (lower proof) ethanol,

- straight anhydrous ethanol, and

- dual-carbureted diesel fuel supplement.

Ethanol-Gasoline Blends. The market for gasohol (a blend of $90 \%$ unleaded gasoline and $10 \%$ agriculturally derived anhydrous ethanol) is already well established in many parts of the country. It is expected that considerably more ethanol production capacity could be made available to make gasohol, within a few years, increasing volume by several fold.

Hydrated Ethanol. Hydrated ethanol can be burned efficiently in spark-ignited internal combustion engines with minor alterations to the engine. Regular motor vehicle engines have been successfully modified to run on ethanol. The jet size in the carburetor needs to be enlarged slightly when converting from a gasoline to an ethanol-powered engine because ethanol contains less useful thermal energy per unit volume than gasoline. Accordingly, more ethanol than gasoline must be introduced into an engine to generate the equivalent amount of energy. With most engines, it is also necessary to modify the intake manifold to insure proper vaporization of the ethanol so that all cylinders will be operating with equal air-fuel mixtures. There are many possible methods for doing this, such as installing preheaters in the fuel system or enlarging the heat stove on the exhaust manifold, with accompanying adjustment of the heat stove control gate for the higher temperature requirement. However, none of these systems is commercially available. However, problems associated with the burning characteristics of the ethanol-water mixture can complicate performance and become a serious impairment as the concentration of water increases.

Anhydrous Ethanol. Anhydrous ethanol can be burned directly in spark-ignition engines using essentially the same engine modifications discussed above for the use of hydrated ethanol. However, hydrated ethanol is less costly and it is not likely that anhydrous ethanol would

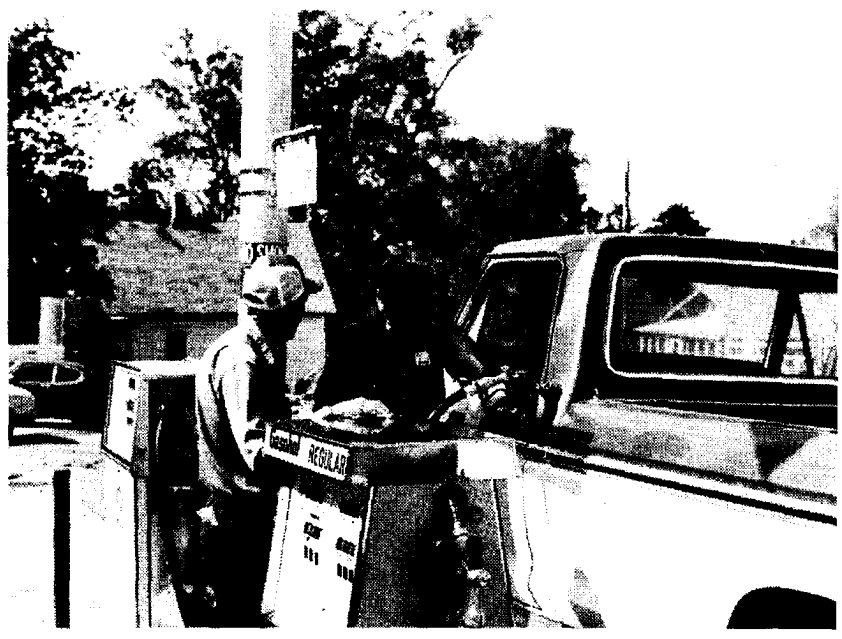

Anhydrous Ethanol can be Blended With Gasoline for Direct Use in Unmodified Vehicles

find extensive use as motor fuel. Its primary use is likely to be as an additive to gasoline to produce gasohol.

In the United States, gasohol usage has been demonstrated in a large number of tests to be a motor fuel essentially equivalent to gasoline. Gasohol does have less total thermal energy per unit volume than gasoline, however, no significant decrease in terms of "miles per gallon" results from the use of gasohol.

The addition of ethanol to gasoline increases the octane rating of the mixture because anhydrous ethanol is a high-octane fuel. In the past, the octane of fuels was increased by adding tetraethyllead. Because the lead compounds have significant adverse impacts on the environment, the conversion to unleaded gasoline was mandated. The changes in refinery operations that are required to produce fuel of the same octane without lead reduce the quantity of fuel that can be produced from a barrel of crude oil. This is because the chemical constituency of the gasoline is altered by reforming lower hydrocarbons to increase the percentage of octaneboosting aromatic compounds. This reforming process consumes additional energy in the refining processenergy directly lost from every barrel processed. The addition of ethanol to gasoline effectively gives the required octane boost and the reforming requirement is correspondingly reduced. This means that every barrel of gasohol produced decreases crude oil demand not only by the quantity of gasoline directly replaced by ethanol, but also by the crude oil saved due to the value of ethanol as an octane enhancer [2].

The use of a mixture of hydrated ethanol and unleaded gasoline can lead to complications. Mixtures of water, ethanol, and gasoline can encounter problems when the three components do not remain in solution. Depending upon the amount of water, the characteristics of the gasoline, and the temperature, two distinct phases can 


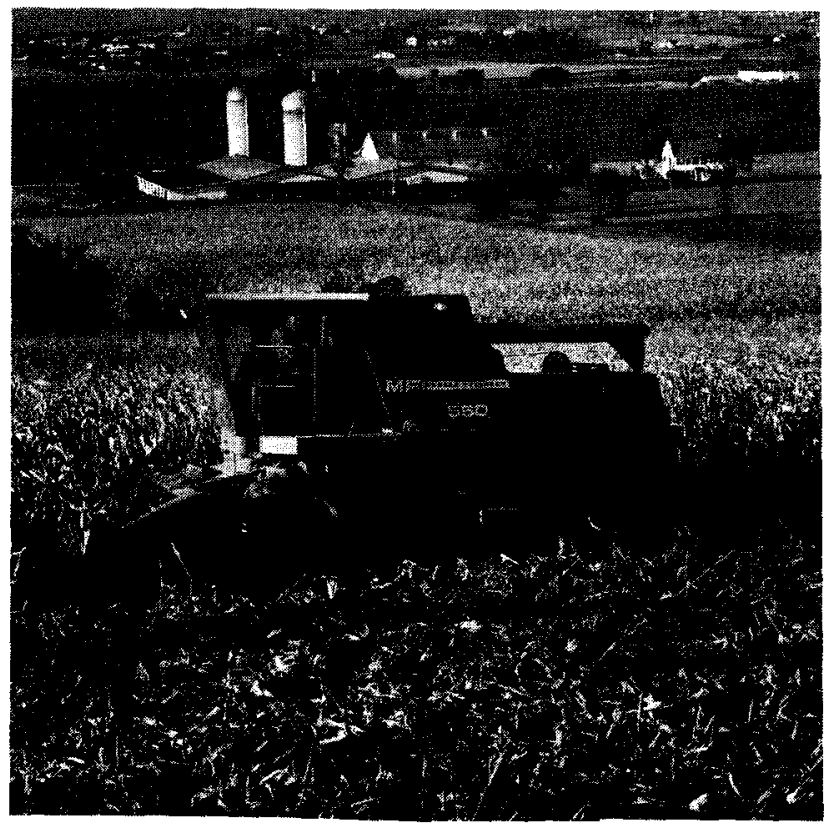

Corn Stover can be Burned to Provide the Heat Needed for Ethanol Production

separate out. When this separation occurs, the upper phase (layer) is comprised of gasoline and the lower phase (layer) is comprised of water and most of the ethanol. Because the air-fuel requirements are different for the ethanol and gasoline fuels, vehicle operations will not be satisfactory if the fuels separate. Heating and agitating these two phases will cause them to go back into solution, but subsequent cooling will result in phase separation again.

Data from tests on gasohol used in vehicles in Brazil and domestically in Nebraska, Iowa, Indiana, and other states indicate no adverse effects on engine life.

Dual-Carbureted Diesel Fuel Supplement. Diesel engines can operate on separately carbureted ethanol and diesel fuel. When low-quality diesel fuel is used, the amount of ethanol injected is generally less than $25 \%$. When the intent is to reduce "diesel smoke" and increase power, the amount of ethanol used can range as high as $50 \%$ [3].

Industrial Chemical Feedstocks. The chemical industry consumes large quantities of ethanol either as a basic feedstock or for use as a solvent. Most of the ethanol currently used by industry is produced from petroleumor natural gas-derived ethylene. Thus, the cost of ethylene conversion to ethanol is a direct function of petroleum and natural gas costs. As petroleum-derived ethanol costs continue to increase, industrial consumers will look for less expensive sources of ethanol. The current selling price of ethanol produced in this manner is in excess of $\$ 1.80$ (plus shipping) per gallon [4]. These markets are highly localized and generally far removed from rural areas.
The largest industrial chemical markets in the United States are for acetic acid and ethylene because of their wide use in the production of polymers. Ethanol can be catalytically dehydrogenated to ethylene, which, in turn, may be polymerized to plastics. Acetates (acetic acid polymers) constitute the raw material for synthetic fabrics, plastics, and an enormous variety of common products. Ethanol can be fermented directly to acetic acid (this is what happens when wine turns to vinegar). Acetic acid is also a byproduct of ethanol fermentation. Hence, consideration may be given to recovery of this material.

The pharmaceutical industry also consumes large quantities of ethanol for use as solvent. The quality control requirements for this market are extremely stringent and the costs of producing a pure product (not just anhydrous, but free of fusel oils and other contaminants) is quite high.

Fermentation ethanol has replaced a significant portion of petroleum-derived ethanol in India and Brazil $[5,6]$. In fact, ethylene is produced from fermentation ethanol in these countries. Similar programs are being developed in the Philippines, South Africa, Australia, and other countries, and it is reasonable to assume that such a development could also occur in the United States.

Other Uses. Other possible uses of ethanol are as fuel for

- crop drying,

- general heating, and

- electricity generation with small generators.

\section{Coproducts}

Stillage can be fed to farm animals as a protein supplement either whole (as produced), wet (35\%-60\% solids), solid (screened), or dry. The stillage from cereal grains ranges from $26 \%$ to $32 \%$ protein on a dry basis. The basic limitation on the amount that can be fed at any one time to an animal is palatability (acid concentration caused by drying makes the taste very acrid). Mature cattle can consume about 7 pounds of dry stillage per day or, roughly, the stillage resulting from the production of 1 gallon of ethanol. The feeding of whole stillage is limited by the normal daily water intake of the animal and the requirements for metabolizable energy and forage fiber. The feeding value to swine and poultry is somewhat limited. Wet stillage cannot be stored for long periods of time unless stored under $\mathrm{CO}_{2}$ or ensiled with added cellulosics to give $50 \%-60 \%$ solids, and the lack of locally available herds of animals to consume it may lower its value. Stillage from grains contaminated with aflatoxins cannot be used as animal feed.

The cellulosic coproducts may be directly fermented to produce methane gas or dried for use as boiler fuel. 
Carbon dioxide $\left(\mathrm{CO}_{2}\right)$ produced by fermentation can be compressed and sold to users of refrigerants, soft drink bottlers, and others. It also has many agricultural applications which are beyond the scope of this handbook.

\section{MARKET ASSESSMENT}

Before a decision to produce can be made, it is necessary to accurately determine if markets for the ethanol and coproducts exist close enough to allow for economical distribution. The size of the market is defined by the quantities of ethanol and coproducts that can be used directly on the farm and/or sold. The ethanol on-farm use potential can be determined from the consumption of gasoline and diesel fuel in current farming operations. Then, a decision must be made on the degree of modification that is acceptable for farm equipment. If none is acceptable, the on-farm use will range from $10 \%$ to $20 \%$ of the total gasoline consumption. If direct modification to spark ignition equipment is acceptable, the on-farm potential use can be $110 \%$ to $120 \%$ of current gasoline consumption. If the risks associated with attempting undemonstrated technology are considered acceptable, the ethanol replacement of diesel fuel will be roughly $50 \%$ of current diesel fuel consumption [3].

The sale of ethanol off the farm will be dependent upon local conditions and upon the type of Bureau of Alcohol, Tobacco, and Firearms (BATF) license obtained. (Currently, a commercial license from BATF is required for off-farm sale of ethanol.) Market estimates should be based on actual letters of intent to purchase, not an intuitive guess of local consumption.

The on-farm use of stillage must be calculated on the basis of the number of animals that are normally kept and the quantity of stillage they can consume.

The potential for sale of stillage must be computed on the basis of letters of intent to purchase, not just on the existence of a local feedlot. The value of stillage will never exceed the directly corresponding cost of protein from other sources.

Direct on-farm use of carbon dioxide is limited; its principal value may come from sales. If Jerusalem artichokes, sorghum, or sugarcane are used, the bagasse and fiber that remain after the sugar is removed may be sufficient to supply the entire energy requirements of the ethanol plant. This value should be calculated in terms of the next less expensive source of fuel.

\section{PRODUCTION POTENTIAL}

\section{Feedstocks}

The mix of feedstocks determine in part the actual production potential. Chapter IV discusses the use and production of the various feedstocks individually and in

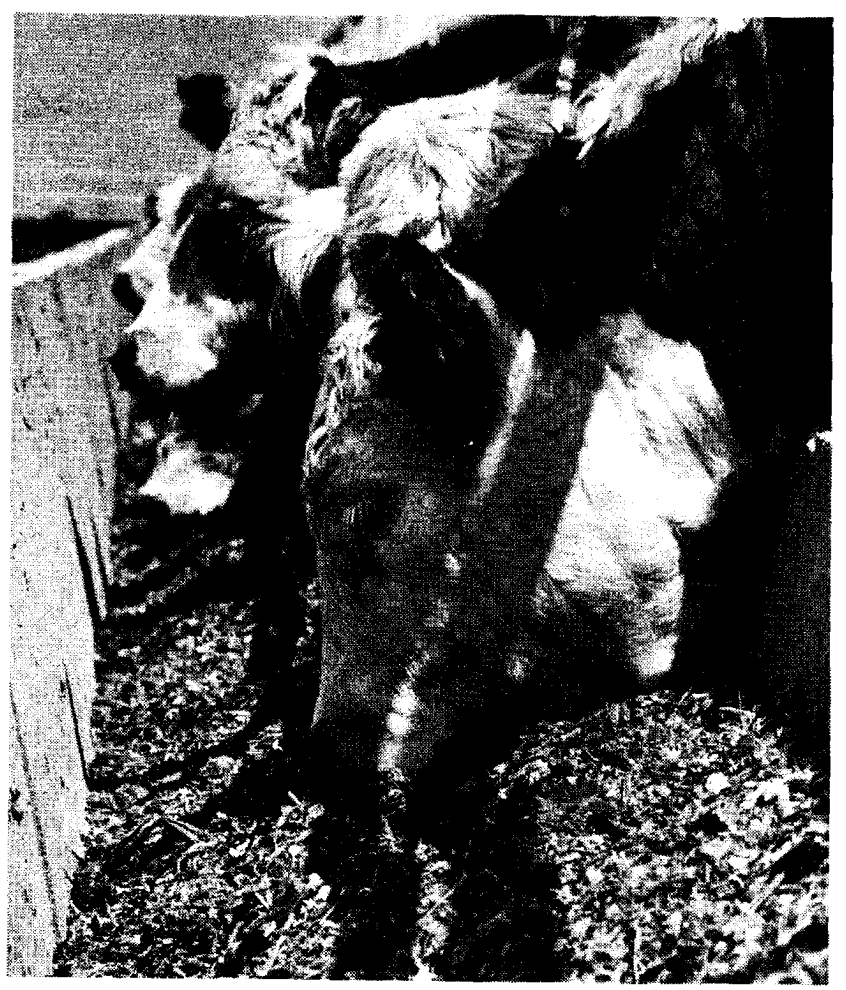

Stillage can be Used as a Protein Supplement When Mixed With the Proper Quantities of Grain and Forage

combination. The guidance offered in that chapter will help define the sizing of the plant from the viewpoint of output once the potential of the available feedstocks is determined. Additional feedstocks may also be purchased and combined with products available on-site.

\section{Water}

Significant amounts of water are used in the ethanol production process (about 16 gallons of water per gallon of ethanol produced). This demand includes requirements for generating steam, cooling, and preparing mashes. Also, it may be desirable to grow a crop not normally produced in the area. If additional irrigation water is necessary for this crop, the increment must be included, but it is likely that stillage liquids can be directly applied to fulfill this need.

\section{Heat Sources}

Heat is required in the conversion of feedstocks to ethanol, primarily in cooking, distillation, and stillage drying. An accurate assessment must be made to determine the type and quantity of available heat sources. Waste materials can contribute as energy sources and, from a national energy perspective, the use of petroleum fuels is not desirable. In some cases, other renewable sources of energy such as methane, solar, wind, and geothermal may be used as supplements.

\section{EQUIPMENT SELECTION}

The determination of the best equipment that can be obtained to fill the defined production needs is based on 
the operation's financial constraints and the labor and/or product compromises that can be made. All the options must be considered in relation to each other rather than independently.

The following variables related to equipment selection affect the decision to produce.

\section{Labor Requirements}

The availability of labor determines the schedule of plant operations and the degree of automation required. Labor availability is determined from normal farming routine and the disruptions which are tolerable.

\section{Investment/Financing}

Financing is a pivotal factor in the decision to produce. The options chosen depend initially upon capital and operating costs (which are in turn dependent upon plant size), and on individual financial situations. The potential income from the operation is the second line of consideration. An inability to qualify for capital financing makes consideration of succeeding concerns a futile exercise.

\section{Maintenance}

Equipment maintenance varies in relation to the type of component and its use. In general, it can be assumed that the highest quality equipment will cost the most. Critical components should be identified and investments concentrated there. Noncritical or easily replaceable components can be less expensive. Routine maintenance should not interfere with production schedules.

\section{Regulations}

State and federal environmental protection standards must be observed. In addition, the Bureau of Alcohol, Tobacco, and Firearms (BATF) bonding requirements and regulations must be met. (See Appendix B for more information.)

\section{Intended Use}

Equipment must be selected that is capable of producing the quality, quantity, and form of coproducts dictated by the intended market.

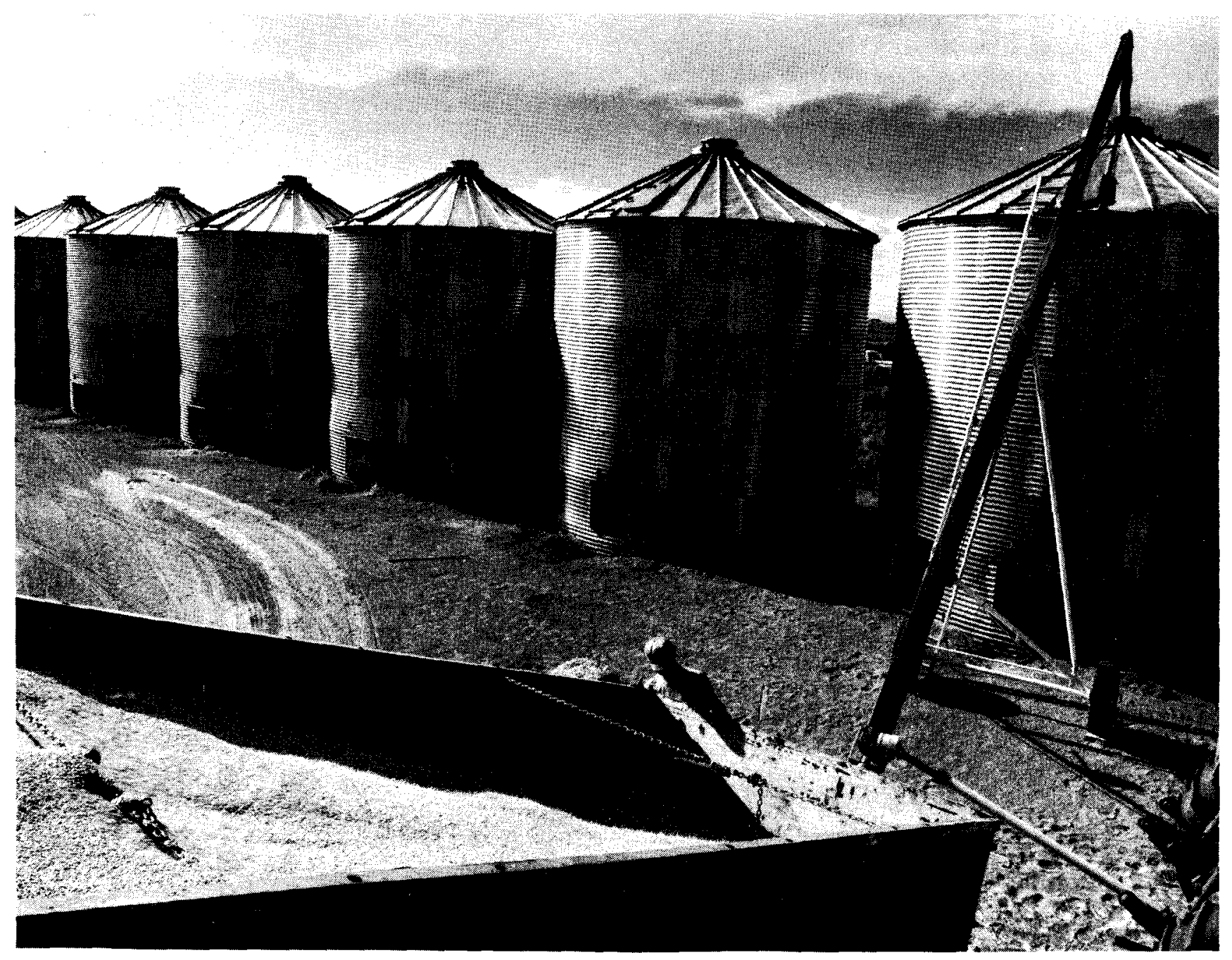

Ethanol Feedstocks can be Stored in Conventional Facilities 


\section{Form of Coproducts}

The form and amounts of coproducts will dictate the type and size of equipment. If stillage is to be sold in wet form, the only required equipment may be a storage tank. If stillage is to be dried, then a centrifuge or screens, driers, and additional dry storage space will be necessary. If carbon dioxide is to be used or collected and sold, equipment for this will be needed.

\section{Safety}

Ethanol is extremely flammable and must be handled accordingly. Ignition sources must be isolated from all possible ethanol leaks. This isolation requirement affects either plant layout or equipment selection. The proper handling of acids and bases mandates resistant types of construction materials.

\section{Heat Sources}

The type or types of fuels available to the operation will dictate the type of equipment necessary to convert this fuel into the required heat source.

\section{Feedstock Mix}

The desired feedstock mix will define the feed preparation equipment necessary (e.g., the production of ethanol from corn requires different front-end processing than sugar beets). Since it may be desirable to process more than one feedstock concurrently, additional equipment may be required in the processing step.

\section{FINANCIAL REQUIREMENTS}

\section{Considerations to Proceed}

Once the considerations for equipment selection are completed, the capital and operating costs may be roughly computed.

The capital cost considerations are:

- equipment,

- real estate and buildings,

- permits and licenses, and

- availability of financing.

The operating costs are:

- labor, maintenance,

- bonds, insurance, property taxes, cost of money,

- chemicals, enzymes, additives, denaturant,

- fuel, water, electricity,

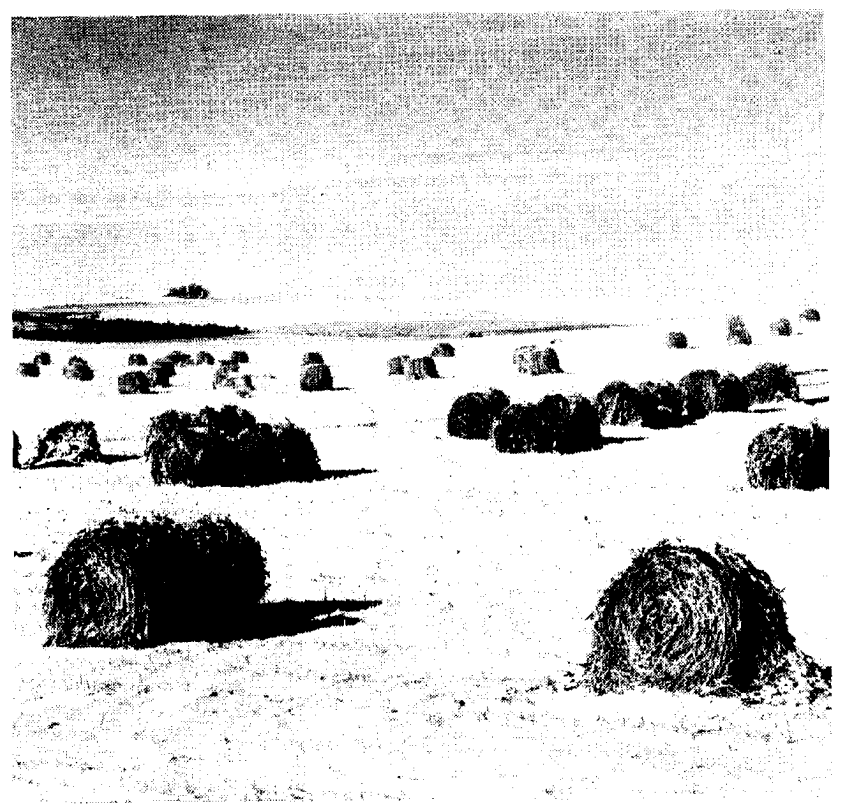

Agricultural Residue can be Collected in Large Round Bales for Storage or as renewable fuel for alcohol plants.

- feedstocks,

- costs of delivery,

- depreciation, and

- overhead (e.g., accounting, legal fees).

These considerations are then compared to the specific financial situtation of the individual. If the results of this comparison are not acceptable, then other options in equipment specifications and plant size must be considered. If all possibilities result in an unfavorable position, the decision to produce is no. If a favorable set of conditions and specifications can be devised, detailed design considerations should be examined (see Chapter V, Plant Design) and an appropriate organization and financial plan developed (see Chapter VI, Business Plan).

\section{DECISION PROCESS}

The final decision to produce ethanol is the result of examining all associated concerns at successively greater levels of detail. Initially a basic determination of feasibility must be made and its results are more a "decision to proceed with further investigation" than an ultimate choice to build a plant or not. This initial evaluation of feasibility is performed by examining: (1) the total market (including on-farm uses and benefits) for the ethanol and coproducts; (2) the actual production potential; (3) the approximate costs for building and operating a plant of the size that appropriately fits the potential market and the production potential; (4) the potential for revenues, savings, or indirect benefits; and (5) personal financial position with respect to the requirements for this plant. There are several points 
during the course of this evaluation that result in a negative answer. This does not necessarily mean that all approaches are infeasible. Retracing a few steps and adjusting conditions may establish favorable conditions; however, adjustments must be realistic, not overly optimistic. Similarly, completion of the exercise with a positive answer is no guarantee of success, it is merely a positive preliminary investigation. The real work begins with specifics. In your analysis you will also want to consider the following questions with regard to organization and financing.

\section{Organizational Form}

Are you willing to assume the costs and risks of running your own EtOH production facility?

Are you capable of handling the additional taxes and debts for which you will be personally liable as a single proprietor? Includes interest on long- and short-term loans.

Is your farm operation large enough or are your potential markets solid enough to handle an $\mathrm{EtOH}$ production facility as a single proprietor?

Is your credit alone sufficient to provide grounds for capitalizing a single proprietorship?

Will a partner(s) enhance your financial position or supply needed additional skills?

a. Do you need a partner to get enough feedstock for your EtOH production facility?

b. Are you willing to assume liabilities for product and partner?

Is your intended production going to be of such a scale as to far exceed the needs for your own farm or several neighboring farms?

Do you need to incorporate in order to obtain adequate funding?

Will incorporation reduce your personal tax burden?

Do you wish to assume product liability personally?

How many farmers in your area would want to join a cooperative?

Do you plan to operate in a centralized location to produce EtOH for all the members?

Is your main reason for producing EtOH to service the needs of the cooperative members, others, or to realize a significant profit?

\section{Financing}

If you are considering borrowing money, you should have a clear idea of what your chances will be beforehand. The following questions will tell you whether debt financing is a feasible approach to your funding problem.

a. How much money do you already owe?

b. What are your monthly payments? 
How much capital will you have to come up with yourself in order to secure a loan?

Have you recently been refused credit?

a. How high are the interest rates going to be?

b. Can you cover them with your projected cash flow?

If the loan must be secured or collateralized, do you have sufficient assets to cover your debt?

If you are already carrying a heavy debt load and/or your credit rating is low, your chances of obtaining additional debt financing is low and perhaps you should consider some other type of financing. Insufficient collateral, exorbitant interest rates, and low projected cash flow are also negative indicators for debt financing.

The choice between debt and equity financing will be one of the most important decisions you will have to face since it will affect how much control you will ultimately have over your operation. The following questions deal with this issue, as well as the comparative cost of the two major types of financing.

Do you want to maintain complete ownership and control of your enterprise?

Are you willing to share ownership and/or control if it does not entail more than a minority share?

How much equity do you already have?

Will the cost of selling the stock (broker's fee, bookkeeper, etc.) be more than the interest you would have to pay on a loan?

If you are reluctant to relinquish any control over your operation, you would probably be better off seeking a loan. On the other hand, if your chances of obtaining a loan are slim, you might have to trade off some personal equity in return for a better borrowing position.

Do you have other funds or materials to match with federal funds? (It is usually helpful.)

Do you live in a geographical area that qualifies for special funds?

Will you need continued federal support at the end of your grant period?

Are you going to apply for grant funds as an individual, as a nonprofit corporation, or as a profit corporation?

Are you a private nonprofit corporation?

Is there something special about your alcohol facility that would make it attractive to certain foundations?

You should now have a good idea as to where you are going to seek your initial funding. Remember that most new businesses start up with a combination of funding sources. It is important to maintain a balance that will give you not only sufficient funding when you need it, but also the amount of control over your operation that you would like to have.

If the financial requirements are greater than the capability to obtain financing, it does not necessarily mean the entire concept will not work. Rather, the organizational form can be reexamined and/or the production base expanded in order to increase financing capability. 


\section{REFERENCES}

1. Reed, Thomas. "Alcohol Fuels." Special Hearing of the U.S. Senate Committee on Appropriations; Washington, D.C.: January 31, 1978; pp. 194-205. U.S. Government Printing Office. Stock Number 052-070-04679-1.

2. Jawetz, Pincas. "Improving Octane Values of Unleaded Gasoline Via Gasohol." Proceedings of the 14th Intersociety Energy Conversion Engineering Conference. Volume I, pp. 301-302; abstract Volume II, p. 102; Boston, MA: August 5-10, 1979. Available from the American Chemical Society, 1155 Sixteenth Street NW, Washington, D.C. 20036.

3. Panchapakesan, M.R.; et al. "Factors That Improve the Performance of an Ethanol Diesel Oil DualFuel Engine." International Symposium on Alcohol Fuel Technology-Methanol and Ethanol.
Wolfsburg, Germany; November 21-23, 1977. CONF-771175.

4. Ethanol Chemical and Engineering News. October 29, 1979; p. 12.

5. Sharma, K.D. "Present Status of Alcohol and Alcohol-Based Chemical Industry in India." Workshop on Fermentation Alcohol for Use as Fuel and Chemical Feedstock in Developing Countries. United Nations International Development Organization, Vienna, Austria; March 1979. Paper no. ID/WG.293/14 UNIDO.

6. Ribeiro, Filho F. A. "The Ethanol-Based Chemical Industry in Brazil." Workshop on Fermentation Alcohol for Use as Fuel and Chemical Feedstock in Developing Countries. United Nations Industrial Development Organization, Vienna, Austria; March 1979. Paper no. ID/WG.293/4 UNIDO. 
CHAPTER III

\section{Basic Ethanol Production}

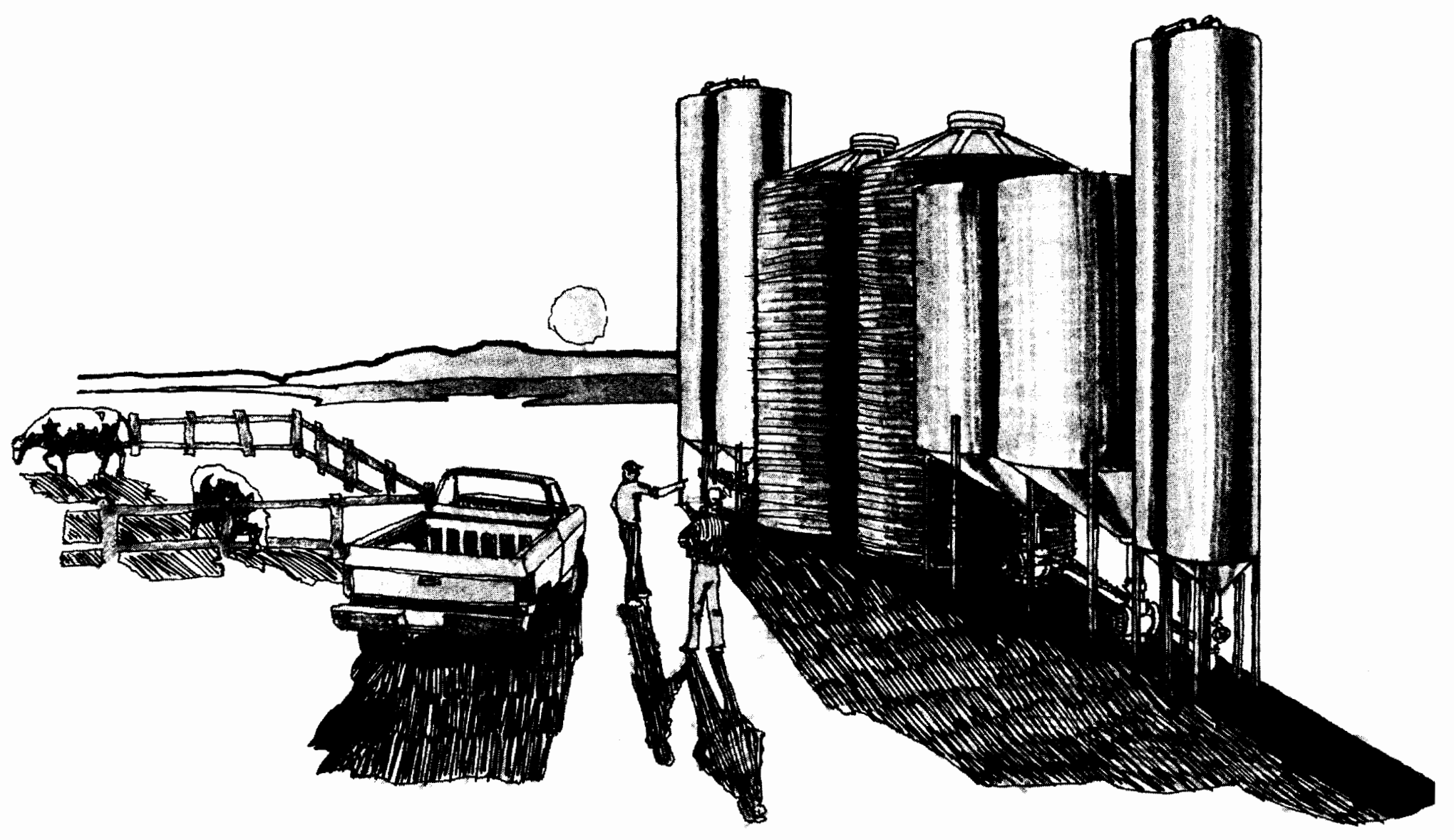




\section{Basic Ethanol Production}

The production of ethanol is an established process. It involves some of the knowledge and skill used in normal farm operations, especially the cultivation of plants. It is also a mix of technologies which includes microbiology, chemistry, and engineering. Basically, fermentation is a process in which microorganisms such as yeasts convert simple sugars to ethanol and carbon dioxide. Some plants directly yield simple sugars; others produce starch or cellulose that must be converted to sugar. The sugar obtained must be fermented and the beer produced must then be distilled to obtain fuelgrade ethanol. Each step is discussed individually. A basic flow diagram of ethanol production is shown in Figure III-1.

\section{PREPARATION OF FEEDSTOCKS}

Feedstocks can be selected from among many plants that either produce simple sugars directly or produce starch and cellulose. The broad category of plants which this includes means there is considerable diversity in the initial processing, but some features are universal:

- simple sugars must be extracted from the plants that directly produce them;

- starch and cellulose must be reduced from their complex form to basic glucose; and

- stones and metallic particles must be removed.

The last feature must be taken care of first. Destoning equipment and magnetic separators can be used to remove stones and metallic particles. Root crops require other approaches since mechanical harvesters don't differentiate between rocks and potatoes or beets of the same size. Water jets or flumes may be needed to accomplish this.

The simple sugars from such plants as sugarcane, sugar beets, or sorghum can be obtained by crushing or pressing the material. The low sugar bagasse and pulp which remain after pressing can be leached with water to remove residual sugars. The fibrous cellulosic material theoretically could be treated chemically or enzymatically to produce more sugar. However, no commercially available process currently exists.

Commonly used starchy feedstocks are grains and potatoes. Starch is roughly $20 \%$ amylose (a hot watersoluble carbohydrate) and $80 \%$ amylopectin (which is not soluble in water). These molecules are linked together by means of a bond that can be broken with relative ease. Cellulose, which is also made up of glucose, differs from starch mainly in the bond between glucose units.

Starch must be broken down because yeast can only act on simple sugars to produce ethanol. This process requires that the material be broken mechanically into the smallest practical size by milling or grinding, thereby breaking the starch walls to make all of the material available to the water. From this mixture, a slurry can be prepared and it can be heated to temperatures high enough to break the cell walls of the starch. This produces complex sugars which can be further reduced by enzymes to the desired sugar product.

\section{Conversion of Starches by Enzymatic Hydrolysis}

Consider the preparation of sugar from grain as an example of enzymatic hydrolysis. The intent is to produce a $20 \%$ sugar solution with water and whole grain. Grain is a good source of carbohydrate, but to gain access to the carbohydrate, the grain must be ground. A rule of thumb is to operate grinders so that the resulting meal can pass a 40 -mesh screen. This ensures that the carbohydrate is accessible and the solids can be removed with a finer screen if desired. If the grain is not ground finely enough, the resultant lumpy material is not readily accessible for enzymatic conversion to sugar. The next step is to prepare a slurry by mixing the meal directly with water. Stirring should be adequate to prevent the formation of lumps and enhance enzyme contact with the starch (thus speeding liquefaction).

High-temperature and high-pressure processes may require a full time operator, thus making it difficult to integrate into farming operations. Therefore, when deciding which enzyme to purchase, consideration should be given to selecting one that is active at moderate temperature, i.e., $200^{\circ} \mathrm{F}\left(93^{\circ} \mathrm{C}\right)$, nearambient pressure, and nearly neutral $\mathrm{pH}$. The acidity of the slurry can be adjusted by addition of dilute basic solution (e.g., sodium hydroxide) if the $\mathrm{pH}$ is too low and addition of an acid if the $\mathrm{pH}$ is too high. 


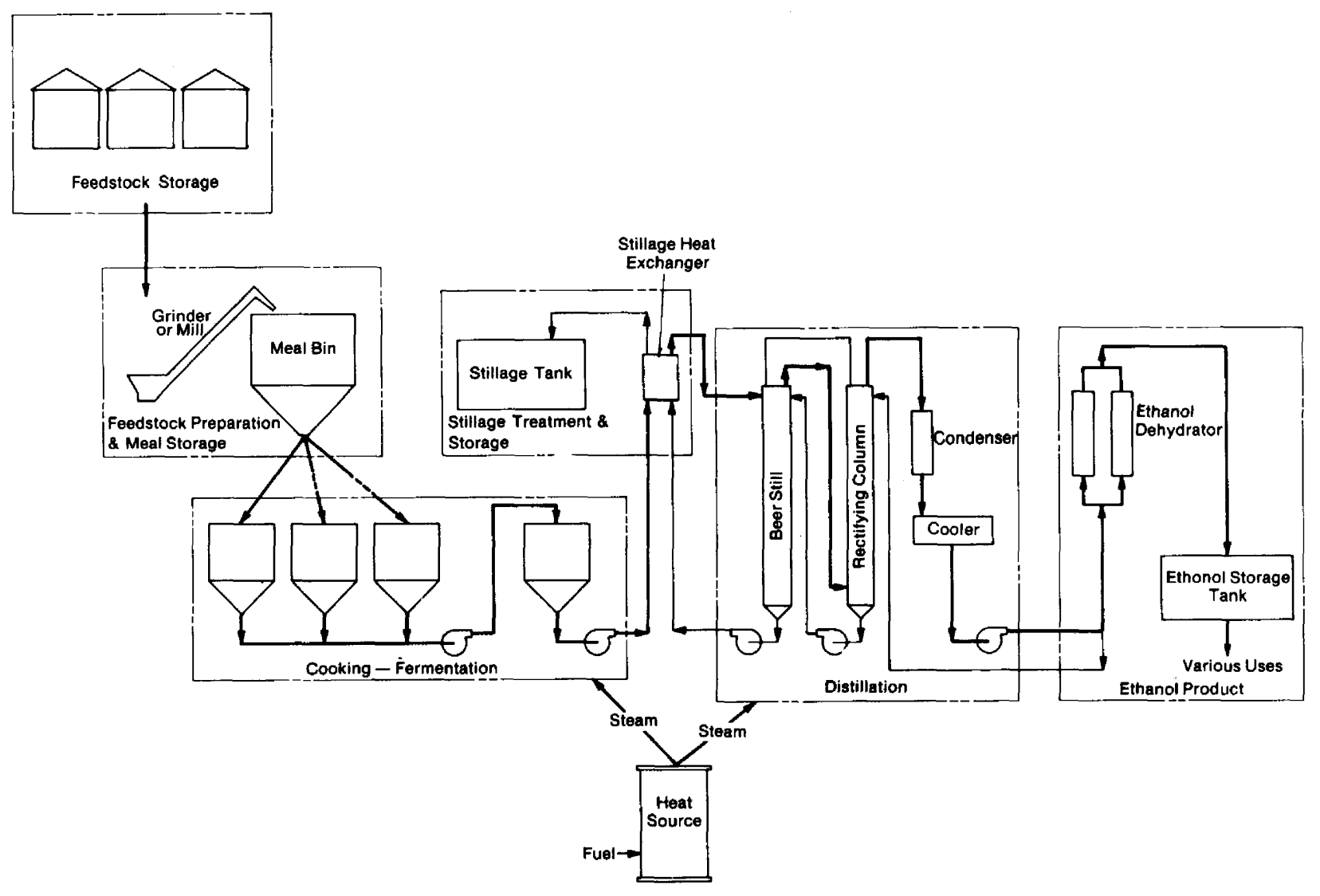

Figure III-1. Ethanol Production Flow Diagram

The enzyme should be added to the slurry in the proper proportion (about $0.1 \%$ by weight) to the quantity of starch to be converted. If not, liquefaction ends up incomplete or takes too long to complete for practical operations. Enzymes vary in activity but thermophilic bacterial amylases, which are commercially available, can be added at rates slightly greater than $3 / 4$ ounce per bushel of meal. Rapid dispersion of the dry enzyme is best accomplished by mixing a premeasured quantity with a small volume of warm water prior to addition to the slurry. Liquefaction should be conducted in the specific temperature range and $\mathrm{pH}$ suggested by the supplier of the specific enzyme used.

After the enzyme is added, the grain mash is heated to break the cell walls of the starch. However, the enzyme must be added before the temperature is raised because once the cell walls rupture, a gel forms and it becomes almost impossible to accomplish good mixing of the enzyme with the starch. The rupture of cell walls, which is caused by heating in hot water, is called gelatinization because the slurry (which is a suspension of basically insoluble material in water) is converted to a highviscosity solution. Under slow cooking conditions and normal atmospheric pressure, gelatinization can be expected to occur around $150^{\circ} \mathrm{F}\left(65.6^{\circ} \mathrm{C}\right)$.
The temperature is then raised to the optimal functional range for the enzyme and held for a period of time sufficient to completely convert the starch to soluble dextrins (polymeric sugars). There are commercially available enzymes that are most active around $200^{\circ} \mathrm{F}\left(93^{\circ} \mathrm{C}\right)$ and require a hold time of $2 \frac{1}{2}$ hours if the proper proportion of enzyme is used. When this step is complete, the slurry has been converted to an aqueous solution of dextrins. Care must be taken to assure that the starch conversion step is complete because the conditions for the glucose-producing enzyme (glucoamylase), which is introduced in the next step, are significantly different from those for liquefaction.

The next step, saccharification, is the conversion of dextrins to simple sugars, i.e., glucose. The mash temperature is dropped to the active range of the glucoamylase, the enzyme used for saccharification, and the $\mathrm{pH}$ of the solution is acidified to optimize conversion activity. The $\mathrm{pH}$ is a critical factor because the enzymatic activity virtually ceases when the $\mathrm{pH}$ is above 6.5. Glucoamylase is added in the proportion required to convert the amount of sugar available. Again, depending upon the variety selected and its activity, the actual required quantity of enzyme varies. 
After the enzyme is added, the temperature of the mash must neither exceed $140^{\circ} \mathrm{F}\left(60^{\circ} \mathrm{C}\right)$ nor drop below $122^{\circ} \mathrm{F}\left(50^{\circ} \mathrm{C}\right)$ during the saccharification step or the enzyme activity is greatly reduced. The mash, as in the prior step, must be stirred continuously to assure intimate contact of enzyme and dextrin. The mash should be held at the proper temperature and $\mathrm{pH}$ (3.0 to 5.0) until conversion of the dextrin to glucose is complete.

\section{FERMENTATION}

Fermentation is the conversion of an organic material from one chemical form to another using enzymes produced by living microorganisms. In general, these bacteria are classified according to their tolerance of oxygen. Those that use oxygen are called aerobic and those that do not are called anaerobic. Those that start with oxygen but continue to thrive after all of the available oxygen is consumed are called facultative organisms. The yeast used to produce ethanol is an example of this type of facultative anaerobe. The breakdown of glucose to ethanol involves a complex sequence of chemical reactions which can be summarized as:

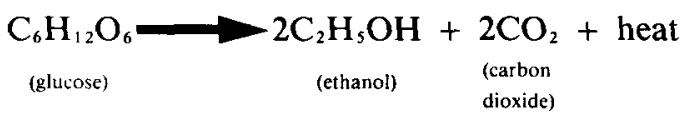

Actual yields of ethanol generally fall short of predicted theoretical yields because about $5 \%$ of the sugar is used by the yeast to produce new cells and minor products such as glycerols, acetic acid, lactic acid, and fusel oils.

Yeasts are the microorganisms responsible for producing the enzymes which convert sugar to ethanol. Yeasts are single-cell fungi widely distributed in nature, commonly found in wood, dirt, plant matter, and on the surface of fruits and flowers. They are spread by wind and insects. Yeasts used in ethanol productions are members of the genus Saccharomyces. These yeasts are sensitive to a wide variety of variables that potentially affect ethanol production. However, $\mathrm{pH}$ and temperature are the most influential of these variables. Saccharomyces are most effective in $\mathrm{pH}$ ranges between 3.0 and 5.0 and temperatures between $80^{\circ} \mathrm{F}\left(27^{\circ} \mathrm{C}\right)$ and $90^{\circ} \mathrm{F}\left(35^{\circ} \mathrm{C}\right)$. The length of time required to convert a mash to ethanol is dependent on the number of yeast cells per quantity of sugar. The greater the number initially added, the faster the job is complete. However, there is a point of diminishing returns.

Yeast strains, nutritional requirements, sugar concentration, temperature, infections, and $\mathrm{pH}$ influence yeast efficiency. They are described as follows:

\section{Yeast Strains}

Yeasts are divided informally into top and bottom yeasts according to the location in the mash in which most of the fermentation takes place. The top yeasts, Saccharomyces cerevisiae, produce carbon dioxide and ethanol vigorously and tend to cluster on the surface of the mash. Producers of distilled spirits generally use top yeasts of high activity to maximize ethanol yield in the shortest time; producers of beer tend to use bottom yeasts which produce lower ethanol yields and require longer times to complete fermentation. Under normal brewing conditions, yeasts tend to flocculate (aggregate together into clusters) and to separate out from the solution when fermentation is complete. The various strains of yeast differ considerably in their tendency to flocculate. Those strains with an excessive tendency toward premature flocculation tend to cut short fermentation and thus reduce ethanol yield. This phenomenon, however, is not singularly a trait of the yeast. Fermentation conditions can be an influencing factor. The cause of premature flocculation seems to be a function of the $\mathrm{pH}$ of the mash and the number of free calcium ions in solution. Hydrated lime, which is sometimes used to adjust $\mathrm{pH}$, contains calcium and may be a contributory factor.

\section{Nutritional Requirements}

Yeasts are plants, despite the fact that they contain no chlorophyll. As such, their nutritional requirements must be met or they cannot produce ethanol as fast as desired. Like the other living things that a farmer cultivates and nurtures, an energy source such as carbohydrate must be provided for metabolism. Amino acids must be provided in the proper proportion and major chemical elements such as carbon, nitrogen, phosphorus, and others must be available to promote cell growth. Some species flourish without vitamin supplements, but in most cases cell growth is enhanced when B-vitamins are available. Carbon is provided by the many carbonaceous substances in the mash.

The nitrogen requirement varies somewhat with the strain of yeast used. In general, it should be supplied in the form of ammonia, ammonium salts, amino acids, peptides, or urea. Care should be taken to sterilize farm sources of urea to prevent contamination of the mash with undesired microbial strains. Since only a few species of yeasts can assimilate nitrogen from nitrates, this is not a recommended source of nitrogen. Ammonia is usually the preferred nitrogen form, but in its absence, the yeast can break up amino acids to obtain it . The separation of solids from the solution prior to fermentation removes the bulk of the protein and, hence, the amine source would be removed also. If this option is exercised, an ammonia supplement must be provided or yeast populations will not propagate at the desired rates and fermentation will take an excessive amount of time to complete. However, excessive amounts of ammonia in solution must be avoided because it can be lethal to the yeast. 
Mineral requirements of yeast can be satisfied by using tap water. Phosphorus and potassium can be supplied by using liquid fertilizers.

\section{Sugar Concentration}

There are two basic concerns that govern the sugar concentration of the mash. First, because of high osmotic pressure, excessively high sugar concentrations (greater than $22 \%$ by weight) can inhibit the growth of yeast cells in the initial stages of fermentation. Osmotic pressure is due to the physical imbalance in concentration of chemicals on either side of a membrane. Since yeasts are cellular organisms, they are enclosed by a cell wall. An excessively high osmotic pressure can cause a rupture of the cell wall which in turn kills the yeast. Second, high ethanol concentrations kill the yeast. If the concentration of ethanol in the solution reaches levels high enough (greater than $12-14 \%$ by weight) to kill yeast before all the sugar is consumed, the quantity of sugar that remains is wasted. The latter concern is the governing control. Yeast growth problems can be overcome by using large inoculations to start fermentation. Saccharomyces strains can effectively utilize all of the sugar in solutions that are $22 \%$ sugar while producing a beer that is $12 \%$ ethanol by volume.

\section{Temperature}

Fermentation is strongly influenced by temperature, because the yeast performs best in a specific temperature range. The rate of fermentation increases with temperature in the temperature range between $80^{\circ}$ $\mathrm{F}\left(27^{\circ} \mathrm{C}\right)$ and $90^{\circ} \mathrm{F}\left(32.2^{\circ} \mathrm{C}\right)$. Above $90^{\circ} \mathrm{F}\left(32.2^{\circ} \mathrm{C}\right)$, the rate of fermentation gradually drops off, and ceases altogether at temperatures above $109^{\circ} \mathrm{F}\left(43^{\circ} \mathrm{C}\right)$. The actual temperature effects vary with different yeast strains and typical operating conditions are generally closer to $80^{\circ} \mathrm{F}\left(27^{\circ} \mathrm{C}\right)$ than $90^{\circ} \mathrm{F}\left(32.2^{\circ} \mathrm{C}\right)$. This choice is usually made to reduce ethanol losses by evaporation from the beer. For every $9^{\circ} \mathrm{F}\left(5^{\circ} \mathrm{C}\right)$ increase in temperature, the ethanol evaporation rate increases 1.5 times. Since scrubbing equipment is required to recover the ethanol lost by evaporation and the cost justification is minimal on a small scale, the lower fermentation temperature offers advantages of simplicity.

The fermentation reaction gives off energy as it proceeds (about 500 Btu per pound of ethanol produced). There will be a normal heat loss from the fermentation tank as long as the temperature outside the tank is less than that inside. Depending upon the location of the plant, this will depend on how much colder the outside air is than the inside air and upon the design of the fermenter. In general, this temperature difference will not be sufficient to take away as much heat as is generated by the reaction except during the colder times of the year. Thus, the fermenters must be equipped with active cooling systems, such as cooling coils and external jackets, to circulate air or water for convective cooling.

\section{Infections}

Unwanted microbial contaminants can be a major cause of reductions in ethanol yield. Contaminants consume sugar that would otherwise be available for ethanol production and produce enzymes that modify fermentation conditions, thus yielding a drastically different set of products. Although infection must be high before appreciable quantities of sugar are consumed, the rate at which many bacteria multiply exceeds yeast propagation. Therefore, even low initial levels of infection can greatly impair fermentation. In a sense, the start of fermentation is a race among the microorganisms present to see who can consume the most. The objective is the selective culture of a preferred organism. This means providing the conditions that are most favorable to the desired microorganism. As mentioned previously, high initial sugar concentrations inhibit propagation of Saccharomyces cerevisiae because it is not an osmophylic yeast (i.e., it cannot stand the high osmotic pressure caused by the high concentration of sugar in the solution). This immediately gives an advantage to any bacteria present.

Unwanted microbes can be controlled by using good cleaning and steaming.

\section{DISTILLATION}

The purpose of the distillation process is to separate ethanol from the ethanol-water mixture. There are many means of separating liquids comprised of two or more components in solution. In general, for solutions comprised of components of significantly different boiling temperatures, distillation has proved to be the most easily operated and thermally efficient separation technique.

At atmospheric pressure, water boils around $212^{\circ} \mathrm{F}$ $\left(100^{\circ} \mathrm{C}\right)$ and ethanol boils around $173^{\circ} \mathrm{F}\left(78.2^{\circ} \mathrm{C}\right)$. It is this difference in boiling temperature that allows for distillative separation of ethanol-water mixtures. If a pan of an ethanol and water solution is heated on the stove, more ethanol molecules leave the pan than water molecules. If the vapor leaving the pan is caught and condensed, the concentration of ethanol in the condensed liquid will be higher than in the original solution, and the solution remaining in the pan will be lower in ethanol concentration. If the condensate from this step is again heated and the vapors condensed, the con- 


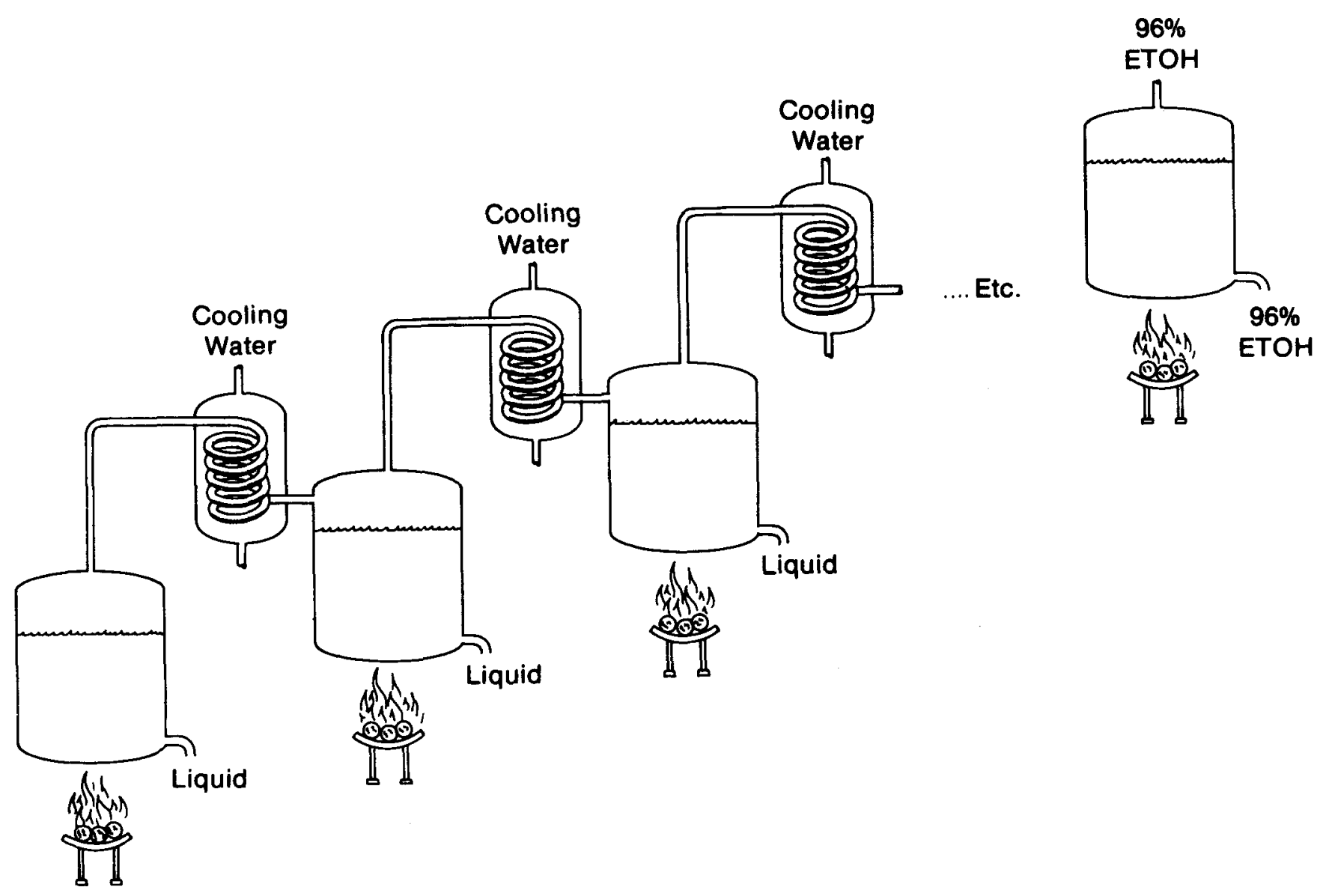

Figure III-2. Basic Process of Successive Distillation to Increase Concentration of Ethanol

centration of ethanol in the condensate will again be higher. This process could be repeated until most of the ethanol was concentrated in one phase. Unfortunately, a constant boiling mixture (azeotrope) forms at about $96 \%$ ethanol. This means that when a pan containing a $96 \%$-ethanol solution is heated, the ratio of ethanol molecules to water molecules in the condensate remains constant. Therefore, no concentration enhancement is achieved beyond this point by the distillation method.

The system shown in Figure III-2 is capable of producing $96 \%$-pure ethanol, but the amount of final product will be quite small. At the same time there will be a large number of products of intermediate ethanol-water compositions that have not been brought to the required product purity. If, instead of discarding all the intermediate concentrations of ethanol and water, they were recycled to a point in the system where the concentration was the same, we could retain all the ethanol in the system. Then, if all of these steps were incorporated into one vessel, the result would be a distillation column. The advantages of this system are that no intermediate product is discarded and only one external heating and one external cooling device are required. Condensation at one stage is affected when vapors contact a cooler stage above it, and evaporation is affected when liquid contacts a heating stage below.
Heat for the system is provided at the bottom of the distillation column; cooling is provided by a condenser at the top where the condensed product is returned in a process called reflux. It is important to note that without this reflux the system would return to a composition similar to the mixture in the first pan that was heated on the stove.

The example distillation sieve tray column given in Figure III-3 is the most common single-vessel device for carrying out distillation. The liquid flows down the tower under the force of gravity while the vapor flows upward under the force of a slight pressure drop.

The portion of the column above the feed is called the rectifying or enrichment section. The upper section serves primarily to remove the component with the lower vapor pressure (water) from the upflowing vapor, thereby enriching the ethanol concentration. The portion of the column below the feed, called the stripping section, serves primarily to remove or strip the ethanol from the down-flowing liquid.

Figure III-4 is an enlarged illustration of a sieve tray. In order to achieve good mixing between phases and to provide the necessary disengagement of vapor and liquid between stages, the liquid is retained on each plate 


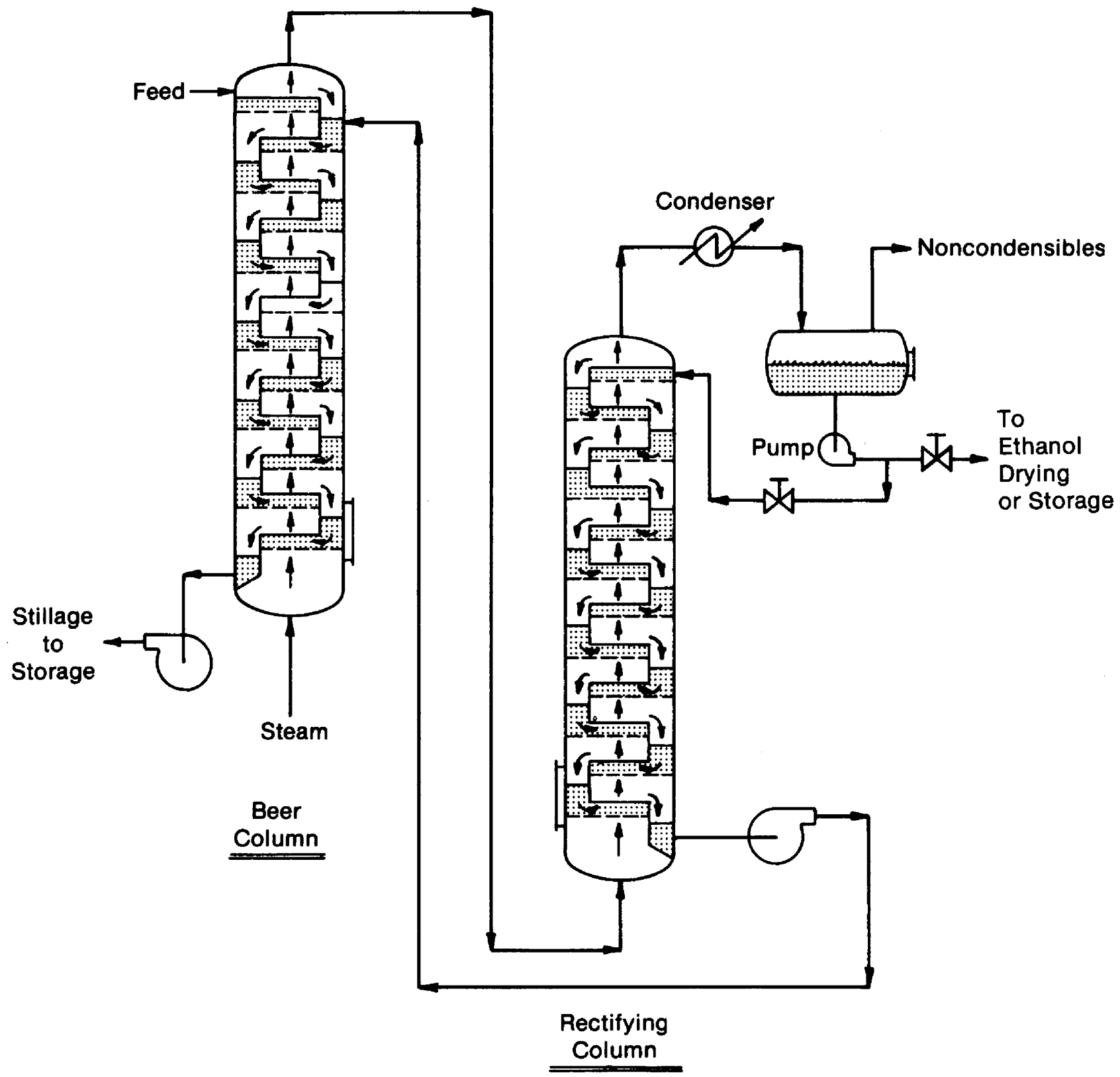

Figure III-3. Schematic Diagram of Sieve Tray Distillation of Ethanol 


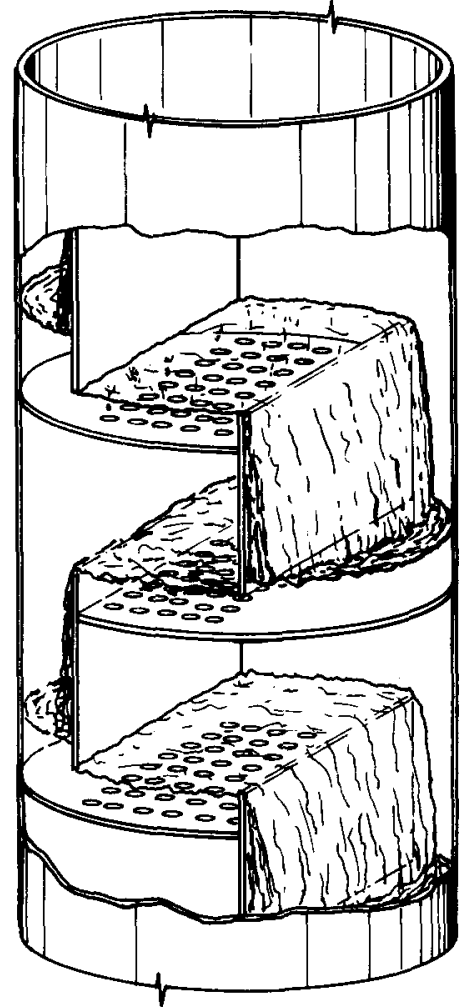

Figure III-4. Enlarged IIlustration of Sieve Tray by a weir (a dam that regulates flow) over which the solution flows. The effluent liquid then flows down the downcomer to the next stage. The downcomer provides sufficient volume and residence time to allow the vaporliquid separation.

It is possible to use several devices other than sieve tray columns to achieve the counter-current flow required for ethanol-water distillation. A packed column is frequently used to effect the necessary vapor-liquid contacting. The packed column is filled with solid material shaped to provide a large surface area for contact. Counter-current liquid and vapor flows proceed in the same way described for the sieve tray column.

Production of fuel-grade ethanol is a practical operation to include in farm activities. Texts in microbiology and organic chemistry portray it as a complex procedure, but this is not necessarily true. Fermentation is affected by a variety of conditions. The more care used in producing optimum conditions, the greater the ethanol yield. Distillation can range from the simple to the complex. Fortunately, the middle line works quite satisfactorily for on-farm ethanol production. 


\section{CHAPTER IV}

\section{Feedstocks and Coproducts}

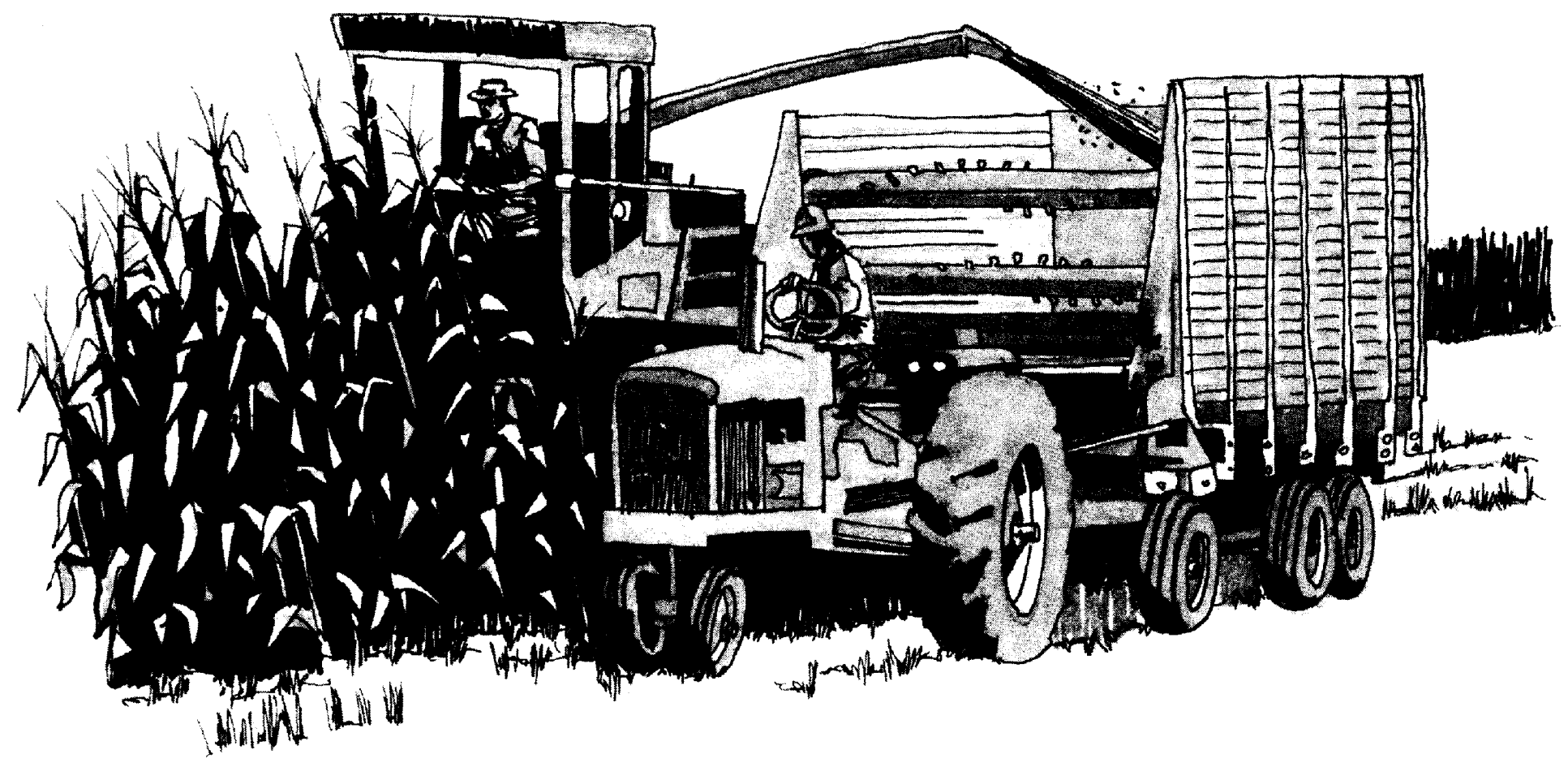




\section{CHAPTER IV}

\section{Feedstocks and Coproducts}

The previous chapter discussed the basic process for fermenting sugar into ethanol. The purposes of this chapter are (1) to describe the types of agricultural crops and crop residues that make up the feedstocks used in the production of ethanol; (2) to provide data on the yield of the three principal coproducts derived from fermentation of these feedstocks; and (3) to present agronomic and feedstock considerations of ethanol production.

\section{TYPES OF FEEDSTOCKS}

Biological production of ethanol is accomplished by yeast through fermentation of six-carbon sugar units (principally glucose). All agricultural crops and crop residues contain six-carbon sugars, or compounds of these sugars, and therefore can be used in the production of ethanol. Three different arrangements of the basic sugar units are possible, as seen in the three different types of agricultural feedstocks available for fermentation: sugar crops, starch crops, and lignocellulosic residues. The starch crops and lignocellulosic residues contain six-carbon sugar compounds which must be broken down into simple six-carbon sugar units before fermentation can take place.

\section{Sugar Crops}

In sugar crops, the majority of the six-carbon sugar units occur individually or in bonded pairs. Once a sugar crop has been crushed to remove the sugar, no additional processing is needed prior to fermentation since the six-carbon sugar units are already in a form that the yeast can use. This fact is both an advantage and a disadvantage. Preparation of the feedstock for fermentation involves comparatively low cost equipment, labor, and energy costs, since the only major steps involved are milling and extraction of the sugar. However, sugar crops tend to spoil easily. Numerous types of microorganisms (including the type of yeast that produces ethanol) thrive on these crops during storage because of their high moisture and sugar content. Therefore, steps must be taken during storage to slow the loss of sugar. The only proven storage method is evaporation of water from the sugar solution-an effective, but costly method in terms of equipment (evaporators) and energy. Sterilization of the juice by use of heat, chemicals, or ultrafiltration to remove microbes is currently under investigation [1].
The two sugar crops that have been cultivated in the United States for many years at a commercial level of production are sugarcane and sugar beets. Other alternative sugar crops that can be cultivated in the United States include sweet sorghum, Jerusalem artichokes, fodder beets, and fruits.

Sugarcane. Sugarcane is considered a favorable feedstock because of its high yield of sugar per acre (as high as 50 tons per acre per year) and a correspondingly high yield of crop residue, known as bagasse, that can be used as a fuel for production of process heat. The major drawback with this feedstock is the limited availability of land suitable for economical cultivation. Presently, only four states (Florida, Louisiana, Texas, and Hawaii) cultivate sugarcane.

Sugar Beets. Sugar beets are a much more versatile crop than sugarcane. They are presently grown in 19 states, and the potential for cultivation in other parts of the country is high because sugar beets tolerate a wide range of climatic and soil conditions. An important advantage of sugar beets is the comparatively high yield of crop coproducts: beet pulp and beet tops. Beet pulp, the por-

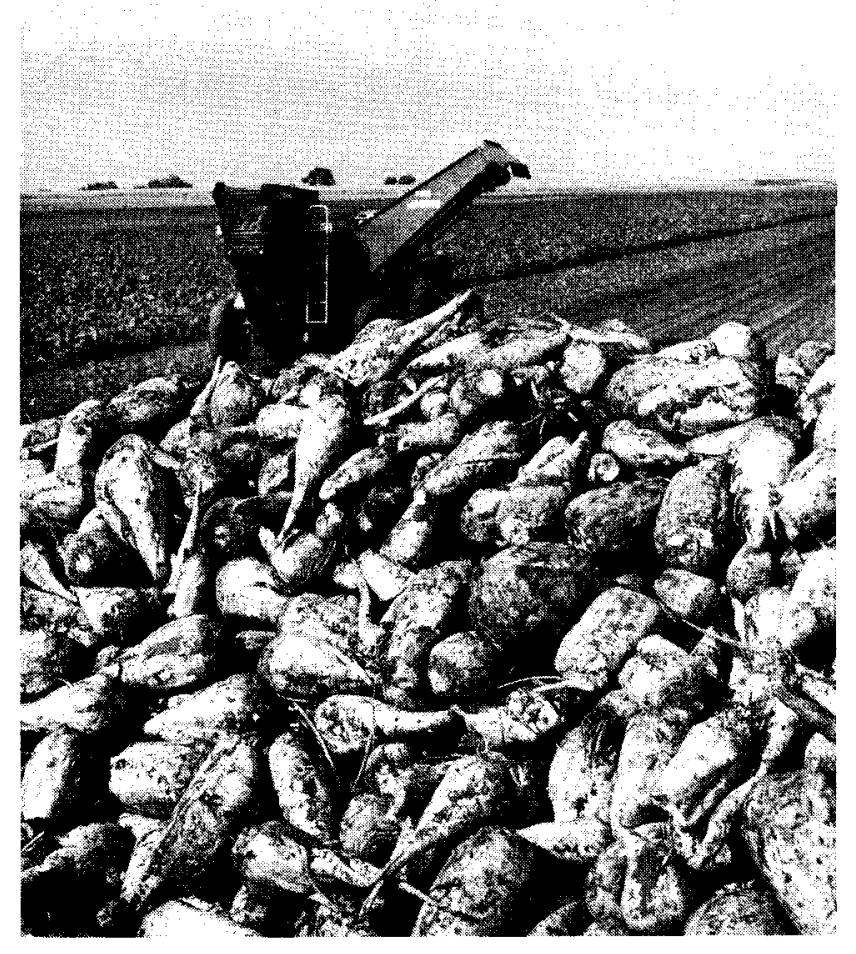

Sugar Beets are a Good Ethanol Feedstock 


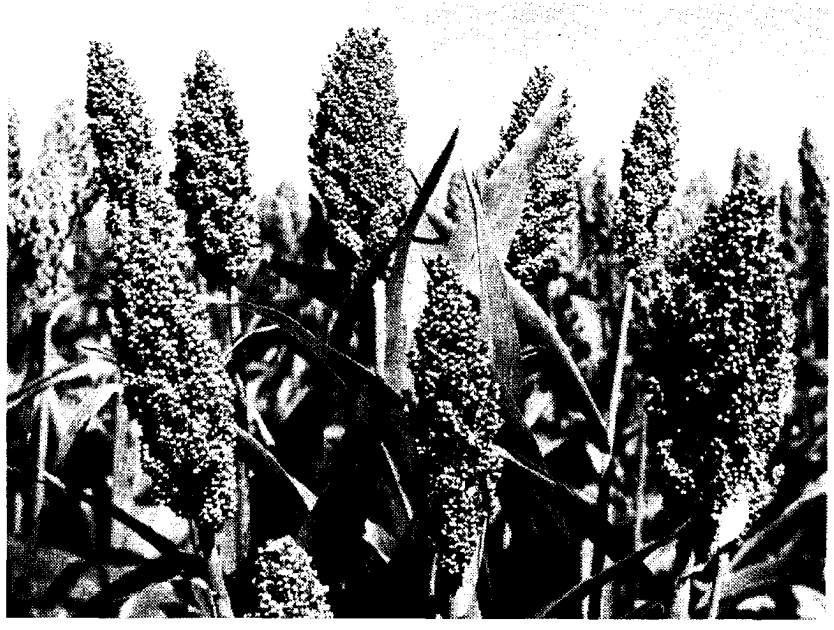

Sweet Sorghum Yields Grain and Sugar, Both of Which can be Used as Ethanol Feedstocks

tion of the root that remains after the sugar has been removed, is bulky and palatable and may be fed in either wet or dry form. Beet tops have alternative uses that include leaving them on the field for organic material (fertilizer) and as cover to lessen soil erosion.

Widespread expansion of sugar beet cultivation is limited to some extent by the necessity to rotate with nonroot crops, in order to lower losses caused by a buildup of nematodes, a parasitic worm that attacks root systems. A general guideline of one beet crop per 4-year period should be followed. None of the sugar beet crop coproducts is suitable for use as a boiler fuel.

Interest in ethanol production from agricultural crops has prompted research on the development of sugar crops that have not been cultivated on a widespread commercial basis in this country. Three of the principal crops now under investigation are sweet sorghum, Jerusalem artichokes, and fodder beets.

Sweet Sorghum. Sweet sorghum is a name given to varieties of a species of sorghum: Sorghum bicolor. This crop has been cultivated on a small scale in the past for production of table syrup, but other varieties can be grown for production of sugar. The most common types of sorghum species are those used for production of grain.

There are two advantages of sweet sorghum over sugarcane: its great tolerance to a wide range of climatic and soil conditions, and its relatively high yield of ethanol per acre. In addition, the plant can be harvested in three ways: (1) the whole plant can be harvested and stored in its entirety; (2) it can be cut into short lengths (about 4 inches long) when juice extraction is carried out immediately; and (3) it can be harvested and chopped for ensilage. Since many varieties of sweet sorghum bear significant quantities of grain (milo), the harvesting procedure will have to take this fact into account.
The leaves and fibrous residue of sweet sorghum contain large quantities of protein, making the residue from the extraction of juice or from fermentation a valuable livestock feed. The fibrous residue can also be used as boiler feed.

Jerusalem Artichokes. The Jerusalem artichoke has shown excellent potential as an alternative sugar crop. A member of the sunflower family, this crop is native to North America and well-adapted to northern climates [2]. Like the sugar beet, the Jerusalem artichoke produces sugar in the top growth and stores it in the roots and tuber. It can grow in a variety of soils, and it is not demanding of soil fertility. The Jerusalem artichoke is a perennial; small tubers left in the field will produce the next season's crop, so no plowing or seeding is necessary.

Although the Jerusalem artichoke traditionally has been grown for the tuber, an alternative to harvesting the tuber does exist. It has been noted that the majority of the sugar produced in the leaves does not enter the tuber until the plant has nearly reached the end of its productive life [3]. Thus, it may be possible to harvest the Jerusalem artichoke when the sugar content in the stalk reaches a maximum, thereby avoiding harvesting the tuber. In this case, the harvesting equipment and procedures are essentially the same as for harvesting sweet sorghum or corn for ensilage.

Fodder Beets. Another promising sugar crop which is presently being developed in New Zealand is the fodder beet. The fodder beet is a high yielding forage crop obtained by crossing two other beet species, sugar beets and mangolds. It is similar in most agronomic respects to sugar beets. The attraction of this crop lies in its higher yield of fermentable sugars per acre relative to sugar beets and its comparatively high resistance to loss of fermentable sugars during storage [4]. Culture of fodder beets is also less demanding than sugar beets.

Fruit Crops. Fruit crops (e.g., grapes, apricots, peaches, and pears) are another type of feedstock in the sugar crop category. Typically, fruit crops such as grapes are used as the feedstock in wine production. These crops are not likely to be used as feedstocks for production of fuel-grade ethanol because of their high market value for direct human consumption. However, the coproducts of processing fruit crops are likely to be used as feedstocks because fermentation is an economical method for reducing the potential environmental impact of untreated wastes containing fermentable sugars.

\section{Starch Crops}

In starch crops, most of the six-carbon sugar units are linked together in long, branched chains (called starch). Yeast cannot use these chains to produce ethanol. The starch chains must be broken down into individual six- 


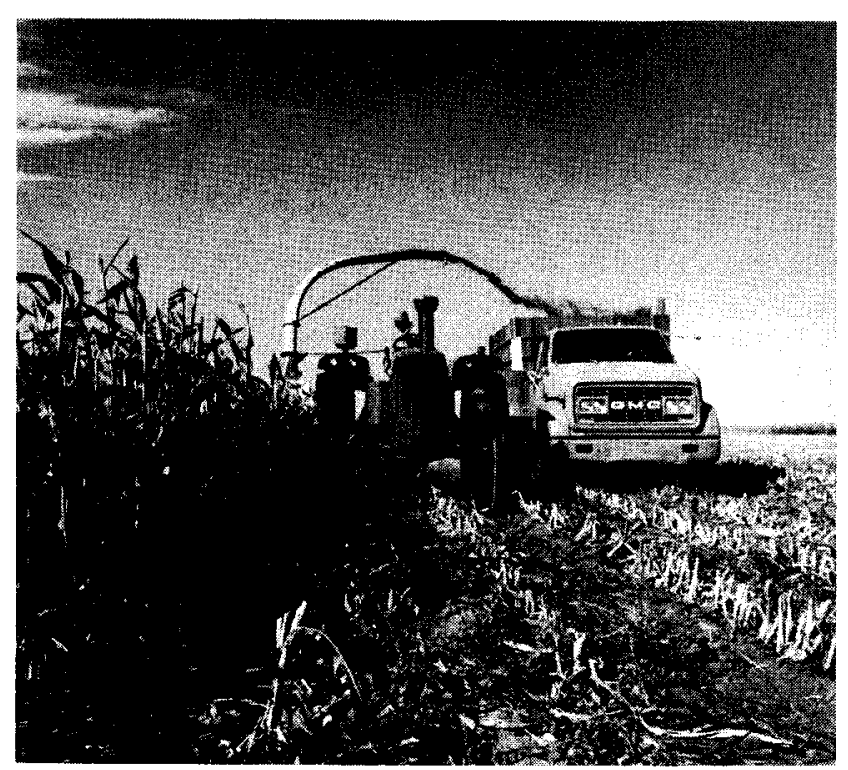

Corn is one of the Most Popular Ethanol Feedstocks, in Part Due to its Relatively Low Cost of Production

carbon units or groups of two units. The starch conversion process, described in the previous chapter, is relatively simple because the bonds in the starch chain can be broken in an inexpensive manner by the use of heat and enzymes, or by a mild acid solution.

From the standpoint of ethanol production, the long, branched chain arrangement of six-carbon sugar units in starch crops has advantages and disadvantages. The principal disadvantage is the additional equipment, labor, and energy costs associated with breaking down the chain so that the individual sugar units can be used by the yeast. However, this cost is not very large in relation to all of the other costs involved in ethanol production. The principal advantage in starch crops is the relative ease with which these crops can be stored, with minimal loss of the fermentable portion. Ease of storage is related to the fact that a conversion step is needed prior to fermentation: many microorganisms, including yeast, can utilize individual or small groups of sugar units, but not long chains. Some microorganisms present in the environment produce the enzymes needed to break up the chains, but unless certain conditions (such as moisture, temperature, and $\mathrm{pH}$ ) are just right, the rate of conversion is very slow. When crops and other feeds are dried to about $12 \%$ moisture-the percentage at which most microorganisms cannot survive-the deterioration of starch and other valuable components (for example, protein and fats) is minimal. There are basically two subcategories of starch crops; i.e., grains and tubers.

Grains. The most common grains used in alcohol fuel production are corn, barley, wheat and sorghum. With the exception of sorghum, all of these grains have been used extensively for years as feedstocks for the pro- duction of beverage-grade alcohols. Now, with the new demand for non-fossil liquid fuels, these same grains are being called upon as basic feedstock for production of fuel-grade alcohols as well. At least in the early stages of the small-scale ethanol production movement, grains have been the most popular and widely used feedstock of all varieties mentioned.

Tubers. The most common tubers used in alcohol fuels production are potatoes and sweet potatoes. Both are common farm products containing high concentrations of starch and are excellent feedstocks for conversion to alcohol fuels.

Much of the current agronomic research on optimizing the production of ethanol and livestock feed from agricultural crops is focused on unconventional sugar crops such as sweet sorghum. However, opportunities also exist for selecting new varieties of grains and tubers that produce more ethanol per acre. For example, when selecting a wheat variety, protein content is usually emphasized. However, for ethanol production, high starch content is desired. It is well known that wheat varieties with lower protein content and higher starch content usually produce more grain per acre and, consequently, produce more ethanol per acre.

\section{Crop Residue}

The "backbone" of sugar and starch crops-the stalks and leaves-is composed mainly of cellulose. The individual six-carbon sugar units in cellulose are linked together in extremely long chains by a stronger chemical bond than exists in starch. As with starch, cellulose must be broken down into sugar units before it can be used by yeast to make ethanol. However, the breaking of the cellulose bonds is much more complex and costly than the breaking of the starch bonds. Breaking the cellulose into individual sugar units is complicated by the presence of lignin, a complex compound surrounding cellulose, which is even more resistant than cellulose to enzymatic or acidic pretreatment. Because of the high cost of converting liquefied cellulose into fermentable sugars, agricultural residues (as well as other crops having a high percentage of cellulose) are not yet a practical feedstock source for small ethanol plants. Current research may result in feasible cellulosic conversion processes in the future.

\section{Forage Crops}

Forage crops (e.g., forage sorghum, Sudan grass) hold promise for ethanol production because, in their early stage of growth, there is very little lignin and the conversion of the cellulose to sugars is more efficient. In addition, the proportion of carbohydrates in the form of cellulose is less than in the mature plant. Since forage crops achieve maximum growth in a relatively short 


\section{Processing \\ Needed \\ Type of \\ Prior to \\ Feedstock \\ Fermentation \\ Principal \\ Advantage(s) \\ Principal \\ Disadvantage(s)}

Sugar Crops (e.g., sugar beets, sweet sorghum, sugarcane, fodder beet, Jerusalem artichoke)
Milling to extract sugar.

1. Preparation is minimal.

2. High yields of ethanol per acre.

3. Except for sugarcane, al crop coproducts have value as fuel, livestock feed, or soil amendment.

\author{
wheat, sorghum, barley) \\ Tubers (e.g., potatoes, \\ sweet potatoes)
}

Grains (e.g., corn,

\author{
Cellulosic: \\ Crop Residues (e.g., \\ corn stover, wheat \\ straw) \\ Forages (e.g., alfalfa, \\ Sudan grass, forage \\ sorghum )
}

Milling, liquefaction, and saccharification.

1. Storage techniques are well developed.

2. Cultivation practices are widespread with grains.

3. Livestock coproduct is relatively high in protein.

Milling and hydrolysis of the linkages.

1. Use involves no integration with the livestock feed market.

2. Availability is widespread.
1. Crop storage may result in loss of sugar. (Second stage molasses may be stored.)

2. Cultivation practices are not widespread, especially with "nonconventional" crops.

1. Preparation involves additional equipment, labor, and energy costs.

2. DDG from aflatoxincontaminated grain is not suitable as animal feed.

1. No commercially costeffective process exists for hydrolysis of the linkages, period, they can be harvested as many as four times in one growing season [5]. For this reason, forage crops cut as green chop may have the highest yield of dry material of any storage crop. In addition to cellulose, forage crops contain significant quantities of starch and fermentable sugars which can also be converted to ethanol. The residues from fermentation containing nonfermentable sugars, protein, and other components may be used for livestock feed.

The principal characteristics of the feedstock types considered in this section are summarized in Table IV-1.

\section{COPRODUCT YIELDS}

\section{Ethanol}

The yield of ethanol from agricultural crops can be estimated if the amount of fermentable components- sugar, starch, and cellulose-is known prior to fermentation. If the yield is predicted based on percentages at the time of harvest, then the loss of fermentable solids during storage must be taken into account. This factor can be significant in the case of sugar crops, as discussed earlier.

The potential yield of ethanol is roughly one-half pound of ethanol for each pound of sugar. However, not all of the carbohydrate is made available to the yeasts as fermentable sugars, nor do the yeasts convert all of the fermentable sugars to ethanol. Thus, for estimating purposes, the yield of ethanol is roughly one gallon for each 15 pounds of sugar or starch in the crop at the time the material is actually fermented. Because of the many variables in the conversion of liquefied cellulose to fermentable sugar, it is difficult to estimate active ethanol yields from cellulose. 


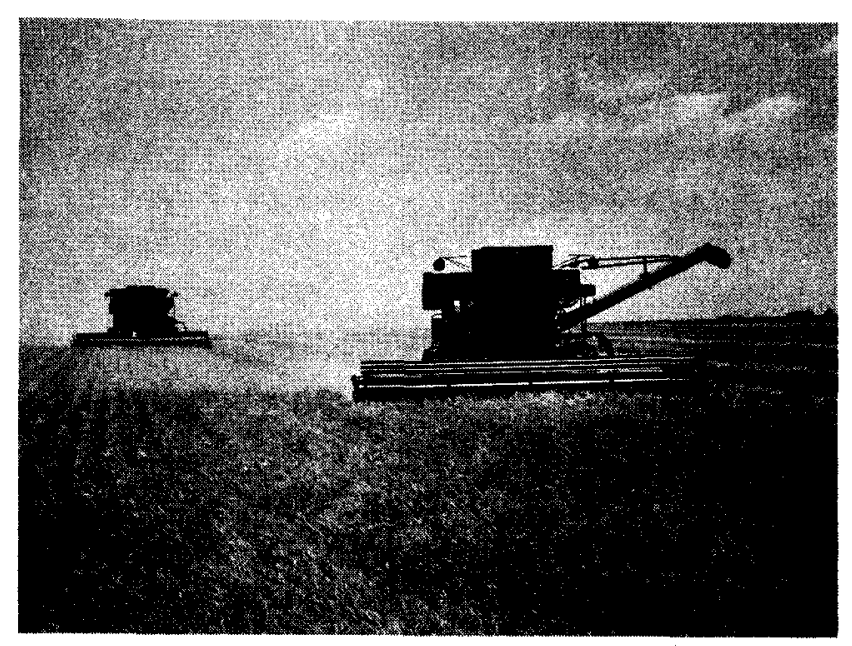

Wheat, Like the Other Cereal Grains, Produces High Ethanol Yields and the Chaff can be Burned for Process Heat

\section{Carbon Dioxide}

The fermentation of six-carbon sugars by yeast results in the formation of carbon dioxide as well as ethanol. For every pound of ethanol produced, 0.957 pound of carbon dioxide is formed; stated another way, for every 1 gallon of ethanol produced, 6.33 pounds of carbon dioxide are formed. This ratio is fixed; it is derived from the chemical equation:

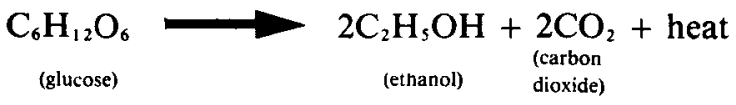

\section{Other Coproducts}

The conversion and fermentation of agricultural crops yield products in addition to ethanol and carbon dioxide. For example, even if pure glucose is fermented, some yeast will be grown, and they would represent a coproduct. These coproducts have considerable economic value, but, since they are excellent cultures for microbial contaminants, they may represent a pollutant if dumped onto the land. Therefore, it becomes doubly important that these coproducts be put to goo'd use.

Sugar crops, after the sugar has been extracted, yield plant residues which consist mostly of cellulose, unextracted sugar, and protein. Some of this material can be used as livestock feed, although the quantity and quality will vary widely with the particular crop. If the crop is of low feeding value, it may be used as fuel for the ethanol plant. This is commonplace when sugarcane is the feedstock.

Sweet sorghum may yield significant quantities of grain (milo), and the plant residue is suitable for silage, which is comparable to corn or sorghum silage except that it has a lower energy value for feeding. Sugar beet pulp from the production of sugar has always been used for livestock feed, as have the tops. Jerusalem artichokes, grown in the Soviet Union on a very large scale, are en-

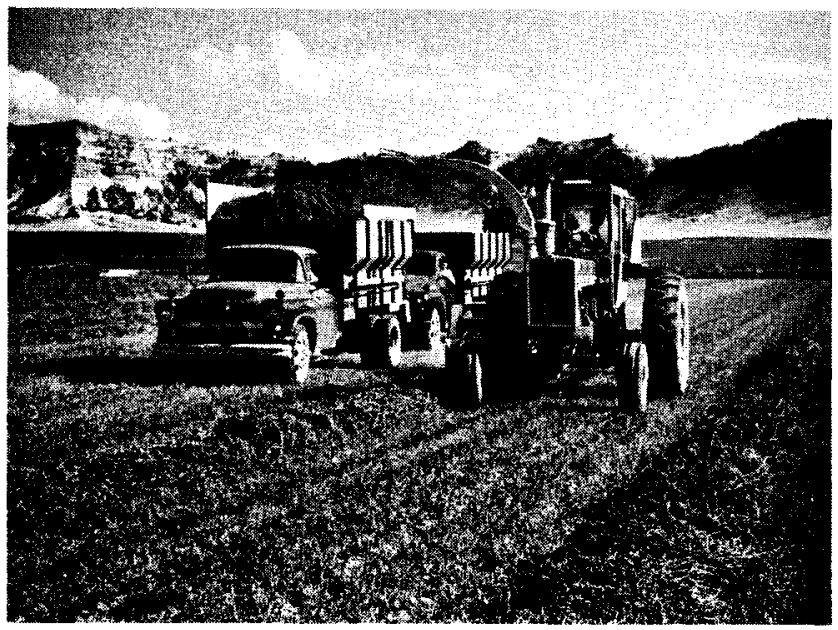

Chopped Forage Crops May Represent Significant Ethanol Production Potential as Technology for Their Use Improves

siled and fed to cattle, so the plant residue in this case would be suitable for silage. All of these residues can supply significant amounts of protein and roughage to ruminants.

It is evident that all silage production has the potential for the production of significant quantities of ethanol without affecting the present uses or agricultural markets. By planting silage crops of high sugar content and extracting a part of the sugar for the production of ethanol, the ensiled residue satisfies the existing demand for silage.

Starch feedstocks consist mostly of grains and, to a smaller extent, root crops such as potatoes (white or sweet). The production of nonfermentable material in these root crops is much less than in grains, and the use of the residue is similar.

In the case of grains, it is commonplace to cook, ferment, and distill a mash containing the whole grain. The nonfermentable portion then appears in the stillage (the liquid drawn off the bottom of the beer column after stripping off the ethanol). About three-quarters of the nonfermentable material is in suspension in the form of solids ranging from very coarse to very fine texture, and the remainder is in solution in the water. The suspended material may be separated from the liquid and dried. The coarser solids, in this case, are distillers' light grains. The soluble portion may be concentrated to a syrup with from $25 \%$ to $45 \%$ solids, called distillers' solubles. When dried together with the coarser material, the product is called distillers' dark grains. These nonfermentable solids derived from grain are valuable as high-protein supplements for ruminants in particular. However, if very large quantities of grain are fermented, the great quantity supplied may exceed the demand and lower the prices. Fortunately, the potential demand exceeds the present usage as a protein supplement, since feeding experience has shown that these 
coproducts can substitute for a significant part of the grain. When the liquid stillage is fed either as it comes from the still or somewhat concentrated, it is especially valuable, since it permits the substitution of straw for a significant proportion of the hay (e.g., alfalfa) normally fed to ruminants.

The nonfermentable portion of the grain can also be used as human food. In the wet milling industry, the grain components are normally separated and the oil is extracted. The starch may be processed for a number of uses, or it may be used as feedstock for ethanol production. The gluten (the principal portion of the protein in the grain) may be separated and processed for sale as, for example, vital gluten (from wheat) or corn gluten. As another option, the solids may be sent through the fermenters and the beer still to appear as distillers' grains.

Grain processing as practiced in large plants is not feasible for small plants. However, a simple form of processing to produce human food may be feasible. Wheat can be simply processed to separate the starch from the combined germ, gluten, and fiber. They form a cohesive, doughy mass which has long been used as a base for meat-analogs. This material can also be incorporated into bread dough to enhance its nutritional value by increasing the protein, fiber, and vitamin (germ) content.

Work at the University of Wisconsin has resulted in the development of a simple, practical processing machine that extracts about $60 \%$ of the protein from forage crops in the form of a leaf juice [6]. The protein in the juice can be separated in a dry form to be used as a very high-quality human food. The fibrous residue is then in good condition to be hydrolyzed to fermentable sugars. Most of the plant sugars are in the leaf juice and, after separation of the protein, are ready for fermentation. Forage crops have the potential for producing large amounts of ethanol per acre together with large amounts of human-food-grade protein. The protein production potential is conservatively 1,000 pounds per acre, equivalent to 140 bushels per acre of $12 \%$-protein wheat [7].

Representative feedstock composition and coproduct yields are given in Table IV-2. Appendix D provides additional information in the table comparing raw materials for ethanol production. As discussed earlier, these data cannot be applied to specific analyses without giving consideration to the variable nature of the composition of the feedstock and the yield per acre of the crop.

\section{TABLE IV-2. REPRESENTATIVE YIELDS \\ OF SOME MAJOR \\ DOMESTIC FEEDSTOCKS}

Crop Ethanol Yield

Cereal grains
Potatoes
Sugar beets
Sugarcane

$2.5 \mathrm{gal} / \mathrm{bu}$

$1.0 \mathrm{gal} / \mathrm{cwt}$

$20 \mathrm{gal} / \mathrm{ton}$

$17 \mathrm{gal} / \mathrm{ton}$

\section{AGRONOMIC CONSIDERATIONS}

A simple comparison of potential ethanol yield per acre of various crops will not rank the crops in terms of economic value for production of ethanol. The crops vary considerably in their demands on the soil, demands for water, need for fertilization, susceptibility to disease or insect damage, etc. These factors critically influence the economics of producing a crop. Fortunately, forage crops which have the potential for producing large amounts of ethanol per acre have specific agronomic advantages relative to some of the principal grain crops (e.g., corn).

The nonfruiting crops, including forage crops, some varieties of high-sugar sorghum, and Jerusalem artichokes, are less susceptible to catastrophic loss (e.g., due to hail, frost, insects, disease, etc.), and, in fact, are less likely to suffer significant loss of production due to adverse circumstances of any sort than are fruiting crops such as grains. Furthermore, forage crops and Jerusalem artichokes are less demanding in their culture than almost any grain. Their cost of culture is usually lower than for grains on the same farm, and they have great potential for planting on marginal land.

\section{FEEDSTOCK CONSIDERATIONS}

It is apparent from the foregoing discussion that the selection of feedstocks for ethanol production will vary from region to region, and even from farm to farm. The results of development work now being carried out will influence choices but, most significantly, the additional choices open to farmers resulting from the opportunity to produce feedstocks for ethanol production from a large variety of crops will alter the patterns of farming. It is not possible to predict what new patterns will evolve. However, it is clear that there will be benefits from the creation of choices in the form of new markets for existing crops and alternative crops for existing markets.

In the near future, ethanol is likely to be produced primarily from grain. However, the development of processes for the effective use of other crops should yield results in the near term which could bring about a rapid increase in the use of nongrain feedstocks. 


\section{REFERENCES}

1. Nathan, R. A. Fuels from Sugar Crops. DOE Critical Review Series. 1978. Available from NTIS, \#TID-22781.

2. Stauffer, M. D.; Chubey, B. B.; Dorrell, D. G. Jerusalem Artichoke. A publication of Agriculture Canada, Research Station, P. O. Box 3001, Morden, Manitoba, ROG 1JO, Canada. 1975.

3. Incoll, L. D.; Neales, T. F. "The Stem as a Temporary Sink before Tuberization." Helianthus Tuberosus L. Journal of Experimental Botany 21. (67); 1970; pp. 469-476.

4. Earl, W. B.; Brown, W. A. "Alcohol Fuels from Biomass in New Zealand: The Energetics and Economics of Production and Processing." Third International Symposium on Alcohol Fuels Technology. Vol. 1, pp. 1-11. Asilomar, CA; May 28-31, 1979.
5. Linden, J. D.; Hedrick, W. C.; Moreira, A. R.; Smith, D. H.; Villet, R. H. Enzymatic Hydrolysis of the Lignocellulosic Component from Vegetative Forage Crops. Paper presented before the Second Symposium on Biotechnology in Energy Production and Conversion; October 3-5, 1979. Available from James C. Linden, Department of Agricultural and Chemical Engineering, Colorado State University, Fort Collins, CO 80523.

6. Besken, K. E.; et al. "Reducing the Energy Requirements of Plant Juice Protein Production."'Paper presented at the 1975 Annual Meeting of the American Society of Agricultural Engineers; paper no. 75-1056, 1975.

7. Mann, H. O.; et al. "Yield and Quality-Sudan, Sorghum-Sudan, and Pearl Millet Hybrids." Progress Report, Colorado State University, Fort Collins, CO; 1975. 
CHAPTER V

\section{Plant Design}
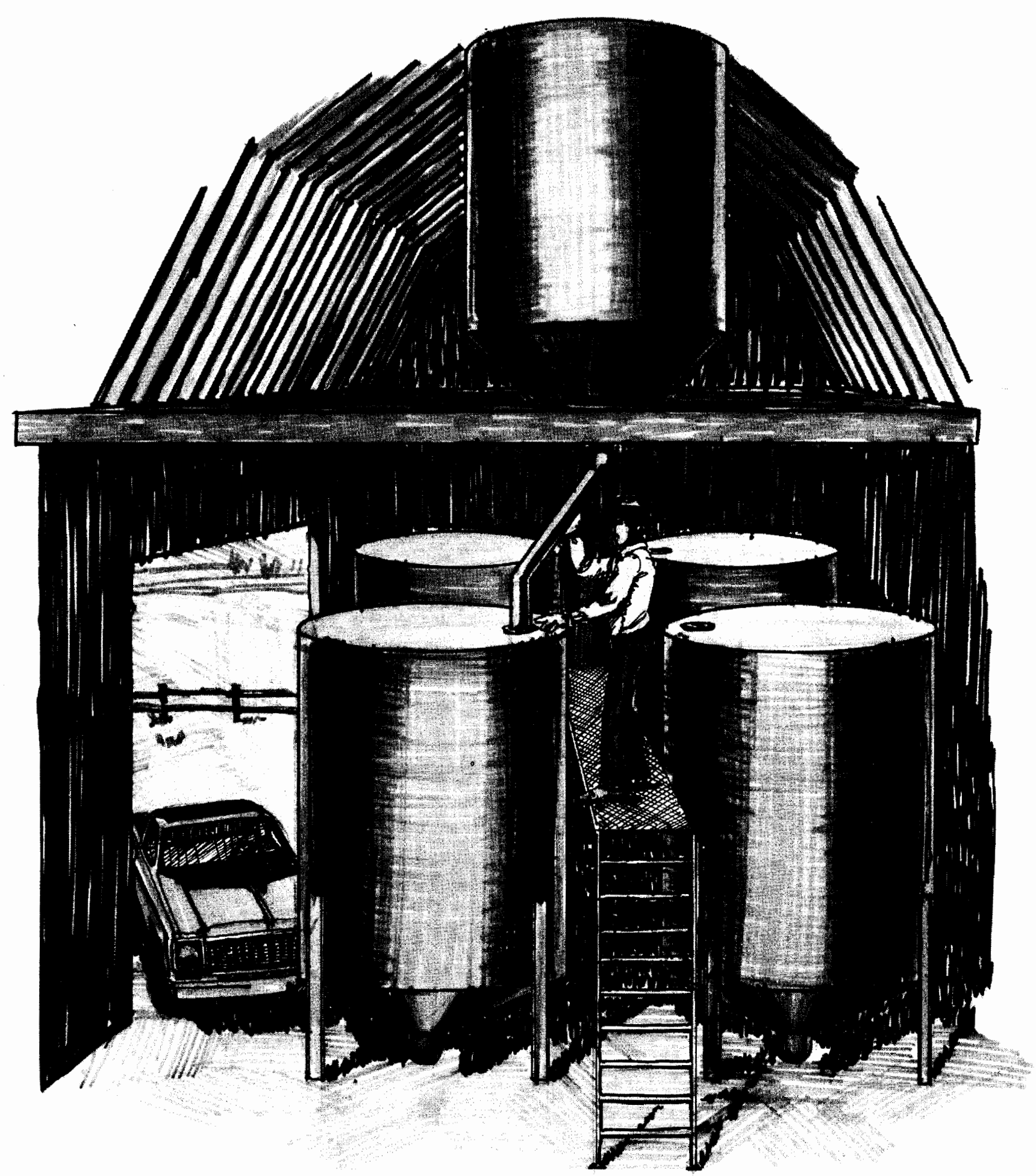
The criteria affecting the decision to produce ethanol and establishing a production facility can be categorized into two groups: fixed and variable. The fixed criteria are basically how much ethanol and coproducts can be produced and sold. These issues were discussed in Chapter II. This chapter is concerned with the second set of criteria and their effect on plant design.

Plant design is delineated through established procedures which are complex and interrelated. The essential elements, however, are described here.

The first step is to define a set of criteria which affect plant design. These criteria (not necessarily in order of importance) are:

- amount of labor that can be dedicated to operating a plant;

- size of initial investment and operating cost that can be managed in relation to the specific financial situation and/or business organization;

- ability to maintain equipment both in terms of time to do it and anticipated expense;

- federal, state, and local regulations on environmental discharges, transportation of product, licensing, etc;

- intended use (on-farm use and/or sales) of products;

- desired form of coproducts;

- safety factors;

- availability and expense of heat source; and

- desired flexibility in operation and feedstocks.

The second step is to relate these criteria to the plant as a whole in order to set up a framework or context for plant operations. The third step is complex and involves relating the individual systems or components of production to this framework and to other connected systems within the plant. Finally, once the major systems have been defined, process control systems can be integrated where necessary. This design process leads to specifying equipment for the individual systems and process control.

After the process is discussed from overall plant considerations through individual system considerations to process control, a representative ethanol plant is described. It is an example to illustrate ethanol production technology and not a state-of-the-art or recommended design.

\section{OVERALL PLANT CONSIDERATIONS}

Before individual systems and their resulting equipment specifications are examined, the criteria listed above are examined in relation to the overall plant. This establishes a set of constraints against which individual systems can be correlated.

\section{Required Labor}

The expense the operation can bear for labor must be considered. To some extent the latter concern is modified by the size of plant selected (the expense for labor is less per gallon the more gallons produced). If it is possible to accomplish the required tasks within the context of daily farming activities, additional outside labor will not be required. A plant operated primarily by one person should, in general, require attention only twice-or at most three times-a day. If possible, the time required at each visit should not exceed 2 hours. The labor availability directly affects the amount and type of control and instrumentation that the plant requires, but it is not the sole defining criteria for plant specification.

\section{Maintenance}

The plant should be relatively easy to maintain and not require extensive expertise or expensive equipment.

\section{Feedstocks}

The process should use crop material in the form in which it is usually or most economically stored (e.g., forage crops should be stored as ensilage).

\section{Use}

The choice of whether to produce anhydrous or lowerproof ethanol depends upon the intended use or market and may also have seasonal dependencies. Use of lowerproof ethanols in spark-ignition tractors and trucks poses no major problems during summertime (or other 


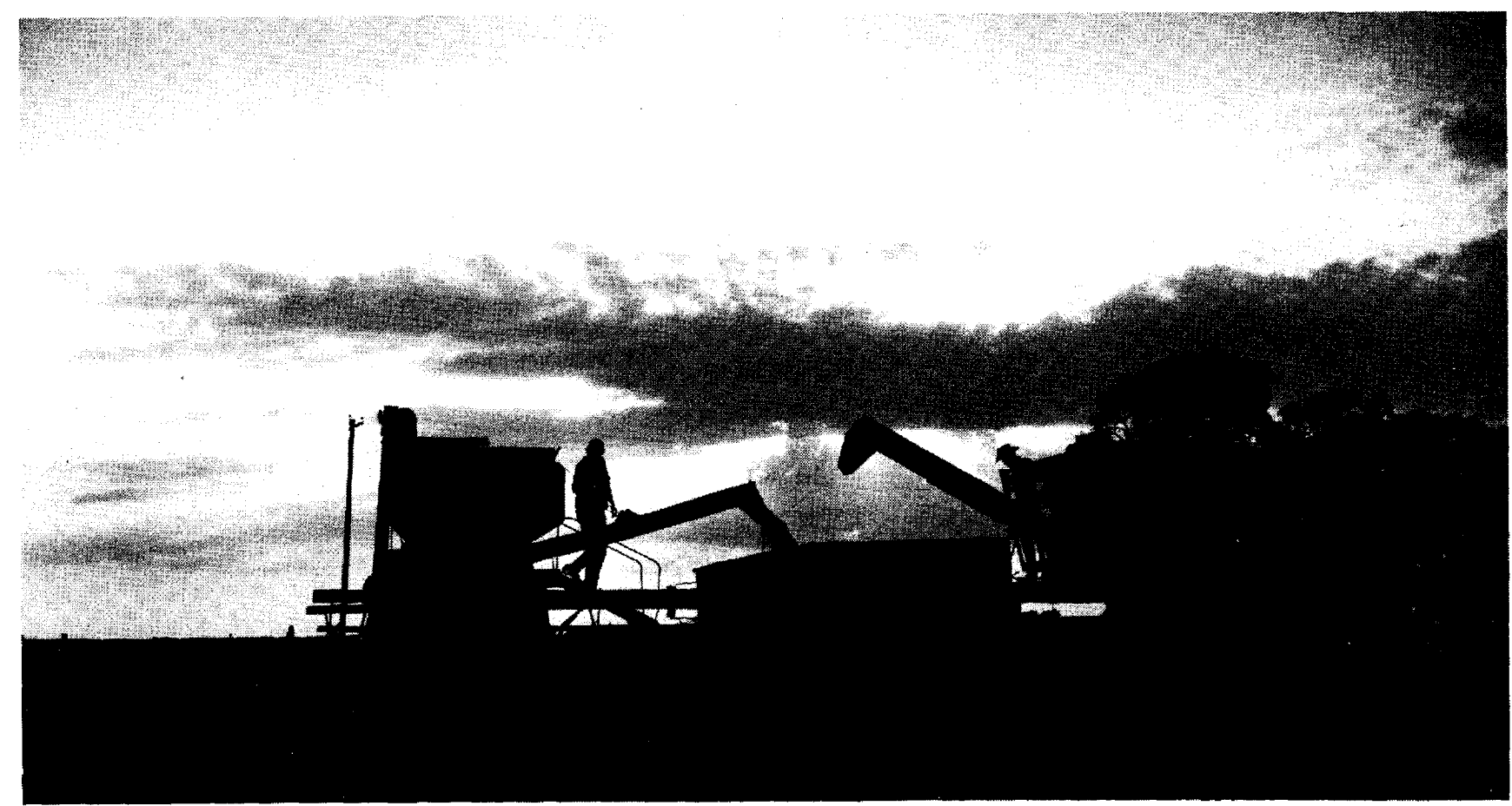

Labor Requirements for Ethanol Production can be a Part of the Normal Farm Work Routine

periods of moderate ambient temperature). Any engine equipped for dual injection does not require anhydrous ethanol during moderate seasons (or in moderate climates). If the ethanol is to be sold to blenders for use as gasohol, the capability to produce anhydrous ethanol may be mandatory.

\section{Heat Source}

Agricultural residues, coal, waste wood, municipal waste, producer gas, geothermal water, solar, and wind are the preferred possibilities for heat sources. Examples of these considerations are shown in Table V-1. Each poses separate requirements on the boiler selected, the type and amount of instrumentation necessary to fulfill tending (labor) criteria, and the cash flow necessary to purchase the necessary quantity (if not produced on-farm). This last consideration is modified by approaches that minimize the total plant energy demand.

\section{Safety}

An ethanol plant poses several specific hazards. Some of these are enumerated in Table V-2 along with options for properly addressing them.

\section{Coproduct Form and Generation}

Sale or use of the coproducts of ethanol production is an important factor in overall profitability. Markets must be carefully weighed to assure that competitive influences do not diminish the value of the coproduct that results from the selected system. In some areas, it is conceivable that the local demand can consume the coproduct produced by many closely located small plants; in other areas, the local market may only be able to absorb the coproducts from one plant. If the latter situation occurs, this either depresses the local coproduct market value or encourages the purchase of equipment to modify coproduct form or type so that it can be transported to different markets.

\section{Flexibility in Operation and Feedstocks}

Plant profitability should not hinge on the basis of theoretical maximum capacity. Over a period of time, any of a myriad of unforeseen possibilities can interrupt operations and depress yields. Market variables or farm operation considerations may indicate a need to swtich feedstocks. Therefore, equipment for preparation and conversion should be capable of handling cereal grain and at least one of the following:

- ensiled forage material;

- starchy roots and tubers; or

- sugar beets, or other storable, high-sugarcontent plant parts.

\section{Compliance with Environmental Regulations and Guidelines}

Liquid and gaseous effluents should be handled in compliance with appropriate regulations and standards.

\section{Initial Investment and Operating Costs}

All of the preceding criteria impact capital or operating costs. Each criterion can influence production rates 


\begin{tabular}{|c|c|c|c|c|c|c|c|}
\hline $\begin{array}{l}\text { Heat } \\
\text { Source }\end{array}$ & $\begin{array}{c}\text { Heating } \\
\text { Value } \\
\text { (dry basis) }\end{array}$ & Form & $\begin{array}{c}\text { Special } \\
\text { Equipment } \\
\text { Req'd }\end{array}$ & $\begin{array}{l}\text { Boiler } \\
\text { Types }\end{array}$ & Source & $\begin{array}{c}\text { Particular } \\
\text { Advantages }\end{array}$ & $\begin{array}{c}\text { Particular } \\
\text { Disadvantages }\end{array}$ \\
\hline $\begin{array}{l}\text { Agriculture } \\
\text { Residuals }\end{array}$ & $\begin{array}{c}3,000- \\
8,000 \\
\text { Btu/lb }\end{array}$ & Solid & $\begin{array}{l}\text { Handling and } \\
\text { feeding eqpmt.; } \\
\text { collection eqpmt. }\end{array}$ & $\begin{array}{l}\text { Batch burner- } \\
\text { fire tube; } \\
\text { fluidized bed }\end{array}$ & Farm & $\begin{array}{l}\text { Inexpensive; } \\
\text { produced on- } \\
\text { farm }\end{array}$ & $\begin{array}{l}\text { Low bulk } \\
\text { density; re- } \\
\text { quires very } \\
\text { large storage } \\
\text { area }\end{array}$ \\
\hline Coal & $\begin{array}{l}9,000- \\
12,000 \\
\text { Btu/lb }\end{array}$ & Solid & $\begin{array}{l}\text { High sulfur } \\
\text { coal requires } \\
\text { stack scrubber }\end{array}$ & $\begin{array}{l}\text { Conventional } \\
\text { grate- } \\
\text { fire tube; } \\
\text { fluidized bed }\end{array}$ & Mines & $\begin{array}{l}\text { Widely available } \\
\text { demonstrated } \\
\text { technology } \\
\text { for combustion }\end{array}$ & $\begin{array}{l}\text { Potentially } \\
\text { expensive; } \\
\text { no assured } \\
\text { availability; } \\
\text { pollution } \\
\text { problems }\end{array}$ \\
\hline $\begin{array}{l}\text { Waste } \\
\text { Wood }\end{array}$ & $\begin{array}{l}5,000 \\
12,000 \\
\text { Btu/lb }\end{array}$ & Solid & $\begin{array}{l}\text { Chipper or } \\
\text { log feeder }\end{array}$ & $\begin{array}{l}\text { Conventional } \\
\text { fluidized bed }\end{array}$ & Forests & $\begin{array}{l}\text { Clean burning; } \\
\text { inexpensive } \\
\text { where available }\end{array}$ & $\begin{array}{l}\text { Not uniformly } \\
\text { available }\end{array}$ \\
\hline $\begin{array}{l}\text { Municipal } \\
\text { Solid } \\
\text { Waste }\end{array}$ & $\begin{array}{l}8,000 \\
\text { Btu/lb }\end{array}$ & Solid & Sorting eqpmt. & $\begin{array}{l}\text { Fluidized bed } \\
\text { or conventional } \\
\text { fire tube }\end{array}$ & Cities & Inexpensive & $\begin{array}{l}\text { Not widely } \\
\text { available in } \\
\text { rural areas }\end{array}$ \\
\hline $\begin{array}{l}\text { Pyrolysis } \\
\text { Gas }\end{array}$ & & Gas & $\begin{array}{l}\text { Pyrolyzer- } \\
\text { fluidized bed }\end{array}$ & $\begin{array}{l}\text { Conventional } \\
\text { gas-boiler }\end{array}$ & $\begin{array}{l}\text { Carbon- } \\
\text { aceous } \\
\text { materials }\end{array}$ & $\begin{array}{l}\text { Can use conven- } \\
\text { tional gas-fired } \\
\text { boilers }\end{array}$ & $\begin{array}{l}\text { Requires addi- } \\
\text { tional piece of } \\
\text { equipment }\end{array}$ \\
\hline Geothermal & 1 N.A. & $\begin{array}{l}\text { Steam/ } \\
\text { hot water }\end{array}$ & Heat exchanger & $\begin{array}{l}\text { Heat exchanger } \\
\text { water tube }\end{array}$ & $\begin{array}{l}\text { Geothermal } \\
\text { source }\end{array}$ & $\begin{array}{l}\text { Fuel cost is } \\
\text { zero }\end{array}$ & $\begin{array}{l}\text { Capital costs } \\
\text { for well and } \\
\text { heat exchanger } \\
\text { can be ex- } \\
\text { tremely high }\end{array}$ \\
\hline Solar & N.A. $\quad R$ & Radiation & $\begin{array}{l}\text { Collectors, } \\
\text { concentrators, } \\
\text { storage batteries, } \\
\text { or systems }\end{array}$ & Water tube & Sun & $\begin{array}{l}\text { Fuel cost is } \\
\text { zero }\end{array}$ & $\begin{array}{l}\text { Capital costs } \\
\text { can be high } \\
\text { for required } \\
\text { equipment }\end{array}$ \\
\hline Wind & N.A. & $\begin{array}{l}\text { Kinetic } \\
\text { energy }\end{array}$ & $\begin{array}{l}\text { Turbines, } \\
\text { storage batteries, } \\
\text { or systems }\end{array}$ & Electric & $\begin{array}{l}\text { Indirect } \\
\text { solar }\end{array}$ & $\begin{array}{l}\text { Fuel cost is } \\
\text { zero }\end{array}$ & $\begin{array}{l}\text { Capital costs } \\
\text { can be high } \\
\text { for required } \\
\text { equipment }\end{array}$ \\
\hline
\end{tabular}

which, in turn, change the income potential of the plant. An optimum investment situation is reached only through repeated iterations to balance equipment requirements against cost in order to achieve favorable earnings.

\section{INDIVIDUAL SYSTEM CONSIDERATIONS}

Design considerations define separate specific jobs which require different tools or equipment. Each step depends upon the criteria involved and influences related steps. Each of the components and systems of the plant must be examined with respect to these criteria Figure V-1 diagrams anhydrous ethanol production. The typical plant that produces anhydrous ethanol contains the following systems and/or components: feedstock handling and storage, conversion of car- 
bohydrates to simple sugars, fermentation, distillation, drying ethanol, and stillage processing.

\section{Feedstock Handling and Storage}

Grain. A small plant should be able to use cereal grains. Since grains are commonly stored on farms in large quantity, and since grain-growing farms have the basic equipment for moving the grain out of storage, handling should not be excessively time consuming. In general, grains should be dried before storing to prevent premature decomposition and growth of unwanted organisms. It may be possible to irradiate grain or use other techniques that permit storage without the need for drying. If the grain is ground and stored in a bunker, the handling involves additional labor since it must be removed from the bunker and loaded into a grainery from which it can be fed by an auger into the cooker. This operation probably could be performed once each week, so the grains need not be ground daily as with whole (wet) grain.

Roots and tubers. Beets and Jerusalem artichokes can be left in the ground until needed for processing. Potatoes are generally stored whole in cool, dry locations to forestall fermentation by bacteria. The juice from beets and artichokes can be extracted but can only be stored if the sugar concentration is extremely high. This requires expensive evaporation equipment and large storage tanks.

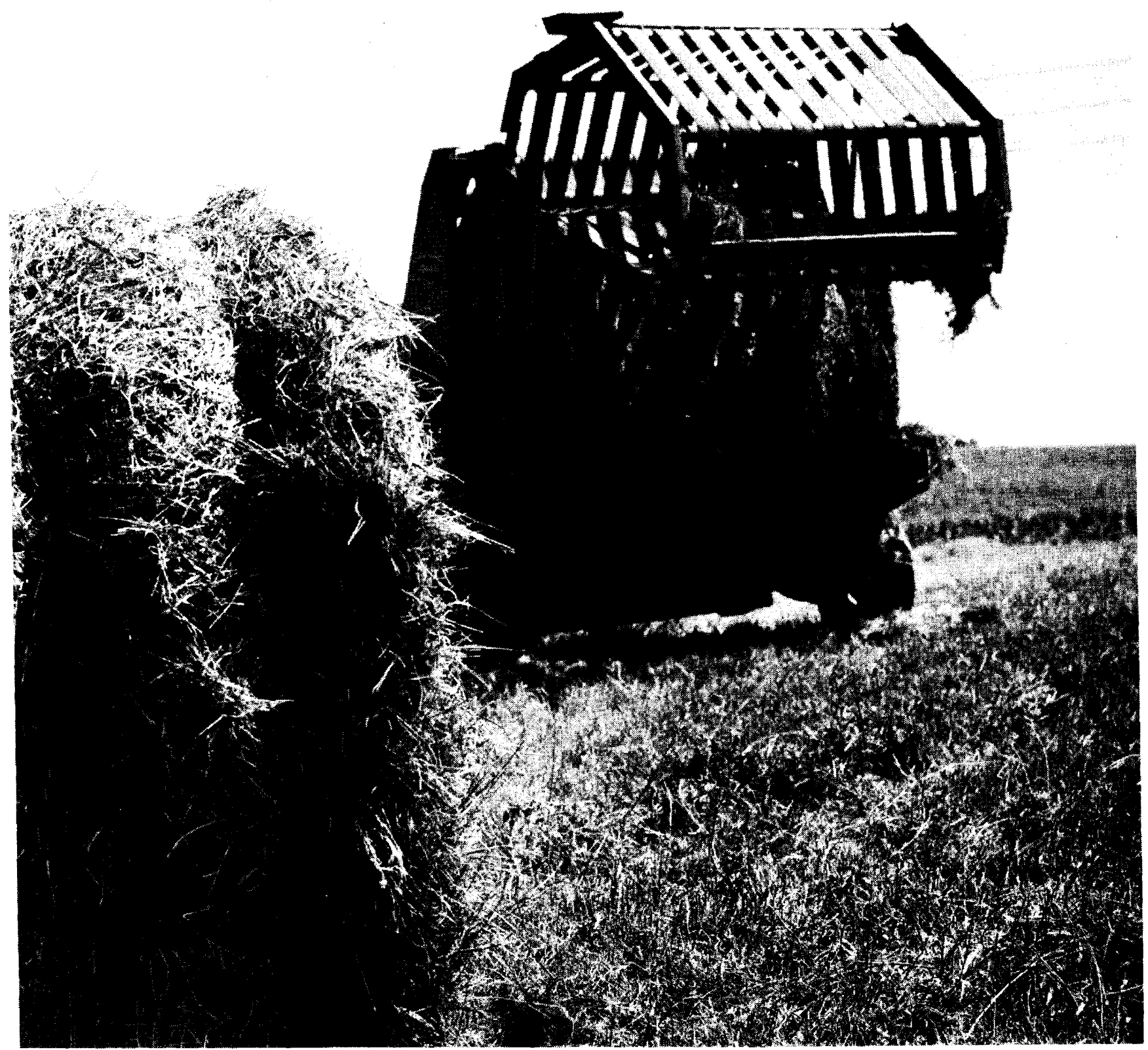

Equipment for Handling and Storage of Crop Residues is Currently Available from Farm Equipment Manufacturers 
1. Overpressurization; explosion of boiler

2. Scalding from steam gasket leaks

3. Contact burns from steam lines

4. Ignition of ethanol leaks/fumes or grain dust
- Regularly maintained/checked safety boiler "pop" valves set to relieve when pressure exceeds the maximum safe pressure of the boiler or delivery lines.

- Strict adherence to boiler manufacturer's operating procedure.

- If boiler pressure exceeds 20 psi, acquire ASME boiler operator certification. Continuous operator attendance required during boiler operation.

- Place baffles around flanges to direct steam jets away from operating areas.

- (Option) Use welded joints in all steam delivery lines.

- Insulate all steam delivery lines.

- If electric pump motors are used, use fully enclosed explosion-proof motors.

- (Option) Use hydraulic pump drives; main hydraulic pump and reservoir should be physically isolated from ethanol tanks, dehydration section, distillation columns, condenser.

- Fully ground all equipment to prevent static electricity build-up.

- Never smoke or strike matches around ethanol tanks, dehydration section, distillation columns, condenser.

- Never use metal grinders, cutting torches, welders, etc. around systems or equipment containing ethanol. Flush and vent all vessels prior to performing any of these operations.

- Never breathe the fumes of concentrated acids or bases.

- Never store concentrated acids in carbon steel containers.

- Mix or dilute acids and bases slowly-allow heat of mixing to dissipate.

- Immediately flush skin exposed to acid or base with copious quantities of water. 


\section{Suffocation}

Belt conveyers will suffice for handling these root crops and tubers. Cleaning equipment should be provided to prevent dirt and rocks from building up in the fermentation plant.

Sugar Crops. Stalks from sugarcane, sweet sorghum, and Jerusalem artichokes cannot be stored for long periods of time at high moisture content. Drying generally causes some loss of sugar. Field drying has not been successful in warm climates for sugarcane and sweet sorghum. Work is being conducted in field drying for sweet sorghum in cooler climates; results are encouraging though no conclusions can be drawn yet.

Canes or stalks are generally baled and the cut ends and cuts from leaf stripping are seared to prevent loss of juice.

A large volume of material is required to produce a relatively small amount of sugar, thus a large amount of storage space is necessary. Handling is accomplished with loaders or bale movers.

\section{Conversion of Carbohydrates to Simple Sugars}

Processing options available for converting carbohydrates to simple sugars are:

- enzymatic versus acid hydrolysis;

- high-temperature versus low-temperature cooking;

- continuous versus batch processing; and

- separation versus nonseparation of fermentable nonsolids.
- Wear goggles whenever handling concentrated acids or bases; flush eyes with water and immediately call physician if any gets in eyes.

- Do not store acids or bases overhead work areas or equipment.

- Do not carry acids or bases in open buckets.

- Select proper materials of construction for all acid or base storage containers, delivery aides, valves, etc.

- Never enter the fermenters, beer well, or stillage tank unless they are properly vented.
Enzymatic versus acid hydrolysis. Enzymatic hydrolysis of the starch to sugar is carried out while cooling the cooked liquified starch to fermentation temperature. The saccharifying enzyme is added at about $140^{\circ} \mathrm{F}$, and this temperature is maintained for about 30 minutes to allow nearly complete hydrolysis following which the mash is cooled to fermentation temperature. A highactivity enzyme is added prior to cooking so that the starch is quickly converted to liquid polymeric sugars. The saccharifying enzyme reduces these sugars to monomeric sugars. Temperature and $\mathrm{pH}$ must be controlled within specific limits or enzyme activity decreases and cooking time is lengthened. Thus the

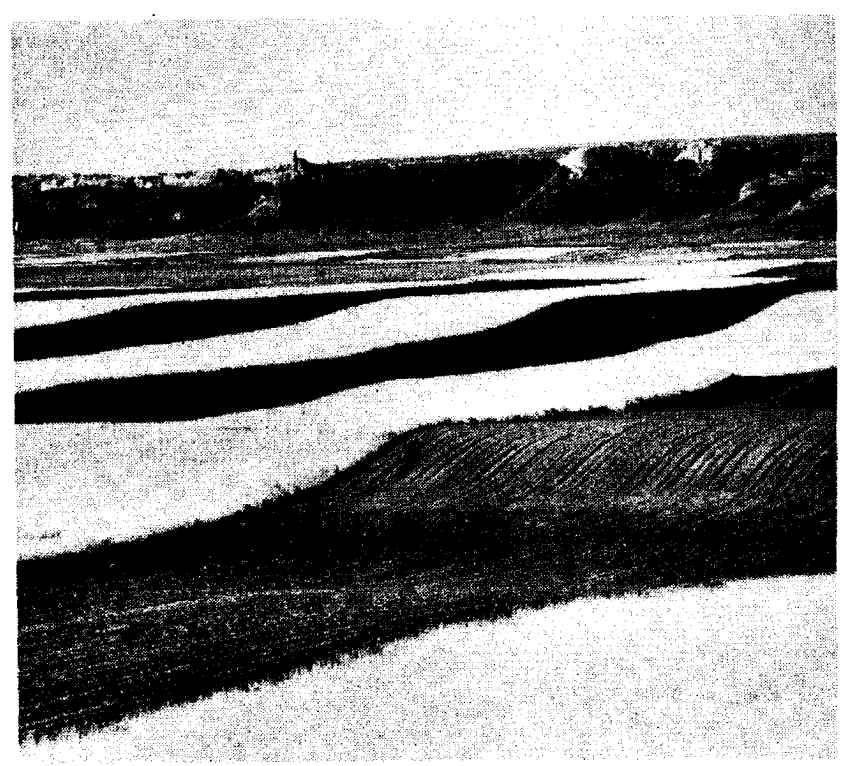

Crops for Ethanol Production fit Well into Normal Rotation Practices 


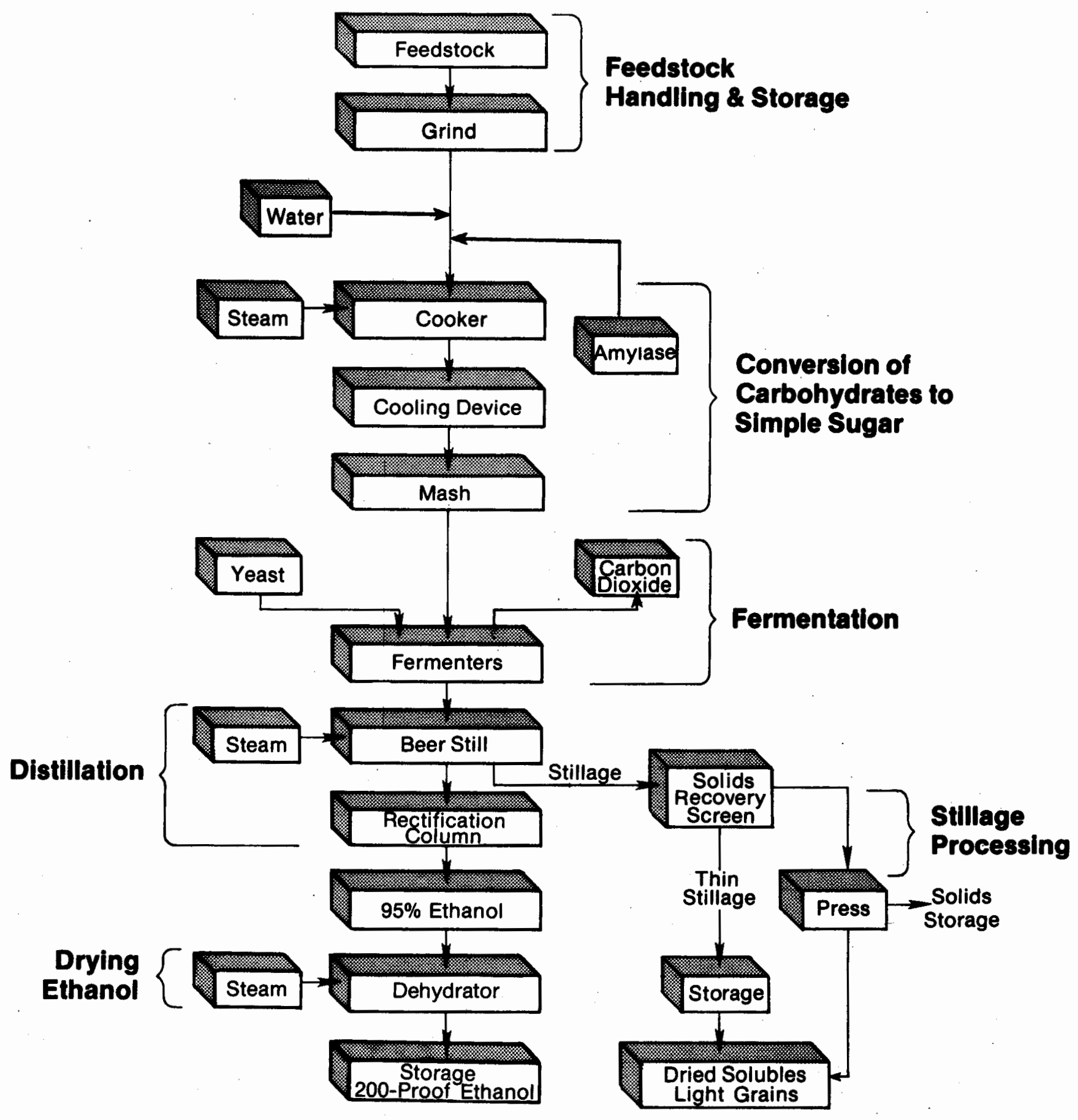

Figure V-1. Anhydrous Ethanol Production Flow Chart 
equipment for heating and cooling and the addition of acid or base are necessary.

Acid hydrolysis of starch is accomplished by directly contacting starch with hot dilute acid to break the polymer bonds. This process hydrolyzes the starch very rapidly at cooking temperatures and reduces the time needed for cooking. Since the resulting $\mathrm{pH}$ is lower than desired for fermentation, it must be increased after fermentation is complete by neutralizing some of the acid with either powdered limestone or ammonium hydroxide. It also may be desirable to add a small amount of gluco-amylase enzyme after $\mathrm{pH}$ correction in order to convert the remaining dextrins.

High-temperature versus low-temperature cooking. Grain must be cooked to rupture the starch granules and to make the starch accessible to the hydrolysis agent. Cooking time and temperature are related in an inverse ratio; high temperatures shorten cooking time. Industry practice is to heat the meal-water mixture by injecting steam directly rather than by heat transfer through the wall of the vessel. The latter procedure runs the risk of causing the meal to stick to the wall; the subsequent scorching or burning would necessitate a shutdown to clean the surface.

High-temperature cooking implies a high-pressure boiler. Because regulations may require an operator in constant attendance for a high-pressure boiler operation, the actual production gain attributable to the high temperature must be weighed against the cost of the operator. If there are other supporting rationale for having the operator, the entire cost does not have to be offset by the production gain.

Continuous versus batch processes. Cooking can be accomplished with continuous or batch processes. Batch cooking can be done in the fermenter itself or in a separate vessel. When cooking is done in the fermenter, less pumping is needed and the fermenter is automatically sterilized before fermenting each batch. There is one less vessel, but the fermenters are slightly larger than those used when cooking is done in a separate vessel. It is necessary to have cooling coils and an agitator (or heat exchanger and pump) in each fermenter. If cooking is done in a separate vessel, there are advantages to selecting a continuous cooker. The continuous cooker (or continuous extruder) is smaller than the fermenter, and continuous cooking and hydrolysis lend themselves very well to automatic unattended operation. Energy consumption is less because it is easier to use counterflow heat exchangers to heat the water for mixing the meal while cooling the cooked meal. The load on the boiler with a continuous cooker is constant. Constant boiler load can be achieved with a batch cooker by having a separate vessel for preheating the water, but this increases the cost when using enzymes.
Continuous cooking (or continuous extruding) offers a high-speed, high-yield choice that does not require constant attention. Cooking at atmospheric pressure with a temperature a little over $200^{\circ} \mathrm{F}$ yields a good conversion ratio of starch to sugar, and no high pressure piping or pumps are required.

Separation versus nonseparation of nonfermentable solids. The hydrolyzed mash contains solids and dissolved proteins as well as sugar. There are some advantages to separating the solids before fermenting the mash, and such a step is necessary for continuous fermentation. Batch fermentation requires separation of the solids if the yeast is to be recycled. If the solids are separated at this point, the beer column will require cleaning much less frequently, thus increasing the feasibility of a packed beer column rather than plates. The sugars that cling to the solids are removed with the solids. If not recovered, the sugar contained on the solids would represent a loss of $20 \%$ of the ethanol. Washing the solids with the hot mash water or with hot stillage from the centrifuge is a way of recovering most of the sugar.

\section{Fermentation}

Continuous fermentation. The advantage of continuous fermentations of pure sugar are routinely accomplished in less than 30 hours. High conversion efficiency is attained as sugar is converted to $10 \%$-alcohol beer without yeast recycle. Further reductions in fermentation require very large quantities of yeast. The increases attained in ethanol production must be weighed against the additional costs of the equipment and time to culture large yeast populations for inoculation.

Batch fermentation. Fermentation time periods similar to those possible with continuous processes can be attained by using high concentrations of yeast in batch fermentation. The high yeast concentrations are economically feasible when the yeast is recycled. Batch fermentations of pure sugar are routinely accomplished in less than $\mathbf{3 0}$ hours. High conversion efficiency is attained as sugar is converted to $10 \%$-alcohol beer without yeast recycle. Further reductions in fermentation require very large quantities of yeast. The increases attained in ethanol production must be weighed against the additional costs of the equipment and time to culture large yeast populations for inoculation.

Specifications of the fermentation tank. The configuration of the fermentation tank has some influence on system performance. In general, the proportions of the tank should not be extreme. Commonly, tanks are upright cylinders with the height somewhat greater than the diameter. The bottom may be flat (but sloped for drainage) or conical. The construction materials may be carbon steel (commonplace), stainless steel, copper, wood, fiberglass, reinforced plastic, or concrete coated on the inside with sprayed-on vinyl. Usually, the 
tanks are covered to permit collection of the $\mathrm{CO}_{2}$ evolved during fermentation so that the ethanol which evaporates with it can be recovered.

Many potential feedstocks are characterized by relatively large amounts of fibrous material. Fermentation of sugar-rich material such as sugar beets, sweet sorghum, Jerusalem artichokes, and sugarcane as chips is not a demonstrated technology and it has many inherent problems. Typically, the weight of the nonfermentable solids is equal or somewhat greater than the weight of fermentable material. This is in contrast to grain mashers which contain roughly twice as much fermentable material as nonfermentable material in the mash. The volume occupied by the nonfermentable solids reduces the effective capacity of the fermenter. This means that larger fermenters must be constructed to equal the production rates from grain fermenters. Furthermore, the high volume of nonfermentable material limits sugar concentrations and, hence, the beer produced is generally lower in concentration (6\% versus $10 \%)$ than that obtained from grain mashes. This fact increases the energy spent in distillation.

Since the nonfermentable solid chips are of larger size, it is unlikely that the beer containing the solids could be run through the beer column. It may be necessary to separate the solids from the beer after fermentation because of the potential for plugging the still. The separation can be easily accomplished, but a significant proportion of the ethanol (about $20 \%$ ) would be carried away by the dewatering solids. If recovery is attempted by "washing out," the ethanol will be much more dilute than the beer. Since much less water is added to these feedstocks than to grain (the feedstock contains large amounts of water), only part of the dilute ethanol solution from the washing out can be recycled through the fermenter. The rest would be mixed with the beer, reducing the concentration of ethanol in the beer which, in turn, increases the energy required for distillation. Another approach is to evaporate the ethanol from the residue. By indirectly heating the residue, the resulting ethanol-water vapor mixture can be introduced into the beer column at the appropriate point. This results in a slight increase in energy consumption for distillation.

The fermenter for high-bulk feedstocks differs somewhat from that used for mash. The large volume of insoluble residue increases the demands on the removal pump and pipe plugging is more probable. Agitators must be sized to be self-cleaning and must prevent massive settling. High-speed and high-power agitators must be used to accomplish this.

The equipment for separating the fibrous residue from the beer when fermenting sugar crops could be used also to clarify the grain mash prior to fermentation. This would make possible yeast recyle in batch fermentation of grain.

Temperature control. Since there is some heat generated during fermentation, care must be taken to ensure that the temperature does not rise too high and kill the yeast. In fermenters the size of those for on-farm plants, the heat loss through the metal fermenter walls is sufficient to keep the temperature from rising too high when the outside air is cooler than the fermenter. Active cooling must be provided during the periods when the temperature differential cannot remove the heat that is generated. The maximum heat generation and heat loss must be estimated for the particular fermenter to assure that water cooling provisions are adequate.

\section{Distillation}

Preheater. The beer is preheated by the hot stillage from the bottom of the beer column before being introduced into the top of the beer column. This requires a heat exchanger. The stillage is acidic and hot so copper or stainless steel tubing should be used to minimize corrosion to ensure a reasonable life. Because the solids are proteinaceous, the same protein build-up that plugs the beer still over a period of time can be expected on the stillage side of the heat exchanger. This mandates accessibility for cleaning.

Beer column requirements. The beer column must accept a beer with a high solids content if the beer is not clarified. Not only are there solids in suspension, but also some of the protein tends to build up a rather rubbery coating on all internal surfaces. Plate columns offer the advantage of relatively greater cleaning ease when compared to packed columns. Even if the beer is clarified, there will be a gradual build-up of protein on the inner surfaces. This coating must be removed periodically. If the plates can be removed easily, this cleaning may be done outside of the column. Otherwise, a caustic solution run through the column will clean it.

The relatively low $\mathrm{pH}$ and high temperature of the beer column will corrode mild steel internals, and the use of stainless steel or copper will greatly prolong the life expectancy of the plates in particular. Nevertheless, many on-farm plants are being constructed with mild steel plates and columns in the interest of low first cost and ease of fabrication with limited shop equipment. Only experience will indicate the life expectancy of mild steel beer columns.

Introducing steam into the bottom of the beer column rather than condensing steam in an indirect heat exchanger in the base of the column is a common practice. The latter procedure is inherently less efficient but does not increase the total volume of water in the stillage as does the former. Indirect heating coils also tend to suffer from scale buildup. 
Rectifying column. The rectifying column does not have to handle liquids with high solids content and there is no protein buildup, thus a packed column suffers no inherent disadvantage and enjoys the advantage in operating stability. The packing can be a noncorroding material such as ceramic, glass, or stainless steel.

General considerations. Plate spacing in the large columns of commercial distilleries is large enough to permit access to clean the column. The small columns of on-farm plants do not require such large spacing. The shorter columns can be installed in farm buildings of standard eave height and are much easier to work on.

All items of equipment and lines which are at a significantly higher temperature than ambient should be insulated, including the preheated beer line, the columns, the stillage line, etc. Such insulation is more significant for energy conservation in small plants than for large plants.

\section{Drying Ethanol}

Addition of a third liquid to the azeotrope. Ethanol can be dehydrated by adding a third liquid such as gasoline to the 190-proof constant boiling azeotrope. This liquid changes the boiling characteristics of the mixture and further separation to anhydrous ethanol can be accomplished in a reflux still. Benzene is used in industry as a third liquid, but it is very hazardous for on-farm use. Gasoline is a suitable alternative liquid and does not pose the same health hazards as benzene, but it fractionates in a distillation column because gasoline is a mixture of many organic substances. This is potentially an expensive way to break the azeotrope unless the internal reflux is very high, thereby minimizing the loss of gasoline from the column. Whatever is choosen for the third liquid, it is basically recirculated continually in the reflux section of the drying column, and thus only very small fractions of makeup are required. The additional expense for equipment and energy must be weighed carefully against alternative drying methods or product value in uses that do not require anhydrous ethanol.

Molecular sieve. The removal of the final $4 \%$ to $6 \%$ water has also been accomplished on a limited basis using a desiccant (such as synthetic zeolite) commonly known as a molecular sieve. A molecular sieve selectively absorbs water because the pores of the material are smaller than the ethanol molecules but larger than the water molecules. The sieve material is packed into two columns. The ethanol-in either vapor or liquid form-is passed through one column until the material in that column can no longer absorb water. Then the flow is switched to the second column, while hot $\left(450^{\circ} \mathrm{F}\right)$ and preferably nonoxidizing gas is passed through the first column to evaporate the water. Carbon dioxide from the fermenters would be suitable for this. Then the flow is automatically switched back to the other column. The total energy requirement for regeneration may be significant (the heat of absorption for some synthetic zeolites is as high as $2,500 \mathrm{Btu} / \mathrm{lb}$ ). Sieve material is available from the molecular sieve manufacturers listed in Appendix E, but columns of the size required must be fabricated. The molecular sieve material will probably serve for 2,000 cycles or more before significant deterioration occurs.

Selective absorption. Another very promising (though undemonstrated) approach to dehydration of ethanol has been suggested by Ladisch [1]. Various forms of starch (including cracked corn) and cellulose selectively absorb water from ethanol-water vapor. In the case of grains, this opens the possibility that the feedstock could be used to dehydrate the ethanol and, consequently, regeneration would not be required. More investigation and development of this approach is needed.

\section{Stillage Processing}

The stillage can be a valuable coproduct of ethanol production. The stillage from cereal grains can be used as a high-protein component in animal feed rations, particularly for ruminants such as steers or dairy cows. Small on-farm plants may be able to directly use the whole stillage as it is produced since the number of cattle needed to consume the stillage is not large (about one head per gallon of ethanol production per day).

Solids separation. The solids can be separated from the water to reduce volume (and hence shipping charges) and to increase storage life. Because the solids contain residual sugars, microbial contaminants rapidly spoil stillage if it is stored wet in warm surroundings. The separation of the solids can be done easily by flowing the stillage over an inclined, curved screen consisting of a number of closely-spaced transverse bars. The solids slide down the surface of the screen, and the liquid flows through the spaces between the bars. The solids come off the screen with about $85 \%$ water content, dripping wet. They can drop off the screen into the hopper of a dewatering press which they leave at about $65 \%$ water content. Although the solids are still damp, no more water can be easily extracted. The liquid from the screen and dewatering press contains a significant proportion of dissolved proteins and carbohydrates.

Transporting solids. The liquid from the screen and dewatering press still contains a significant proportion of dissolved proteins and carbohydrates. If the damp solids are packed in airtight containers in $\mathrm{CO}_{2}$ atmosphere, they may be shipped moderate distances and stored for a short time before microbes cause major spoilage. This treatment would enable the solids from most small plants to reach an adequate market. While the solids may easily be separated and dewatered, concentrating the liquid (thin stillage) is not simple. It can be concentrated by evaporation, but the energy con- 
sumption is high unless multiple-effect evaporators are used. These evaporators are large and expensive, and may need careful management with such proteinaceous liquids as thin stillage.

Stillage from aflatoxin-contaminated grains or those treated with antibiotics are prohibited from use as animal feed.

Distillers' solubles, which is the low-concentration ( $3 \%$ to $4 \%$ solids) solution remaining after the solids are dewatered, must be concentrated to a syrup of about $25 \%$ solids before it can be economically shipped moderate distances or stored for short times. In this form it can be sold as a liquid protein to be used in mixed feed or it can be dried along with the damp distillers' grains.

Disposing of thin stillage. If the distance from markets for the ethanol coproduct necessitates separating and dewatering the stillage from an on-farm plant, and if the concentration of the stillage for shipment is not feasible, then the thin stillage must be processed so that it will not be a pollutant when discharged. Thin stillage can be anaerobically fermented to produce methane. Conventional flow-through type digesters are dependent upon so many variables that they cannot be considered commercially feasible for on-farm use. Experimental work with packed-bed digesters is encouraging because of the inherent stability observed.

Another way to dispose of the thin stillage is to apply it to the soil with a sprinkler irrigation system. Trials are necessary to evaluate the various processes for handling the thin stillage. Because the stillage is acidic, care must be taken to assure that soil acidity is not adversely affected by this procedure.

\section{PROCESS CONTROL}

Smooth, stable, and trouble-free operation of the whole plant is essential to efficient conversion of the crop material. Such operation is, perhaps, more important to the small ethanol plant than to a larger plant, because the latter can achieve efficiency by dependence on powerful control systems and constant attention from skilled operators. Process control begins with equipment characteristics and the integration of equipment. There is an effect on every part of the process if the conditions are changed at any point. A good design will minimize negative effects of such interactions and will prevent any negative disturbance in the system from growing. Noncontinuous processes (e.g., batch fermentation) tend to minimize interactions and to block such disturbances. The basic components requiring process control in a small-scale ethanol plant are cooking and hydrolysis, fermentation, distillation, ethanol drying system pumps and drives, and heat source.

\section{Control of Cooking and Hydrolysis}

Input control. All inputs to the process must be controlled closely enough so that the departures from the desired values have inconsequential effects. The batch process has inherently wider tolerances than the continuous process. Tolerances on the grain-water ratio can be fairly loose. A variation of $1 / 2 \%$ in ethanol content will not seriously disturb the system. This corresponds to about a $3 \%$ tolerance on weight or volume measure. Meal measurement should be made by weight, since the weight of meal filling a measured volume will be sensitive to many things, such as grain moisture content, atmospheric humidity, etc. Volume measurement of water is quite accurate and easier than weighing. Similarly, volume measurement of enzymes in liquid form is within system tolerances. Powdered enzymes ideally should be measured by weight but, in fact, the tolerance on the proportion of the enzymes is broad enough so that volume measure also is adequate.

Temperature, pH, and enzyme control. The temperature, $\mathrm{pH}$, and enzyme addition must also be controlled. The allowed variation of several degrees means that measurement of temperature to a more than adequate precision can be easily accomplished with calibrated, fast-response indicators and read-outs. The time dependence brings in other factors for volume and mass. A temperature measurement should be representative of the whole volume of the cooker; however, this may not be possible because, as the whole mass is heating, not all parts are receiving the same heat input at a given moment since some parts are physically far removed from the heat source. This affects not only the accuracy of the temperature reading but also the cooking time and the action of the enzyme. Uniformity of temperature and of enzyme concentration throughout the mass of cooking mash is desired and may be attained by mixing the mass at a high rate. Thus, agitation is needed for the cooker. The temperature during the specific phases of cooking and hydrolysis must be controlled by regulating steam and cooling water flow-rates based on temperature set-points.

Automatic controls. An automatic controller could be used to turn steam and cooling water on and off. The flow of meal, water, enzymes, and yeast could be turned on and off by the same device. Therefore, the loading and preparation of a batch cooker or fermenter could easily be carried out automatically. Safety can be ensured by measuring limiting values of such quantities as temperature, water level, $\mathrm{pH}$, etc., and shutting down the process if these were not satisfied. Any commercial boiler used in a small plant would be equipped with simple, automatic controls including automatic shutdown in case certain conditions are not met. There is a need for an operator to check on the system to assure that nothing goes wrong. For example, the mash can set 
up during cooking, and it is better to have an operator exercise judgment in this case than to leave it entirely to the controls. Since cooking is the step in which there is the greatest probability of something going wrong, an operator should be present during the early, critical stages of batch cooking. If continuous cooking is used, unattended operation requires that the process be well enough controlled so that there is a small probability of problems arising.

\section{Control of Fermentation}

Temperature and $\mathrm{pH}$ control. Batch fermentation does not need direct feedback control except to maintain temperature as long as the initial conditions are within acceptable limits. For the small plant, these limits are not very tight. The most significant factors are $\mathrm{pH}$ and temperature. Of the two, temperature is most critical. It is very unlikely that the change in $\mathrm{pH}$ will be great enough to seriously affect the capacity of the yeast to convert the sugar. Fermentation generates some heat, so the temperature of the fermenter tends to rise. Active cooling must be available to assure that summertime operations are not drastically slowed because of hightemperature yeast retardation.

The temperature of the fermenter can be measured and, if the upper limit is exceeded, cooling can be initiated. It is possible to achieve continuous control of the fermenter temperature through modulation of the cooling rate of the contents. Such a provision may be necessary for very fast fermentation.

Automatic control. Continuous fermentation, like continuous cooking, should have continuous, automatic control if constant attendance by an operator is to be avoided.

The feasibility of continuous, "unattended fermentation in on-farm plants has not been demonstrated, although it is a real possibility.

Control with attention at intervals only. The feasibility of batch fermentation with attention at intervals has been established. After initiating the cooking and hydrolysis steps, the operator could evaluate the progress of fermentation at the end of the primary phase and make any adjustments necessary to assure successful completion of the fermentation. This interval between the points requiring operator attention can vary widely, but is usually from 8 to 12 hours. Fermentation can be very fast-as short as 6 hours-but the conditions and procedures for reliably carrying out such fast fermentations have not yet been completely identified and demonstrated. The schedule for attending the plant should allow about $15 \%$ additional time over that expected for completion of the fermentation process. This permits the operator to maintain a routine in spite of inevitable variations in fermentation time.

\section{Controls for Distillation}

The distillation process lends itself well to unattended operation. Continuous control is not mandatory because the inputs to the columns can easily be established and maintained essentially constant. These inputs include the flow rate of beer, the flow rate of steam, and the reflux flow rate. These are the only independent variables. Many other factors influence column operation, but they are fixed by geometry or are effectively constant. Once the distillation system is stabilized, only changes in ambient temperature might affect the flow balance as long as the beer is of constant ethanol content. Sensitivity to ambient temperature can be minimized by the use of insulation on all elements of the distillation equipment, and by installing the equipment in an insulated building. Occasional operator attention will suffice to correct the inevitable slow drift away from set values. The system also must be adjusted for changes in ethanol content from batch to batch.

Distillation column design can aid in achieving stable operation. Packed columns are somewhat more stable than plate columns, particularly as compared to simple sieve plates.

Starting up the distillation system after shutdown is not difficult and can be accomplished either manually or automatically. An actual sequence of events is portrayed in the representative plant described at the end of this chapter. The process is quite insensitive to the rate of change of inputs, so the demands made on the operator are not great. It is important that the proper sequence be followed and that the operator know what settings are desired for steady-state operation.

\section{Control of Ethanol Drying System}

Operation of a molecular sieve is a batch process. As such, it depends on the capacity of the desiccant to ensure completion of drying. No control is necessary except to switch ethanol flow to a regenerated column when the active column becomes water-saturated. Water saturation of the sieve can be detected by a rise in temperature at the discharge of the column. This temperature rise signals the switching of flow to the other column, and regeneration of the inactive column is started immediately. The regeneration gas, probably $\mathrm{CO}_{2}$ from the fermenter, is heated by flue gas from the boiler. The control consists of initiating flow and setting the temperature. The controller performs two functions: it indicates the flow and sets the temperature of the gas. Two levels of temperature are necessary: the first (about $250^{\circ} \mathrm{F}$ ) is necessary while alcohol clinging to the molecular sieve material is being evaporated; the second (about $450^{\circ} \mathrm{F}$ ) is necessary to evaporate the adsorbed water. Here again, the completion of each phase of the regeneration cycle is signaled by a temperature change at the outlet from the column. Finally, the col- 


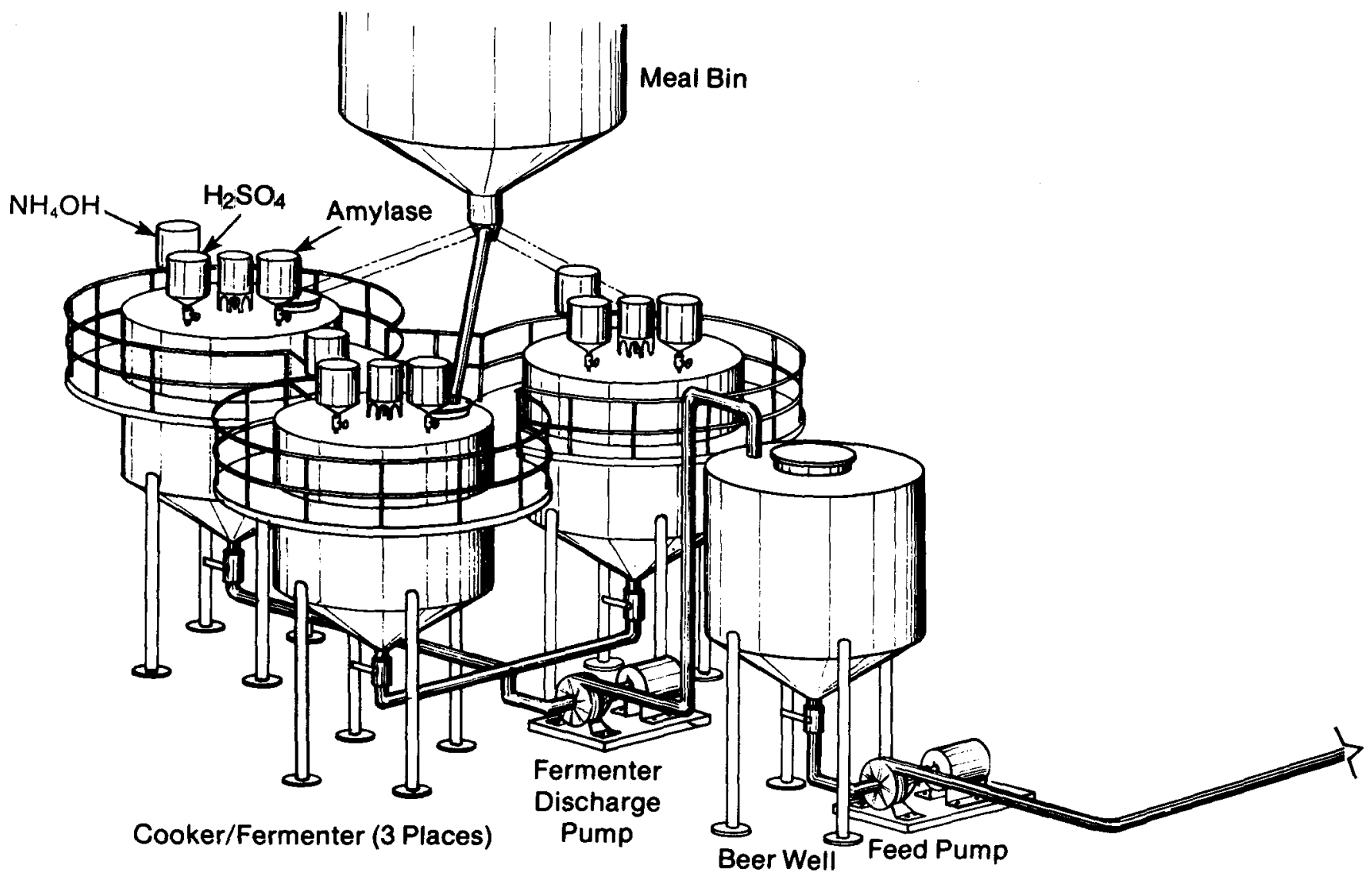

Figure V-2. Generic

umn is cooled by passing cool $\mathrm{CO}_{2}$ through it until another outlet temperature change indicates completion of the regeneration cycle. The controls required for a dehydration distillation column are essentially the same as those required for the rectification column.

\section{Controls for Pumps and Drives}

The pumps used in this plant can be either centrifugal or any one of a number of forms of positive displacement pumps. The selection of the pump for mash or beer needs to take into account the heavy solids loading (nearly 25\% for mash), the low pH (down to 3.5 for the beer), and the mild abrasive action of the mash.

The pumps might be powered by any of a number of different motors. The most probable would be either electric or hydraulic. If electric motors are used, they should be explosion-proof. Constant speed electric motors and pumps are much less expensive than variable-speed motors. Control of the volume flow for the beer pump, the two reflux pumps, and the product pump would involve either throttling with a valve, recirculation of part of the flow through a valve, or variable-speed pumps. Hydraulic drive permits the installation of the one motor driving the pumps to be located in another part of the building, thereby eliminating a potential ignition source. It also provides inexpensive, reliable, infinitely variable speed control for each motor. Hydraulic drives could also be used for the augers, and the agitators for the cookers and fermenters. Since hydraulics are used universally in farm equipment, their management and maintenance is familar to farmers.

\section{Heat Source Controls}

There are basically two processes within the ethanol production system that require heat: the cooking and the distillation steps. Fortunately, this energy can be supplied in low-grade heat (less than $250^{\circ} \mathrm{F}$ ). Potential sources of heat include coal, agriculture residues, solar, wood wastes, municipal wastes, and others. Their physical properties, bulk density, calorific value, moisture content, and chemical constituency vary widely. This, in turn, requires a greater diversity in equipment for handling the fuel and controls for operating the boilers. Agriculture residues vary in bulk 


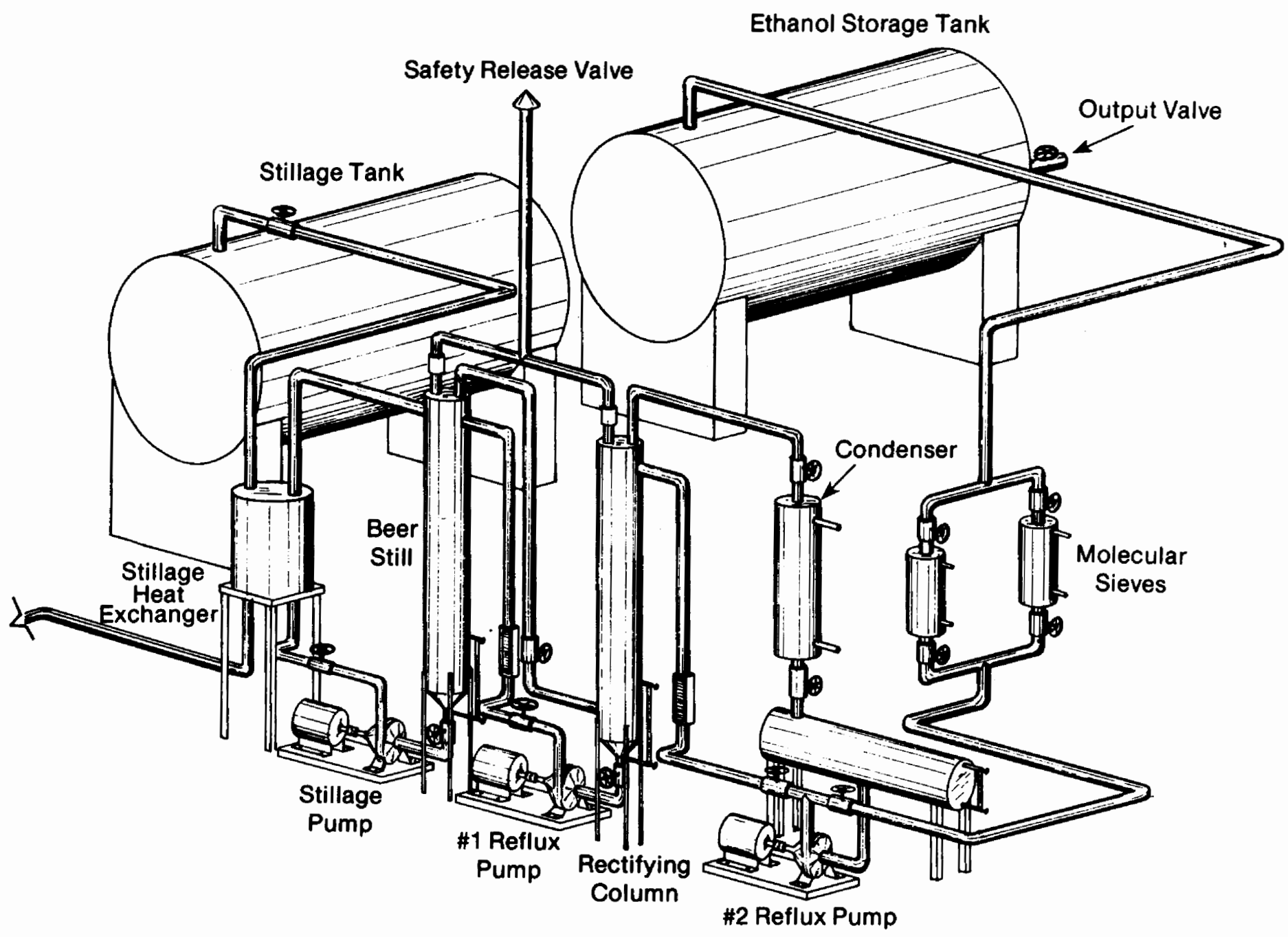

Anhydrous Ethanol Plant

density from 15 to 30 pounds per cubic foot and the calorific value of oven-dry material is generally around 8,000 Btu per pound. This means that a large volume of fuel must be fed to the boiler continuously. For example, a burner has been developed that accepts large, round bales of stover or straw. The boiler feed rate will vary in direct proportion to the demand for steam. This in turn is a function of the distillation rate, the demand for heat for cooking (which varies in relation to the type of cooker and fermenter used-batch or continuous).

Emissions. Emissions controls on the boiler stack are probably minimal, relying instead upon efficient burner operation to minimize particulate emissions. If exhaust gas scrubbers or filters are required equipment, they in turn require feedback control. Filters must be changed on the basis of pressure drop across them which indicates the degree of loading (plugging). Scrubbers require control of liquid flow rate and control of critical chemical parameters.

Boiler safety features. Safety features associated with the boiler are often connected to the control scheme to protect the boiler from high-pressure rupture and to prevent burnout of the heat expander tubes. Alarm systems can be automated and have devices to alert an operator that attention is needed. For instance, critical control alarms can activate a radio transmitter, or "beeper," that can be worn by the farmer while performing other normal work routine.

\section{REPRESENTATIVE ETHANOL PLANT}

General descriptions of major components serve only to define possibilities. In the previous section, considerations for specifying the appropriate equipment to accomplish desired objectives were examined. The following is a description of a specific representative ethanol plant producing ethanol and wet stillage. This representative plant normally produces 25 gallons of anhydrous ethanol per hour. The distillation section can be operated continuously with shutdown as required to remove protein buildup in the beer column. Heat is provided by a boiler that uses agricultural residue as fuel. The plant is designed for maximum flexibility, but 
its principal feedstocks are cereal grain, with specific emphasis on corn.

This representative plant should not be construed as a best design or the recommended approach. Its primary purpose is to illustrate ethanol production technology.

\section{Overview of the Plant}

As shown in Figure V-2, the representative plant has seven main systems: (1) feed preparation and storage, (2) cooker/fermenter, (3) distillation, (4) stillage storage, (5) dehydration, (6) product storage, (7) and boiler. Grain from storage is milled once a week to fill the meal bin. Meal from the bin is mixed to make mash in one of three cooker/fermenters. The three cooker/fermenters operate on a staggered schedule-one starting, one fermenting, and one pumping out-to maintain a full beer well so the distillation section can be run continuously. The beer well provides surge capacity so that the fermenters can be emptied, cleaned, and restarted without having to wait until the still can drain them down. Beer is fed from the beer well to the beer still through a heat exchanger that passes the cool beer counter-current to the hot stillage from the bottom of the beer still. This heats up the beer and recovers some of the heat from the stillage.

The beer still is a sieve-plate column. The feed is introduced at the top of the stripping section. Vapors from the beer column flow into the bottom of the rectifying column where the ethanol fraction is enriched to $95 \%$. The product is condensed and part of it is recycled (refluxed) to the top of the column and if ethanol is being dried at the time, part of it is pumped to the dehydration section. If the ethanol is not being dried, it flows directly to a storage tank for 190-proof ethanol (a separate tank must be used for the anhydrous ethanol).

The stillage that is removed from the bottom of the beer column is pumped through the previously mentioned heat exchanger and is stored in a "whole stillage" tank. This tank provides surge capacity when a truck is unavailable to haul the stillage to the feeder operation.

The distillation columns are designed for inherent stability once flow conditions are established so a minimum of automatic feedback control and insirumentation is required. This not only saves money for this equipment but it reduces instrument and/or controller-related malfunctions. Material flows for cooling and fermentation are initiated manually but proceed automatically. A sequencer microprocessor (a miniature compuier) controls temperature and $\mathrm{pH}$ in the cooker/fermenters. It also activates addition of enzymes and yeast in the proper amounts at the proper times. At any point, the automatic sequence can be manually overridden.
The period of operation is quite flexible, and allows for interruptions of operation during planting or harvest time. The 25 gallons per hour production is a nominal capacity, not a maximum. All support equipment is similarly sized so that slightly higher production rates can be achieved if desired.

The control and operating logic for the plant is based on minimal requirements for operator attention. Critical activities are performed on a routine periodic basis so that other farming operations can be handled during the bulk of the day. All routines are timed to integrate with normal chore activities without significant disruption.

A complete equipment list is given in Table V-3. The major components are described in Table V-4.

\section{Start-Up and Shutdown}

The following is a sequence for starting-up or shutting down the plant.

Preliminaries. For the initial start-up, a yeast culture must be prepared or purchased. The initial yeast culture can use a material such as molasses; later cultures can be grown on recycled stillage. Yeast, molasses, and some water should be added to the yeast culture tank to make the culture. Although yeasts function anaerobically, they propagate aerobically, so some oxygen should be introduced by bubbling a small amount of air through the culture tank. The initial yeast culture will take about 24 hours to mature.

At this time, the boiler can be started. Instructions packaged with the specific boiler will detail necessary steps to bring the unit on-line (essentially the boiler is filled with water and the heat source started). These instructions should be carefully followed, otherwise there is the possibility of explosion.

The next step is the milling of grain for the cooker/ fermenter. Enough grain should be milled for two fermentation batches (about 160 bushels).

Prior to loading the fermenter, it should be cleaned well with a strong detergent, rinsed, decontaminated with a strong disinfectant, and then rinsed with cold water to flush out the disinfectant.

Mash Preparation. The amount of meal put in the cooker/fermenter depends upon the size of batch desired. For the first batch it is advisable to be conservative and start small. If the batch is ruined, not as much material is wasted. A 2,000-gallon batch would be a good size for this representative plant. This will require mixing 80 bushels of ground meal with about 500 gallons of water to form a slurry that is about $40 \%$ starch. 


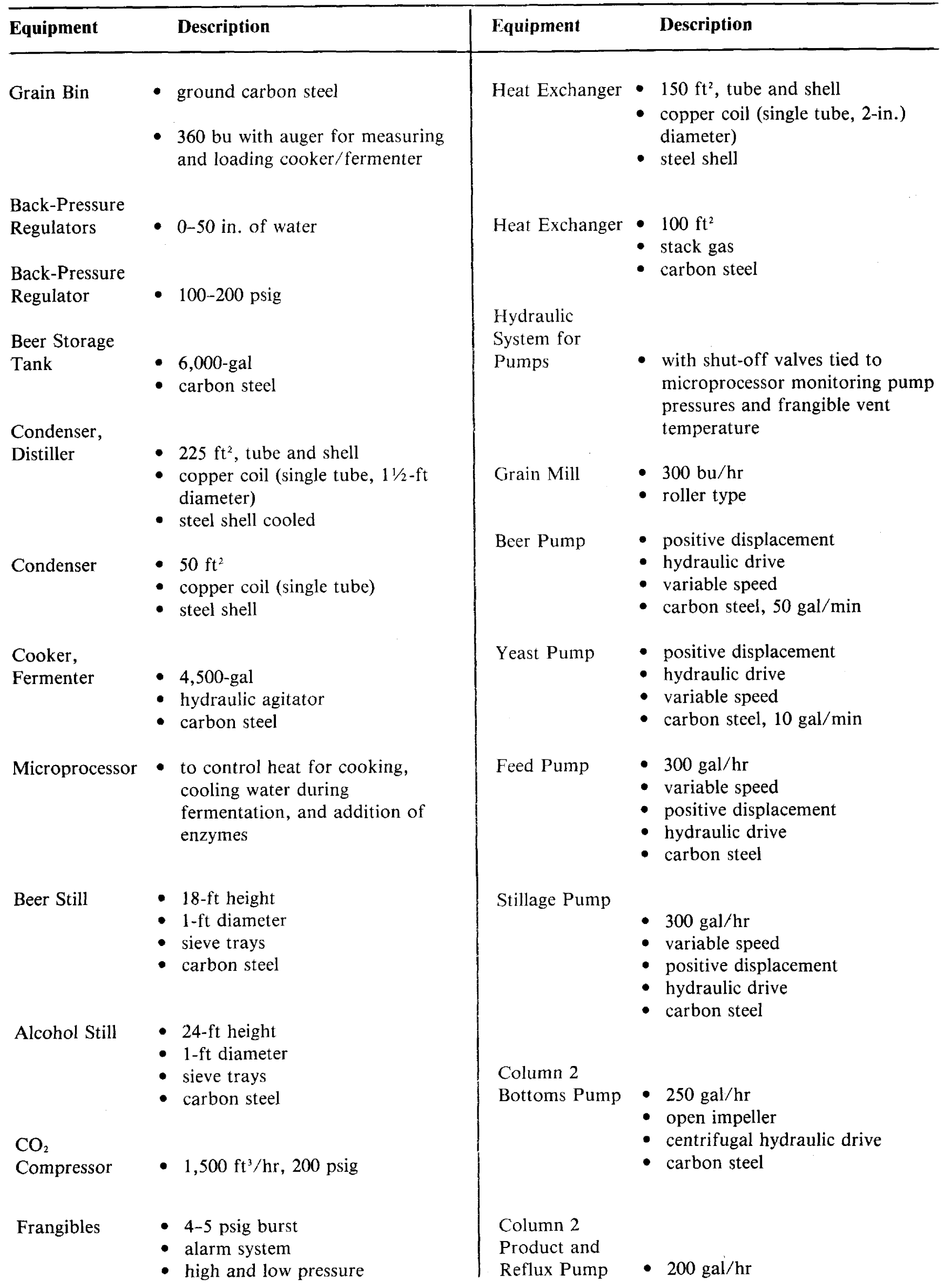




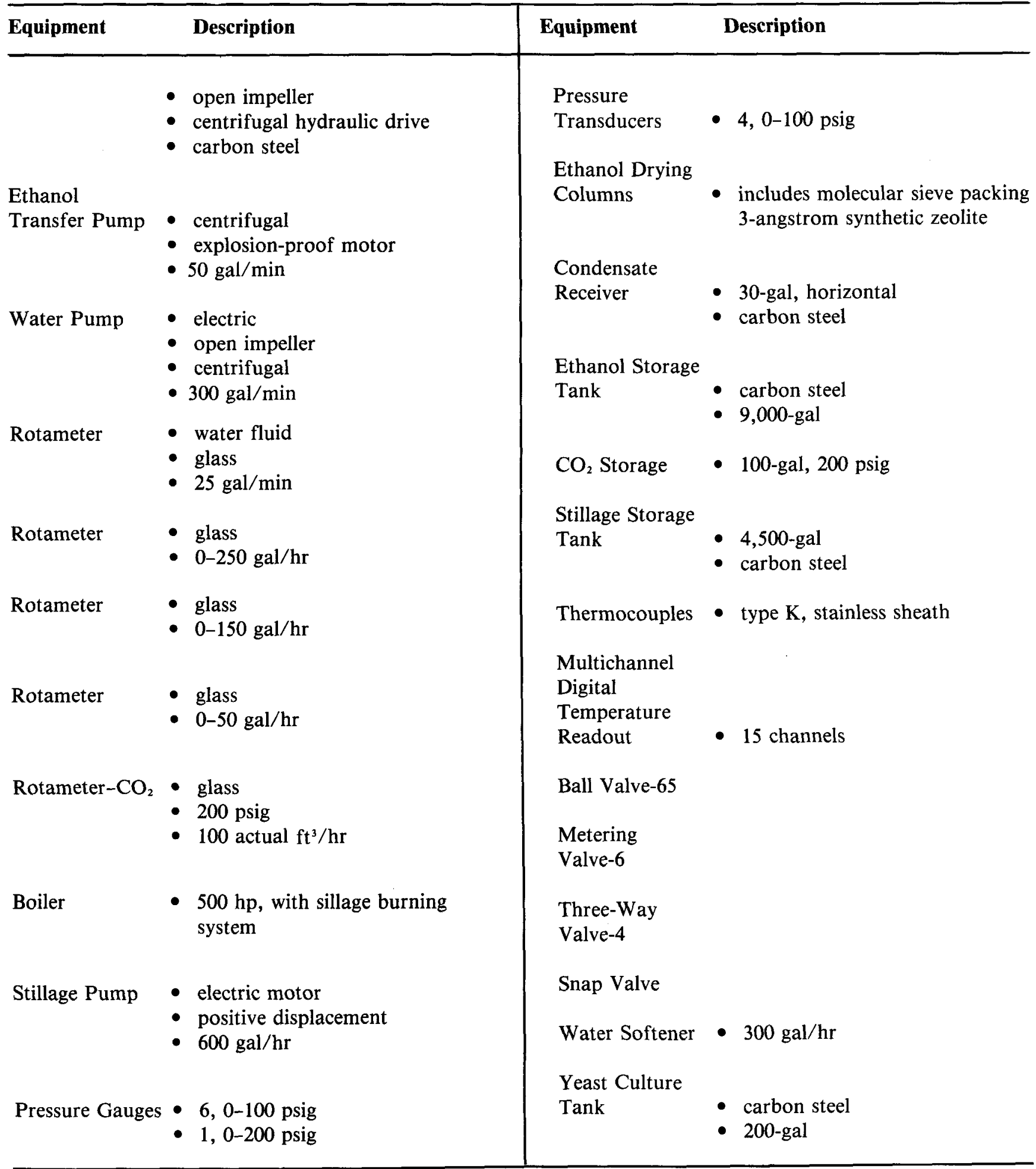

TABLE V-4. FEATURES OF MAJOR PLANT COMPONENTS

\begin{tabular}{l|l}
\hline Components $\quad$ Features & Components \\
\hline Feedstock Storage and Preparation & Features \\
Grain Mill $\quad \begin{array}{l}\text { roller mill that grinds product to } \\
\text { pass a 20-mesh screen }\end{array}$ & Meal Bin $\bullet \begin{array}{l}\text { corrugated, rolled galvanized steel } \\
\text { with 360-bu capacity }\end{array}$
\end{tabular}




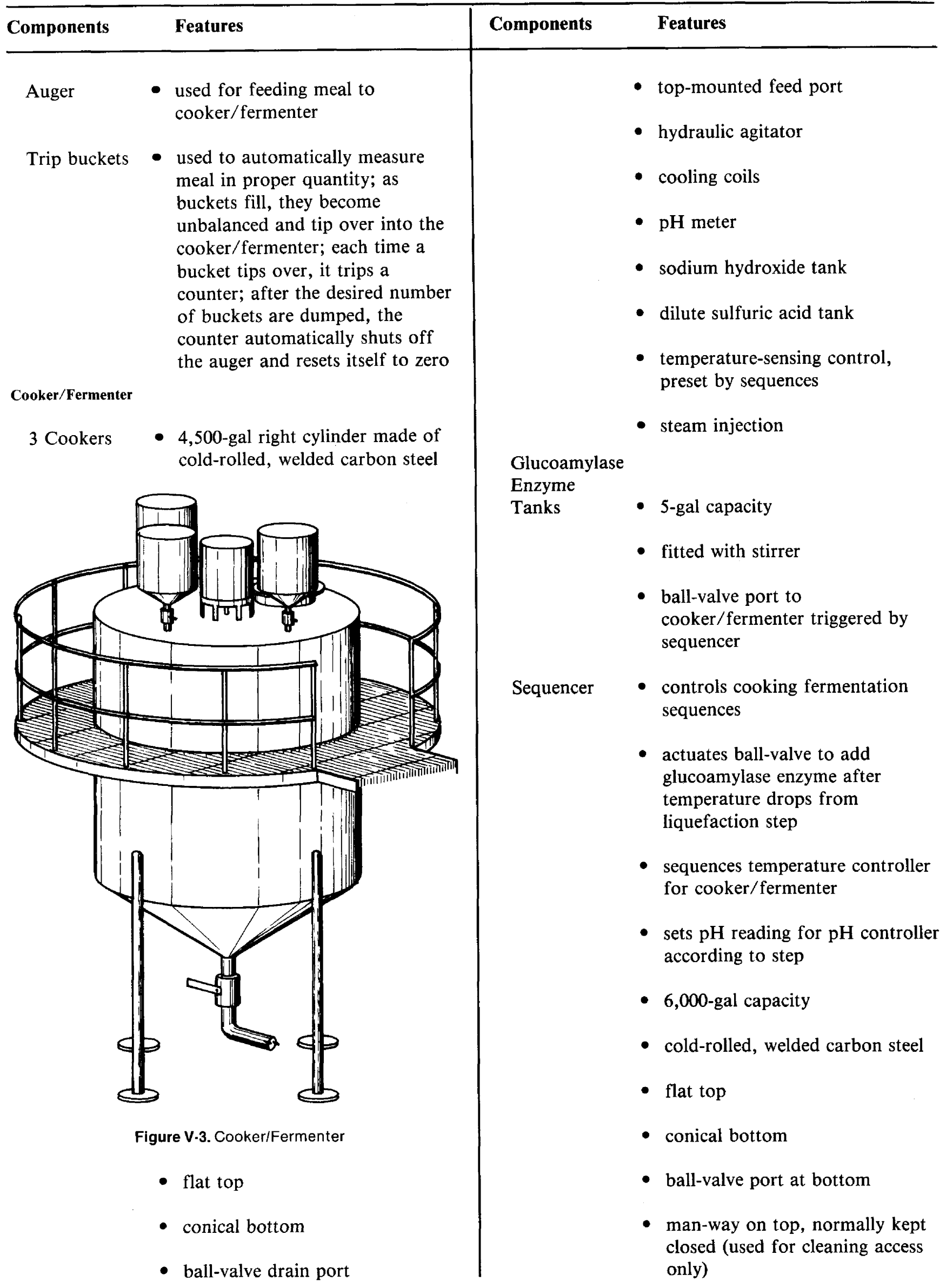




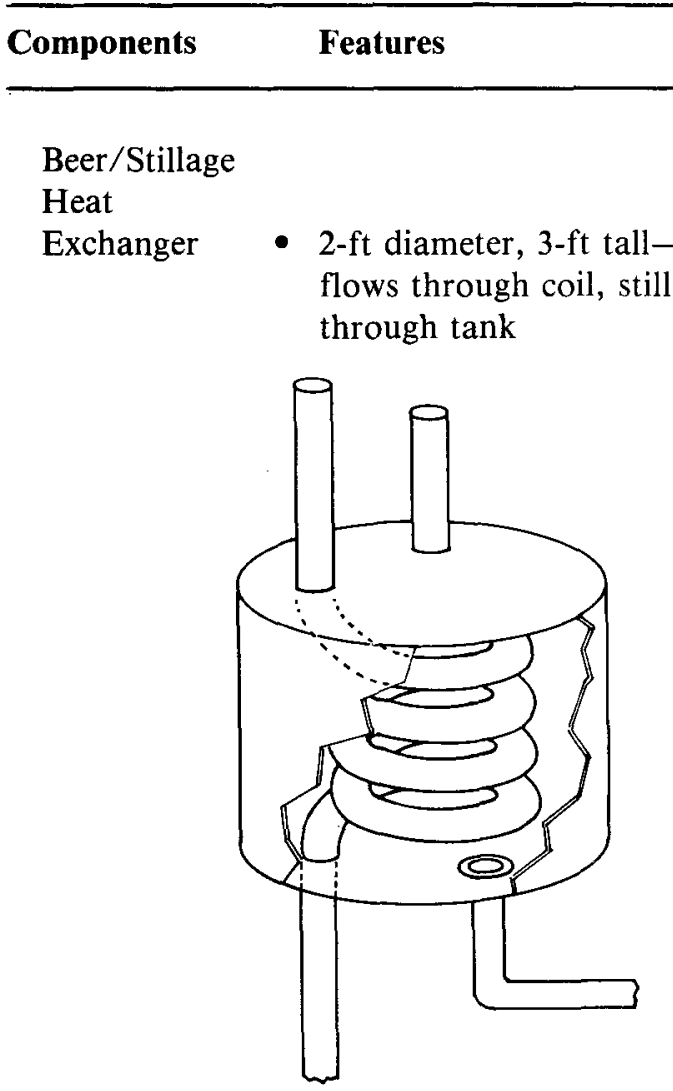

Figure V.4. Beer/Stillage Heat Exchanger

Beer Pump - pump from any of the three cooker/fermenters to beer well, hydraulic motor on pump

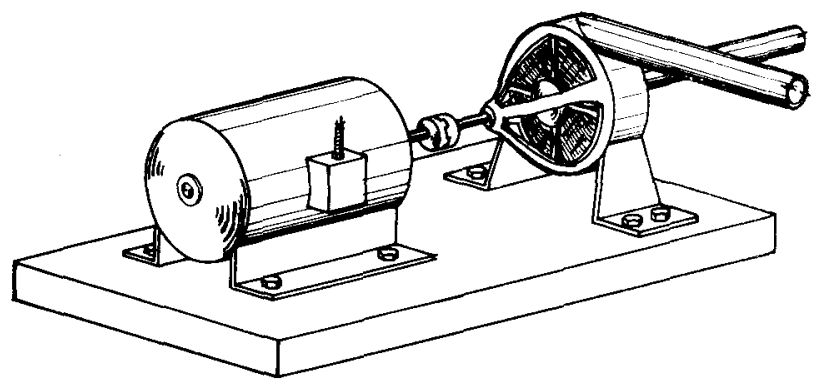

Figure V-5. Beer Pump

Feed Pump - pump beer to distillation system, hydraulic motor on pump

Distillation

Beer Still

- 1 -ft diameter

- 20-ft tall coated carbon steel pipe with flanged top and bottom

- fitted with a rack of sieve trays that can be removed either through the top or bottom

\section{Components Features}

- steam introduced at bottom through a throttle valve

- pump at the bottom to pump stillage out, hydraulic motor on pump

- input and output flows are controlled through manually adjusted throttle valves

- safety relief valves prevent excess pressure in column

- instrumentation includes temperature indication on feed line and at the bottom of the still, sight-glass on bottom to maintain liquid level, pressure indicators on the outlet of the stillage pump

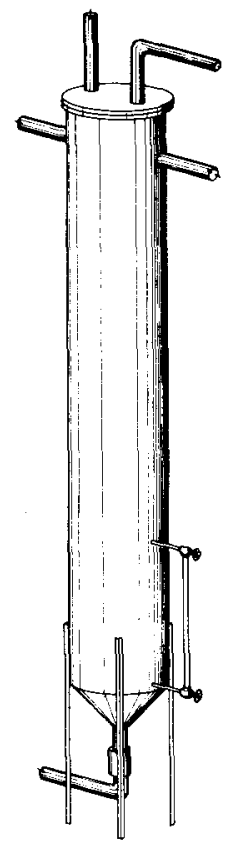

Figure V-6. Beer Still

Rectifying

Column

- 20-ft tall

- 1-ft diameter

- coated carbon steel pipe with flanged top, welded bottom to prevent ethanol leaks

- fitted with rack of sieve-plates which can be removed through the top 


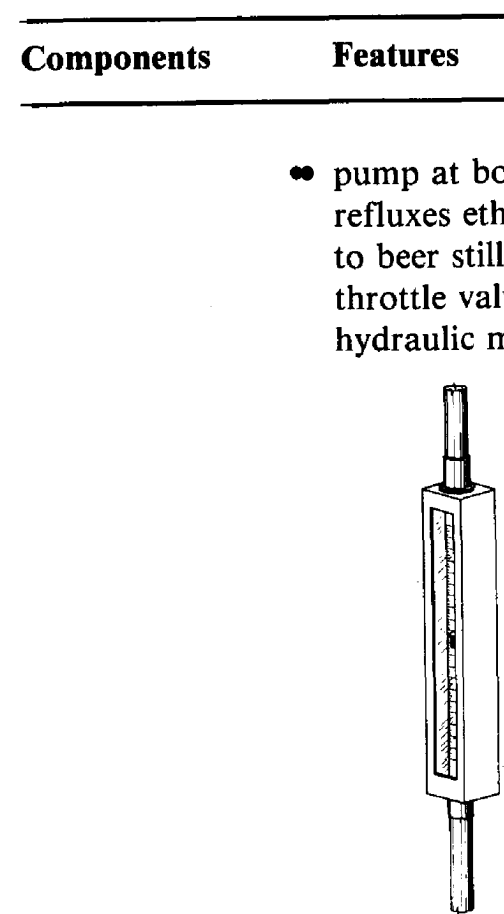

Figure V-7. Rectifying Column Rotameter

- instrumentation consists of temperature indication at top and bottom of column and level indication at bottom by sightglass, pressure is indicated on the outlet of the recirculation pump

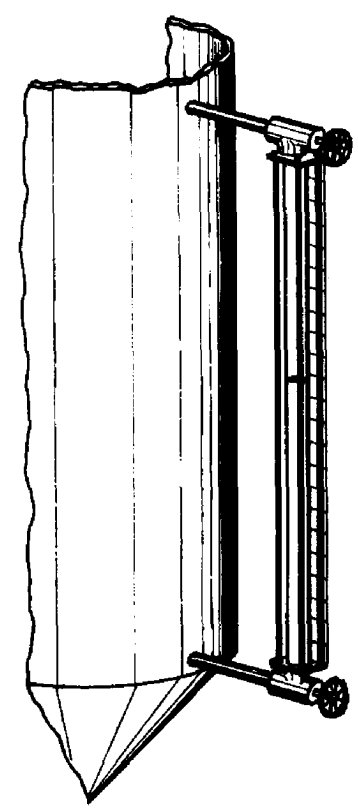

Figure V-8. Rectifying Column Sight-Glass

Condenser

- ethanol condenses (in copper coil), water flows through tank

- cooling water flow-rate is manually adjusted

\section{Components Features}

Dehydration Secton

2 Molecular

Sieves

- packed bed

- synthetic zeolite, type

3A-molecular sieve material

- automatic regeneration

- automatic temperature control during regeneration

- throttle flow control to sieves adjusted manually

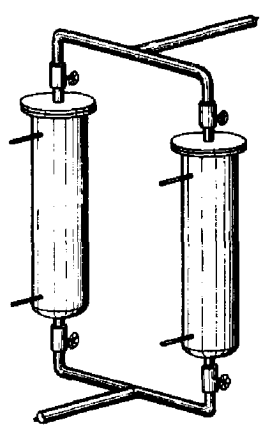

Figure V.9. Molecular Sieves

$\mathrm{CO}_{2}$

Compressor

- 2-stage air compressor with reservoir (conventional)

Denaturing

Tank

- meets Bureau of Alcohol, Tobacco, and Firearms specifications (See Appendix B)

Ethanol Storage

2 Ethanol

Storage Tanks $\bullet$ 3,000-gal capacity each

- same as gasoline storage tanks

- cold-rolled, welded carbon steel

Stillage

Storage

Tank

- 6,000-gal capacity

- cold-rolled, welded carbon steel 
Cooking. The water and meal are blended together as they are added to the cooker/fermenter. It is crucial to use rates that promote mixing and produce no lumps (the agitator should be running). The alpha-amylase enzyme can be blended-in during the mixing (the enzyme must be present and well mixed before the temperature is raised because it is very difficult to disperse the enzyme after gelatinization occurs).

Since cooking in this representative plant is initiated by steam injection during slurry-mixing, the enzyme must be blended in simultaneously. (Dry enzymes should be dispersed in a solution of warm water before mixing is started. This only takes a small amount of water, and the directions come on the package. Liquid enzymes can be added directly.) If the $\mathrm{pH}$ is lower than 5.5, it should be adjusted by addition of a calculated amount of sodium hydroxide. If the $\mathrm{pH}$ is higher than 7.0 , a calculated amount of sulfuric acid should be added. Steam is added at a constant rate to achieve uniform heating. When the temperature reaches $140^{\circ} \mathrm{F}\left(60^{\circ} \mathrm{C}\right)$, the physical characteristics of the mash change noticeably as the slurry of starch becomes a solution of sugar. If there is insufficient enzyme present or if heating is too rapid, a gel will result that is too thick to stir or add additional enzyme to. If a gel does form, more water and enyzme can be added (if there is room in the tank) and the cook can start over.

Once liquefaction occurs, the temperature is uniformly raised to the range for optimum enzyme activity (from $194^{\circ} \mathrm{F}$ to $204^{\circ} \mathrm{F}$ ) and held for about half an hour. At the end of this time, a check is made to determine if all of the starch has been converted to paste. A visual inspection usually is sufficient; incomplete conversion will be indicated by white specks of starch or lumps; a thin, fluid mash indicates good conversion. The mash is held at this temperature until most of the starch is converted to dextrin.

Saccharification. Once the mash is converted to dextrin, the microprocessor is manually started and (1) reduces the temperature of the mash to about $140^{\circ} \mathrm{F}\left(60^{\circ} \mathrm{C}\right)$ by circulating cooling water through the coils; and (2) adds dilute sulfuric acid $\left(\mathrm{H}_{2} \mathrm{SO}_{4}\right)$ until the $\mathrm{pH}$ drops to between 3.7 and $4.5\left(\mathrm{H}_{2} \mathrm{SO}_{4}\right.$ addition is controlled by a $\mathrm{pH}$ meter and a valve on the $\mathrm{H}_{2} \mathrm{SO}_{4}$ tank). Once the $\mathrm{pH}$ and temperature are within specified ranges, the microprocessor triggers the release of liquid glucoamylase (which must be premixed if dry enzyme is used) from its storage tank. Either sodium hydroxide or sulfuric acid is added automatically as required to maintain proper $\mathrm{pH}$ during conversion. The microprocessor also holds the mash at a constant temperature by regulating steam and/or cooling water flow for a preset period of time. The sequencer can be overridden if the conversion is not complete.
Fermentation. After hydrolysis is complete, the sequencer lowers the temperature of the mash to about $85^{\circ} \mathrm{F}$ by adding the remaining 1,500 gallons of water (and by circulating cooling water thereafter as necessary). The water addition will raise the $\mathrm{pH}$ of the solution so the sequencer automatically adjusts the $\mathrm{pH}$ to between 4.5 and 5.0. Next, the sequencer adds a premeasured quantity of dispersed distillers' yeast from the yeast tank. (Note that the yeast tank is not on top of the cooker/fermenter as high temperatures during cooking would kill the culture.) Thereafter, the sequencer maintains the temperature between $80^{\circ} \mathrm{F}$ and $85^{\circ} \mathrm{F}$ and the $\mathrm{pH}$ between 4.0 and 5.0. The agitator speed is reduced from that required during cooking to a rate which prevents solids from settling, but does not disturb the yeast. The batch is then allowed to ferment for 36 to 40 hours.

Pump-Out and Cleanup. After a batch is complete, it is pumped to the beer well and the fermenter is hosed out to remove any remaining solids.

Distillation. Once the beer well is full, the distillation system can be started up. This process involves the following steps.

\section{Turn on the condenser cooling water.}

2. Purge the still with steam. This removes oxygen from the system by venting at the top of the second column. When steam is seen coming out of the vent, the steam can be temporarily shut off and the vent closed. Purging the still with steam not only removes oxygen, but also helps to preheat the still.

3. Pump beer into the still. The beer is pumped in until it is visible at the top of the sight-glass.

4. Turn steam on and add beer. This process of adding beer and watching the liquid level movement to adjust the steam level will be repeated several times as the columns are loaded. Initially, steam flows should be set at a low level to prevent overloading the trays which might require shutdown and restart. During this period the valves in the reflux line are fully opened but the reflux pump is left off until enough liquid has built up in the condensate receiver. This prevents excessive wear on the pump. The reflux line between the two columns should also be opened and that reflux pump should be left off. The liquid level in the bottom of the beer still should be monitored and when it drops to half way, beer should be fed back into the column to refill the bottom of the still. The liquid level should continue to drop; if it does not, additional steam should be fed into the still bottom. 
5. Start reflux pump between the beer still and rectifying column. When liquid starts to accumulate in the bottom of the rectifying column, the reflux pump between this still and the beer still is started. Flow in this line should be slow at first and then increase as more and more material reaches the rectifying column. When reflux is started to the beer still, the steam feed-rate will have to be slightly increased, because reflux tends to cool down a column.

6. Start pump for reflux from the condensate receiver to rectifying column. Eventually, enough vapor will have been condensed to fill the condensate receiver. Then, the pump for the reflux to the rectifying column can be started. Flow for this reflux line should be slow at first and then increased as more and more material distills. It should be noted that temperatures in the columns will be increasing as this process takes place. When the top temperature of the rectifying column is no longer increasing, the liquid levels in the bottom of the two columns are changing, and the condensate receiver level is no longer changing. Then, the reflux flow rates are at their designed flow and the column has reached equilibrium.

7. Set beer feed pump, stillage pump, and product take-off at their designed flow. Initially, the beer feed entering the beer still will be cooler than nor$\mathrm{mal}$; the heat exchanger has not heated up yet. For this reason the steam to the beer still will need to be slightly increased. The thermocouple at the feed point will indicate when the feed is being heated to its designed temperature. At this time, the steam rate can be slightly lowered. Some minor adjustments will probably be needed. It must be kept in mind that this is a large system, and it takes some time for all points to react to a change in still conditions. All adjustments should be made, and then a period of time should be allowed before any additional adjustments are made.

8. Check product quality. Product quality at this time should be checked to insure that ethanol concentration is at the designed level. If it is lower than anticipated, the reflux ratio should be increased slightly. An increase in reflux cools the columns and additional heat must be applied to compensate for this. Also, the product flow-rate will be slightly decreased; therefore, flow rate to the still should also be varied. The ethanol concentration in the stillage should be checked to ensure that it does not exceed design concentration significantly.

9. Dry ethanol. After the ethanol leaves the distil- lation column, it must be further dried by passing through the molecular sieve drying columns and then stored in the ethanol storage tank. Literature from the vendor of the molecular sieve material will indicate at what temperature that flow must be switched to the other unit.

10. Regenerate spent sieve material. Carbon dioxide $\left(\mathrm{CO}_{2}\right)$ is used to regenerate the molecular sieve material. The $\mathrm{CO}_{2}$ is collected from the fermentation system and compressed- $\mathrm{CO}_{2}$ storage tank. To regenerate the molecular sieve material, the lines for regeneration are opened. Next, the $\mathrm{CO}_{2}$ line is opened to allow flow to the stack heat exchanger and then on to the sieve columns. A rotameter in the $\mathrm{CO}_{2}$ line is set to control the $\mathrm{CO}_{2}$ flow-rate to the desired level. The molecular sieve columns are heated to about $450^{\circ} \mathrm{F}$ during regeneration. After regeneration is complete, the column is cooled down by $\mathrm{CO}_{2}$ which bypasses the stack heat exchanger.

This essentially covers all the steps involved in the start-up of the plant. It should again be emphasized that caution must be exercised when operating any system of this complexity. If proper care is taken, and changes to the system operation are thought out sufficiently, successful plant operation will be achieved.

Shutdown. The second period of operation which differs significantly from normal operation is that period when the plant is being shut down. Proper care must be taken during shutdown to ensure both minimal losses of product and ease of restarting the process.

As the fermenters are individually shut down, they should be cleaned well to inhibit any unwanted microbial growth. The initial rinse from the fermenters can be pumped to the beer storage tank. Subsequent rinses should be discarded. The processing of this rinse material through the stills can continue until the top temperature of the beer column reaches $200^{\circ} \mathrm{F}$. At this time, the unit should be put on total reflux.

During this shutdown period, the product quality will have degraded slightly, but the molecular sieve column will remove any additional water in the ethanol product. The stillage from the distillation system can be sent to the stillage storage system until the stillage is essentially clean. At this point, the steam to the column should be shut off and the column should be allowed to cool. During cooling, the column should be vented to prevent system damage. The pressure inside the column will be reduced as it cools. The air which enters the column at this time can be purged with steam prior to the next period of operation. The molecular sieve drying columns can be regenerated if necessary. The boiler should be shut down. If the shutdown period is of any 
significant duration, the boiler should be drained. If the plant is to be shut down for a short term, the fermenters should not require any additional cleaning. After an extended shutdown period, it is advisable to clean the fermenters in a manner similar to that performed at the initial start-up.

Shutdown periods are the best time to perform preventive maintenance. The column trays can be cleaned, pump seals replaced, etc. The important thing to remember is that safety must not be overlooked at this time. Process lines should be opened carefully because, even after extended periods of shutdown, lines can still be pressurized. If it is necessary to enter tanks, they must be well vented. It is suggested that an air line be placed in the tanks and that they be purged with air for several hours before they are entered. Also, a tank should never be entered without another person stationed outside the tank in case an emergency situation arises.

\section{Daily Operation}

The day-by-day operation of the representative on-farm plant requires the attention of the operator for two periods of about two hours each every day.

Each morning, the operator begins by checking the condition of the plant. All systems are operative because the operator would have been alerted by the alarm if there had been a shutdown during the night. A quick check will confirm that the beer flow and reflux flows are near desired values. The temperature of the top plate of the rectifying column and the proof of the product before drying should be checked. Even if the proof is low, the final product should be dry because the dryer removes essentially all of the water, regardless of input proof. However, excessively low entering proof could eventually overload the regeneration system. If the proof before drying is low, reflux flow is adjusted to correct it.

Next the fermenter that has completed fermentation is checked. The concentration of ethanol is checked and compared to the value indicated by the sugar content at the beginning of fermentation. If the concentration is suitable, the contents of the fermenter are dumped into the beer well. The inside of the fermenter is washed briefly with a high-pressure water stream. Then the fermenter is filled with preheated water from the holding tank.

The operator next checks the condition of the boiler and bale burner. The bale burner is reloaded with two of the large, round bales of corn stover from the row outside of the building. A front-end loader is used for this.
The operator returns to the fermenter that is being filled. It is probably half filled at this time, and the flow of meal into the tank is begun from the overhead meal bin. The flow rate is continuously measured and indicated, and will cut off when the desired amount is reached. The agitator in the tank is started. The liquefying enzyme is added at this time. The operator checks the temperature. When the tank is nearly full, steam is admitted to bring the temperature up to cooking value. The operator checks the viscosity until it is clear that liquefaction is taking place.

The operator now prepares for the automatically controlled sequence of the remaining steps of cooling and fermenting. The microprocessor controls these steps, and it will be activated at this time. However, the operator must load the saccharifying enzyme into its container. The enzyme is dumped into the fermentation tank on signal from the microprocessor. The yeast is pumped into the fermenter from the yeast tub, also on signal from the microprocessor. After cooking is complete, the microprocessor initiates the flow of cold water into coils in the vessel which cools the mash to the temperature corresponding to saccharification. When the appropriate temperature is reached, the enzyme is introduced. After a predetermined time, the converted mash is cooled to fermentation temperature, again by circulating cold water through the coils. When fermentation temperature is reached, the yeast is pumped into the fermenter. All of these operations are controlled by the microprocessor and do not require the operator's presence.

Once the fermentation is initiated, the operator can check the condition of the distillation columns and turn his/her attention to the products. The driver of the truck which delivers the whole stillage to the dairies and feeding operations will have finished filling the tank truck. If it is time for the pick-up of the ethanol, the operator may be joined by a field agent of the BATF who supervises the denaturing operation and checks the recorded flows of the plant to ensure that the product in storage is all that has been produced since the last pickup. The distributions driver would then load the truck and start back to the bulk station.

In the evening the operator repeats the same operation with the exception of grinding meal and delivering the product.

\section{MAINTENANCE CHECKLIST}

Table V-5 provides a general timetable for proper maintenance of a representative ethanol plant. 


\begin{tabular}{|c|c|c|c|}
\hline Bale Burner & & Steam Lines & \\
\hline Remove ash & daily & Blow condensate & daily \\
\hline Lubricate fans & monthly & & \\
\hline Check fan belts & monthly & $\begin{array}{l}\text { Beer Preheater } \\
\text { Clean both sides }\end{array}$ & weekly \\
\hline Water Softener & & & \\
\hline Regenerate and backwash & weekly & Beer Column & \\
\hline Check effectiveness & yearly & Clean out & weekly \\
\hline Boiler & & Sight Glasses & \\
\hline $\begin{array}{l}\text { Blow flues and } \mathrm{CO}_{2} \text { heater } \\
\text { Check tubes and remove scale }\end{array}$ & $\begin{array}{l}\text { monthly } \\
\text { monthly }\end{array}$ & Clean out & weekly \\
\hline & & Flow Meters & \\
\hline Roller Mill & & Clean out & as needed \\
\hline Check for roller damage & weekly & & \\
\hline Check driver belts & monthly & $\begin{array}{l}\text { Condenser } \\
\text { Descale water side }\end{array}$ & monthly \\
\hline Elevator Leg to Meal Bin & & & \\
\hline Lubricate & monthly & $\begin{array}{l}\text { Stillage Tank } \\
\quad \text { Clean and sterilize }\end{array}$ & monthly \\
\hline Yeast Tubs & & & \\
\hline $\begin{array}{l}\text { Change air filter } \\
\text { Fermenters }\end{array}$ & monthly & $\begin{array}{l}\text { Pumps } \\
\text { Check seals and end play } \\
\text { Lubricate }\end{array}$ & $\begin{array}{r}\text { weekly } \\
\text { per manufacturer }\end{array}$ \\
\hline Sterilize & every 3rd week & & \\
\hline $\begin{array}{c}\text { Wash down outside } \\
\text { Back Pressure Bubblers }\end{array}$ & weekly & $\begin{array}{l}\text { Hydraulic System and Motors } \\
\text { Check for leaks } \\
\text { Change filter }\end{array}$ & $\begin{array}{r}\text { daily } \\
\text { per manufacturer }\end{array}$ \\
\hline Clean out & weekly & Top-up & $\begin{array}{r}\text { per manufacturer } \\
\text { as necessary }\end{array}$ \\
\hline $\begin{array}{l}\text { Beer Well } \\
\text { Sterilize and wash down }\end{array}$ & weekly & & \\
\hline
\end{tabular}


CHAPTER VI

\section{Business Plan}

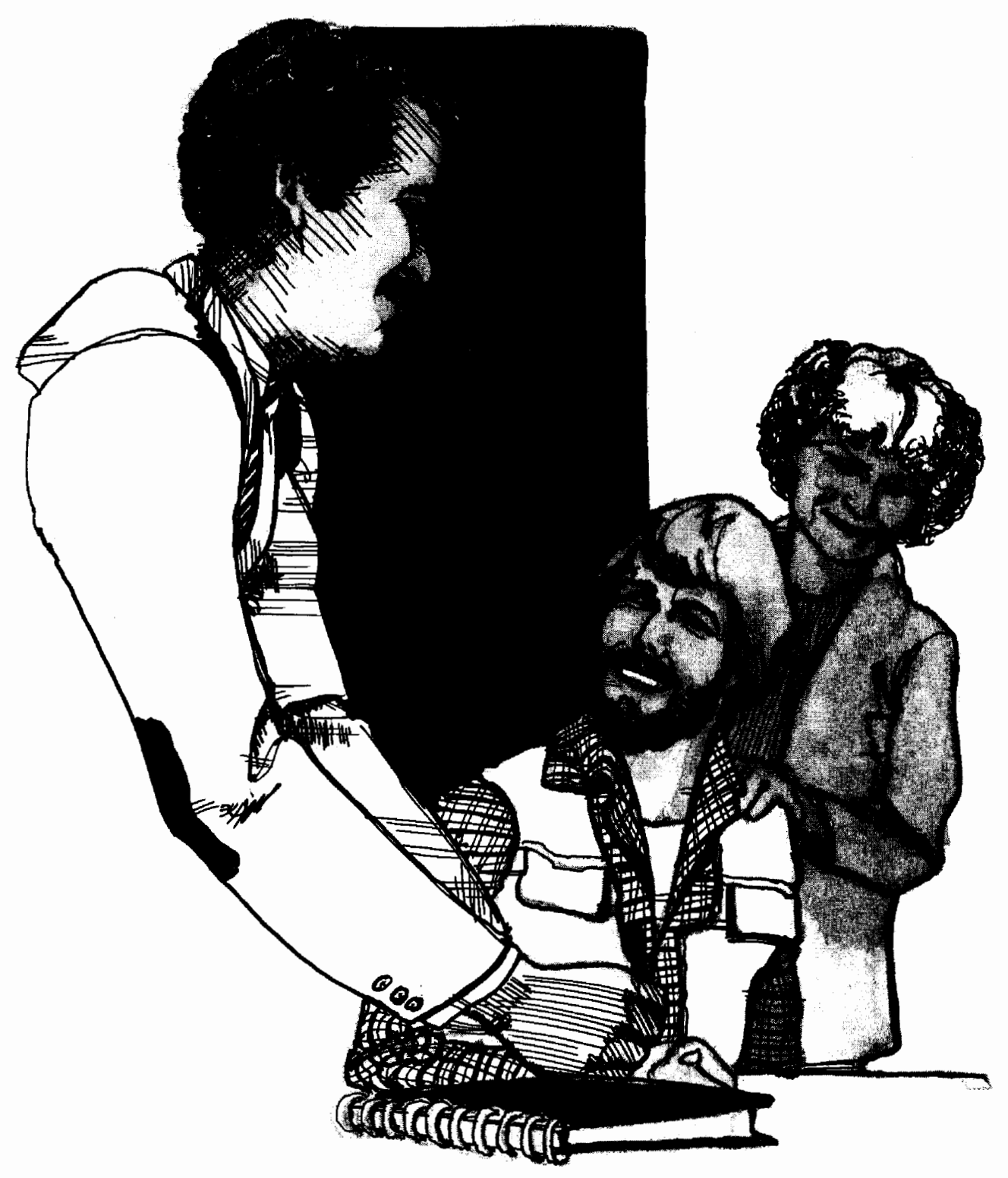




\section{CHAPTER VI \\ Business Plan}

Preliminary planning is a prerequisite for the success of any project. Development of an ethanol plant involves planning not only the production process but also the management form and financial base.

The first step is to determine the financial requirements and relate them to the individual situation. From this the optimal organizational form can be selected, and the financing options can be examined.

The case study included in this chapter is an example of how a business plan may be completed. Every situation is different, however, and this can serve only as an example. The decision and planning process described at the end of Chapter II can be used in conjunction with the information in this chapter as tools in the decisionmaking process, which includes analyzing financial requirements, choosing an organizational form, and selecting potential financing sources.

\section{ANALYSIS OF FINANCIAL REQUIREMENTS}

Financial requirements are determined by delineating capital costs, equity requirements, and operating costs. These requirements are then compared to potential earnings. Capital requirements include the costs for:

- real estate,

- equipment,

- business formation,

- installing equipment, and

- cost of licenses.

Although additional real estate may not be necessary, transfer of real estate to the business entity may be a consideration. Some of the equipment required for ethanol production has other farm uses and need not be charged totally to the ethanol production costs, e.g., grain bins and tractors with front-end loaders.

Equity requirements are established by the financial lending institution if borrowed capital is used. Equity can be in the form of money in savings, stocks and bonds, equipment, real estate, etc. Operating costs include:
- labor,

- maintenance,

- taxes,

- mortgages,

- supplies (raw materials, additives, enzymes, yeast, water),

- delivery expenses,

- energy (electricity and fuels),

- insurance and interest on short-term and long-term financing, and

- bonding.

Potential earnings are determined by estimating the sales price of ethanol per gallon and then multiplying by the number of gallons that the facility can sell, as well as income that may be derived from the sale of coproducts fdetermined by the sales price times the quantity that can actually be sold). Careful planning of markets for coproducts can significantly affect the net income of an ethanol production plant. In the case study projected financial statement included in this chapter, note the difference in net income based on different coproduct prices. In addition to actual income derived from the sale of ethanol and the coproducts, any savings realized by using ethanol to replace other fuels for on-farm use can be added to earnings. This is also true for coproducts such as stillage that might replace purchased feed.

Once the financial requirements and potential earnings are determined, they can be related to the specific situation. Capital costs and equity requirements are related to the individual capability to obtain financing. Operation costs are compared to potential earnings to illustrate cash flow.

Once this information is acquired and analyzed in relation to the individual's specific situation, a decision can be made about the organizational form for the production business. 


\section{ORGANIZATIONAL FORM}

The organizational basis is the legal and business framework for the ethanol production facility. Broadly speaking, there are three principal kinds of business structures: proprietorship, partnership, and corporation.

A proprietor is an individual who operates without partners or other associates and consequently has total control of the business. A proprietorship is the easiest type of organization to begin and end, and has the most flexibility in allocating funds. Business profits are taxed as personal income and the owner/proprietor is personally liable for all debts and taxes. The cost of formation is low, especially in this case, since licensing involves only the BATF permit to produce ethanol and local building permits.

A partnership is two or more persons contractually associated as joint principals in a business venture. This is the simplest type of business arrangement for two or more persons to begin and end and has good budgetary flexibility (although not as good as a proprietorship). The partners are taxed separately, with profits as personal income, and all partners are personally liable for debts and taxes. A partnership can be established by means of a contract between two or more individuals. Written contractual agreements are not legally necessary, and therefore oral agreements will suffice. In a general partnership, each partner is personally liable for all debts of the partnership, regardless of the amount of equity which each partner has contributed.

A corporation is the most formalized business structure. It operates under the laws of the state of incorporation; it has a legal life all its own; it has its scope, activity, and name restricted by a charter; it has its profits taxed separately from the earnings of the executives or managers, and makes only the company (not the owners and managers) liable for debts and taxes. A Board of Directors must be formed and the purposes of the organization must be laid out in a document called "The Articles of Incorporation." Initial taxes and certain filing fees must also be paid. Finally, in order to carry out the business for which the corporation was formed, various official meetings must be held. Since a corporation is far more complex in nature than either a proprietorship or a partnership, it is wise to have the benefit of legal counsel. A corporation has significant advantages as far as debts and taxes are concerned. Creditors can only claim payments to the extent of a corporation's assets; no shareholder can be forced to pay off creditors out of his or her pocket, even if the company's assets are unequal to the amount of the debt.

There are often differences in the ease with which a business may obtain start-up or operating capital. Sole proprietors stand or fall on their own merits and worth. When a large amount of funding is needed, it may be difficult for one person to have the collateral necessary to secure a loan or to attract investors. Partnerships have an advantage in that the pooled resources of all the partners are used to back up the request for a loan and, consequently, it is often easier to obtain a loan because each and all of the partners are liable for all debts. Corporations are usually in the best position to obtain both initial funding and operating capital as the business expands. New shares may be issued; the company's assets may be pledged to secure additional funding; and bonds may be issued, backed up by the assets of the corporation.

A nonprofit cooperative is a special form of corporation. Such a cooperative can serve as a type of tax shelter. While the cooperative benefits each of its members, they are not held liable, either individually or collectively, for taxes on the proceeds from the sale of their products.

After determining the organizational form, financing options can be explored.

\section{FINANCING}

The specific methods of financing ethanol production plants can be divided into three general classes: private financing, public grants and loans, and foundations.

\section{Private Financing}

Private financing may be obtained from banks, savings and loan associations, credit unions, finance corporations, venture capital corporations, corporation stock issues, and franchise arrangements.

\section{Foundations}

Foundations provide funding either through grants or through direct participation by gaining equity, usually in the form of stocks in the production company. Often the investment portfolios that are used to generate income for foundations are composed in part of stocks in enterprises they deem appropriate to support the mission of the foundation.

\section{Public Financing}

Grants or loans are available from several federal agencies. Each of the agencies has operating procedures and regulations that define appropriate use of their funding. The availability of funds varies from year to year.

\section{CASE STUDY}

The following case study of the Johnson family demonstrates the process for determining the feasibility of a farm-sized fermentation ethanol plant by developing a 
business plan. It is a realistic example, but the specific factors are, of course, different for every situation. This process may be used by anyone considering ethanol plant development, but the numbers must be taken from one's own situation. Table VI-1 delineates the assumptions used in the case study.

TABLE VI-1. CASE STUDY ASSUMPTIONS

- Corn is the basic feedstock.

- 25-gal EtOH/hr production rate.

- Operate 24 hrs/day; 5 days/week; 50 .weeks/yr.

- Feed whole stillage to own and neighbors' animals.

- Sell ethanol to jobber for $\$ 1.74 /$ gal.

- Sell stillage for $3.9 \llbracket / g a l$.

- Corn price is $\$ 2.30 / \mathrm{bu}$ (on-farm, no delivery charge, no storage fees).

- Operating labor is $4 \mathrm{hrs} /$ day at $\$ 10 / \mathrm{hr}$.

- Corn stover cost is $\$ 20 /$ ton.

- Equity is $\$ 69,000$.

- Debt is $\$ 163,040$; at $15 \%$ per annum; paid semiannually.

- Loan period is $\mathbf{1 5}$ yrs for plant; 8 yrs for operating capital and tank truck.

- Miscellaneous expenses estimated at $12 \mathbb{6}$ /gal EtOH produced.

- Electricity costs estimated at $2 \mathbb{c} /$ gal EtOH produced.

- Enzymes estimated at 4థ/gal EtOH produced.

\section{Background Information}

The Johnson family operates a 1,280-acre corn farm which they have owned for 15 years. They feed 200 calves in their feedlot each year. The family consists of Dave, Sue, and three children: Ted, 24 years old and married, has been living and working at the farm for 2 years, and he and his wife have a strong commitment to farming; Sara is 22 years old, married, and teaches in a town about 250 miles away; Laura is 15 years old, goes to high school in town 25 miles away, and also works on the farm.
The Johnsons are concerned about the future cost and availability of fuel for their farm equipment. The Johnsons have known about using crops to produce ethanol for fuel for a long time, and recent publicity about it has rekindled their interest.

They have researched the issues and believe there are five good reasons for developing a plan to build a fermentation ethanol plant as an integral part of their farm operation:

- to create another market for their farm products,

- to produce a liquid fuel from a renewable resource,

- to gain some independence from traditional fuel sources and have an alternate fuel available,

- to gain cost and fuel savings by using the farm product on the farm rather than shipping it, and by obtaining feed supplements as a coproduct of the ethanol production process, and

- to increase profit potential by producing a finished product instead of a raw material.

They first analyzed the financial requirements in relation to their location, farm operations, and personal financial situation.

\section{Analysis of Financial Requirements}

The local trade center is a town of 5,000 people, 35 miles away. The county population is estimated at 20,000 . Last year 7,000,000 gallons of gasoline were consumed in the county according to the state gasoline tax department. A survey of the Johnsons' energy consumption on the farm for the last year shows:

$$
\begin{aligned}
& \text { Gasoline }=13,457 \text { gals } \\
& \text { Diesel }=9,241 \text { gals } \\
& \text { LP Gas }=11,487 \text { gals }
\end{aligned}
$$

They decided to locate the plant close to their feedlot operation for ease in using the stillage for their cattle. They expect the plant to operate 5 days a week, 24 hours a day, 250 days a year. It is designed to produce 25 gallons of anhydrous ethanol per hour or 150,000 gallons in one year, using 60,000 bushels of corn per year. In addition to ethanol, the plant will produce stillage at the rate of 230 gallons per hour as well as carbon dioxide.

After researching the question of fuel for the plant, this family has decided to use agricultural residue as the fuel source. This residue will be purchased from the family farm. The cost of this fuel is figured at $\$ 20$ per ton. 
They will have to purchase one year's supply of fuel since it is produced seasonally in the area. The tonnage of residue per acre available is 6 tons per acre based on measurements from the past growing season.

The water source is vitally important. They will need about $\mathbf{4 0 0}$ gallons of water each hour. To meet this demand, a well was drilled and an adequate supply of water was found. The water was tested for its suitability for use in the boiler, and the test results were favorable.

The family has determined that they can operate both the plant and the farm without additional outside labor. The ethanol they produce will be picked up at the farm as a return load by the jobbers making deliveries in the rural area. The Johnsons will deliver stillage in a tank truck to neighbors within 5 miles.

At the present there are no plans to capture the carbon dioxide, since the capital cost of the equipment is too high to give a good return on their investment. There is no good local market for the carbon dioxide; but there are many uses for carbon dioxide, and selling it as a coproduct may prove to be profitable in other situations.

The family's plans are to market their products locally. They have contacted local jobbers who have given them letters of intent to purchase the annual production of ethanol. They plan to use the distillers grains in their own feedlot and to sell the rest to their neighbors. The neighbors have given them letters stating they would purchase the remainder of the distillers grains produced. These letters are important in order to accurately assess the market.

\section{Organizational Form}

The Johnsons chose to establish a closely held corporation for this business. Other possibilities they considered included partnerships, sole proprietorships, and profit and nonprofit corporations. If additional equity had been needed, a broader corporation or a partnership would have been selected. However, their financial status was sufficient to allow them to handle the investment themselves, as shown by their balance sheet which follows.

Dave and Sue Johnson

Balance Sheet as of January 1979

\begin{tabular}{lr}
\hline Assets: & \\
Current Assets: & \\
Cash & $\$ 15,000$ \\
Inventory & $\$ 70,000$ \\
$\quad$ Total current assets & $\$ 85,000$ \\
Equipment & $\$ 125,000^{*}$ \\
Land and buildings & $\$ 512,000^{*}$ \\
$\quad$ Total assets & $\$ 722,000$ \\
\hline
\end{tabular}

Liabilities and Capital:

Operating notes at local bank

$\$ 20,000$

$\$ 69,000$

Federal Land Bank loan

$\$ 350,000$

Total Liabilities

$\$ 439,000$

Total Capital

Total Liabilities and Capital

*These assets shown at fair market value.

The Johnsons formed a corporation because it afforded the ability to protect themselves from product liability and gave them the option to give stock to all family members as an incentive compensation package. Also, the use of a corporation avoids an additional burden on their credit line at the bank for their farming operation since they were able to negotiate a loan with no personal guarantee of the corporate debt. In a partnership they would have had personal liability for the product, the debt, and the actions of the partners in the business. The record-keeping requirements of the corporation and the limited partnership were equal, and the former afforded greater security. Co-ops and nonprofit corporations were considered also, but these two options were discarded because of operating restrictions.

After formation of the corporation, they transferred (tax-free) half of a year's supply of corn $(30,000$ bushels) in exchange for stock in the corporation. They elected Subchapter S treatment upon incorporation and had the first year of operation reported on a short-period return. Generally, Subchapter S has many of the advantages of a partnership but not the liabilities. (Consult an accountant or lawyer for a detailed description of this.) They could pass through the investment credit which is proposed to be $20 \%$ of the capital cost, assuming that the Internal Revenue Service would authorize a fuelgrade ethanol plant to qualify for the additional investment credit for being a producer of renewable energy. After the first short-period return is filed, the stockholders can then elect not to be a Subchapter S corporation. This plan helps the cash flow as they would personally recover some tax dollars through the investment credit.

The corporation will lease from the family, on a longterm basis, 2 acres of land on which to locate the plant. They considered transferring this land to the corporation, but the land is pledged as security for the Federal Land Bank so it would be cumbersome to get the land cleared of debt. Also, the 2 acres would require a survey and legal description, thereby adding additional cost, and there are no local surveyors who could do this work.

The corporation will purchase corn and agricultural residue from the family farm and damaged corn from neighbors when there is a price advantage to do so. The 
family will also purchase the distillers' grains and ethanol used on the farm from the corporation as would any other customer. All transactions between the family farm and the corporation will use current prices that would be paid or received by third parties.

\section{Conclusion}

The initial visit with the bank was encouraging. The local banker was well acquainted with ethanol production through the publicity it had been receiving. The bank was receptive to the financing, saying they would consider it an equipment loan. The bank required a schedule of production, funds-flow projections, projected income statements, and projected balance sheets for the next 2 years. The bank was primarily concerned that these statements demonstrate how the plant could be paid for.

Before meeting with their accountant, the Johnsons prepared decision and planning worksheets as described in Chapter II. This work on their part saved them some accountant's fees and gave them an idea as to the feasibility of such a plant. The projected financial statements were then prepared with the assistance of their accountant for the bank's use.
The following projected financial statement is based on decisions made about the operations and management of the plant. It served the Johnsons as a tool in deciding whether or not the plant would be a good investment for them and also as a final presentation to the bank for loan approval. The assumptions used in preparing these financial statements are included with the financial statements and represent an integral part of the manage ment plan.

After the financial projections were completed and the bank had reviewed them, there was one more area of concern. The bank wanted to know whether the system as designed was workable and could produce what it was projected to do from a technical feasibility standpoint. The family furnished the bank with the engineer's report which documented systems that were in operation and that were successfully using their proposed technology. The bank contacted some of the people operating these plants to verify their production. The bank then completed their paperwork and made a loan to the family's corporation secured only by the equipment. They also approved the line of credit for the working capital required based on the projected financial statements. 


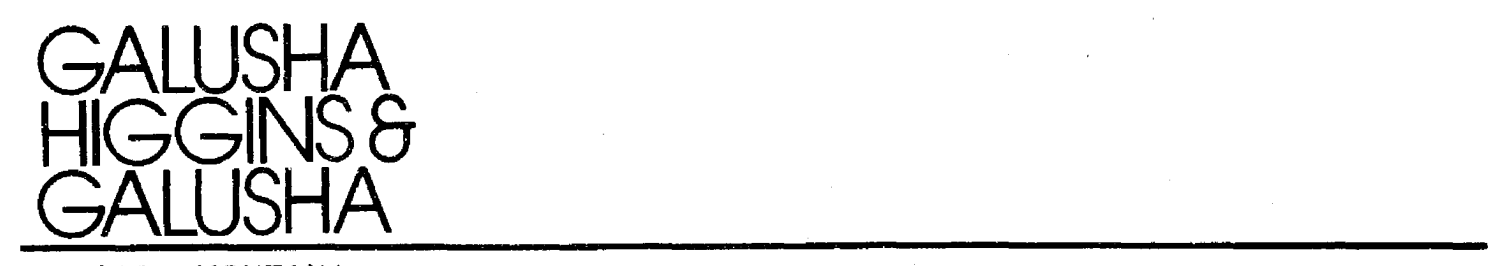

GLASGOW, MONTANA

November 6,1979

National Bank of Golden Rise

Golden, Colorado

We have assisted in the preparation of the accompanying projected balance sheet of Johnson Processors, Inc. (a sample company), as of December 31, 1980 and 1981, and the related projected statements of income and changes in financial position for the years then ended. The projected statements are based solely on management's assumptions and estimates as described in the footnotes.

Our assistance did not include procedures that would allow us to develop a conclusion concerning the reasonableness of the assumptions used as a basis for the projected financial statements. Accordingly, we make no representation as to the reasonableness of the assumptions.

Since the projected statements are based on assumptions about circumstances and events that have not yet taken place, they are subject to the variations that will arise as future operations actually occur. Accordingly, we make no representation as to the achievability of the projected statements referred to above.

The terms of our engagement are such that we have no obligation or intention to revise this report or the projected statements because of events and transactions occurring after the date of the report unless we are subsequently engaged to do so.

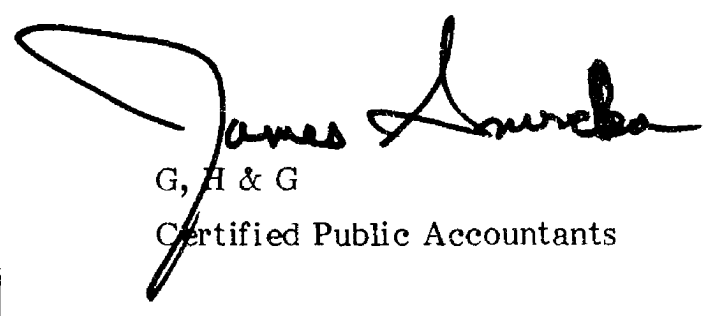




\section{JOHNSON PROCESSORS, INC. \\ PROJECTED BALANCE SHEET \\ UNAUDITED}

(NOTES 1 THROUGH 4 ARE AN INTEGRAL PART OF THESE PROJECTED FINANCIAL STATEMENTS AND PROVIDE AN EXPLANATION OF ASSUMPTIONS USED IN THIS REPORT)

FOR YEAR ENDED

December 31, December 31,

1980

1981

Assets

Current assets

Cash

Accounts receivable

$\$ 24,617$

55,350

$\$ 18,452$

Raw materials and supplies

22,214

1,362

55,350

Work in process inventory

18,765

26,785

Finished goods inventory

30,000

Marketable securities

Total current assets

$\$ 152,308$

1,601

22,041

30,000

$\$ 154,229$

Plant, equipment, and structures

Plant and equipment

Building

Total plant and equipment

Less accumulated depreciation

Net plant and equipment

Total assets

$\begin{array}{r}\$ 107,000 \\ 17,280 \\ \hline \$ 124,280 \\ 8,605 \\ \hline\end{array}$

$\$ 107,000$

17,280

$\$ 124,280$

17,210

115,675

$\$ 267,983$

107,070

$\$ 261,299$

Liabilities and Capital

Current liabilities

Accounts payable

Current portion of loans

Total current liabilities

$\$ 156,043$

2,997

Less current portion

Total long-term liabilities

Total liabilities

Capital

Total liabilities and capital
$\$ 3,800$

2,997

$\$ 6,797$

153,046

$\$ 159,843$

$\$ 113,821$

3,500

$\$ 4,130$

3,500

$\$ 7,630$

108,140

$\$ 267,983$
110,321

$\$ 117,951$

143,348

$\$ 261,299$ 


\section{JOHNSON PROCESSORS, INC. \\ PROJECTED INCOME STATEMENT \\ UNAUDITED}

(NOTES 1 THROUGH 4 ARE AN INTEGRAL PART OF THESE PROJECTED FINANCIAL STATEMENTS AND PROVIDE AN EXPLANATION OF ASSUMPTIONS USED IN THIS REPORT)

FOR YEAR ENDED

December 31, 1980

December 31, 1981

Revenue

Alcohol

Stillage

Total sales

Cost of goods sold

Beginning finished goods inventory

Cost of goods manufactured

Cost of goods available for sale

Ending finished goods inventory

Cost of goods sold

Gross profit

Selling expenses

Marketing and delivery expenses $\$ 25,545$

$\$ 229,680$

55,525

$\$ 285,205$

$\begin{array}{r}0 \\ \$ 225,634 \\ \hline \$ 225,634 \\ 18,765 \\ \hline \$ 206,869 \\ \hline \$ 78,336 \\ \hline\end{array}$

$\$ 18,765$

266,634

$\$ 285,399$

22,041

$\$ 263,358$

$\$ 76,115$ (scheduled)

Total selling expenses

Net operating profit

Income taxes

$\$ 25,545$

$\$ 52,791$

$\$ 29,074$

13,651

$\$ 47,041$

Net income

$\$ 39,140$

11,833

$\$ 35,208$ 
JOHNSON PROCESSORS, INC.

PROJECTED STATEMENT OF CHANGES IN FINANCIAL POSITION (Cash Basis) UNAUDITED

(NOTES 1 THROUGH 4 ARE AN INTEGRAL PART OF THESE PROJECTED FINANCIAL STATEMENTS AND PROVIDE AN EXPLANATION OF ASSUMPTIONS USED IN THIS REPORT)

\begin{tabular}{|c|c|c|}
\hline & \multicolumn{2}{|c|}{ FOR YEAR ENDED } \\
\hline & $\begin{array}{c}\text { December } 31 \text {, } \\
1980\end{array}$ & $\begin{array}{c}\text { December 31, } \\
1981\end{array}$ \\
\hline \multicolumn{3}{|l|}{ CASH GENERATED } \\
\hline Net income & $\$ 39,140$ & $\$ 35,208$ \\
\hline \multicolumn{3}{|l|}{$\begin{array}{l}\text { Add (deduct) items not requiring or } \\
\text { generating cash during the period }\end{array}$} \\
\hline Trade receivable increase & $(55,350)$ & $(0)$ \\
\hline Trade payable increase & 3,800 & 330 \\
\hline Inventory increase & $(42,341)$ & $(8,086)$ \\
\hline Depreciation & 8,605 & 8,605 \\
\hline Subtotal & $\$(46,146)$ & $\$ 36,057$ \\
\hline \multicolumn{3}{|l|}{ Other sources } \\
\hline Contributed by shareholders & 69,000 & \\
\hline Bank loan & 163,040 & \\
\hline Total cash generated & $\$ 185,894$ & $\$ 36,057$ \\
\hline \multicolumn{3}{|l|}{ CASH APPLIED } \\
\hline Additional loan repayment & $\$ 4,000$ & $\$ 38,722$ \\
\hline Purchase of plant and equipment & 107,000 & \\
\hline Purchase of building & 17,280 & \\
\hline Reduction of bank loan & 2,997 & $\$ 3,500$ \\
\hline Total cash applied & $\$ 131,277$ & $\$ 42,222$ \\
\hline Increase in cash & $\$ 54,617$ & $\$(6,165)^{*}$ \\
\hline
\end{tabular}

${ }^{*}$ Net decrease in cash is caused by an accelerated pay-off of the operating capital rate in the amount of $\$ 38,722$. 
JOHNSON PROCESSORS, INC.

EXHIBIT I

UNAUDITED

(NOTES 1 THROUGH 4 ARE AN INTEGRAL PART OF THESE PROJECTED FINANCIAL STATEMENTS AND PROVIDE AN EXPLANATION OF ASSUMPTIONS USED IN THIS REPORT)

\begin{tabular}{|c|c|c|}
\hline & \multicolumn{2}{|c|}{ FOR YEAR ENDED } \\
\hline & $\begin{array}{l}\text { December 31, } \\
1980\end{array}$ & $\begin{array}{c}\text { December 31, } \\
1981\end{array}$ \\
\hline \multicolumn{3}{|l|}{ ETHANOL } \\
\hline \multicolumn{3}{|l|}{ Projected Production Schedule } \\
\hline $\begin{array}{l}\text { Projected gallons sold } \\
\text { Projected inventory requirements }\end{array}$ & $\begin{array}{r}132,000 \\
18,000 \\
\end{array}$ & $\begin{array}{r}150,000 \\
18,000 \\
\end{array}$ \\
\hline $\begin{array}{l}\text { Total gallons needed } \\
\text { Less inventory on hand }\end{array}$ & $\begin{array}{r}150,000 \\
0 \\
\end{array}$ & $\begin{array}{r}168,000 \\
18,000 \\
\end{array}$ \\
\hline Projected production & 150,000 & 150,000 \\
\hline Sales price per gallon & $\$ 1.74$ & $\$ 1.89$ \\
\hline \multicolumn{3}{|l|}{ Projected Cost of Goods Manufactured } \\
\hline \multicolumn{3}{|l|}{ Projected production costs: } \\
\hline Labor & $\$ 20,805$ & $\$ 20,328$ \\
\hline Corn & 138,000 & 180,000 \\
\hline Electricity & 3,000 & 3,300 \\
\hline Straw & 10,714 & 11,785 \\
\hline Miscellaneous (scheduled) & 18,000 & 19,800 \\
\hline Depreciation & 6,730 & 6,730 \\
\hline Interest & 23,747 & 18,330 \\
\hline Enzymes & 6,000 & 6,600 \\
\hline $\begin{array}{l}\text { Total costs of production } \\
\text { Add beginning work-in-process inventory }\end{array}$ & $\$ 226,996$ & $\begin{array}{r}\$ 266,873 \\
1,362 \\
\end{array}$ \\
\hline $\begin{array}{l}\text { Subtotal } \\
\text { Less ending work-in-process inventory }\end{array}$ & $\begin{array}{r}\$ 226,996 \\
1,362 \\
\end{array}$ & $\begin{array}{r}\$ 268,235 \\
1,601 \\
\end{array}$ \\
\hline Projected cost of goods manufactured & $\$ 225,634$ & $\$ 266,634$ \\
\hline
\end{tabular}




\section{JOHNSON PROCESSORS, INC. \\ NOTES TO THE PROJECTED FINANCIAL STATEMENTS \\ UNAUDITED}

\section{SIGNIFICANT ACCOUNTING POLICIES}

Following is a summary of the significant accounting policies used by Johnson Processors, Inc. in the projected financial statements.

- Assets and liabilities, and revenues and expenses are recognized on the accrual basis of accounting.

- Inventory is recorded at the lower value (cost or market) on the first-in, first-out (FIFO) basis.

- Accounts receivable are recorded net of bad debts.

- Depreciation is calculated on the straight line basis.

\section{ASSETS}

\section{Current Assets}

- Accounts receivable are projected at each balance sheet date using $\mathbf{3 0}$ days of sales for ethanol and 90 days of sales for stillage.

- Inventory-raw materials-is made up of corn and corn stover. Thirty days in inventory is used for corn and one year's supply is used for stover.

- Inventory-work in process-consists of $1 \frac{112}{2}$ days' production.

- Inventory of finished goods consists of raw materials and cost of production. Thirty days in inventory is used for ethanol and 2 days is used for stillage.

The estimates of number of days in accounts receivable and finished goods inventory are higher than those quoted in Robert Morris Associates averages for feed manufacturers and wholesale petroleum distributors.

\section{Fixed Assets}

Management anticipates purchasing the equipment for production of ethanol. Consulting engineers contacted verified that the equipment and plant costs listed in Table VI-2 were reasonable.

\section{REPRESENTATIVE PLANT COSTS}

\begin{tabular}{|c|c|}
\hline Equipment and Materials & $\$ 71,730$ \\
\hline Piping & 4,000 \\
\hline Electrical & 1,500 \\
\hline Excavation and Concrete & 2,000 \\
\hline Total Equipment and Materials & 79,230 \\
\hline $10 \%$ Contingency & 7;923 \\
\hline Total & 87,153 \\
\hline Tank Truck & 14,847 \\
\hline Erection Costs & 5,000 \\
\hline Grand Total & $\$ 107,000$ \\
\hline
\end{tabular}




\section{Investments}

Investments consist of the amount of excess cash accumulated from operation during the first and second year of operation.

\section{LIABILITIES AND CAPITAL}

Management estimated accounts payable using 30 days in payables for conversion costs. It is anticipated that corn will be paid for a month in advance.

Management estimates that a bank loan in the amount of $\$ 163,040$ will be required, payable semiannually at $15 \%$ interest. Anticipated payback period for the portion of the loan covering plant and equipment is 15 years. The payback period for the portion covering working capital is 8 years. The payback period for the truck is 8 years. An additional $\$ 4,000$ the first year is projected to be paid on the equipment loans and to repay the working capital loan in the second year. The loan will be used to finance plant and equipment and working capital. The anticipated plant and equipment and working capital for the first year is estimated as follows.

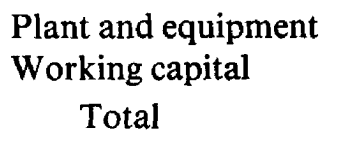

$$
\begin{aligned}
& \$ 124,280 \\
& \$ 107,760 \\
& \hline \$ 232,040
\end{aligned}
$$

Cash could be very lean during the first year that the plant operates at capacity because of dramatic increases in working capital resulting from accounts receivable and inventory requirements. Inadequate financing would make maximum production impossible because of inability to fund working capital demands.

\section{INCOME STATEMENT \\ Sales}

Sales volume was estimated at maximum production (150,000 gallons of ethanol and 1,380,000 gallons stillage) for the first year. Ethanol price was taken to be $\$ 1.74$ per gallon (the actual delivered price at Council Bluffs, lowa on November 6,1979 ). The price of ethanol is projected to increase by $9.1 \%$ for the entire period covered by the projections. The increase of $9.1 \%$ is the projected price increase by a marketing firm from Louisiana.

It is conceivable that as the price of gasoline increases to a point greater than the price of ethanol, producers could raise the price of ethanol to equalize the prices of the two liquid fuels. In order to be conservative, management did not consider this effect .

The stillage sales price was taken to be 3.9 cents per gallon for the 2 years. This sales price was based on the sales price charged by Dan Weber in Weyburn, Saskatchewan, Canada. The local stillage market is, however, worthy of a thorough study before a decision is made to enter the fermentation ethanol business. If a large brewery or distillery is located in the area, the price of stillage can be severely depressed. For example, Jack Daniels and Coors sell their stillage for 0.4 cents per gallon and 0.8 cents per gallon, respectively.

\section{Cost of Sales}

Management has projected cost of sales to include raw materials and production costs. The cost of corn is projected at $\$ 2.30$ per bushel during the first year of operation (the price received by farmers in Iowa on November 6, 1979). Management has the total amount of corn available from the corporate shareholder. To demonstrate the effect of substantial increases in corn prices on profitability and cash flow, management projected that the cost of corn would rise to $\$ 3.00$ per bushel for year two.

Management anticipates that depreciation will remain constant using the straight line method. A 15-year life for the plant was used with a salvage value of $\$ 4,000$, while an 8-year life and 20-year life were used for the truck and building respectively. No other salvage values were taken into consideration.

Labor cost was computed allowing 4 hours per day for work necessary in the processing of the ethanol, based on the engineer's time requirement estimates. The labor was valued at $\$ 10$ per hour, including a labor overhead factor. Bookkeeping labor was computed at $\$ 6,000$ per year, assuming this plant would only require part-time services. It is anticipated that some additional time may be required the first year. For this, $\$ 2,325$ has been added to the labor cost as a contingency. 
Enzyme cost was estimated at $\$ 6,000$ per year by the engineers working on the project. Electricity was estimated at 2 cents per gallon of ethanol produced.

Stover cost was computed based on a cost of $\$ 20$ per ton. A Btu value of 7,000 Btu per pound (as estimated by the engineers) was used. An $80 \%$ efficiency for the boiler was assumed, so anticipated Btu values were 5,600 Btu per pound of straw, and a total Btu requirement of 40,000 per gallon of ethanol produced.

\section{Miscellaneous Expenses}

Miscellaneous expenses were estimated at 12 cents per gallon. These expenses are shown in the detail schedule at the end of this report. To be conservative, figures are included in the miscellaneous expenses for shrinkage due to the grain handling and a contingency for any minor items that may have been overlooked.

Interest expense is for the bank loan. Interest expense is calculated at $15 \%$. In year two of the operation, it is projected that the working capital portion of the notes payable will be paid off.

Management projects that other projected costs will increase $10 \%$ per year because of inflation. To be conservative, management did not estimate the cost savings potential of improved technology. Research is currently being performed in crops that have the potential of producing several times the amount of ethanol as does corn. Use of such crops could produce substantial cost savings in ethanol production. The process is very new in design, so improvements in the production process are also probable. Such improvements could further reduce the cost of producing ethanol.

\section{Selling and Administrative Expenses}

To be conservative, management estimated marketing expenses at $5 \%$ of sales. It is anticipated that this expense may not actually be necessary. Delivery expenses take into consideration the following items:

- interest was computed at $15 \%$ on the bank loan for the truck based on semi-annual payments;

- the time necessary to deliver the stillage was estimated based on 10 hours per week at $\$ 10$ per hour including labor overhead;

- maintenance for the truck was estimated at $\$ 1,000$; and

- fuel for the truck was computed based on 75 miles per week and a fuel consumption of 4 miles per gallon and a fuel cost of $\$ 1.025$ per gallon. The cost is estimated to increase $36.5 \%$ for the second year of operation.

\section{Income Taxes}

The shareholders of Johnson Processors, Inc. plan to elect to have income taxed to the shareholder rather than to the corporation, under Internal Revenue Code Section 1372(a). The shareholders anticipate changing the election after the first year of operation. Taxes have been estimated based on a $6 \%$ state tax rate and a $6.75 \%$ federal tax rate in effect during 1979. For purposes of these projections, the projected financial statements (assuming a conventional corporation and a full 12 months of operation in each period) have been shown to demonstrate the projected results of operation that could be anticipated.

The shareholders of Johnson Processors, Inc. anticipate contributing $\$ 69,000$ to the corporation. This amount is $30 \%$ of the total project. This will be contributed by transferring corn inventory equal to the $1 / 2$-year supply necessary for processing. For purposes of this illustration, the contribution of corn is treated as cash to demonstrate to the bank the payback potential of the plant. 
JOHNSON PROCESSORS, INC.

DETAIL SCHEDULES

UNAUDITED

(NOTES I THROUGH 4 ARE AN INTEGRAL PART OF THESE PROJECTED FINANCIAL STATEMENTS AND PROVIDE AN EXPLANATION OF ASSUMPTIONS USED IN THIS REPORT)

\begin{tabular}{|c|c|c|}
\hline & \multicolumn{2}{|c|}{ FOR YEAR ENDED } \\
\hline & $\begin{array}{c}\text { December 31, } \\
1980\end{array}$ & $\begin{array}{c}\text { December 31, } \\
1981\end{array}$ \\
\hline \multicolumn{3}{|c|}{ Schedule of Marketing and Delivery Expenses } \\
\hline Marketing $5 \%$ of sales & $\$ 14,260$ & $\$ 16,974$ \\
\hline Interest on truck & 2,211 & 2,045 \\
\hline Depreciation & 1,875 & 1,875 \\
\hline Labor & 5,200 & 5,720 \\
\hline Maintenance & 1,000 & 1,100 \\
\hline Fuel & 1,000 & 1,360 \\
\hline Total & $\$ 25,546$ & $\$ 29,074$ \\
\hline \multicolumn{3}{|c|}{ Schedule of Miscellaneous Expenses } \\
\hline Property taxes & $\$ 2,250$ & $\$ 2,475$ \\
\hline Insurance & 2,100 & 2,310 \\
\hline Chemicals and supplies & 600 & 660 \\
\hline Yeast & 450 & 495 \\
\hline Shrinkage & 4,200 & 4,620 \\
\hline Other & 2,550 & 2,805 \\
\hline Contingencies & 5,850 & 6,435 \\
\hline Total & $\$ 18,000$ & $\$ 19,800$ \\
\hline
\end{tabular}




\section{Appendices}

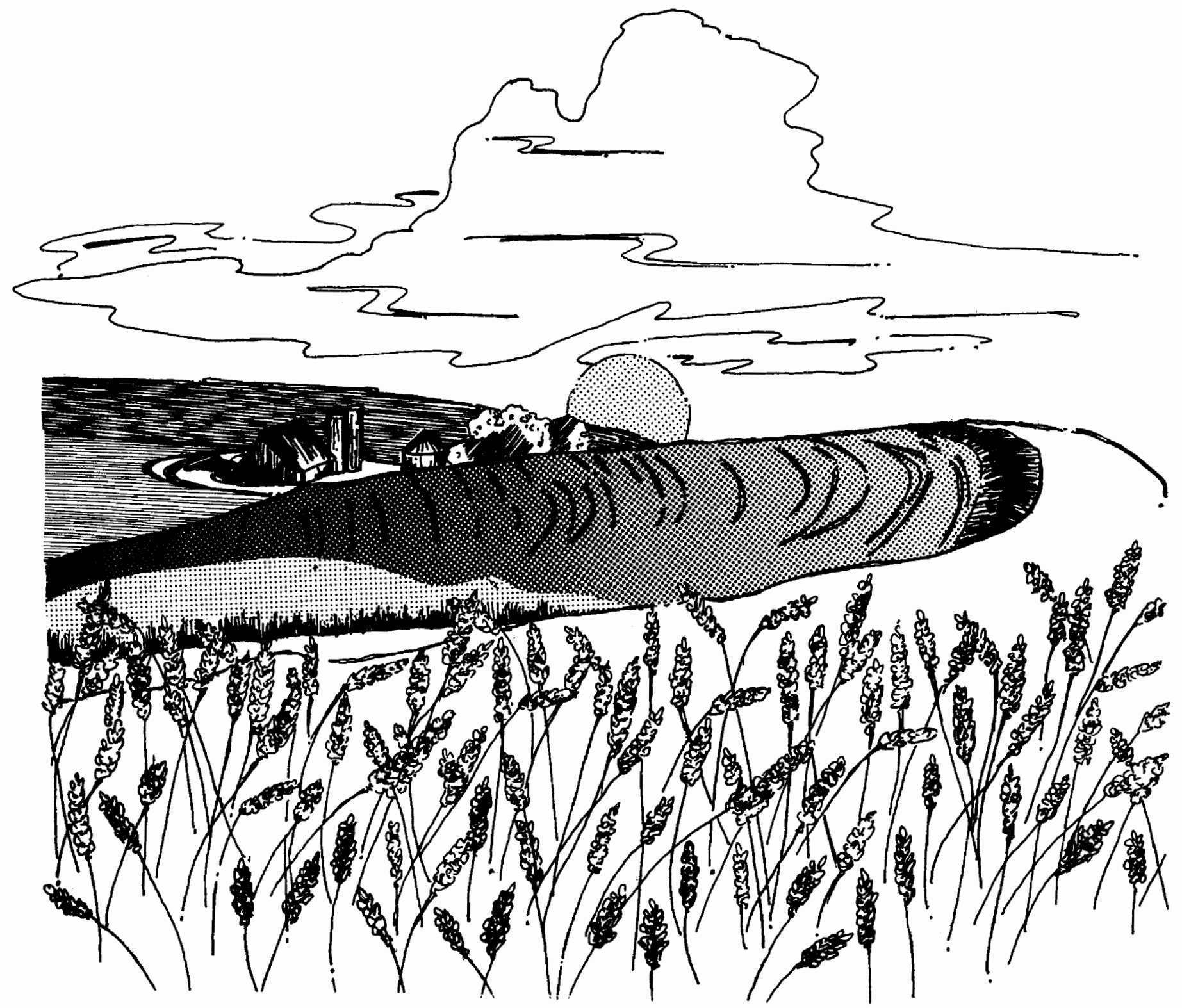




\section{APPENDIX A}

\section{Summary of Ethanol Legislation}

- National Legislation

- State Legislation 


\section{NATIONAL LEGISLATION}

\section{Farm Act of 1977}

Provided $\$ 60$ million in loan guarantees to build four pilot alcohol fuel plants in the United States.

\section{National Energy Act of 1978}

Provided motor fuel excise tax exemptions on gasoline/alcohol blends worth 4 cents per gallon of blend or 40 cents per gallon or $\$ 16.80$ per barrel of alcohol in 10 percent blends. Alcohol fuels are also eligible for Department of Energy entitlements, currently worth approximately $\$ 2.10$ per barrel of ethanol or five cents per gallon.

\section{Alcohol Fuels Production Incentive Act of 1979 (S. 906)}

Proposes a 10 percent investment tax credit (in addition to the current 10 percent credit) for alcohol fuels production equipment; provides a new 5 percent investment tax credit for buildings used in alcohol fuel production; authorizes the Department of Treasury to make up to $\$ 250$ million in loan guarantees to cover up to 50 percent of the cost (up to $\$ 10$ million per loan) of building or refinancing alcohol fuel plants or equipment; amends the Emergency Petroleum Allocation Act to provide priority to producers and marketers of gasohol or gasoline for use in gasohol when petroleum supplies are short.

\section{Public Works and Economic Development Act of 1979 (S. 914)}

Awaiting House-Senate Conference Committee consideration. The legislation proposes:

\section{Senate-Passed Provisions}

Authorizes EDA grants for facilities for production of alcohol for use as motor fuel when such grants will create or preserve jobs in small towns.

Funds for such grants are limited to 5 percent of funds under Titles I \& II of EDA Act. Under authorization levels in S.914, funding would total \$39.1 million annually.

\section{House-Passed Provisions}

Authorizes $\$ 100$ million in FY80 \& FY81 in EDA grants and loans for construction and operation of facilities producing alcohol or methane from renewable resources.

\section{Energy Security Act (S. 932)}

Awaiting action by the House-Senate Conference Committee. The legislation proposes:

\section{House-Passed Provisions}

Sets national goal for total synthetic fuel (including gasohol) production of 500,000 barrels per day in 1985 , 2 million barrels per day in 1990 .
Authorizes $\$ 3$ billion for the President to buy synfuels and allows him to establish a federal synfuel corporation.

\section{Senate-Passed Provisions}

- I-Title I: Synthetic Fuels Corporation Act of 1979

- Goal: production of synfuels equal to 1.5 million barrels of oil by 1995 .

- Establishes Synthetic Fuels Corporation with authorization of $\$ 20$ billion, with up to $\$ 1$ billion eligible to aid projects that use biomass and are basically large scale.

- Authorizes corporations to provide price guarantees, purchase agreements, loan guarantees, loans, joint ventures, and direct construction to secure synfuel production.

- II-Title II: Agricultural, Forestry, and Rural Energy Act of 1979

- Goal: achieve net energy independence for agricultural and forest production, processing and marketing; and 50 percent reduction in petroleum and natural gas use by rural residents and communities by the year 2000 .

- Establishes Agricultural, Forestry and Rural Energy Board in USDA which will report to Congress by $9-30-80$ on agricultural, forestry, and rural energy needs and resources; and will provide a rural energy production, use, and conservation program by December 31, 1981 .

- Authorizes $\$ 50$ million annually for applied research on agriculture, forestry, and rural energy production, use, and conservation.

- USDA to complete study by 12-31-82 on alternative crop-livestock systems to produce foodstuffs and fiber,as well as biomass for use in energy production.

- Mandates four to eight USDA Wood Energy Centers, and four to eight USDA Agricultural Biomass Energy Centers, which will do research, demonstration projects, field tests, and provide technical information. Authorizes $\$ 3$ million annually for Wood Centers, and same amount for Biomass Centers.

- State extension services to hold agricultural biomass energy workshops with goal of 100 workshops each year.

- Authorizes $\$ 250$ million annually in USDA loans for on-farm or commercial biomass energy projects. One-third must go to projects 
which produce no more than 2 million gallons of alcohol per year.

- Authorizes $\$ 500$ million annually in USDA loan guarantees for commercial or on-farm biomass energy projects, with one-third going to projects that use wood, and one-fourth going to small-scale projects that produce no more than 2 million gallons of alcohol per year.

- Authorizes $\$ 100$ million annually in USDA grants for biomass energy demonstration projects.

- Amends existing USDA programs to provide $\$ 390$ million in authorization for loans, loan guarantees, insured loans, and makes eligible loans for energy systems using nonfossil fuels.

- Authorizes $\$ 85$ million over 4 years for rural electric projects using alternative energy sources (biomass, wood, solar, etc.) and conservation technologies.

- Allows USDA to permit acreage set aside to be used to produce commodities for use in making alcohol for fuel.

\section{- III-Title III: Gasohol Motor Fuels Act of 1979}

- Goal: establishes national goals of 60,000 barrels per day of alcohol fuels in 1982, and a volume of alcohol fuels from renewable resources equal to 10 percent of estimated domestic gasoline consumption in 1990.

- Establishes Office of Alcohol Fuels in DOE and authorizes $\$ 1.2$ billion in loan guarantees, price guarantees, and purchase agreements for alcohol fuel production facilities that use renewable resources, with at least one-third of that total going to facilities that produce no more than 2 million gallons of alcohol per year.

- Authorizes the CCC to sell its sugar holdings at less than normal prices to producers of ethanol for use in motor fuel.

- Mandates use of gasohol in all federal motor vehicles where it is available at reasonable prices and quantities (exceptions are possible for national security reasons).

- Mandates USDA-DOT study on possible requirement that all new cars use gasohol or alcohol, and on barriers to the widespread marketing of gasohol.

- Amends Natural Gas Policy Act of 1978 to facilitate natural gas allocations to certain types of activities related to the production of alconol for fuel.

- Authorizes Presidential allocation of gasoline to utilize alcohol not able to be blended into gasohol due to a lack of gasoline.

\section{- IV-Title IV: Domestic Energy Policy Act of 1979}

- Establishes procedure for setting and updating national energy targets for imports and domestic production, which includes energy produced from renewable resources.

- Requires an energy impact report on every bill, rulemaking, or executive order in the federal government.

\section{STATE LEGISLATION}

The following is a brief summary of legislation that has been passed by state legislatures within the United States.

Many of the state legislatures were in session at the time the information was accumulated for this book. We recommend that any further information needed regarding state legislative bills be obtained directly from the clerks or secretaries of the respective legislature. The reader should recognize that errors in the interpretation of the legislation contained in this report are possible. Gasohol Tax Credit legislation is highlighted within each state's legislation summary.

\section{Arkansas}

\section{S.B. 454-passed 1979.}

Gasohol Tax Exemption. Exempts gasohol from motor fuel tax (9.5 cents).

\section{California}

\section{S.B. 318-passed 1979.}

The Department of General Services would prepare a plan utilizing a fuel containing at least $5 \%$ alcohol for use in at least $25 \%$ of the vehicles maintained by the Department.

\section{A.B. 1401-passed 1979.}

Authorizes the Department of Motor Vehicles to establish a 10-year methanol fuel experimentation program.

\section{S.B. 771-passed 1979.}

The State Energy Resources Conservation and Development Commission shall implement a program to demonstrate residue conversion technologies at appropriate locations throughout the state to encourage private-, public-, and investor-owned utility participation in this program. Fifteen million dollars have been appropriated from the general fund to carry out the purpose of this bill. 


\section{Colorado}

\section{S.B. 80-passed 1978.}

A nine-member committee was created to promote the production of gasohol, alcohol, and related industrial hydrocarbons from Colorado agricultural and forest products. Eighty thousand dollars were appropriated for administration of the bill.

H.B. 1135-passed 1978.

Gasohol Tax Exemption - 5 cents. Motor fuel which contains at least $10 \%$ alcohol, derived in Colorado, will receive a 5-cent excise tax reduction if sold in counties with a population exceeding 200,000 . As the availability of gasohol increases, all state and local vehicles will be required to use gasohol.

\section{H.B. 1463-passed 1979.}

Gasohol Tax Exemption - 5 cents. The tax exemption applies to a blend of gasoline and 95\%-pure alcohol derived from agriculture commodities and forest products. Reduces the real and personal property tax assessment for alcohol production facilities producing alcohol for use in motor vehicles. Provides a voluntary check-off of off-highway gasoline refund tax money to be placed into a special fund for the use of gasohol promotion.

\section{H.B. 1607-passed 1979.}

Gasohol Tax Exemption - 5 cents. Expands the definition of gasohol to include motor fuels containing alcohol derived from hydrocarbon or carbon-containing by-products or waste products. Grants a reduction in the property tax to facilities used for the production of such alcohol. The tax exemption applies to a blend of gasoline and alcohol that is produced from Colorado products derived from hydrocarbon or carboncontaining by-products or waste products with a purity of at least $95 \%$.

\section{Connecticut}

\section{Public Act 627-passed 1979.}

Gasohol Tax Exemption - 1 cent. Lowers state sales tax on gasohol from 11 cents to 10 cents per gallon, and exempts the motor fuel used in van pool vehicles (which is already exempt from the motor fuel tax) from the state sales tax.

\section{Hawaii}

S.B. 1581, S.D. 1, H.D. 1-passed.

\section{(Act 131, Session Laws of Hawaii 1978)}

Act 131, which is an omnibus appropriating bill for alternate energy research and development, appropriates $\$ 500,000$ for the conversion of an old Seagram distillery to a plant capable of producing 700,000 gallons of ethanol per year for gasohol purposes. The Act also appropriates $\$ 330,000$ to establish a corn-toethanol research and development program.

\section{Indiana}

\section{S. 218-passed 1979.}

Gasohol Tax Exemption - 4\% Sales Tax. The tax exemption applies to a $10 \%$ blend of agriculturally derived ethyl alcohol in fuel.

lowa

H.F. 491-passed 1978.

Gasohol Tax Exemption - 10 cents. Effective July 1, 1979, exempts fuel excise tax on motor fuel containing at least $10 \%$ alcohol, distilled from agriculture products. from July 1, 1978, ending June 30, 1983. (In Iuwa there is a sales tax on excise tax-exempted gasohol which in effect decreases the total tax credit to approximately 7 cents.)

\section{Kansas}

\section{H.B. 2345-passed 1979.}

Funds totaling $\$ 60,000$ shall be transferred from the Corn Commission, Grain Sorghum Commission, Soybean Commission, and Wheat Commission to the Kansas Energy Office to be used for the purpose of study and analysis of grains for use as energy resource alternatives.

\section{H.B. 2324-passed 1979.}

Gasohol Tax Exemption - 5 cents. The tax exemption applies to a $10 \%$ blend of 190-proof ethyl alcohol produced from grain grown in Kansas used in all motor vehicle fuels and shall be effective July 1,1979 . The tax exemption shall be reduced 1 cent per year until no tax exemption remains after July 1, 1984. All motor vehicles owned and operated by the State of Kansas and subdivisions shall be operated with a $10 \%$ blend of ethyl alcohol when reasonably obtainable.

\section{Louisiana}

\section{H.B. 571-passed 1979.}

Gasohol Tax Exemption - 8 cents. Exempts the retail sale of gasohol from state sales tax use, and motor fuel $\operatorname{tax}$.

\section{S.C.R. 99-adopted 1979.}

Requests the Department of Natural Resources to conduct a feasibility study for obtaining methane gas from sugarcane as an alternate energy source.

\section{H.B. 1033-passed 1979.}

To qualify for the purchase of oil, a small refiner must have in operation a facility for the distillation of methanol or ethanol produced from Louisiana agricultural commodities.

\section{Maryland}

\section{S.B. 807-passed 1979.}

Gasohol Tax Exemption - 1 cent. The tax exemption shall apply to a $10 \%$ blend of ethyl or methyl alcohol. 


\section{S.B. 823-passed 1979.}

To permit the Maryland Industrial Development Financing Authority to encourage and insure loans for the development and production of a certain motor fuel known as gasohol.

\section{H.B. 1628-passed 1979.}

Requires the Secretary of Agriculture to study the effectiveness of an ethanol and gasoline mixture. Requires the Secretary of Agriculture to inititate a 1-year program of tests using gasohol in eight state-owned vehicles.

\section{Missouri}

\section{H.B. 72-passed 1979.}

Authorizes the Department of Natural Resources to analyze the potential for increased utilization of coal, nuclear, solar, resource recovery and reuse, energyefficient technologies, and other energy alternatives, and to make recommendations for the expanded use of alternate energy sources and technologies.

\section{Montana}

\section{Resolution 28-adopted 1979.}

Provides for a State Oversight Gasohol Committee to be appointed under the Department of Natural Resources for the Gasohol Program.

\section{S.B. 523-passed 1979.}

Provides a lower property tax on equipment, buildings, and inventory of gasohol production by as much as $3 \%$.

\section{H.B. 402-passed 1979.}

Gasohol Tax Exemption. The tax exemption for gasohol is reduced by 2 cents for each of three succeeding 2-year periods, and the remaining 1 cent tax exemption expires in 1989.

In $1978, \$ 25,000$ was allocated from the alternate energy program to study gasohol in Montana.

\section{Nebraska}

\section{L.B. 776-passed 1971.}

Established the Agricultural Products Utilization Committee to promote research and development of gasohol, and to analyze the marketing and testing of gasohol. The Grain Alcohol Fuel Tax Fund was created with an initial appropriation of $\$ 40,000$ and a provision whereby one/eighth of the motor fuels tax, which is refundable to nonhighway uses, is used to promote the activities of the committee. L.B. 776 also provided for a 3-cent tax credit for the sale of gasohol.

\section{L.B. 1207-passed 1972.}

Made changes in L.B. 776. Stated that in order to qualify as a special fuel the blend had to be at least $10 \%$ agricultural ethyl alcohol or at least 190 proof. L.B. 1207 also directed the Committee to sponsor research and development of industrial uses of by-products resulting from the amended L.B. 776, to increase the exemption from 3 cents to 5 cents on gasohol, and increased the Legislative tax review limitation from 10 million to 20 million gallons of gasohol sold which permits the legislature to review the tax credits.

\section{L.B. 424-passed 1978.}

Provided for matching funds (up to $\$ 500,000$ ) to any city, county, or village wishing to build a gasohol plant.

\section{L.B. 52-approved 1979.}

Gasohol Tax Exemption - 5 cents. Amended L.B. 776 to increase the exemption from 3 cents to 5 cents on gasohol and increased the legislative tax review limitation from 10 million to 20 million gallons of gasohol sold which permits the legislature to review the tax credit.

\section{L.B. 74-passed 1979.}

Requires that the Department of Roads implement a program using gasohol in its vehicles to the extent that gasohol supplies are available. Gasohol must contain Nebraska-produced alcohol.

\section{L.B. 571-passed 1979.}

The Governor is authorized to enter into agreements with municipalities or counties to build and maintain grain alcohol plants. The State of Nebraska will have the option to purchase the plant. An Alcohol Plant Fund is created, to be established from funds transferred from the Highway Trust Fund or as appropriated from the legislature; the state gas tax is increased one cent to provide additional revenue for the Highway Fund to support the Alcohol Plant Fund.

\section{New Hampshire}

\section{H.B. 201-passed 1979.}

Gasohol Tax Exemption - 5 cents. The gasohol tax exemption applies to a $10 \%$ blend of alcohol manufactured in New Hampshire, derived from agriculture commodities and forest products, with a purity of $99 \%$.

\section{New Jersey}

\section{A.R. 3034-passed 1979.}

Directs the Energy and Natural Resources Committee of the General Assembly to study large-scale use of gasohol and other alcohol-based fuels.

\section{New Mexico}

\section{S.J.M. 9-adopted 1978.}

Resolution requesting the Division of Energy and Minerals Department to study the feasibility of using gasohol in New Mexico. 
New York

\section{S.B. 9860-A-passed 1978.}

Directs the Commissioner of General Services to conduct a study of the feasibility of using gasohol for stateoperated vehicles through a comprehensive road test.

\section{S.B. 2393-passed 1979.}

The Commissioner of General Services is directed to conduct an experimental program to test the feasibility of using a mixture of gasoline and alcohol as fuel for state-operated motor vehicles.

\section{North Dakota}

\section{S.B. 2338-passed 1979.}

Gasohol Tax Exemption - 4 cents. The tax exemption applies to a blend of $10 \%$ agriculture ethyl alcohol $(99 \%$ pure) and $90 \%$ unleaded gasoline.

\section{H.B. 1384-passed 1979.}

Establishes an Agriculture Products Utilization Commission funded by a 1/8-cent gasoline refund tax reduction, $\$ 200,000$ appropriated from July 1,1979 to June $30,1980$.

\section{Oklahoma}

\section{S.B. 248-passed 1979.}

Gasohol Tax Exemption - 6.5 cents. The gasohol tax exemption applies to a $10 \%$ blend of ethanol, alcohol, and gasoline.

\section{Oregon}

\section{H.B. 2779-passed 1979.}

Requires use of gasohol in certain state-owned vehicles to the maximum extent commercially feasible effective January, 1980.

\section{S.B. 927-passed 1979.}

Creates solar, wind, geothermal, water, agricultural and forest residue, and gasohol energy task forces and an Alternate Energy Development Commission to prepare comprehensive alternate resources plans to be submitted to the governor and legislature.

\section{H.B. 2780-passed 1979.}

Exempts commercial ethanol or methanol gasohol plants from property tax and corporate income tax effective June 30,1981 , of which $90 \%$ is used for a $10 \%$ blend of gasohol and not produced from petroleum, natural gas, or coal.
Rhode Island

\section{H.R. 7891-adopted 1978.}

Requesting that the State Director of Transportation conduct experiments with the public to determine the feasibility of a gasoline-alcohol fuel blend.

\section{South Carolina}

\section{H.B. 2443-passed 1979.}

Provides that gasohol be sold tax-free until October 1, 1979; imposes a 6-cent per gallon tax from October 1 , 1979 to July 1, 1985, and a 7-cent per gallon tax from July 1, 1985 to July 1, 1987; provides for removal of these incentives if loss of revenue totals $\$ 5$ million.

\section{South Dakota}

\section{H.B. 1064-passed 1979.}

Gasohol Tax Exemption - 5 cents. The gasohol tax exemption applies to a $10 \%$ blend of alcohol derived from agriculture and forest products.

\section{Tennessee}

H.J.R. 161-passed 1979.

Creates a special joint committee to study the development and use of methanol as an alternative fuel.

\section{Texas}

\section{H.B. 1803-passed 1979.}

Provides for state loans for establishment of plants to manufacture fuel from renewable resources, $\$ 25,000$ may be loaned to any one legal entity and $\$ 500,000$ may be loaned to a small business corporation. The total unpaid principles balance shall not exceed \$15 million.

\section{H.B. 1986-passed 1979.}

Provides for annual alcohol manufacturers permit of $\$ 100$. A Texas Legislative Council preliminary draft provides an alcohol users license of $\$ 10$, an alcohol fuel manufacturers license of $\$ 25$, an agriculture fuel marketing license of $\$ 50$, and a beverage alcohol manufacturers permit of $\$ 1,000$.

\section{Washington}

S.H.B 302-passed 1979.

Exempts B\&O Tax on alcohol manufactured for gasohol when alcohol is sold to another person in Washington. Does not apply to out-of-state sales.

\section{Wyoming}

\section{H.B. 114-passed 1979.}

Gasohol Tax Exemption - 4 cents. Sales of gasohol would be subject to a 4-cent per gallon tax rather than an 8-cent per gallon tax until July 1, 1984. 
TABLE A-1. SUMMARY OF STATE ALCOHOL FUEL EXEMPTIONS

\begin{tabular}{lcc}
\hline & & STATE \\
STATE & STATE & GASOHOL TAX \\
& GASOLINE TAX & EXEMPTION
\end{tabular}

\begin{tabular}{lll}
\hline Arkansas & .095 & .095 \\
Colorado & .07 & .05 \\
Connecticut & .11 & .01 \\
Indiana & .04 & .04 \\
Iowa & .10 & .07 \\
Kansas & .08 & .05 \\
Louisiana & .08 & .08 \\
Maryland & .09 & .01 \\
Montana & .09 & .02 \\
Nebraska & .105 & .05 \\
New Hampshire & .10 & .05 \\
North Dakota & .08 & .04 \\
Oklahoma & .065 & .065 \\
South Carolina & .10 & .05 \\
South Dakota & .09 & .04 \\
Wyoming & .08 & .04
\end{tabular}




\section{APPENDIX B}

\section{Department of Treasury \\ Bureau of Alcohol, \\ Tobacco, and Firearms}

\section{Permit Information}

- Alcohol Fuels and BATF

- Regulatory Requirements

- BATF Regional Offices

- Sample Application 


\section{BATF REGULATIONS}

The design, construction, and operation of alcohol fuel plants require attention from Federal, State, and local authorities in order to ensure maintenance of the public good. Specific aspects of alcohol fuel production relating to safety and environmental concerns have been addressed in the main body of this document; other more general requirements, such as meeting building codes and zoning regulations, are site-specific and must be complied with, based on the individual case. Again, specific to alcohol fuels, this appendix addresses BATF regulations and other regulations and permits as they concern the potential investor.

In the Energy Tax Act of 1978 (Public Law 95-618), Congress required the Secretary of the Treasury to propose legislative recommendations to facilitate fuel use of distilled spirits. In compliance with this mandate, the BATF submitted a proposal in 1979. Congress incorporated the proposed legislation, with modifications, in Public Law 96-223.

Public Law 96-223 added a new section to Subchapter B of Chapter 51 of the Internal Revenue Code of 1954. New Section 5181, Distilled Spirits for Fuel Use, provides for the establishment of distilled spirits plants solely for the purpose of producing, processing and storing, and using or distributing distilled spirits to be used exclusively for fuel use. The Secretary of the Treasury is directed to expedite all applications, establish a minimum bond, and generally encourage and promote (through regulation or otherwise) the production of alcohol for fuel purposes. The Law gives the Secretary authority to provide by regulation for the waiver of any provision of Chapter 51 (except Section 5181 or any provision requiring the payment of tax). This waiver authority may be exercised with respect to alcohol fuel plants as necessary to carry out the provisions of Section 5181 .

Plants which are established for the production of alcohol for purposes other than fuel, such as beverage or other industrial use, must qualify to operate under previously existing provisions of the law. You may wish to contact BATF for further details (see Appendix E).

The law exempts alcohol fuel plants which produce less than 10,000 proof gallons of distilled spirits annually from furnishing a bond to cover the tax liability on the spirits. Also, persons wishing to establish such plants are assured by law that their applications for permits to operate will be acted upon within 60 days after receipt of a completed application. If this limit is exceeded, the application is automatically approved.

Distilled spirits may be withdrawn from alcohol fuel plants free of tax after having been rendered unfit for beverage use. The term "rendered unfit for beverage use" is used to clearly distinguish this requirement for fuel spirits from "denaturation", which is required for spirits withdrawn from other distilled spirits plants.

A principal reason for encouraging production of distilled spirits for fuel use is that these spirits are substituted for scarce fossil fuels. Therefore, in defining distilled spirits for purposes of the alcohol fuel provisions, the law excludes distilled spirits produced from petroleum, natural gas, or coal.

Finally, Public Law 96-223 amended Section 5601 to impose criminal penalties on any person who withdraws, uses, sells, or otherwise disposes of distilled spirits produced under Section 5181 for other than fuel use.

This section addresses those portions of regulations dealing with large alcohol fuel plants (defined by BATF as more than 500,000 proof gallons of spirits per calendar year). We will cover the following permits; bonds; construction, equipment, and security; supervision; accounting for spirits; transfers and withdrawals; and transfers between plants. Our intent is to be informative, but we suggest that the Bureau be contacted for more specific interpretation and guidance where needed.

\section{The following is a brief summary of the regulations now in force:}

\section{DEPARTMENT OF THE TREASURY}

\author{
Bureau of Alcohol, Tobacco, and Firearms \\ (27 CFR Part 19) \\ T.D. ATF-71
}

FUEL USE OF DISTILLED SPIRITS IMPLEMENTING A PORTION OF THE CRUDE. OIL

\section{WINDFALL PROFITS TAX ACT OF 1980 (PUBLIC LAW 96-223)}

AGENCY: Bureau of Alcohol, Tobacco, and Firearms, Department of the Treasury.

ACTION: Temporary rule (Treasury decision).

SUMMARY: This temporary rule implements Section 232, Alcohol Fuels, in Part III of Title II of the Crude Oil Windfall Profits Tax Act of 1980 (Public Law 96-223). The temporary rule provides for the establishment and operation of distilled spirits plants solely for producing, processing and storing, and using or distributing distilled spirits (ethyl alcohol) exclusively for fuel use. Public Law 96-223 vests the Secretary of the Treasury with authority to simplify and liberalize statutory requirements for such alcohol fuel plants. The BATF will issue final regulations only after careful consideration of the comments received on these temporary regulations. 
EFFECTIVE DATE OF TEMPORARY REGULATIONS: July 1, 1980.

\section{FOR FURTHER INFORMATION CONTACT:}

\author{
John V. Jarowski, Alcohol Fuels Coordinator \\ Bureau of Alcohol, Tobacco, and Firearms \\ Washington, DC 20226 \\ Telephone 202-566-7591
}

(Persons interested in applying for a permit should contact their BATF regional office. A list of addresses and toll-free telephone numbers is provided in Appendix E.)

SUPPLEMENTARY INFORMATION: This document contains temporary regulations implementing a portion of the Crude Oil Windfall Profits Tax Act of 1980 (Public Law 96-223). The temporary regulations provided by this document will remain in effect until superseded by final regulations on this subject.

\section{REGULATIONS}

\section{New Subpart Y of 27 CFR Part 19.}

Regulations applicable to alcohol fuel plants have been included in a new subpart, Subpart Y, of Part 19, Distilled Spirits Plants. Except for those portions of Subparts A through X of Part 19 which have been incorporated in the new subpart by reference, alcohol fuel plants are not subject to the provisions applicable to other distilled spirits plants. While this document provides simplified BATF regulations for alcohol fuel plants, persons wishing to establish a plant should check with other Federal (EPA), state, and local authorities as to their specific requirements.

\section{Definitions.}

Where necessary, terms have been defined as used in the new subpart. In some instances, BATF needed to redefine a term used elsewhere in Part 19. For instance, the term "distilled spirits", as used in Subpart $Y$, does not include distilled spirits produced from petroleum, natural gas, or coal. In addition, BATF introduces some new terms. For example, the term "alcohol fuel plant" means a distilled spirits plant established under Subpart $Y$ solely for producing, processing and storing, and using or distributing distilled spirits to be used exclusively for fuel use. The term "fuel alcohol" means spirits which have been rendered unfit for beverage use as provided in Subpart $Y$ and are eligible to be withdrawn free of tax exclusively for fuel use.

\section{Permits.}

Any person wishing to establish an alcohol fuel plant must first make application for and obtain an Alcohol
Fuel Producer's Permit. For purposes of the type of application required (as well as for bonding and other requirements), BATF classifies alcohol fuel plants into three categories:

(a) Small plants - produce (including receipts of) not more than 10,000 proof gallons per calendar year;

(b) Medium plants - produce (including receipts of) more than 10,000 but not more than 500,000 proof gallons per calendar year; and,

(c) Large plants - produce (including receipts of) more than 500,000 proof gallons per calendar year.

These classes are based on the tax liabilities incident to the various levels of activity, as well as differences in capital expenditures and attendant technical sophistication required to set up plants of different sizes. By law, small plants are exempt from bonding and special rules apply to their applications.

In determining the level of activity at a plant for purposes of bonding and qualification, BATF considers spirits received from another plant as additional production. With respect to small plants, this approach has no effect on a proprietor who will receive no spirits from other plants. Proprietors of other small plants, however, may wish to distill less than 10,000 proof gallons of spirits per year and receive additional spirits from other plants. Those proprietors may produce and receive up to a total of 10,000 proof gallons per year and still be exempt from bonding. Counting receipts as additional production simplifies the regulations for bonds and qualification of plants.

\section{Application Requirements.}

Applications are filed on BATF Form 5110.74 furnished by the Bureau (See Figure B-1). For small plants, only the form needs to be filed. For medium and large plants, a bond must be placed and some additional information (to be identified in Section 6) must be provided. Also, the law requires bonds for the medium and large plants. Applications are to be submitted to the regional regulatory administrator of the BATF region in which the plant is located.

Having an application form should avoid confusion as to the information required to be submitted and serve to expedite processing of applications.

Although BATF expects numerous applications to be filed in response to the temporary regulations, BATF anticipates that permits will be issued expeditiously. With respect to the small plants in particular, action well within the 60-day statutory limitation should be possible. 
In general, a permit will be issued to any person who files a completed application (together with a bond for medium and large plants). Criteria for denial of applications, and for subsequent suspension or revocation of permits in the case of false or incomplete applications, are set forth in Sections 19.936 and 19.953 of the regulations. Time permitting, BATF may conduct an investigation and on-site inspection prior to issuance of the permit.

\section{Changes Affecting Permits.}

Permits may not be sold or transferred. If a different person purchases or acquires control of the plant, that person must file a new application. Also, BATF issues permits to cover specified plant premises. Any change in the location or extent of plant premises requires submission of an application to the regional regulatory administrator to amend the permit. Sections 19.945 through 19.953 provide more details on changes affecting permits and administrative and procedural matters relative to permits.

\section{Bonds.}

Bonds give the government security against possible loss of distilled spirits tax revenue. While tax is not collected on distilled spirits for fuel use lawfully produced and used as fuel, liability for tax, by law, attaches to the spirits on creation. The proprietor generally obtains a bond from a surety or insurance company, by paying a premium based on the penal sum required for the bond.

The law exempts small plants producing (including receipts of) not more than 10,000 proof gallons per year from furnishing bonds. For medium and large plants which are required to file bonds, the penal sum required is based on the tax liability to be covered. There are two sources of this tax liability:

(a) The tax on spirits that will be produced (including spirits rendered unfit for beverage use in the process of production, as provided in Section 19.983); and,

(b) The tax on spirits that will be received by transfer in bond (see Sections 19.996 through 19.999).

In the temporary regulations, the penal sum of the bond is based on the quantity in proof gallons of spirits that will be produced (including receipts) in a calendar year.

The bond for a medium plant producing (including receipts of) between 10,000 and 20,000 proof gallons per year is $\$ 2,000$. For each increase of 10,000 proof gallons (or fraction thereof) in total annual production (including receipts), the bond penal sum is increased $\$ 1,000$. The maximum bond for a medium plant is
$\$ 50,000$ (applicable to plants producing (including receipts) between 490,000 and 500,000 proof gallons per year).

For large plants, the amount of the bond is $\$ 50,000$ plus an additional $\$ 2,000$ for each 10,000 proof gallons (or fraction) produced and received in excess of 500,000. The maximum bond for a large plant is $\$ 200,000$. Any plant producing (including receipts) in excess of $1,240,000$ proof gallons of spirits in a calendar year must furnish a bond in the amount of $\$ 200,000$.

Documentation required is BATF Form 5110.56, as shown in Figure B-2.

\section{Premises, Equipment, and Security.}

The premises of an alcohol fuel plant include all areas where distilled spirits are produced, processed, stored, used, or held for distribution. BATF requires buildings and equipment used in alcohol fuel plant operations to be constructed and arranged to enable the proprietor to maintain security adequate to deter diversion of the spirits. Regional regulatory administrators can require additional measures if security at a plant is found to be inadequate.

\section{Supervision of Operations.}

Regional regulatory administrators may assign BATF officers to alcohol fuel plants to supervise operations or to conduct inspections and audits. Authorities of BATF officers to carry out their duties have been incorporated by reference in the temporary regulations. BATF officers have a right of access to plant premises at all times to perform their official duties. The regulatic " $s$ require proprietors to render assistance to BATF officers in performing gauges and examining equipment and containers, as necessary, to determine that all spirits are lawfully accounted for.

\section{Accounting for Spirits.}

The regulations require proprietors to determine and record the quantities of spirits produced, received, rendered unfit for beverage use, and used or removed from the premises. The records must be adequate to allow BATF officers to verify that the proprietor has lawfully disposed of all spirits. BATF requires no government forms or specific formats for these records. Commercial invoices, books of account, and other proprietary records are sufficient, so long as they show the information required by the regulations.

The regulations also require proprietors to file periodic reports of their operations. Frequency of reporting varies with the size of the plant: annually for small plants, semiannually for medium plants, and quarterly for large 
plants. The required form is BATF Form 5110.75, as shown in Figure B-3.

\section{Withdrawal of Spirits.}

Distilled spirits withdrawn from alcohol fuel plants may be used only for fuel purposes. Before withdrawing spirits from plant premises, the proprietor must render the spirits unfit for beverage use. The only exception to this requirement is for spirits transferred to other plants.

The regulations in Section 19.992 provide that fuel alcohol is considered unfit for beverage use when, for each 100 gallons of spirits, the proprietor has added to the spirits five gallons or more of gasoline, automotive gasoline, kerosene, deodorized kerosene, rubber hydrocarbon solvent, methyl isobutyl ketone, mixed isomers of nitropropane, any combination of the foregoing, or 5 gallons of isopropyl alcohol and 1/8-ounce of denatonium benzoate N.F. (Bitrex). BATF selected these substances based on denatured alcohol and solvent formulations currently provided by regulation or ruling, and on requests and inquiries from persons currently involved in producing alcohol fuels. Proprietors may request authorization to use substitute materials under Section 19.993 of the regulations.

Once rendered unfit for beverage use, fuel alcohol is eligible to be withdrawn free of tax. However, BATF does require proprietors to account for fuel alcohol remaining on plant premises and keep records of all sales and other dispositions of fuel alcohol.

\section{Use on Premises.}

Proprietors may use spirits for fuel on the premises of an alcohol fuel plant without rendering the spirits unfit for beverage use. The proprietor must record the quantities of spirits so used.

\section{Transfers in Bond.}

Proprietors may transfer spirits to another alcohol fuel plant. The proprietor need not render the spirits unfit for beverage use prior to transfer. Generally, liability for the tax on the spirits while in transit is the responsibility of the receiving proprietor.

The temporary regulations prescribe procedures to be followed when transferring spirits between alcohol fuel plants. A commercial invoice or shipping document is required to cover each shipment of spirits. These procedures are necessary to guard against diversion of spirits to beverage use.

Spirits also may be transferred between other distilled spirits plants and alcohol fuel plants. For such transfers, procedures and forms are prescribed in Sections 19.506 through 19.510 of the regulations.
The following are the Bureau of Alcohol, Tobacco, and Firearms regulations now in force, effective date of temporary regulations is July 1, 1980.

\section{DEPARTMENT OF THE TREASURY}

\author{
Bureau of Alcohol, Tobacco and Firearms
}

\section{FUEL USE OF DISTILLED SPIRITS- IMPLEMENTING A PORTION OF THE CRUDE OIL \\ WINDFALL PROFIT TAX ACT OF 1980 \\ (Public Law 96-223)}

AGENCY: Bureau of Alcohol, Tobacco and Firearms, Department of the Treasury

ACTION: Temporary rule (Treasury decision)

SUMMARY: This temporary rule implements Section 232, Alcohol Fuels, in Part III of Title II of the crude Oil Windfall Profit Tax Act of 1980 (P.L. 96-223). The temporary rule provides for the establishment and operation of distilled spirits plants solely for producing, processing and storing, and using or distributing distilled spirits (ethyl alcoho1) exclusively for fuel use. P.L. 96-223 vests the Secretary of the Treasury with authority to simplify and liberalize statutory requirements for such alcohol fuel plants. The Bureau of Alcohol, Tobacco and Firearms (ATF) will issue final regulations only after careful consideration of the comments received on these temporary regulations.

\section{FOR FURTHER INFORMATION CONTACT:}

John V. Jarowski, Research and Regulations Branch, Bureau of Alcohol, Tobacco and Firearms, Washington, DC 20226, Telephone 202-566-7626.

(Persons interested in applying for a permit should contact their ATF regional of fice. A list of addresses and toll free telephone numbers is provided in Appendix E.)

SUPPLEMENTARY INFORMATION: This document contains temporary regulations implementing a portion of the Crude Oil Windfall Profit Tax Act of 1980 (Public Law 96-223). The temporary regulations provided by this document will remain in effect until superseded by final regulations on this subject. A notice of proposed rulemaking with respect to final regulations appears elsewhere in this issue of the Federal Register.

\section{Legislative Background}

In the Energy Tax Act of 1978 (P.L. 95-618) Congress required the Secretary of the Treasury to propose legislative recommendations to facilitate fuel use of distilled spirits. In compliance with this mandate, the 
Bureau submitted a proposal in 1979. Congress incorporated the proposed legislation, with modifications, in P.L. 96-223.

Public Law 96-223 added a new section to Subchapter B of Chapter 51 of the Internal Revenue Code of 1954. New Section 5181, Distilled Spirits for Fuel Use, provides for the establishment of distilled spirits plants solely for the purpose of producing, processing and storing, and using or distributing distilled spirits to be used exclusively for fuel use. The Secretary of the Treasury is directed to expedite all applications, to establish a minimum bond, and to generally encourage and promote (through regulation or otherwise) the production of alcohol for fuel purposes. The law gives the Secretary authority to provide by regulation for the waiver of any provision of Chapter 51 (except section 5181 or any provision requiring the payment of tax). This waiver authority may be exercised with respect to alcohol fuel plants as necessary to carry out the provisions of Section 5181 .

The law exempts alcohol fuel plants which produce not more than 10,000 proof gallons of distilled spirits annually from furnishing a bond to cover the tax liability on the spirits. Also, persons wishing to establish such plants are assured by law that their applications for permits to operate will be acted upon within 60 days or less after receipt of a completed application. If this limit is exceeded, the application is automatically approved.

Distilled spirits may be withdrawn from alcohol fuel plants free of tax after having been rendered unfit for beverage use. The term "rendered unfit for beverage use" is used to clearly distinguish this requirement for fuel spirits from "denaturation," which is required for spirits withdrawn from other distilled spirits plants.

A principal reason for encouraging production of distilled spirits for fuel use is that these spirits are substituted for scarce fossil fuels. Therefore, in defining distilled spirits for purposes of the alcohol fuel provisions, the law excludes distilled spirits produced from petroleum, natural gas, or coal.

Finally, P.L. 96-223 amended Section 5601 to impose criminal penalties on any person who withdraws, uses, sells, or otherwise disposes of distilled spirits produced under Section 5181 for other than fuel use.

\section{Regulations}

1. New Subpart Y of 27 CFR Part 19. Regulations applicable to alcohol fuel plants have been included in a new subpart, Subpart Y, of Part 19, Distilled Spirits Plants. Except for those portions of Subparts A through X of Part 19 which have been incorporated in the new subpart by reference, alcohol fuel plants are not subject to the provisions applicable to other distilled spirits plants. While this document provides simplified ATF regulations for alcohol fuel plants, persons wishing to establish a plant should check with other Federal (EPA), State and local authorities as to their specific requirements.

2. Definitions. Where necessary, terms have been defined as used in the new subpart. In some instances, ATF needed to redefine a term used elsewhere in Part 19. For instance, the term "distilled spirits" as used in Subpart Y does not include distilled spirits produced from petroleum, natural gas, or coal. In addition, ATF introduces some new terms. For example, the term "alcohol fuel plant" means a distilled spirits plant established under Subpart $Y$ solely for producing, processing and storing, and using or distributing distilled spirits to be used exclusively for fuel use. The term "fuel alcohol" means spirits which have been rendered unfit for beverage use as provided in Subpart $\mathrm{Y}$ and are eligible to be withdrawn free of tax exclusively for fuel use.

3. Permits. Any person wishing to establish an alcohol fuel plant must first make application for and obtain an Alcohol Fuel Producer's Permit. For purposes of the type of application required (as well as for bonding and other requirements), ATF classifies alcohol fuel plants into three categories:

(a) Small plants--producing (including receipts of) not more than 10,000 proof gallons per calendar year;

(b) Medium plants-produce (including receipts of) more than 10,000 but not more than 500,000 proof gallons percalendar year; and

(c) Large plants-produce (including receipts of) more than 500,000 proof gallons per calendar year.

These classes are based on the tax liabilities incident to the various levels of activity, as well as differences in capital expenditures and attendant technical sophistication required to set up plants of different sizes. By law, small plants are exempt from bonding and special rules apply to their applications.

In determining the level of activity at a plant for purposes of bonding and qualification, ATF considers spirits received from another plant as additional production. With respect to small plants, this approach has no effect on a proprietor who will receive no spirits from other plants. Proprietors of other small plants, however, may wish to distill less than 10,000 proof gallons of spirits per year and receive additional spirits from other plants. Those proprietors may produce and receive up to a total of 10,000 proof gallons per year and still be exempt from 
bonding. Counting receipts as additional production simplifies the regulations for bonds and qualification of plants.

4. Application Requirements. Applications are filed on a form (ATF Form 5110.74) furnished by the Bureau. For small plants, only the form needs to be filed. For medium and large plants, some additional information must be provided. Also, the law requires bonds for the medium and large plants. Applications are to be submitted to the regional regulatory administrator of the ATF region in which the plant is located.

Having an application form should avoid confusion as to the information required to be submitted and serve to expedite processing of applications. Comments as to the design of the form, the information required, and as to whether the use of form is desirable, are specifically requested. Although ATF expects numerous applications to be filed in response to the temporary regulations, ATF anticipates that permits will be issued expeditiously. With respect to the small plants in particular, action well within the 60 day statutory limitation should be possible.

In general, a permit will be issued to any person who files a completed application (together with a bond for medium and large plants). Criteria for denial of applications, and for subsequent suspension or revocation of permits in the case of false or incomplete applications, are set forth in Sections 19.936 and 19.953 of the regulations. Time permitting, ATF may conduct an investigation and on-site inspection prior to issuance of the permit.

5. Changes Affecting Permits. Permits may not be sold or transferred. If a different person purchases or acquires control of the plant, that person must file a new application. Also, ATF issues permits to cover specified plant premises. Any change in the location or extent of plant premises requires submission of an application to the regional regulatory administrator to amend the permit. Sections 19.945 through 19.953 provide more details on changes affecting permits and administrative and procedural matters relative to permits.

6. Bonds. Bonds give the Government security against possible loss of distilled spirits tax revenue. While tax is not collected on distilled spirits for fuel use lawfully produced and used as fuel, liability for tax, by law, attaches to the spirits on creation. The proprietor generally obtains a bond from a surety or insurance company, by paying a premium based on the penal sum required for the bond.

The law exempts small plants producing (including receipts of) not more than 10,000 proof gallons per year from furnishing bonds. For medium and large plants which are required to file bonds, the penal sum required is based on the tax liability to be covered. There are two sources of this tax liability:

(a) The tax on spirits that will be produced (including spirits rendered unfit for beverage use in the process of production, as provided in Sec. 19.983); and,

(b) The tax on spirits that will be received by transfer in bond (see Sections 19.996 through 19.999).

In the temporary regulations, the penal sum of the bond is based on the quantity in proof gallons of spirits that will be produced (including receipts) in a calendar year.

The bond for a medium plant producing (including receipts of) between 10,000 and 20,000 proof gallons per year is $\$ 2,000$. For each increase of 10,000 proof gallons (or fraction thereof) in total annual production (including receipts), the bond penal sum is increased $\$ 1,000$. The maximum bond for a medium plant is $\$ 50,000$ (applicable to plants producing (including receipts) between 490,000 and 500,000 proof gallons per year).

For large plants, the amount of the bond is $\$ 50,000$ plus an additional $\$ 2,000$ for each 10,000 proof gallons (or fraction) produced and received in excess of 500,000 . The maximum bond for a large plant is $\$ 200,000$. Any plant producing (including receipts) in excess of $1,240,000$ proof gallons of spirits in a calendar year must furnish a bond in the amount of $\$ 200,000$.

7. Premises, Equipment and Security. The premises of an alcohol fuel plant includes all areas where distilled spirits are produced, processed, stored, used or held for distribution. ATF requires buildings and equipment used in alcohol fuel plant operations to be constructed and arranged to enable the proprietor to maintain security adequate to deter diversion of the spirits. Regional regulatory administrators can require additional measures if security at a plant is found to be inadequate.

8. Supervision of Operations. Regional regulatory administrators may assign ATF officers to alcohol fuel plants to supervise operations or to conduct inspections and audits. Authorities of ATF officers to carry out their duties have been incorporated by reference in the temporary regulations. ATF officers have a right of access to plant premises at all times to perform their official duties. The regulations require proprietors to render assistance to ATF officers in performing gauges and examining equipment and containers, as necessary to determine that all spirits are lawfully accounted for. 
9. Accounting for Spirits. The regulations require proprietors to determine and record the quantities of spirits produced, received, and rendered unfit for beverage use, and used or removed from the premises. The records must be adequate to allow ATF officers to verify that the proprietor has disposed of all spirits lawfully. ATF requires no Government forms or specific formats for these records. Commercial invoices, books of account, and other proprietary records are sufficient, so long as they show the information required by the regulations.

The regulations also require proprietors to file periodic reports of their operations. Frequency of reporting varies with the size of the plant: annually for small plants, semiannually for medium plants, and quarterly for large plants.

10. Withdrawal of Spirits. Distilled spirits withdrawn from alcohol fuel plants may be used only for fuel purposes. Before withdrawing spirits from plant premises, the proprietor must render the spirits unfit for beverage use. The only exception to this requirement is for spirits transferred to other plants.

The regulations in Sec. 19.992 provide that fuel alcohol is considered unfit for beverage use when for each 100 gallons of spirits, the proprietor has added to the spirits five gallons or more of gasoline, automotive gasoline, kerosene, deodorized kerosene, rubber hydrocarbon solvent, methyl isobutyl ketone, mixed isomers of nitropropane, any combination of the foregoing, or 5 gallons of isopropyl alcohol and $1 / 8$ ounce of denatonium benzoate N.F. (Bitrex). ATF selected these substances based on denatured alcohol and solvent formulations currently provided by regulation or ruling, and on requests and inquirites from persons currently involved in producing alcohol fuels. Proprietors may request authorization to use substitute materials under Sec. 19.993 of the regulations.

Once rendered unfit for beverage use, fuel alcohol is eligible to be withdrawn free of tax. However, ATF does require proprietors to account for fuel alcohol remaining on plant premises and to keep records of all sales and other dispositions of fuel alcohol.

11. Use on Premises. Proprietors may use spirits for fuel on the premises of an alcohol fuel plant without rendering the spirits unfit for beverage use. The proprietor must record the quantities of spirits so used.

12. Transfers in Bond. Proprietors may transfer spirits to another alcohol fuel plant. The proprietor need not render the spirits unfit for beverage use prior to transfer. Generally, liability for the tax on the spirits while in transit is the responsibility of the receiving proprietor.
The temporary regulations prescribe procedures to be followed when transferring spirits between alcohol fuel plants. A commercial invoice or shipping document is required to cover each shipment of spirits. These procedures are necessary to guard against diversion of spirits to beverage use.

Spirits also may be transferred between other distilled spirits plants and alcohol fuel plants. For such transfers, procedures and forms are prescribed inSections 19.506 through 19.510 of the regulations.

\section{Issues for Comment}

While all comments on these regulations are welcome and will receive careful consideration before final regulations are issued, ATF specifically requests comments on the following two issues.

1. Location of Plants in dwellings. Under existing regulations in 27 CFR Part 19, plants may not be located in any dwelling house, in any yard, shed, or enclosure connected with a dwelling house, or in certain other areas. Since ATF has not incorporated these restrictions in the temporary regulations, they do not apply to alcohol fuel plants.

As to yards, sheds, or enclosures, ATF feels the existing restrictions would place undue constraints on farm production of alcohol fuel. For urban and suburban areas, ATF feels that local zoning ordinances, fire codes, and similar provisions will preclude establishment of plants at inappropriate locations. The alcohol fuel producer's permit does not relieve the proprietor of the obligations imposed by State or local law.

However, ATF will consider prohibiting the establishment of plants in residential dwelling units. Accordingly, comments are requested as to whether such a prohibition is necessary or desirable.

2. Specifications for fuel alcohol and materials authorized for use in rendering spirits unfit for beverage use. In contrast to existing denatured alcohol regulations in 27 CFR Parts 211 and 212, the temperary regulations do not require fuel alcohol to be of any particular proof. In addition, proprietors have the option to choose among a number of materials or combinations thereof to use in rendering spirits unfit. Proprietors will decide both on the proof of the spirits and on what materials to use to render the spirits unfit, based on cost factors and on what works effectively for the particular fuel uses selected by themselves or their customers. The regulations do point out, however, that if gasoline is to be added to the spirits, unleaded gasoline may be required if the fuel alcohol will be used in certain engines. 
For some uses higher proof spirits (anhydrous or nearly so) are necessary. For other uses, lower proof spirits may be adequate.

ATF gives the proprietor options in this area because, beyond the blended motor fuels (e.g., gasohol) which are coming into widespread use, there is interest in using alcohol (once rendered unfit) for fuel purposes without blending with other fuels. ATF recognizes, however, that there may be a demand for tighter controls. For this reason, ATF will consider modifying the requirements for spirits rendered unfit, including specifying minimum proof levels for fuel alcohol. Accordingly, ATF specifically requests comments on the following questions:

(a) Are minimum proof standards necessary or desirable for fuel alcohol?

(b) Should the list of materials authorized for rendering spirits unfit for beverage use be broadened to include other substances, or sould some materials or options permitted under the temporary regulations be deleted?

(c) Are more detailed specifications for rendering spirits unfit necessary? If adopted, should these specifications be geared to the end use of the fuel alcohol?

\section{Experimental Plants}

1. General.Many persons have obtained permits to operate experimental distilled spirits plants (Section 5312) to produce distilled spirits for fuel purposes. The majority of these operations would qualify as small alcohol fuel plants under the temporary regulations. The authorized operations for experimental plants are generally more limited than under these temporary regulations, particularly as to removal or distribution of any spirits produced. The proprietor must furnish a bond. Also, experimental distilled spirits plant permits are issued for a limited time, usually two years. In contrast to experimental distilled spirits plants, alcohol fuel plants:

(a) Hold a permit which generally continues in effect indefinitely with no renewal required:

(b) Are authorized to sell or distribute the fuel alcohol they produce;

(c) Are exempt from bonding of annual production (including receipts) totals not more than 10,000 proof gallons; and,

(d) May transfer spirits between plants. Given the advantages of operating as an alcohol fuel plant, ATF has developed a simplified procedure to convert outstanding experimental distilled spirits plant permits to alcohol fuel producer's permits, on the assumption that most proprietors will elect conversion. The proprietor of an experimental plant does not have to file an application to have the permit converted. With respect to any bond that was furnished, ATF regional offices will advise proprietors how to cancel surety bonds or secure refunds of cash or securities deposited in lieu of obtaining a surety bond.

2. Status of Existing Experimental Plants. Effective July 1, 1980, any person holding a permit to operate an experimental distilled spirits plant for fuel purposes will be considered as authorized to operate under these regulations. ATF regional offices are notifying all affected proprietors. Before expiration of the outstanding permit, a new alcohol fuel producer's permit will be issued to each such proprietor. Applications which are currently pending to establish experimental distilled spirits plants for fuel purposes will be treated as applications for alcohol fuel producer's permits. Proprietors who do not wish to be converted to alcohol fuel plant status should file a written request with the regional regulatory administrator.

\section{Addresses of Regional Regulatory Administrators}

Any person who wishes to apply for a permit under the regulations in this document may obtain the required forms and further information from the regional regulatory administrator of the region in which the plant will be located. A list of addresses and toll-free telephone numbers is provided in Appendix E.

\section{Effective Date}

The Energy Tax Act of 1978 (Pub. L. 95-618, 92 Stat. 3174) directed the Secretary to expedite, to the maximum extent possible, the applications of persons desiring to produce distilled sirits for fuel use, and to suggest legislative amendments which could reduce the amount of regulation to which such fuel producers would be subject. In furtherance of the first mandate, existing waiver authority under 26 U.S.C. 5312 was used to facilitate establishment of alcohol fuel plants on an experimental basis. The proposed legislative amendments have not been enacted as part of Pub. L. 96-223.

Pub. L. 96-223 gives the Secretary broad authority to waive or reduce existing regulatory requirements for plants which will produce distilled spirits exclusively for fuel use, such as, by allowing simplified application and recordkeeping procedures, and by providing reduced control and bonding requirements. In addition, an expedited application procedure (with no bond) is provided for small producers. For such producers, the law 
requires action on the issuance of a permit within sixty days of submission of a completed application. Pub. L. 96-223 is effective July $1,1980$.

Immediate guidance is necessary for the affected parties, both potential new applicants to produce distilled spirits for fuel purposes and persons currently operating as proprietors of experimental distilled spirits plants, to reap the benefits of the new law upon its becoming effective.

The issuance of this Treasury decision with notice and public procedure under 5 U.S.C. 553(d) is impracticable and not in the public interest, because absence of these regulations would create a serious delay in the production of alcohol fuel, inconsistent with the intent of the Energy Tax Act of 1978 (Pub. L. 95-618, 92 Stat. 3174) and the Crude Oil Windfall Profit Tax Act of 1980 (Pub. L. 96-223, 94 Stat. 229) to encourage the expeditious production of alcohol fuels. Immediate action is necessary to avoid delay and facilitate production of alcohol fuel, in implementing the Crude Oil Windfall Profit Tax Act of 1980, which is effective July 1, 1980. Accordingly, this Treasury decision becomes effective on July 1, 1980.

\section{Authority and Issuance}

These regulations are issued under the authority contained in 26 U.S.C. 5181 (94 Stat. 278) and 26 U.S.C. 7805 (68A Stat. 917, as amended).

Accordingly, Title 27 Code of Federal Regulations is amended as follows:

\section{PART 19-DISTILLED SPIRITS PLANTS}

Paragraph 1. The table of sections is amended to reflect the addition of $\$ 19.63 \mathrm{a}$ immediately following $\$ 19.63$ and the addition of Subpart Y-Distilled Spirits for Fuel Use. As amended, the table of sections reads as follows:

Subpart D-Administrative and Miscellaneous Provisions

\$19.63a Alcohol fuel plants.

Subpart Y-Distilled Spirits for Fuel Use

$\$ 19.931$ Scope of subpart

$\$ 19.932$ Taxes

$\$ 19.933$ Status of existing experimental distilled spirits plants

$\$ 19.934$ Meaning of terms
Permits

\$19.935 Application for permit required

$\$ 19.936$ Criteria for issuance of permit

$\$ 19.937$ Small plants

$\$ 19.938$ Waiver of bond requirement for small plants

$\$ 19.939$ Medium plants

$\$ 19.940$ Large plants

$\$ 19.942$ Information already on file and supplemental information

Changes Affecting Permits

$\$ 19.945$ Automatic termination of permits

$\$ 19.946$ Change in type of alcohol fuel plant

$\$ 19.947$ Change in name of proprietor

$\$ 19.948$ Changes in officers, directors, or principal persons

$\$ 19.949$ Change in proprietorship

$\$ 19.950$ Continuing partnerships

$\$ 19.951$ Change in location

\section{Permanent Discontinuance of Business}

$\$ 19.952$ Notice of permanent discontinuance

Suspension or Revocation of Permits

$\$ 19.953$ Suspension or revocation

\section{Bonds}

$\$ 19.956$ Bonds

$\$ 19.957$ Amount of bond

$\$ 19.958$ Instructions to compute bond penal sum

$\$ 19.959$ Conditions of bond

$\$ 19.960$ Additional provisions with respect to bonds

Construction, Equipment and Security

$\$ 19.972$ Construction and equipment

$\$ 19.973$ Security

$\$ 19.974$ Additional security

\section{Supervision}

\section{$\$ 19.975$ Supervision of operations}

\section{Accounting for Spirits}

$\$ 19.980$ Gauging

$\$ 19.981$ Inventories

$\$ 19.982$ Records

$\$ 19.983$ Spirits rendered unfit in the production process

$\$ 19.984$ Record of spirits received

$\$ 19.985$ Record of spirits rendered unfit for beverage use 
$\$ 19.986$ Record of dispositions

$\$ 19.987$ Maintenance and retention of records

$\$ 19.988$ Reports

Transfers and Withdrawals

\begin{tabular}{|ll}
$\$ 19.989$ & Withdrawal free of tax \\
$\$ 19.990$ & Other uses prohibited \\
$\$ 19.991$ & Requirement for rendering spirits unfit for \\
& beverage use \\
$\$ 19.992$ & Authorized formulas for fuel alcohol \\
$\$ 19.993$ & Substitute materials \\
$\$ 19.994$ & Marks \\
$\$ 19.995$ & Container size
\end{tabular}

\section{Transfers Between Plants}

\section{$\$ 19.996$ Transfer in bond \\ $\$ 19.997$ Consignor premises \\ $\$ 19.998$ Reconsignment in transit \\ $\$ 19.999$ Consignee premises}

Paragraph 2. A new $\$ 19.63 \mathrm{a}$ is added immediately following $\$ 19.63$. The new section incorporates authority to waive provisions of law and regulations with respect to alcohol fuel plants under the authoritites of the Director in Part 19. As added, \$19.63a reads as follows:

\section{\$19.63a Alcohol fuel plants}

Under the provisions of Subpart $\mathrm{Y}$ of this part, distilled spirits plants may be established solely for producing, processing and storing, and using distributing distilled spirits to be used exclusively for fuel use. To the extent the Director finds it necessary to carry out the provisions of 26 U.S.C. 5181, the Director may waive any provision of 26 U.S.C. Chapter 51 or this part (other than 26 U.S.C. 5181 , this section, Subpart Y, or any provisions requiring the payment of tax).

(\$232, Pub. L. 96-223, 94 Stat. 278 (26 U.S.C. 5181))

Paragraph 3. $\$ 19.505$ is amended to provide for the transfer of spirits between plants qualified under 26 U.S.C. 5171 and alcohol fuellants. The statutes at large citation is also amended. As amended, $\$ 19.505$ reads as follows:

\section{$\$ 19.505$ Authorized transfers.}

(a) Spirits. Pursuant to approval of an application as provided for in $\$ 19.506$, bulk spirits (including denatured spirits) may be transferred in bond between bonded premises in bulk conveyances, or by pipeline, or in bulk containers into which spirits may be filled on bonded premises. However, spirits (including denatured spirits) produced from petroleum, natural gas, or coal, may not be transferred to alcohol fuel plants. Spirits transferred in bond from alcohol fuel plants to plants qualified under 26 U.S.C. 5171 shall be accounted for separately by the consignee proprietor, and shall not subsequently be withdrawn, used, sold or otherwise disposed of for other than fuel use.

(b) $* * *$

(\$201, Pub. L. $85-859,72$ Stat. 1362, as amended, 1380, as amended (26 U.S.C. 5212, 5362); \$232, Pub. L. 96-223, 94 Stat. 278 (26 U.S.C. $5(81))$.

Paragraph 4. A new Subpart Y-Distilled Spirits for Fuel Use, is added to provide regulations for alcohol fuel plants. As added, Subpart $\mathrm{Y}$ reads as follows:

\section{Subpart Y-Distilled Spirits for Fuel Use}

\section{$\$ 19.931$ Scope of subpart.}

This subpart relates to the qualification and operation of distilled spirits plants established solely for producing, processing and storing, and using or distributing distilled spirits to be used exclusively for fuel use. Except where incorporated in this subpart by reference, the provisions of Subparts A through X of this part do not apply to alcohol fuel plants (see $\$ 19.63 a$ ).

(\$232, Pub. L. 96-223, 94 Stat. 278 (26 U.S.C. 5181))

\section{$\$ 19.932$ Taxes}

(a) Distilled spirits tax. Distilled spirits may be withdrawn free of tax from the premises of an alcohol fuel plant exclusively for fuel use in accordance with this subpart. Payment of tax will be required in the case of diversion of spirits to beverage use or other unauthorized dispositions. The provisions of Subpart $\mathrm{C}$ of this part are applicable to distilled spirits for fuel use as follows:

(1) Imposition of tax liability ( $\$ 19.21$ through 19.25 );

(2) Assessment of tax ( $\S \S 19.31$ and 19.32); and,

(3) Claims for tax ( $\$ 19.41$ and 19.44).

(b) Still tax. A commodity tax is imposed by 26 U.S.C. 5101 on the manufacturer for each still or condenser for distilling made by him. Manufacturers of stills are subject to a special occupational tax. However, a proprietor manufacturing stills or condensers exclusively for use in his plant or plants is exempt from these taxes. In addition, proprietors of alcohol fuel plants are exempt from the requirement of 26 U.S.C. 5105 to file an application and obtain a permit before setting up distilling apparatus. Provisions relating to stills are contained in 27 CFR Part 196.

(\$201, Pub. L. 85-859, 72 Stat. 1314, as amended, 1339 (26 U.S.C. 5001, 5101, 5103); \$232, Pub. L. 96-223, 94 Stat. 278 (26 U.S.C. $5(81))$ 


\section{$\$ 19.933$ Status of existing experimental distilled spirits plants}

Notwithstanding any other provisions of this subpart, effective July 1, 1980, the prior application and permit of existing experimental plants for alcohol fuel production under Section $\mathbf{5 3 1 2}$ will be considered as approved applications to operate under the provisions of 26 U.S.C. 5181 as alcohol fuel plants. Such existing plants may continue to operate and the operations shall be conducted pursuant to the provisions of this subpart. A new permanent permit as an alcohol fuel plant will be issued in lieu of, and prior to the expiration date of, the existing permit as an experimental plant. However, persons who wish to retain their permits under 26 U.S.C. 5312 as experimental distilled spirits plants, instead of converting to alcohol fuel plant status, may do so by filing a written request with the regional regulatory administrator.

\section{$\$ 19.934$ Meaning of terms}

When used in this subpart, and in forms prescribed under this subpart, terms shall have the meaning given in this section. Words in the plural form include the singular and vice versa, and words indicating the masculine gender include the feminine. The terms "includes" and "including" do not exclude things not enumerated which are in the same general class.

Alcohol fuel plant or plant. An establishment qualified under this subpart solely for producing, processing and storing, and using or distributing distilled spirits to be used exclusively for fuel use.

Alcohol fuel producer's permit. The document issued pursuant to 26 U.S C. 5181 authorizing the person named therein to engage in business as an alcohol fuel plant.

ATF officer. An officer or employee of the Bureau of Alcohol, Tobacco and Firearms (ATF) authorized to perform any function relating to the administration or enforcement of this subpart.

Bonded Premises. The premises of an alcohol fuel plant where distilled spirits are produced, processed and stored, and used or distributed. Premises of small alcohol fuel plants, which are exempt from bonding under $\$ 19.938$, shall be treated as bonded premises for purposes of this subpart.

CFR. The Code of Federal Regulations.

Director. The Director, Bureau of Alcohol, Tobacco and Firearms, the Department of the Treasury, Washington, D.C.
Fuel alcohol. Distilled spirits which have been rendered unfit for beverage use at an alcohol fuel plant as provided in this subpart.

Gallon or wine gallon. The liquid measure equivalent to the volume of 231 cubic inches.

Person. An individual, trust, estate, partnership, association, company or corporation.

Proof. The ethyl alcohol content of a liquid at 60 degrees Fahrenheit, stated as twice the percent of ethyl alcohol by volume.

Proof gallon. A gallon of liquid at 60 degrees Fahrenheit which contains 50 percent by volume of ethyl alcohol having a specific gravity of 0.7939 at 60 degrees Fahrenheit referred to water at 60 degrees Fahrenheit as unity, or the alcoholic equivalent thereof.

Proprietor. The person qualified under this subpart to operate the alcohol fuel plant.

Region. A Bureau of Alcohol, Tobacco and Firearms region.

Regional regulatory administrator. The principal regional official responsible for administering regulations in this subpart.

Secretary. The Secretary of the Treasury or his delegate.

Spirits or distilled spirits. That substance known as ethyl alcohol, ethanol, or spirits of wine in any form (including all dilutions and mixtures thereof by whatever process produced), but not fuel alcohol unless specifically stated. For purposes of this subpart, the term does not include spirits produced from petroleum, natural gas, or coal.

This chapter. Title 27, Code of Federal Regulations, Chapter I (27 CFR Chapter I).

Transfer on bond. The transfer of spirits between alcohol fuel plants or between a distilled spirits plant qualified under 26 U.S.C. 5171 and an alcohol fuel plant.

Type of plant. The following three types of alcohol fuel plants are recognized in this subpart:

(a) Small plant. An alcohol fuel plant which produces -including receipts) not more than 10,000 proof gallons of spirits per calendar year.

(b) Medium plant. An alcohol fuel plant which produces (including receipts) more than 10,000 and not more than 500,000 proof gallons of spirits per calendar year. 
(c) Large plant. An alcohol fuel plant which produces (including receipts) more than 500,000 proof gallons of spirits per calendar year.

\section{U.S.C. The United States Code}

\section{Permits}

\$19.935 Application for permit required.

Any person wishing to establish an alcohol fuel plant shall first make application for and obtain an alcohol fuel producer's permit. Alcohol fuel producers permits are continuing. The permit continues in effect unless automatically terminated under $\$ 19.945$, suspended or revoked as provided in $\$ 19.953$, or voluntarily surrendered.

(\$232, Pub. L. 96-223, 94 Stat. 278 (26 U.S.C. 5181))

\section{$\$ 19.936$ Criteria for issuance of permit.}

In general, an alcohol fuel producer's permit will be issued to any person who completes the required application for permit and who furnishes the required bond (if any). However, the regional regulatory administrator may institute proceedings for the denial of the application, if the regional regulatory administrator determines that:

Persons wishing to establish a small plant shall apply for a permit as provided in this section. Except as provided in paragraph (d) of this section, operations may not be commenced until the permit has been issued.

(a) The applicant (including, in the case of a corporation, any officer, director, or principal stockholder, and in the case of a partnership, a partner) is, by reason of business experience, financial standing, or trade connections, not likely to maintain operations in compliance with 26 U.S.C. Chapter 51, or regulations issued thereunder; or

(b) The applicant has failed to disclose any material information required, or has made any false statement, as to any material fact, in connection with the application; or

(c) The premises on which the applicant proposes to conduct the operations are not adequate to protect the revenue. The procedures applicable to denial of applications are set forth in 27 CFR Part 200.

(\$201, Pub. L. 85-859, 72 Stat. 1370, as amended (26 U.S.C. 5271); $\$ 232$, Pub. L. 96-223, 94 Stal. 278 (26 U.S.C. 5181))

\section{$\S 19.937$ Small plants.}

Persons wishing to establish a small plant shall apply for a permit as provided in this section. Except as provided in paragraph (d) of this section, operations may not be commenced until the permit has been issued. (a) Application for permit. The application (ATF Form 5110.74) shall be submitted to the regional regulatory administrator and shall set forth the following information:

(1) Name and mailing address of the applicant, and the location of the alcohol fuel plant if not apparent from the mailing address;

(2) A diagram of the plant premises and a statement as to the ownership of the premises (if the premises are not owned by the proprietor, the owner's consent to access by ATF officers must be furnished);

(3) A description of all stills and a statement of their maximum capacity;

(4) The materials from which spirits will be produced;

(5) A description of the security measures to be used to protect premises, buildings, and equipment where spirits are produced, processed, and stored; and,

(6) A statement as to the environmental impact of the proposed operation.

\section{(b) Receipt by the regional regulatory administrator}

(1) Notice of receipt-Within 15 days of receipt of the application, the regional regulatory administrator shall send a written notice of receipt to the applicant. The notice will include a statement as to whether the application meets the requirements of paragraph (a). If the application does not meet those requirements, the application will be returned and a new 15-day period will commence upon receipt by the regional regulatory administrator of the amended or corrected application.

(2) Failure to give notice-If the required notice of receipt is not sent, and the applicant has a receipt indicating that the regional regulatory administrator has received the application, the 45-day period provided for in paragraphs (c) and (d) will commence on the fifteenth day after the date the regional regulatory administrator received the application.

(3) Limitation-The provisions of subparagraphs (1) and (2) will apply only to the first application submitted with respect to any one small plant in any calendar quarter. However, an amended or corrected first application will not be treated as a separate application. 
(c) Determination by the regional regulatory administrator. Within 45 days from the date the regional regulatory administrator sent the applicant a notice of receipt of a completed application, the regional regulatory administrator shall either (1) issue the permit, or (2) give notice in writing to the applicant, stating in detail the reason that a permit will not be issued. Denial of an application will not prejudice any further application for a permit made by the same applicant.

(d) Presumption of approval. If, within 45 days from the date of the notice to the applicant of receipt of a completed application, the regional regulatory administrator has not notified the applicant of issuance of the permit or denial of the application, the application shall be deemed to have been approved and the applicant may proceed as if a permit had been issued.

(§232, Pub. L. 96-223, 94 Stat. 278 (26 U.S.C. 5181)

\section{$\$ 19.938$ Waiver of bond requirement for small plants.}

No bond is required for small plants.

(§232, Pub. L. 96-223, 94 Stat. 278 (26 U.S.C. 5181))

\section{$\$ 19.939$ Medium plants.}

Any person wishing to establish a medium plant shall make application for and obtain an alcohol fuel producer's permit and furnish a bond as provided in this section. Operations may not be commenced until the application has been approved and the permit issued.

(a) Application for permit. The application (ATF Form 5110.74) shall be submitted to the regional regulatory administrator and shall set forth the following information:

(1) The information required by $\$ 19.937(a)$;

(2) Statement of maximum total proof gallons of spirits that will be produced and received during a calendar year;

(3) Information identifying the principal persons involved in the business and a statement as to whether the applicant or any such person has ever been convicted of a felony or misdemeanor under Federal or State law; and,

(4) Statement of the amount of funds invested in the business and the source of those funds. (b) Bond required. A bond of sufficient penal sum, as prescribed in 19.958, must be submitted and approved before a permit may be issued.

(§232, Pub. L. 96-223, 94 Stat. 278 (26 U.S.C. 5181))

\section{$\$ 19.940$ Large Plants.}

Any person wishing to establish a large plant shall make application for and obtain an alcohol fuel producer's permit and furnish a bond as provided in this section. Operations may not be commenced until the application has been approved and the permit issued.

(a) Application for permit. The application (ATF Form 5110.74) shall be submitted to the regional regulatory administrator and shall set forth the following information:

(1) The information required by $\$ 19.937(a)$;

(2) Statement of the maximum proof gallons of spirits that will be produced and received during a calendar year (not required if the bond is in the maximum sum);

(3) Information identifying the principal persons involved in the business and a statement as to whether the applicant or any such person has ever been convicted of a felony or misdemeanor under Federal or State law;

(4) Statement of the amount of funds invested in the business and the source of those funds; and,

(5) Statement of the type of business organization and of the persons interested in the business, supported by the items of information listed in $\S 19.941$.

(b) Bond required. A bond of sufficient penal sum, as prescribed in $\$ 19.958$, must be submitted and approved before a permit may be issued.

(\$232, Pub. L. 96-223, 94 Stat. 278 (26 U.S.C. 5181))

\section{\$19.941 Organizational documents.}

The supporting information required by paragraph (a)(5) of $\$ 19.940$, includes, as applicable, copies of-

\section{(a) Corporate documents.}

(1) Corporate charter or certificate of corporate existence or incorporation.

(2) List of directors and officers, showing their names and addresses. However, do not list officers who have no responsibilities in connection with the operation of the alcohol fuel plant. 
(3) Certified extracts or digests of minutes of meetings of board of directors, authorizing certain individuals to sign for the corporation.

(4) Statement showing the number of shares of each class of stock or other evidence of ownership, authorized and outstanding, and the voting rights of the respective owners or holders.

\section{(b)Statement of interest.}

(1) Names and addresses of the 10 persons having the largest ownership or other interest in each of the classes of stock in the corporation, or other legal entity, and the nature and amount of the stockholding or other interest of each, whether the interest appears in the name of the interested party or in the name of another for him. If a corporation is wholly owned or controlled by another corporation, those persons of the parent corporation who meet the above standards are considered to be the persons interested in the business of the subsidiary, and the names thereof need be furnished only upon request of the regional regulatory administrator.

(2) In the case of an individual owner or partnership, the name and address of each person interested in the plant, whether the interest appears in the name of the interested party or in the name of another for that person.

(c) Availability of additional documents. The originals of documents required to be submitted under this section and additional items required under $\$ 19.942$ such as the articles of incorporation, bylaws, State certificate authorizing operations, or articles of partnership or association (in the case of a partnership where required by State law) shall be made available to any ATF officer upon request.

(\$201, Pub. L. 85-859, 72 Stat. 1349, as amended, 1370, as amended (26 U.S.C. 5172, 5271); §232, Pub. L. 96-223, 94 Stat. 278 (26 U.S.C. 5181))

\section{\$19.942 Information already on file and supplemental information}

If any of the information required by $\$ \S 19.937$ through 19.941 is on file with the regional regulatory administrator, that information, if accurate and complete, may be incorporated by reference and made a part of the application. When required by the regional regulatory administrator, the applicant shall furnish as a part of the application for permit, additional information as may be necessary to determine whether the application should be approved.

(\$232, Pub. L. 96-223, 94 Stat. 278, (26 U.S.C. 5181))

\section{Changes Affecting Permits}

\section{\$19.945 Automatic termination of permits.}

(a) Permits not transferable. Permits issues under this subpart shall not be transferred. In the event of the lease, sale, or other transfer of such a permit, or of the authorized operations, the permit automatically terminates.

(b) Corporations. In the case of a corporation holding a permit under this subpart, if actual or legal control of the permittee corporation changes, directly or indirectly, whether by reason of change in stock ownership or control (in the permittee corporation or in any other corporation), by operation of law, or in any other manner, the permittee shall, within 10 days of such change, give written notice, executed under the penalties of perjury, to the regional regulatory administrator; the permit may remain in effect until the expiration of 30 days after the change, whereupon the permit will automatically terminate. However, if operations are to be continued after the change in control, and an application for a new permit is filed within $\mathbf{3 0}$ days of the change, then the outstanding permit may remain in effect until final action is taken on the new application. When final action is taken on the application, the outstanding permit automatically terminates.

(\$201, Pub. L. 85-859, 72 Stat. 1370, as amended (26 U.S.C. 5271))

\section{$\$ 19.946$ Change in type of alcohol fuel plant.}

(a) Small plants. If the proprietor of a small plant wishes to increase production (including receipts) to a level in excess of 10,000 proof gallons of spirits per calendar year, the proprietor shall first furnish a bond and obtain an amended permit by filing application under $\S \S 19.939$ or 19.940 , as applicable. Information filed with the original application for permit need not be resubmitted, but may be incorporated by reference in the new application.

(b) Medium plants. Where the proprietor of a medium plant intends to increase production (including receipts) above 500,000 proof gallons of spirits per calendar year, the proprietor shall first obtain an amended permit by filing an application under $\$ 19.940$. A new or strengthening bond may be required (see $\$ 19.957(a)$ ). Information already on file may be incorporated by reference in the new application.

(c) Curtailment of activities. Proprietors of large or medium plants who have curtailed operations to a level where they are eligible to be requalified as medium or small plants may, on approval of a letter 
of application by the regional regulatory administrator, be relieved from the additional requirements incident to their original qualification. In the case of a change to small plant status, termination of the bond and relief of the surety from further liability shall be as provided in Subpart $\mathrm{H}$ of this part.

(\$201, Pub. L. 85-859, 72 Stat. 1370, as amended (26 U.S.C. 5271); $\$ 232$, Pub. L. 96-223, 94 Stat. 278 (26 U.S.C. 5181))

\section{$\$ 19.947$ Change in name of proprietor.}

Where there is to be a change in the individual, firm, or corporate name, the proprietor shall, within 30 days of the change, file an application to amend the permit; a new bond or consent of surety is not required.

(\$101, Pub. L. 85-859, Stat. 1349, as amended, 1370, as amended (26 U.S.C. 5172, 5271); \$232, Pub. L. 96-223, 94 Stat. 278 (26 U.S.C. 5181))

\section{$\$ 19.948$ Changes in officers, directors, or principal persons}

Where there is any change in the list of officers, directors, or principal persons, furnished under the provisions of $\$ \S 19.939,19.940$, or 19.941 , the proprietor shall submit, within 30 days of any such change, a notice in letter form including the new list of officers and a statement of the changes reflected in such list.

(\$232, Pub. L. 96-233, 94 Stat. 278 (26 U.S.C. 5181))

\section{\$19.949 Change in proprietorship.}

(a) General. If there is a change in the proprietorship of a plant qualified under this part, the outgoing proprietor shall comply with the requirements of $\$ 19.952$ and the successor shall, before commencing operations, apply for and obtain a permit and file the required bond (if any) in the same manner as a person qualifying as the proprietor of a new plant.

(b) Fiduciary. A successor to the proprietorship of a plant who is an administrator, executor, receiver, trustee, assignee or other fiduciary, shall comply with the applicable provisions of $\$ 19.186(\mathrm{~b})$.

(§201. Pub. L. 85-859, 72 Stat. 1349, as amended (26 U.S.C. 5172))

\section{$\$ 19.950$ Continuing partnerships.}

If under the laws of the particular State, the partnership is not terminated on death or insolvency of a partner, but continues until the winding up of the partnership affairs is completed, and the surviving partner has the exclusive right to the control and possession of the partnership assets for the purpose of liquidation and settlement, the surviving partner may continue to operate the plant under the prior qualification of the partnership. However, in the case of a large or medium plant, a consent of surety must be filed, wherein the surety and the surviving partner agree to remain liable on the bond. If the surviving partner acquires the business on completion of the settlement of the partnership, he shall qualify in his own name from the date of acquisition, as provided in $\$ 19.949$ (a). The rule set forth in this section shall also apply where there is more than one surviving partner.

(\$201, Pub. L. 85-859, 72 Stat. 1349, as amended (26 U.S.C. 5172); \$232, Pub. L. 96-223, 94 Stat. 278 (26 U.S.C. 5181))

\section{$\$ 19.951$ Change in location.}

Where there is a change in the location of the plant or of the area included within the plant premises, the proprietor shall file an application to amend the permit and, if a bond is required, either a new bond or a consent of surety on ATF Form 1533 (5000.18). Operation of the plant may not be commenced at the new location prior to issuance of the amended permit.

(\$201, Pub. L. $85-859,72$ Stat. 1349, as amended, 1370, as amended (26 U.S.C. 5172, 5271); \$805(c), Pub. L. 96-39, 93 Stat. 276 (26 U.S.C. 5173); \$232, Pub. L. 96-223, 94 Stat. 278 (26 U.S.C. 5181))

\section{Permanent Discontinuance of Business}

\section{$\$ 19.952$ Notice of permanent discontinuance.}

A proprietor who permanently discontinues operations as an alcohol fuel plant shall, after completion of the operations, file a letter head notice with the regional regulatory administrator. The notice shall be accompanied (a) by the alcohol fuel producer's permit, and by the proprietor's request that such permit be canceled; (b) by a written statement disclosing, as applicable, whether (1) all spirits (including fuel alcohol) have been lawfully disposed of, and (2) any spirits are in transit to the premises; and (c) by a report covering the discontinued operations (the report shall be marked "Final Report").

(\$201, Pub. L. 85-859, 72 Stat. 1349, as amended, 1370, as amended (26 U.S.C. 5172, 5271); \$232, Pub. L. 96-223, 94 Stat. 278 (26 U.S.C. 5181))

\section{Suspension or Revocation of Permits}

\section{$\$ 19.953$ Suspension or revocation}

Whenever the regional regulatory administrator has reason to believe that any person holding an alcohol fuel producer's permit-

(a) Has not in good faith complied with the applicable provisions of 26 U.S.C. Chapter 51, or regulations issued thereunder, or

(b) Has violated conditions of the permit; or

(c) Has made any false statement as to any material fact in the application therefore; or 
(d) Has failed to disclose any material information required to be furnished; or

(e) Has violated or conspired to violate any law of the United States relating to intoxicating liquor or has been convicted of any offense under Title 16, U.S.C. punishable as a felony or of any conspiracy to commit such offense: or

(f) Has not engaged in any of the operations authorized by the permit for a period of more than 2 years; the regional regulatory administrator may institute proceedings for the revocation or suspension of the permit in accordance with the procedures set forth in 27 CFR Part 200.

(\$201, Pub. L. 85-859, 72 Stat. 1370, as amended (26 U.S.C. 5271))

\section{Bonds}

\section{$\$ 19.956$ Bonds.}

An operations bond is required for medium and large plants. Surety bonds may be given only with corporate sureties holding certificates of authority from, and subject to the limitations prescribed by, the Secretary as set forth in the current revision of Treasury Department Circular 570. However, in lieu of corporate surety the proprietor may pledge and deposit as surety for his bond, securities which are transferable and are guaranteed as to both interest and principal by the United States, in accordance with the provisions of 31 CFR Part 225. The regional regulatory administrator will not release such securities until liability under the bond for which they were pledged has been terminated.

(\$805(c), Pub. L. 96-39,93 Stat. 276 (26 U.S.C. 5173); CH. 390, Pub. L. 80-280, 61 Stat. 648, 650 (6 U.S.C. 6, 7, 15); \$232, Pub. L. 96-223, 94 Stat. 278 (26 U.S.C. 5181 ))

\section{\$19.957 Amount of bond.}

The penal sum of the bond is based on the total quantity of distilled spirits to be produced (including receipts) during a calendar year. If the level of production and/or receipts at the plant is to be increased, and the bond shall be obtained.

(a) Medium plants. A medium plant which will produce (including receipts of) between 10,000 and 20,000 proof gallons of spirits per year requires a bond in the amount of $\$ 2,000$. For each additional 10,000 proof gallons (or fraction thereof), the bond amount is increased $\$ 1,000$. The maximum bond for a medium plant is $\$ 50,000$.

(b) Large plants. The minimum bond for a large plant is $\$ 52,000$ more than 500,000 , but not more than 510,000 proof gallons annual production (including receipts)). For each additional 10,000 (or fraction) proof gallons, the amount of the bond is increased
$\$ 2,000$. The maximum bond for a large plant is $\$ 200,000$ (more than $1,240,000$ proof gallons).

(§805(c, Pub. L. 96-39, 93 Stat. 276 (26 U.S.C. 5173); §232, Pub. L. 96-233, 94 Stat. 278 (26 U.S.C. 5181))

\section{$\$ 19.958$ Instructions to compute bond penal sum.}

(a) Medium plants. To find the required amount of your bond, estimate the total proof gallons of spirits to be produced and received in a calendar year. The amount of the bond is $\$ 1,000$ for each 10,000 proof gallons (or fraction), subject to a minimum of $\$ 2,000$ and a maximum of $\$ 50,000$. The following table provides some examples:

Annual production and receipts in proof gallons
More than but not over

$$
\begin{array}{r}
10,000 \text { to } 10,000 \\
20,000 \text { to } 30,000 \\
90,000 \text { to } 100,000 \\
190,000 \text { to } 200,000 \\
490,000 \text { to } 500,000
\end{array}
$$

Amount of bond

$$
\begin{array}{r}
\$ 2,000 \\
3,000 \\
10,000 \\
20,000 \\
50,000
\end{array}
$$

(b) Large plants. To find the required amount of your bond, estimate the total proof gallons of spirits to be produced and received in a calendar year. The amount of the bond is $\$ 50,000$ plus $\$ 2,000$ for each 10,000 proof gallons (or fraction) over 500,000 . The following table provides some examples:

Annual production and receipts in proof gallons

$\begin{array}{cc}\begin{array}{c}\text { More than but not } \\ \text { over }\end{array} & \text { Amount of bond } \\ 500,000 \text { to } 510,000 & \$ 52,000 \\ 510,000 \text { to } 520,000 & 54,000 \\ 740,000 \text { to } 750,000 & 100,000 \\ 990,000 \text { to } 1,000,000 & 150,000 \\ 1,240,000 & 200,000\end{array}$

(§805(c), Pub. L. 96-39, 93 Stat. 276 (26 U.S.C. 5173); \$232, Pub. L. 96-223, 94 Stat. 278 (26 U.S.C. 5181$)$ )

\section{\$19.959 Conditions of bond.}

The bond shall be conditioned on payment of all taxes (including any penalties and interest) imposed by 26 U.S.C. Chapter 51 , on compliance with all requirements of law and regulations, and on payment of all penalties incurred or fines imposed for violation of any such provisions.

(\$805(c), Pub. L. 96-39, 93 Stat. 276 (26 U.S.C. 5173); \$232, Pub. L. 96-223, 94 Stat. 278 (26 U.S.C. 5181$)$ )

\section{$\$ 19.960$ Additional provisions with respect to bonds.}

Subpart $\mathrm{H}$ of this part contains further provisions applicable to bonds which, where not inconsistent with 
this subpart, are applicable to bonds of alcohol fuel plants.

\section{Construction, Equipment and Security}

\section{$\$ 19.972$ Construction and equipment.}

Buildings and enclosures where distilled spirits will be produced, processed, or stored shall be constructed and arranged to enable the proprietor to maintain security adequate to deter diversion of the spirits. Distilling equipment shall be constructed to prevent unauthorized removal of spirits, from the point where distilled spirits come into existence until production is complete and the quantity of spirits has been determined. Tanks and other vessels for containing spirits shall be equipped for locking and be constructed to allow for determining the quantities of spirits therein.

(\$201, Pub. L. 85-859, 72 Stat. 1353, as amended (26 U.S.C. 5178))

\section{$\$ 19.973$ Security.}

Proprietors shall provide security adequate to deter the unauthorized removal of spirits. The proprietor shall store spirits either in a building, a storage tank, or within an enclosure, which the proprietor will keep locked when operations are not being conducted.

(\$201, Pub. L. 85-859, 72 Stat. 1353, as amended (26 U.S.C. 5178); \$806, Pub. L. 96-39, 93 Stat. 279 (26 U.S.C. 5202))

\section{\$19.974 Additional security.}

If the regional regulatory administrator finds that security is inadequate to deter diversion of the spirits, as may be evidenced by the occurrence of break-ins or by diversion of spirits to unauthorized purposes, additional security measures may be required. Such additional measures may include, but are not limited to, the following:

\section{(a) The erection of a fence around the plant or the alcohol storage facility;}

\section{(b) Flood lights;}

(c) Alarm systems;

\section{(d) Watchman services; or,}

\section{(e) Locked or barred windows.}

The exact additional security requirements would depend on the extent of the security problems, the volume of alcohol produced, the risk to tax revenue, and safety requirements.

(\$201, Pub. L. 85-859, 72 Stat. 1353, as amended (26 U.S.C. 5178); \$806, Pub. L. 96-39, 93 Stat. 279 (26 U.S.C. 5202))

\section{Supervision}

\section{$\$ 19.975$ Supervision of operations.}

The regional regulatory administrator may assign ATF officers to premises of plants qualified under this subpart. The authorities of ATF officers, provided in $\$ \$ 19.80$ through 19.84 , and the requirement that proprietors keep premises accessible to and furnish facilities and assistance to ATF officers, provided in $\$ \$ 19.85$ and 19.86 , apply to plants qualified under this subpart.

(\$201, Pub. L. 85-859, 72 Stat. 1320, as amended, 1357, as amended, 1358, as amended 1375, as amended (26 U.S.C. 5006, 5203, 5204, 5213))

\section{Accounting for Spirits}

\section{$\$ 19.980$ Gauging.}

(a) Equipment and method. Proprietors shall gauge spirits by accurately determining the proof and quantity of spirits. The proof of the spirits shall be determined using a glass cylinder, hydrometer, and thermometer. However, fuel alcohol may be accounted for in wine gallons, so it is not necessary to determine the proof of fuel alcohbl manufactured, on-hand, or removed. The proprietor may determine quantity either by volume or weight. A tank or receptacle with a calibrated glass scale installed, a calibrated dipstick, conversion charts, or (subject to approval by the Director) meters, may be used to determine quantity by volume. Detailed procedures for gauging spirits are provided in 27 CFR Part 13.

(b) When Required. Proprietors shall gauge spirits and record the results in their records at the following times:

(1) On completion of production of distilled spirits;

(2) On receipt of spirits at the plant;

(3) On addition of materials to render the spirits unfit for beverage use;

(4) Before withdrawal of spirits (including fuel alcohol) from plant premises or other disposition thereof; and,

(5) When spirits are to be inventoried.

\section{$\$ 19.981$ Inventories.}

Proprietors shall take actual physical inventory of all spirits (including fuel alcohol) on bonded premises at least once during each period for which a report is required by $\$ 19.988$. The results of the inventory shall be 
posted in the applicable reocrds required by $\$ 19.982$. (\$201, Pub. L. $85-859,72$ Stat. 1356, as amended (26 U.S.C. 5201))

\section{$\$ 19.982$ Records.}

(a) All plants. All proprietors shall maintain records with respect to:

(1) The quantity and proof of spirits produced;

(2) The proof gallons of spirits on-hand and received;

(3) The quantities and types of materials added to render the spirits unfit for beverage use;

(4) The quantity of fuel alcohol manufactured; and,

(5) All dispositions of spirits (including fuel alcohol). Fuel alcohol may be recorded in wine gallons.

(b) Medium and large plants. Proprietors of medium and large plants shall also record the kind and quantity of materials used to produce spirits.

(c) General requirements. The records must contain sufficient information to allow ATF officers to determine the quantities of spirits produced, received, stored, or processed and to verify that all spirits have been lawfully disposed of or used. However, the proprietor need not prepare records specifically to meet the requirements of this subpart. Records which the proprietor prepares for other purposes (i.e., invoices or other commercial records) are sufficient, so long as they show all the required information.

( $\$ 807$, Pub. L. 96-39, 93 Stat. 284 (26 U.S.C. 5207))

\section{$\$ 19.983$ Spirits rendered unfit in the production process.}

If the proprietor renders spirits unfit for beverage use before removal from the production system, the production records shall also include the kind and quantity of materials added to each lot of spirits. In such a case, a separate record under $\$ 19.985$ is not required. This paragraph applies to in-line addition of materials and to systems in which, before any spirits come off the production equipment, the proprietor adds materials for rendering the spirits unfit for beverage use to the first receptacle where spirits are to be deposited.

(\$807, Pub. L. 96-39, 93 Stat. 284 (26 U.S.C. 5207); \$232, Pub. L. 96-223, 94 Stat. 278 (26 U.S.C. 5181$)$ )

\section{$\$ 19.984$ Record of spirits received.}

The proprietor's copy of the consignor's invoice or other document received with the shipment, on which the proprietor has noted the date of receipt and quantity received, constitutes the required record.

(\$807, Pub. L. 96-39, 93 Stat. 284 (26 U.S.C. 5207))

\section{\$19.985 Record of spirits rendered unfit for beverage use.}

The proprietor shall record the kind and quantity of materials added to render each lot of spirits unfit for beverage use and the quantity of fuel alcohol manufactured (which may be given in wine gallons).

(\$807, Pub.L. 96-39, 93 Stat. 284 (26 U.S.C. 5207)).

\section{$\$ 19.986$ Record of dispositions.}

(a) Fuel alcohol. For fuel alcohol distributed, used, or otherwise disposed of the proprietor shall record the-

(1) Quantity of fuel alcohol;

(2) Date of disposition; and

(3) Name and address of the person to whom distributed or, if used or otherwise disposed of by the proprietor, the purpose for which used or the nature of the other disposition (e.g., destruction or redistillation). Commercial invoices, sales slips, or similar documents are acceptable if they clearly show the required information.

(b) Spirits.

(1) For spirits transferred in bond to another alcohol fuel plant, the commercial invoice or other document required by $\$ 19.997$ constitutes the required record. For transfers to other distilled spirits plants, the form required by $\$ 19.508$ is the required record.

(2) For spirits used or otherwise disposed of (e.g., lost, destroyed, redistilled) on the premises of the alcohol fuel plant, the proprietor shall maintain a record as follows:

(i) the quantity of spirits (in proof gallons) and the date of disposition;

(ii) the purpose for which used or the nature of the other disposition.

(\$807, Pub. L. 96-39, 93 Stat, 284 (26 U.S.C. 5207))

\section{$\$ 19.987$ Maintenance and retention of records.}

The proprietor shall retain the records required by this subpart for a period of not less than three years from the date thereof or from the data of the last entry made 
thereon, whichever is later. The records shall be kept at the plant where the operation or transaction occurs and shall be available for inspection by any ATF officer during business hours. For records maintained on data processing equipment, the provisions of $\$ 19.743$ apply. (\$807, Pub. L. 96-39, 93 Stat. 284 (26 U.S.C. 5207)).

\section{$\$ 19.988$ Reports.}

Proprietors shall file reports of their operations, depending on the type of plant, as follows:

Type of Plant and Reporting Periods

Small plant-Annually (December 31)

Medium plant-Semiannually (June 30 and

December 31)

Large plant-Quarterly (Close of each calendar quarter)

The proprietor shall submit each required report to the regional regulatory administrator within 30 days after the close of the applicable reporting period. The report shall be submitted on a form provided for that purpose. ( $\$ 807$, Pub. L. 96-39, 93 Stat. 284 (26 U.S.C. 5207))

\section{Transfers and Withdrawals}

\section{\$19.989 Withdrawal free of tax.}

Fuel alcohol produced under this subpart, may be withdrawn free of tax from plant premises exclusively for fuel use.

( $\$ 201$, Pub. L. 85-859, 72 Stat. 1362, as amended (26 U.S.C. 5214); $\S 232$, Pub. L. $96-223,94$ Stat. 278 (26 U.S.C. 5181 ))

\section{$\$ 19.990$ Other uses prohibited.}

The law imposes criminal penalties on any person who withdraws, uses, sells or otherwise disposes of distilled spirits (including fuel alcohol) produced under this subpart for other than fuel use.

(\$201, Pub. L. 85-859, 72 Stat. 1398, as amended (26 U.S.C. 5601); \$232, Pub. L. 96-223, 94 Stat. 278 (26 U.S.C. 5181))

\section{$\$ 19.991$ Requirement for rendering spirits unfit for beverage use.}

Before spirits may be withdrawn from plant premises, the spirits must contain, or the proprietor shall add, substances to render the spirits unfit for beverage use as provided in this subpart. However, spirits used for fuel on the premises of the alcohol fuel plant and spirits transferred to other plants need not be rendered unfit for beverage use.

(\$232, Pub. L. 96-223, 94 Stat. 278 (26 U.S.C. 5181))

\section{\$19.992 Authorized formulas for fuel alcohol.}

Spirits will be considered rendered unfit for beverage use and eligible for tax-free withdrawal as fuel alcohol, when for every 100 gallons of spirits, there has been added:

\section{(a) 5 gallons or more of-}

(1) Gasoline or automotive gasoline (for use in engines which require unleaded gasoline. Environmental Protection Agency regulations and manufacturer's specifications may require that unleaded gasoline be used to render the spirits unfit).

\section{(2) Kerosene}

(3) Deodorized kerosene

(4) Rubber hydrocarbon solvent,

(5) Methyl isobutyl ketone,

(6) Mixed isomers of nitropropane, or

(7) Any combination of (1) through (6); or,

(b) 1/8 ounce of denatonium benzoate N.F. (Bitrex) and 5 gallons of isopropyl alcohol.

(\$232, Pub. L. 96-233, 94 Stat. 278 (26 U.S.C. 5181))

\section{$\$ 19.993$ Substitute Materials.}

Other materials may be used to render spirits unfit for beverage use subject to approval by the Director. A proprietor who wishes to use substitute materials to render spirits unfit for beverage use may submit a letter requesting authorization to the Director through the regional regulatory administrator. The letter should state the materials, and the quantity of each, which the proprietor proposes to add to each 100 gallons of spirits. The Director may require the proprietor to submit a sample of the proposed substitute material. The proprietor shall not use any proposed substitute material prior to its approval.

(§232, Pub. L. 96-233, 94 Stat. (26 U.S.C. 5181))

\section{$\$ 19.994$ Marks.}

The proprietor shall conspicuously and permanently mark or securely label each container of fuel alcohol containing 55 gallons or less, as follows:

\section{WARNING-FUEL ALCOHOL-MAY BE HARMFUL OR FATAL IF SWALLOWED}

The mark or label shall be placed on the head or side of the container, and shall be in plain legible letters. Proprietors may place other marks or labels on containers 
so long as they do not obscure the required mark. (\$232, Pub. L. 96-233, 94 Stat. 278 (26 U.S.C. 5181); $\S 201$, Pub. L. $85-859,72$ Stat. 1360 , as amended (26 U.S.C. 5206))

\section{$\$ 19.995$ Container size.}

Spirits, including fuel alcohol, shall not be filled at alcohol fuel plants into containers holding less than five gallons. However, smaller containers may be used for reasonable quantities of samples held or removed to a bonafide laboratory for testing or analysis, so long as the containers are marked as samples.

(§232, Pub. L. 96-223, 94 Stat. 278 (26 U.S.C. 5181))

\section{Transfers Between Plants}

\section{$\$ 19.996$ Transfer in bond.}

(a) Transfers between alcohol fuel plants. Proprietors may remove spirits from the bonded premises of an alcohol fuel plant (including the premises of a small plant) for transfer to another alcohol fuel plant. Bulk conveyances in which spirits are transferred shall be secured with locks or seals. The spirits need not be rendered unfit for beverage use prior to transfer. Spirits so transferred may not be withdrawn, used, sold, or otherwise disposed of from the consignee plant for other than fuel use.

(b) Transfers to or from other distilled spirits plants. Spirits (not including spirits produced from petroleum, natural gas, or coal) may be transferred in bond from distilled spirits plants qualified under Subpart G of this part to alcohol fuel plants. Alcohol fuel plants may transfer spirits in bond to distilled spirits plants qualified under Subpart G. Spirits so transferred may not be withdrawn, used, sold, or otherwise disposed of for other than fuel use.

(c) Transfer procedures. The procedures in $\$ \$ 19.997$ through 19.999 apply only to the transfers between two alcohol fuel plants. See $\$ \$ 19.506$ through 19.510 for requirements where one plant is a distilled spirits plant qualified under subpart $G$ of this part.

(\$201, Pub. L. 85-859, 72 Stat. 1362, as amended (26 U.S.C. 5212); $\$ 232$, Pub. L. 96-223, 94 Stat. 278 (26 U.S.C. 5181))

\section{$\$ 19.997$ Consignor premises.}

The consignor shall prepare, in triplicate, a commercial invoice or shipping document to cover each shipment of spirits. The consignor shall enter on the document the quantity of spirits transferred, a description of the shipment (for example, number and size of drums or barrels, tank truck, etc.), the name, address, and permit number of the consignee, and the serial numbers of any seals, locks, or other devices used to secure the con- veyance. The consignor shall forward the original and one copy of the document to the consignee with the shipment, and retain a copy as a record.

(\$201, Pub. L. 85-859, 72 Stat. 1362, as amended (26 U.S.C. 5212))

\section{\$19.998 Reconsignment in transit.}

When, prior to or on arrival at the premises of a consignee, spirits transferred in bond are found to be unsuitable for the intended purpose, were shipped in error, or, for any other bona fide reason, are not accepted by such consignee, or are not accepted by a carrier, they may be reconsigned, by the consignor, to himself, or to another qualified consignee. In such case, the bond, if any, of the proprietor to whom the spirits are reconsigned shall cover such spirits while in transit after reconsignment on his copy of the document covering the original shipment. Where the reconsignment is to another proprietor, a new document shall be prepared and prominently marked with the word "Reconsignment."

(\$201, Pub. L. 85-859, 72 Stat. 1362, as amended (26 U.S.C. 5212); \$232, Pub. L. 96-223, 94 Stat. 278 (26 U.S.C. 5181))

\section{\$19.999 Consignee premises.}

(a) General. When spirits are received by transfer in bond, the proprietor shall examine each conveyance to detprmine whether the locks or seals, if any, are intact upon arrival at this premises. If the locks or seals are not intact, he shall immediately notify the area supervisor, before removal of any spirits from the conveyance. The consignee shall determine the quantity of spirits received and record the quantity and the date received on both copies of the document covering the shipment. The consignee shall return one receipted copy to the consignor and retain one copy as the record of receipt required by $\$ 19.984$.

(b) Portable containers. When spirits are received in barrels, drums, or similar portable containers, the proprietor shall examine each container and unless the transfer was made in a sealed conveyance and the seals or other devices are intact on arrival, verify the contents of container. The proprietor shall record the quantity received for each container on a list, and attach a copy of the list to each copy of the invoice or other document required by $\$ 19.997$ covering the shipment.

(c) Bulk conveyances and pipelines. When spirits are received in bulk conveyances or by pipeline, the consignee shall gauge the spirits received and record the quantity so determined on each copy of the invoice or other document covering the shipment. However, the regional regulatory administrator may waive the requirement for gauging spirits on 
receipt by pipeline if, because of the location of the premises, there will be no jeopardy to the revenue. (\$201, Pub. L. 85-859, 72 Stat. 1358, as amended 1362, as amended (26 U.S.C. 5204, 5212); §232, Pub. L. 96-223, 94 Stat. 278 (26 U.S.C. $5181)$ )

Signed: $\quad$ May 21, 1980

G. R. Dickerson, Director

Approved: June 9, 1980

Richard J. Davis, Assistant Secretary

(Enforcement Operations)

\section{DEPARTMENT OF TREASURY}

Bureau of Alcohol, Tobacco and Firearms

27 CFT Part 19

(Notice No. 345)

Fuel Use of Distilled Spirits-Implemeting a Portion of the Crude Oil Windfall Profit Tax Act of 1980

(Public Law 96-223)

AGENCY: Bureau of Alcohol, Tobacco and Firearms, Department of the Treasury.

ACTION: Proposed rulemaking cross-reference to temporary regulations.

SUMMARY: In the Rules and Regulations portion of this Federal Register, the Bureau of Alcohol, Tobacco and Firearms (ATF) is issuing temporary regulations regarding implementation of Section 232, Alcohol Fuels, in Part III of Title II of the crude Oil Windfall Profit Tax Act of 1980 (Pub. L. 96-223). The temporary regulations also serve as a notice of proposed rulemaking for final regulations.

DATES:The effective date of the temporary regulations is July 1, 1980. Written comments must be delivered or mailed by October 20, 1980 .

ADDRESS: Send comments to Chief, Regulations and Procedures Division, Bureau of Alcohol, Tobacco and Firearms, P.O. Box 385, Washington, DC 20044

Disclosure of comments: Any person may inspect the written comments or suggestions during normal business hours at the ATF Reading Room, Office of Public Affairs, Room 4407, Federal Building, 12th and Pennsylvania Avenue, NW, Washington, DC 20226.

\section{FOR FURTHER INFORMATION CONTACT:}

John V. Jarowski, Research and Regulations Branch, Bureau of Alcohol, Tobacco and Firearms, Washington, DC 20226,

Telephone: 202-566-7591

\section{SUPPLEMENTARY INFORMATION:}

Public Participation: Interested persorns may submit written comments and suggestions regarding the temperary regulations. All communications received within the comment period will be considered before final regulations are issued. Any person who desires an opport unity to comment orally at a public hearing on the temperary regulations should submit a written request to the Director within the comment period. However, the Director reserves the right to determine whether public hearing should be held.

ATF plans to contact State regulatory officials to obtain their comments on these regulations. ATF seeks to coordinate Federal and State regulation of alcohol fuels in an effort to minimize conflicting or duplicative regulations.

The temporary regulations in the Rules and Regulations portion of this issue of the Federal Register revise and add new regulations in 27 CFR Part 19. For the text of the temporary regulations, see 45 FR (T.D. ATF-71) published in the Rules and Regulations portion of this issue of the Federal Register.

Signed: $\quad$ May 21, 1980

G. R. Dickerson, Director

Approved: June 9, 1980

Richard J. Davis, Assistant Secretary (Enforcement and Operations)

\section{FDA AND OTHER ANIMAL FEED REGULATIONS}

Most plants designed for the production of fuel alcohol from grain will be designed to produce coproducts in the form of grain residues suitable for use as animal feeds. Therefore, a substantial portion of the alcohol plant's activities will be concerned with producing and marketing these products. Most states have adopted commercial feed laws governing the production and marketing of animal feeds. In addition, the sale of feeds on an interstate basis is regulated at the federal level by various agencies, primarily the Food and Drug Administration (FDA). Thus, regulatory compliance will be an important consideration in developing the plant's animal feed operations.

The regulations in each State should be checked for particular requirements; however, the regulations in the majority of States are very similar. In many States, the State legislators have adopted all or part of the Uniform State Feed Bill.' These statutes incorporate by reference provisions of the Food, Drug, and Cosmetic Act and the of-

IOfficially adopted by the Association of American Feed Control Officials and endorsed by the American Feed Manufacturers Association and the National Feed Ingredients Association. 
ficial definitions of feed ingredients as defined by the Association of American Feed Control Officials (AAFCO).

For the alcohol plant, as a manufacturer of animal feeds, ther are three primary areas of concern with regard to feed regulation-registration, adulteration, and misbranding. Registration (licensing) is in most instances quite simple and involves registering the products to be manufactured and paying the fees required. The statutory language in some states may require fee tags or stamps to be purchased and at tached to the labeling used on packaged feeds or, in the case of feeds sold in bulk, to provide these tags or stamps to the buyer along with the invoice or bill of lading. The fees charged are, for the most part, nominal. They are either set at a flat rate for each product produced and sold or are based on tonnage. Some states have registrations involving a combination of a flat rate plus a tonnage fee. ${ }^{2}$ A number of states may also require the filing of affidavits of tonnage on a regular basis in order to advise the state on the level of production at a given plant. In each state the actual mechanism of registration is usually a simple matter of following the statutory guidelines and associated regulations. ${ }^{3}$

After the initial registration has been completed, the primary concerns of management, to ensure continued compliance, will be in the area of quality control. From a licensing standpoint, lapses in quality control can produce charges of adulteration and misbranding. To ensure continuing compliance, most States have (by statute) provided for inspecting, sampling, and analyzing production. Discovery of a violation of the provisions of the Feed Law can result in various penalties (fines) or in detention of the feed (i.e. withholding the feed from sale or distribution).

Contamination of the feed can result in a charge of adulteration. The definition of adulteration is usually specifically provided by statute. The Unitorm Feed Bill provides the following definition:

Section 7. Adulteration.

A commercial feed shall be deemed to be adulterated:

(a)(1) If it bears or contains any poisonous or deleterious substance which may render it injurious to health; but in case the substance is not an added substance, such commercial feed shall not be considered adulterated under this subsection if the quantity of such substance in such commercial feed does not ordinarily render it injurious to health; or
(2) If it bears or contains any added poisonous, added deleterious, or added nonnutritive substance which is unsafe within the meaning of Section 406 of the Federal, Food, and Cosmetic Act (other than one which is (i) a pesticide chemical in or on a raw agricultural commodity; or (ii) a food additive); or

(3) If it is, or it bears or contains any food additive which is unsafe within the meaning of Section 409 of the Federal Food, Drug, and Cosmetic Act; or

(4) If it is a raw agricultural commodity and it bears or contains a pesticide chemical which is unsafe within the meaning of Section 408(a) of the Federal Food, Drug, and Cosmetic Act: Provided, that where a pesticide chemical has been used in or on a raw agricultural commodity in conformity with an exemption granted or a tolerance prescribed under Section 408 of the Federal Food, Drug, and Cosmetic Act and such raw agricultural commodity has been subjected to processing such as canning, cooking, freezing, dehydrating, or milling, the residue of such pesticide chemical remaining in or on such processed feed shall not be deemed unsafe if such residue in or on the raw agricultural commodity has been removed to the extent possible in good manufacturing practice and the concentration of such residue in the processed feed is not greater than the tolerance prescribed for the raw agricultural commodity unless the feeding of such processed feed will result or is likely to result in a pesticide residue in the edible product of the animal, which is unsafe within the meaning of Section 408(a) of the Federal Food, Drug, and Cosmetic Act.

(5) If it is, or it bears or contains any color additive which is unsafe within the meaning of Section 706 of the Federal Food, Drug, and Cosmetic Act.

(b) If any valuable constituent has been in whole or in part omitted or abstracted therefrom or any less valuable substance substituted therefor.

2For example, Wisconsin assesses $\$ 10.00$ per plant per year plus $\$ 0.10$ per ton inspection fee for all feed produced annually. By contrast, Georgia simply charges a flat fee of $\$ 2.00$ annually per product produced.

${ }^{3}$ Most states have provided authority under the respective Administration Procedures Act for the agencies to pass regulations further defining or implementing legisfation and these regulations should be checked. 
(c) If its composition or quality falls below or differs from that which it is purported or is represented in possess by its labeling.

(d) If it contains a drug and the methods used in or the facilities or controls used for its manufacture, processing, or packaging do not conform to current good manufacturing practice regulations promulgated by the (authorized State agency) to ensure that the drug meets the requirement of this Act as to safety and has the identity and strength and meets the quality and purity characteristics which it purports or is represented to possess. In promulgating such regulations, the (authorized State agency) shall adopt the current good manufacturing practice regulations for medicated feed premixes and for medicated feeds established under authority of the Federal Food, Drug, and Cosmetic Act, unless he determines that they are not appropriate to the conditions which exist in this State.

(e) If it contains visable weed seeds in amounts exceeding the limits which the (authorized state agency) shall establish by rule or regulation.

The above statute, in addition to the enumerated provisions, incorporates by reference two important areas of federal regualtion.

First, the feed could be adulterated by containing an added substance not on the list of substances Generally Recognized as Safe by the FDA (The GRAS List) or if it contains a substance on the GRAS List in excess of the limits prescribed for that substance in the Code of Federal Regulations (CFR). Thus, a violation could occur if a plant were to utilize a process that added a substance to the feed during the process of manufacturing which is not in compliance with the above regulations. For example, a process for drying feed residue which utilizes waste gases might produce unacceptable levels of contamination or contamination with some substance not on the GRAS List.

Second, a problem could also arise if the grain used as a substrate contained excessive levels of pesticides. The processing might not eliminate enough of the residue to bring the quantity in the final product within the acceptable limits. ${ }^{+}$

In addition to avoiding the charge of adulteration, quality control is essential to ensure regulatory compliance in other areas. To ensure compliance, it is necessary that a feed that purports to be a certain product must meet the definition established for that product.
Failure to meet the definition or standard could result in the charge of misbranding. The Uniform State Feed Bill provides the following definition for misbranding:

\section{Section 6. Misbranding.}

A commercial feed shall be deemed to be misbranded:

(a) If its labeling is false or misleading in any particular.

(b) If it is distributed under the name of another commercial feed.

(c) If it is not labeled as required in Section 5 of this Act.

(d) If it purports to be or is represented as a commercial feed, or if it purports to contain or is represented as containing a commercial feed ingredient, unless such commercial feed or feed ingredient conforms to the definition, if any, prescribed by regulation by the (authorized state agency).

(e) If any word, statement, or other information required by or under authority of this Act to appear on the label or labeling is not prominently placed theron with such conspicuousness (as comapred with other words, statements, designs, or devices in the labeling) and in such terms as to render it likely to be read and understood by the ordinary individual under customary conditions of purchase and use.

The definitions referred to in the above statutory provisions for feed products have been established by AAFCO and are incorporated by reference.:

This discussion of feed regulations briefly outlines the areas of interest to investors in alcohol fuel plants. Compliance with these regulations can be achieved by properly designing and operating the plant. The grain and feed portions of the operation can be designed to minimize problems with contamination and provide adequate controls to monitor and manage product quality in order to eliminate or minimize regulatory complaince problems. By recognizing and considering these regulatory requirements during the planning and design phases, new plants can do a great deal to minimize potential problems in this area.

\footnotetext{
${ }^{4}$ Limits on pesticides under Setion 408 of FDCA are determined by the EPA and are set forth in the CFR.

sOfficial and tentative definitions of feed ingredients as established by the AAFCO contain definitions for a wide variety of products. These include: maize (corn products) 48.1 to 48.3 ; fermentation products 36.1 to 36.12 ; distiller's products 27.1 to 27.7 .
} 


\section{TRANSPORTATION REGULATIONS}

The surface transportation of raw materials and finished product may be regulated by State and Federal agencies, depending upon the location of the plant and its proximity to the source of materials and its markets. If the plant, material source, and the market are located in the same State, it is highly probable that only the individualistic State law will apply to regulate surface cransportation, at least insofar as for-hire motor truck transportation is concerned. Some States, such as Texas, Nebraska, and South Dakota, choose to regulate truck transportation rather extensively, while others have little or no concern for regulation of the basic types of commodities flowing to and from a plant. Generally, grain transportation is not regulated, while coal and alcohol fuel are. Several States, including Florida, have recently deregulated the transporting of all commodities within their borders, while several others are actively studying deregulation proposals.

Assuming interstate commerce is involved in either obtaining materials or in reaching the market place, the nature of regulation is determined by the Interstate Commerce Commission. Currently, the truck transportation of grain is exempt (or not regulated), while, under the Motor Carrier Reform Act of 1980 (H.R. 6418), the movement of DDG will likely also be exempt. Truck movement of coal and alcohol, on the other hand, is currently regulated. In this context, lawful interstate movements of such commodities can be performed only by a carrier holding Federal ICC authority.*

Primary transportation considerations will necessarily include plant site selection vis a vis existing, visible rail facilities. This is particularly critical where a plant is to be located any distace (perhaps more than 200 or 250 miles) from the primary source of any major raw material (grain or coal).

\section{LOCAL BUILDING CODES}

Like zoning matters, the State's jurisdictional power is the basic authority under which building codes are enacted. Some State legislatures enact statewide building codes while others delegate the authority to the local governments. One or a combination of the four model building codes has been adopted by most States or municipalities. These codes (and the geographic area) dominated by their association/author are: (1) the Uniform Building Code written by the International Conference of Building Officials (adopted primarily in the West); (2) the Basic Building Code compiled by the Building Officials and Code Administrators, International, Inc. (found in the Northeast and North Central areas); (3) the Southern Standard Building Code enacted by the Southern Building Code Conference (adopted in the South); and (4) the National Building Code, developed by the National Board of Fire Underwriters. Local variations exist despite the model codes. Some municipalities have adopted selected provisions rather than the entire code. Interpretations of the same code differ from city to city.

Unlike zoning ordinanaces, most building codes apply retroactively. Three types of information are provided in most codes: definition of terms; licensing requirements; and standards. Taken together, the definitions and licensing requirements have the effect of prescribing who is authorized to conduct particular sorts of construction activity. For example, the International Association of Plumbing and Mechanical Officials Code states that only licensed plumbers may do work defined as plumbing. Many codes require that structural design plans be prepared by a state certified engineer.

Two types of code standards exist: technical specifications and performance standards. Codes prescribing technical specifications set out how, and with what materials, a building is to be constructed. Performance standards represent a more progressive and technically more flexible approach. Codes based on these standards state product requirements that do not prescribe designs and materials. For example, "the structural frame of all buildings, signs, tanks and other exposed structures shall be designed to resist the horizontal pressures due to wind in any direction. . . "Typical construction components specified in codes are structural and foundation loads and stresses, construction material, fireproofing, building height (this represents a common duplication of the zoning ordinance), and electrical installation. The developer is likely to be required to comply with the standards for structural and foundation loads and stresses, as standards set out the minimum force measure in poundsper-square-inch that the design must bear under certain circumstances, e.g., wind or snow. The electrical code regulates the use of all electrical wiring when voltage levels are above 36 volts.

Dissatisfaction with the building inspector's denial of a permit may result in an appeal before the local board of building appeals. The common bases of appeal provided by the codes are: an incorrect interpretation of the code by the building official; the availability of an equally good or better form of construction not specified in the code; and the existence of practical difficulties in carrying out the requirements of the code. The local board members are usually appointed experts in the field of construction. The local board may uphold, modify, or reverse the building official's decision. Further appeals to the state board of building appeals or to the courts are also available.

*As a corollary to this, the rate structures on such transportation are also regulated. 


\section{GASOLINE ALLOCATIONS}

A letter containing the following information is required from the applicant interested in obtaining a gasoline allocation for gasohol:

The office that is final arbiter on increasing gasoline allocation for gasohol usage is:

\section{Office of Hearings and Appeals}

\section{U. S. DEPARTMENT OF ENERGY} 2000 M Street, N.W.

Washington, D.C. 20461

(202) 254-3008

\section{(a) Investment}

1. What is the amount of investment already made?

2. How is/was this investment financed?

3. What would be the value of the investment if approval for reallocation is not granted?

4. Provide photographs of production facilities.

5. For what purpose(s) will the investment be used-gasohol blending, ethanol production, facility construction, feedstock purchase, etc.?

\section{(b) Alcohol}

1. Where are the sources of alcohol?

2. What will be the cost of obtaining the alcohol for each source listed?

3. Supply copies of supply contracts, if any exist.

4. What is the efficiency of the alcohol production techniques(s) to be used?

5. What feedstock will be utilized in producing the alcohol? (c) Unleaded Gasoline

1. What is the availability of unleaded gasoline in the intended marketing area?

2. List refiners in the marketing area.

3. Describe the contacts already made in attempting to obtain unleaded gasoline.

4. List your preferred supplier(s) for unleaded gasoline.

5. Of the gasoline you obtain, what percentage is unleaded?

6. What is your selling price for unleaded gasoline?

7. What quantities of unleaded gasoline do you anticipate needing in the next 12 months? Specify month-by-month.

\section{(d) Marketing}

1. Describe the intended marketing area.

2. Describe your plans for the marketing of gasohol.

3. What is the anticipated sales of gasohol for 12 -month period?

4. Describe any feasibility studies showing demand for gasohol in marketing area.

5. List retailers in the marketing area that would sell gasohol. Describe any contracts that exist with them.

6. What is the expected selling price for the gasohol?

A copy of this letter of application (with confidential information deleted) should be sent to the base supplier of gasoline. 


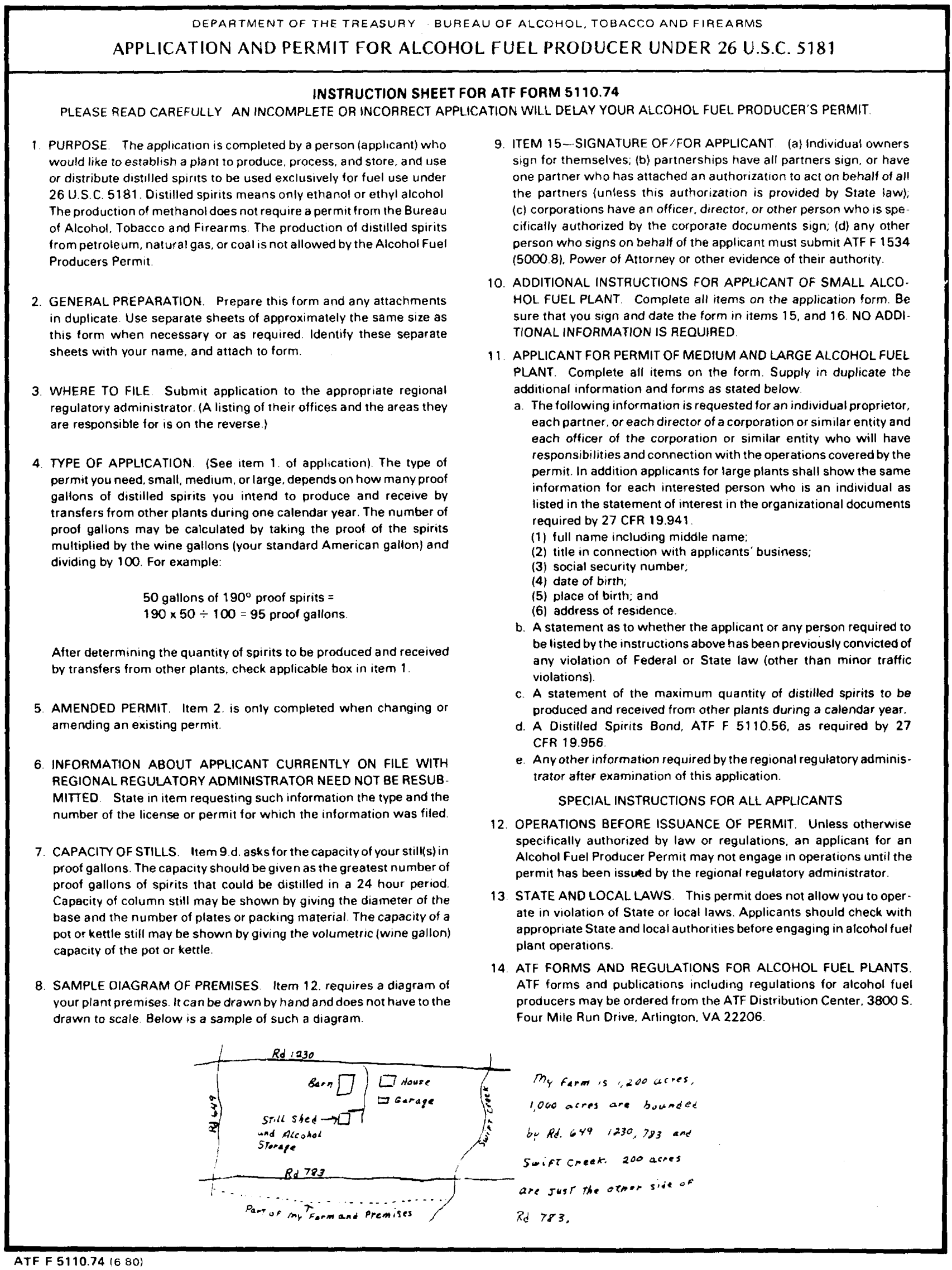

ATF F 5110.74 (6 80)

Figure B.1.-BATF Form 5110.74 
12. DIAGRAM OF PLANT PREMISES (In the space procided or by attached map or diakram, show the area to be included for the alcohal fuel plant. ldentify roads, streams, lakes. railroads, buildings, und other structures or topographical features on the diagram. Show location(s) iuhere alcohol fuel plant operations will occur. The diagram should be in sufficient de tail to locate your operations and premises.) (See directions for sample diagram.)

13. I WILL COMPLY WITH THE CLEAN WATER ACT (33 U.S.C. 1341 (a)). (W'ill not discharge into natigable waters of the U.S.)

$\square$ YES $\square$ NO

14. IF THIS APPLICATION IS APPROVED AND THE PERMIT IS ISSUED, I CONSENT TO THE DISCLOSURE OF THE NAME AND ADDRESS SHOWN ON THE APPLICATION IN AN ATF PUBLICATION, "ALCOHOL FUEL PRODUCERS", GENERAL PUBLIC (including media, business, civic, rovernment agencies, and others) UNDER 26 U.S.C. 6103 YOU HAVE A LEGAL RIGHT NOT TO GIVE THIS RELEASE.

$\square$ YES

NO (A no response will hate no effect on the consideration gilen this application) APPLICANTS FOR MEDIUM AND LARGE ALCOHOL FUEL PLANTS MUST ATTACH THE ADDITIONAL INFORMATION REQUIRED IN INSTRUCTIONS Under the penalties of periury, I deciare that I have examined this application, including the documents submitted in support thereof or incorporated therein by reference, and, to the best of my knowledge and belief, it is true, correct, and complete.

15. SIGNATURE OF/FOR APPLICANT 16 . TITLE (Owner, Partner, Corporate Officer) STOP

MAKE NO FURTHER ENTRIES ON THIS FORM

\section{ALCOHOL FUEL PRODUCERS PERMIT}

UNDER 26 U.S.C. 5181

1. EFFECTIVE DATE

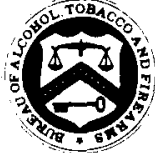

2. PERMIT NUMBER

AFP -

Pursuant to the above application and subject to applicable law and regulations and to the conditions set forth below you are hereby authorized and permitted at the premises described in your application to produce, process and store, and use or distribute distilled spirits (Not including distilled spirits produced from petroleum, natural gas or coal) exclusively for fuel use. The quantity to be produced and received from other plants during the calendar year is limited to the quantity stated in this application.

This permit is continuing and will remain in force until suspended, revoked, voluntarily surrendered, or automatically terminated. This permit does not allow you to operate in violation of State or local laws.

THIS PERMITIS NOT TRANSFERABLE In the event of any lease, sale, or other transfer of the operations authorized, or of any other change in the ownership or control of such operations, this permit shall automatically terminate. (See 27 CFR 19.145 AND 19.949)

3. SIGNATURE OF REGIONAL REGULATORY AOMINISTRATOR, BUREAU OF ALCOHOL, TOBACCO AND FIREARMS

\section{CONDITIONS}

1. That the permittee in good faith complies with the provisions of Chapter 51 of Title 26 of the United States Code and regulations Issued thereunder.

2. That the permittee has made no false statement as to any material fact in his application for this permit

3 That the permittee discloses all the material information required by law and regulation

4. That the permittee shall not violate or conspire to violate any law of the United States relating to intoxicating liquor and shall not be convicted of any offense under the United States Code punishable as a felony or of any conspiracy to commit such an offense.

5. That all persons employed by the permittee in good faith observe and conform to all of the terms and conditions of this permit

6 . That the permittee engages in the operations authorized by this permit within a 2 year period.

7 This permut is conditioned on compliance by you with the Clean Water Act $(33$ U.S.C $1341(a))$

ATF F $5110.74(6.80)$

Figure B.1._BATF Form 5110.74 (continued) 


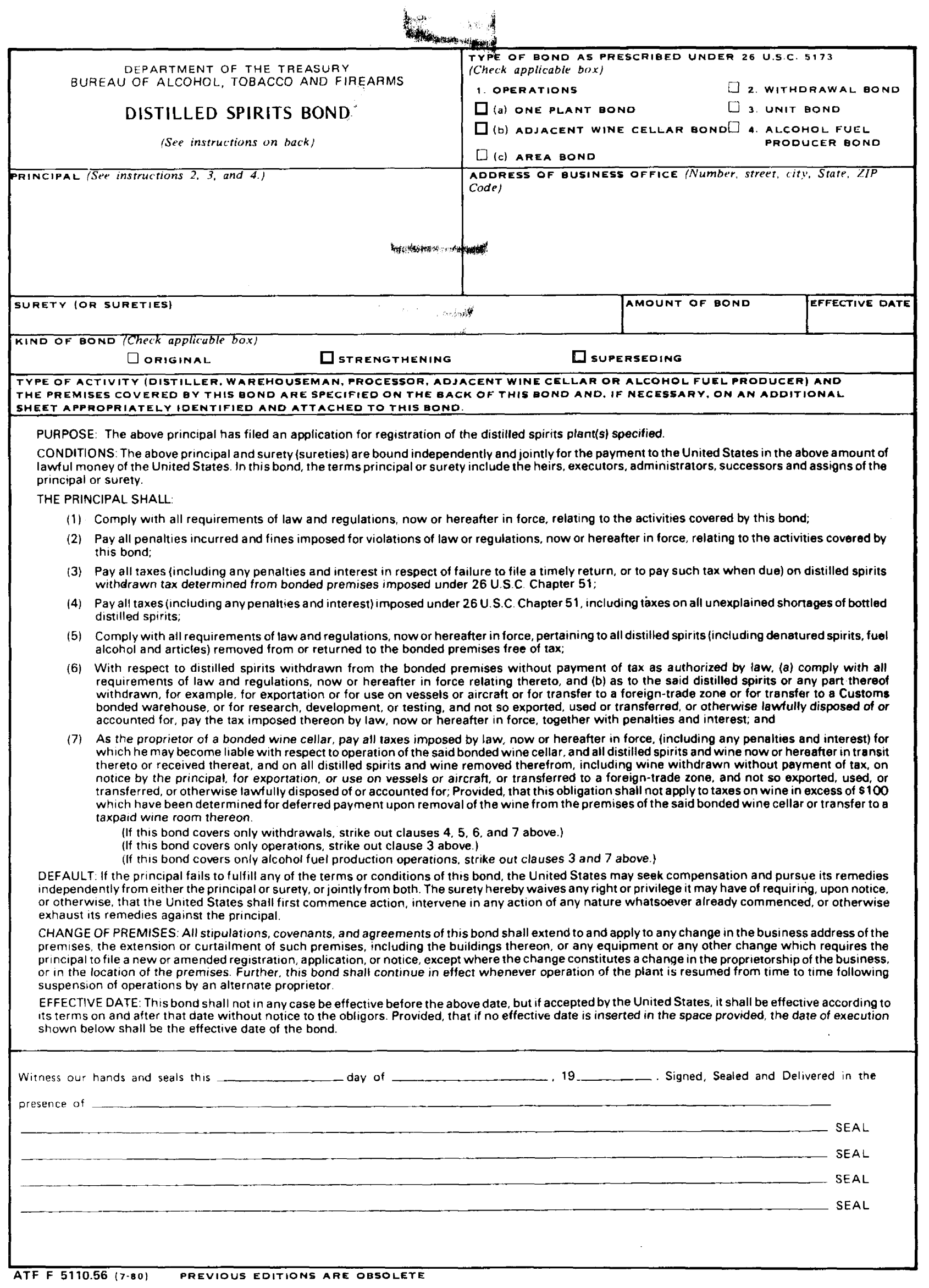

Figure B-2.-BATF Form 5110.56 


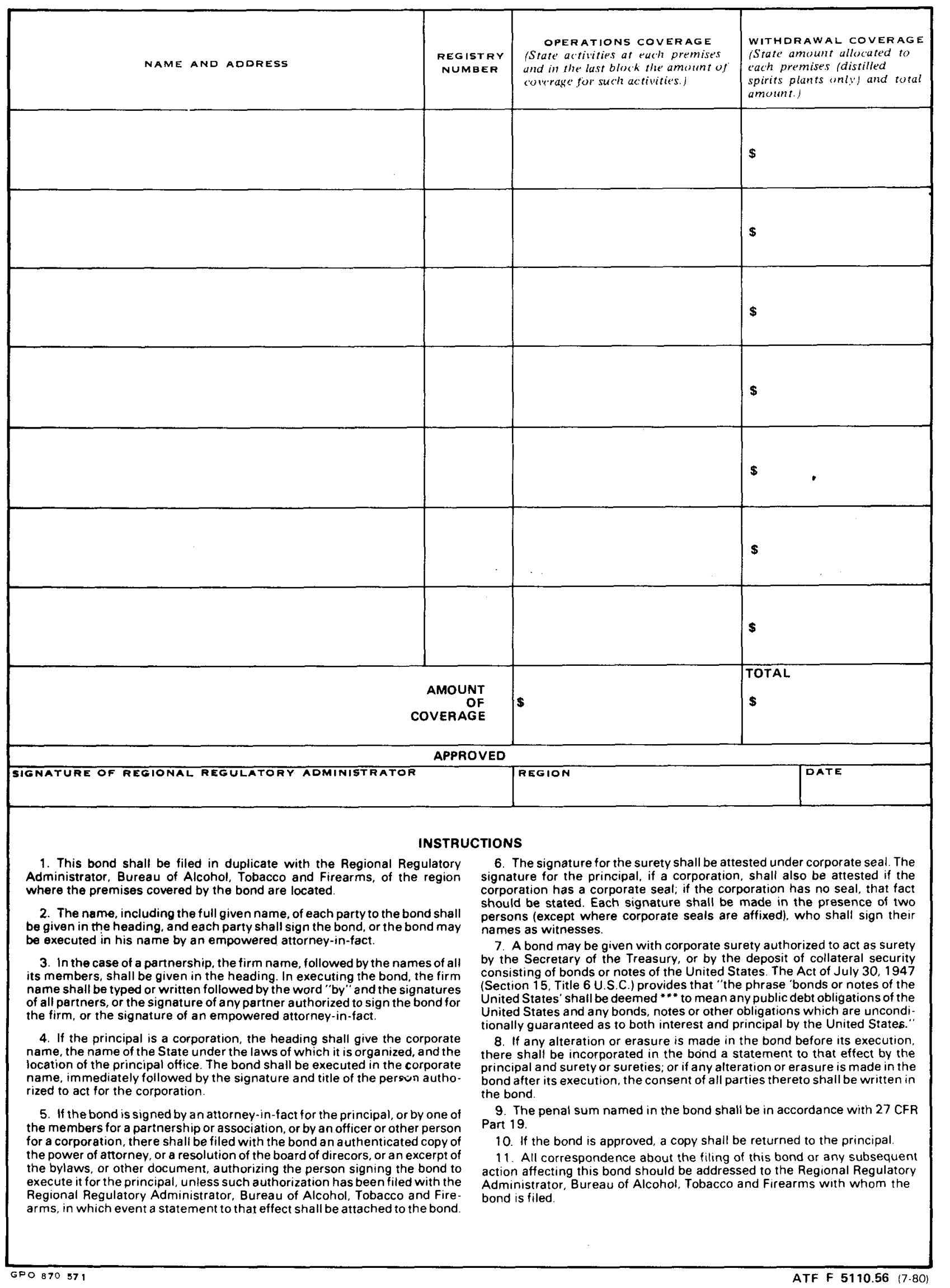

Figure B.2.-BATF Form 5110.56 (continued) 


\section{DEPARTMENT OF THE TREASURY
BUREAU OF ALCOHOL, TOBACCO AND FIREARMS \\ ALCOHOL FUEL PLANT REPORT}

\section{GENERAL INSTRUCTIONS}

1. Each proprietor of an alcohol fuel plant shall file this report of plant operations. The period covered by the report depends on the size of the alcohol fuel plant. A report is due even if no operations were conducted during the period.

2. Prepare in duplicate. Send the original to the Regional Regulatory Administrator, Bureau of Alcohol, Tobacco and Firearms. Keep the copy with your alcohol fuel plant records.

\section{WHEN TO FILE REPORTS}

SMALL PLANT

1. Proprietors of smail plants will prepare and file a report once a year to cover all operations for the calendar year.

2. Report is due by January 30th following the end of the calendar year.

MEDIUM PLANT

1. Proprietors of medium plants will prepare and file a report twice a year. Each report will cover all operations for period reported (January 1 thru June 30 or July 1 thru December 311 and will be due 30 days after the end of the reporting period.

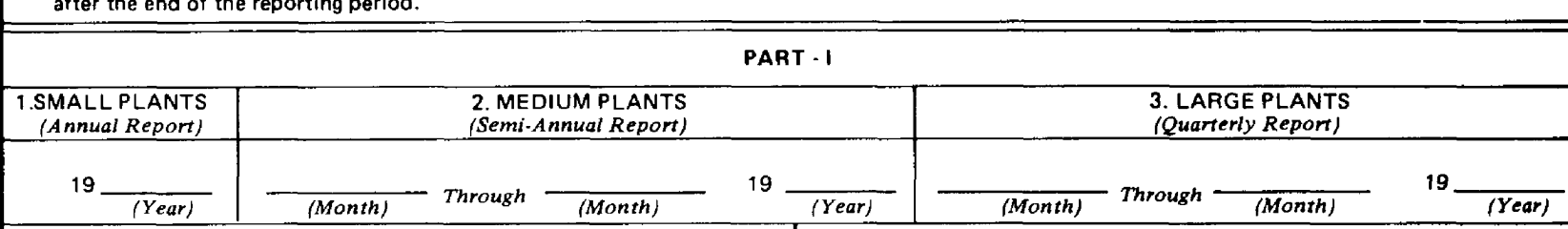

4. NAME OF PROPRIETOR (Jf partnership, include name of each partner)
LARGE PLANT

1. Proprietors of large plants will prepare and file a report 4 times a year. Reports will cover calendar quarters (example Jan. March) and reflect all transactions in that period.

2. Reports are due $\mathbf{3 0}$ days after the end of the reporting period.

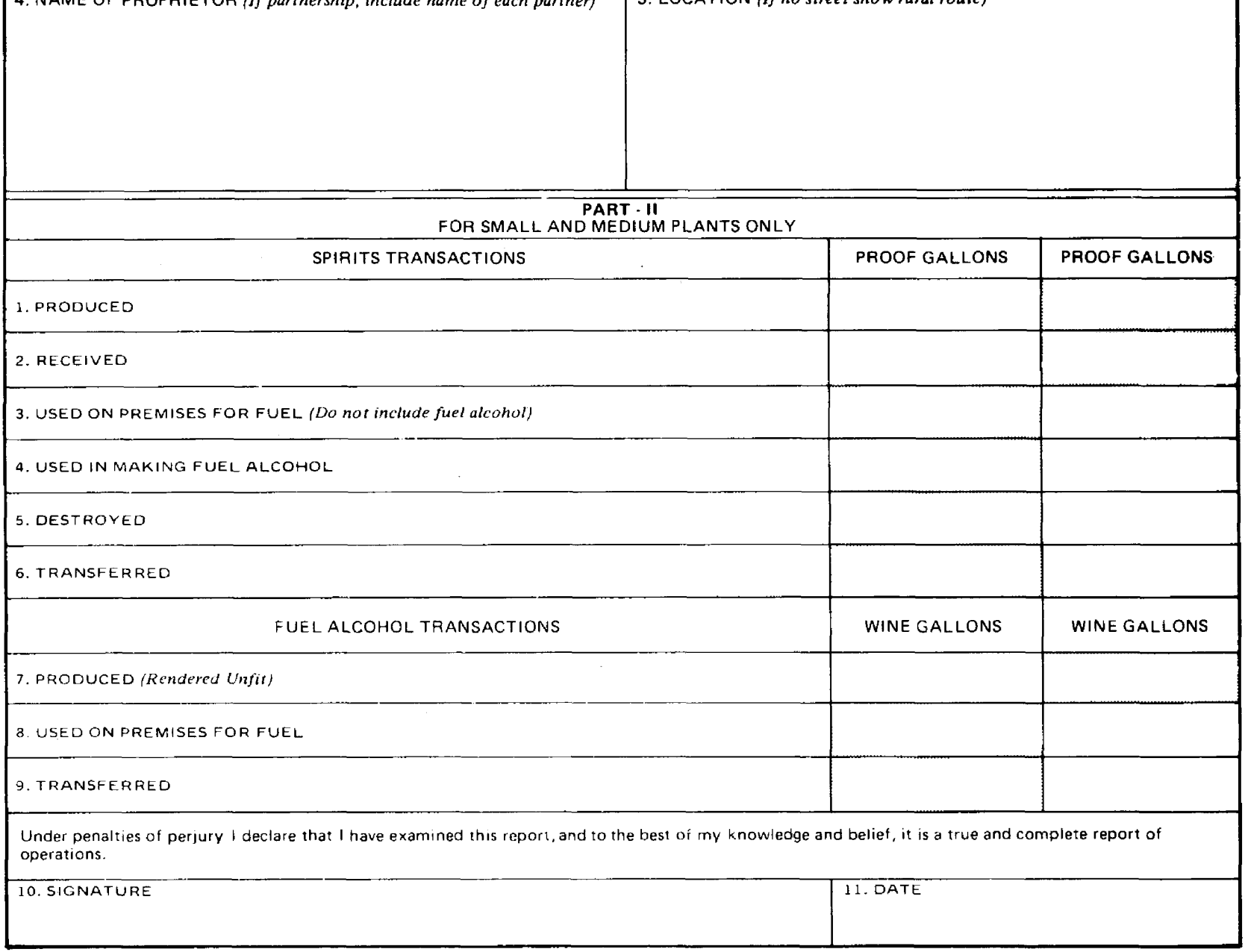

ATF F $5110.75(7.80)$

Figure B-3.-BATF Form 5110.75 
PART - II

FOR LARGE PLANTS ONLY

Report the loss (line 11) or the gain (line 4 ) of spirits found by taking the required physical inventory for the reporting period. Report any losses by theft separately (line 10). Report and identify on line 5 the quantity of any imported spirits received from customs custody.

SPIRITS TRANSACTIONS

1. ON HAND BEGINNING OF REPORTING PERIOD

2. PRODUCED BY DISTILLING

3. RECEIVED FROM OTHER PLANTS

4. INVENTORY GAIN

5.

6. TOTAL - (Lines I through 5$)$

7. USED IN MAKING FUEL ALCOHOL

8. USED ON PLANT PREMISES FOR FUEL (Do not include fuel alcohol)

9. USED AS DISTILLING MATERIAL OR FOR REDISTILLING

10. LOST BY THEFT

11. INVENTORY LOSS

12. TRANSFERRED TO OTHER PLANTS

13. DESTROYED

14.

15. TOTAL $-($ Lines 7 through 14$)$

16. ON HAND END OF PERIOD (Subrract line 15 from line 6)

FUEL ALCOHOL TRANSACTIONS

17. MANUFACTURED

18. DISTRIBUTED OR SOLDFOR FUEL PURPOSES

19. USED ON PLANT PREMISES FOR FUEL PURPOSES

20. DESTROYED

21. ALL OTHER DISPOSITIONS

22. REMARKS

Under penalties of perjury I declare that I have examined this report, and to the best of my knowledge and belief, it is a true and complete report of operations.

23. SIGNATURE

24. DATE

ATF F $5110.75(7.80)$

Figure B-3.-BATF Form 5110.75 (continued) 
BATF REGIONAL OFFICES

Central Region

Indiana, Kentucky

Michigan, Ohio,

West Virginia

Mid-Atlantic Region

Delaware, District of

Columbia, Maryland,

New Jersey, Pennsylvania,

Virginia

Midwest Region

Illinois, Iowa, Kansas,

Minnesota, Missouri,

Nebraska, North Dakota,

South Dakota, Wisconsin

North-Atiantic Region

Connecticut, Maine,

Massachusetts, New Hampshire,

New York, Rhode Island,

Vermont, Puerto Rico,

Virgin Islands

Southeast Region

Alabama, Florida, Georgia, Mississippi, North Carolina, South Carolina, Tennessee

Southwest Region

Arkansas, Colorado, Louisiana, New Mexico,

Oklahoma, Texas, Wyoming

Western Region

Alaska, Arizona, California, Hawaii, Idaho, Montana, Nevada, Oregon, Utah, Washington
Regional Regulatory Administrator

Bureau of Alcohol, Tobacco, and Firearms

550 Main Street

Cincinnati, $\mathrm{OH} 45202$

Phone (513) 684-3334

Toll Free: Ohio (800) 582-1880 Other (800) 543-1932

Regional Regulatory Administrator

Bureau of Alcohol, Tobacco, and Firearms

2 Penn Center Plaza, Room 360

Philadelphia, PA 19102

Phone (215) 597-2248

Toll Free: Pennsylvania (800) 462-0434

Other

(800) 523-0677

Regional Regulatory Administrator Bureau of Alcohol, Tobacco, and Firearms 230 S. Dearborn Street, 15th Floor

Chicago, IL 60604

Phone (312) 353-3883

Toll Free: Illinois (800) 572-3178 Other (800) 621-3211

Regional Regulatory Administrator

Bureau of Alcohol, Tobacco, and Firearms

6 World Trade Center, 6th Floor

(Mail: P.O. Box 15,

Church Street Station)

New York, NY 10008

Phone (212) 264-1095

Toll Free: New York (800) 442-8275

Other (800) 223-2162

Regional Regulatory Administrator

Bureau of Alcohol, Tobacco, and Firearms

3835 Northeast Expressway

(Mail: P.O. Box 2994)

Atlanta, GA 30301

Phone (404) 455-2670

Toll Free: Georgia (800) 282-8878 Other (800) 241-3701

Regional Regulatory Administrator

Bureau of Alcohol, Tobacco, and Firearms

Main Tower, Room 345

1200 Main Street

Dallas, TX 75202

Phone (214) 767-2285

Toll Free: Texas (800) 442-7251

Other (800) 527-9380

Regional Regulatory Administrator

Bureau of Alcohol, Tobacco, and Firearms

525 Market Street, 34th Floor

San Francisco, CA 94105

Phone (415) 556-0226

Toll Free: California (800) 792-9811 Other* (800)227-3072

*Not yet available for Alaska or Hawaii 


\section{APPENDIX C}

\section{Environmental Considerations}

- Areas for Potentially Hazardous Environmental Effects

- Ethanol Production

- Vehicular Fuel Use 


\section{AREAS FOR POTENTIALLY HAZARDOUS ENVIRONMENTAL EFFECTS}

There are two areas to be examined for potentially hazardous environmental effects-the ethanol production process and large-scale use of ethanol as a vehicular fuel.

\section{Ethanol Production}

There will be several types of effects on the environment caused by the production of fermentation ethanol which can be avoided with proper precautions.

Crop Residue Removal. The first and possibly most important environmental impact could be the removal of crop residues for use as a boiler fuel. Crop residues are important because they help control soil erosion through their cover and provide nutrients, minerals, and fibrous material which help maintain soil quality. However, not more than one-third to one-half of the residues from a grain crop devoted to ethanol production need be used to fuel the process. Also, there are several methods, such as crop rotation and winter cover crops, which lessen the impact of crop residue removal.

Use of Wet Stillage. The second environmental impact to be considered is related to the application of thin stillage to the land. Thin stillage, the product of the filtering process whereby the course solids are filtered out of the whole stillage, is composed of very small solid particles and solubles. Two kinds of problems can result from applying thin stillage to the land: odor and acidity. The impacts of applying thin stillage to the land can be attenuated by using a sludge plow, possible recycling of the thin stillage within the plant, or use of anaerobic digestion to reduce the pollution potential of the thin stillage.

Air Pollution. The third potential environmental impact is air pollution. Two forms of air pollution could result from development of an ethanol production scheme on-farm: the release of pollutants from the boiler used to produce steam from process heat, and vaporization of ethanol lost during the production process. If crop residues are used as boiler fuel, which is a preferred plan, the resulting pollutants are primarily particulate matter which can be controlled through the use of flue stack scrubbers. The release of ethanol vapors is not a major concern at this time.

\section{Vehicular Fuel Use}

Under the Clean Air Act of 1977 all fuel additives are automatically banned unless the manufacturer of the fuel additive demonstrates that the additive will not cause or contribute to the failure of any vehicle to meet applicable emission standards. The federally specified reference fuel is indolene and the required tests are for emissions of tailpipe hydrocarbons, carbon monoxide, nitrogen oxides, and evaporative hydrocarbons. The last mentioned test involves the measurement of fuel vapors from the gas tank when the engine is left to idle and from locations such as the pump at the gas station. The requirements in these tests are quite stringent; in fact, in an Environmental Protection Agency (EPA) study [1], commonly accepted pure summer-grade gasoline when compared with indolene failed-in oxidation catalyst vehicles and in three-way catalyst vehicles-all four tests mentioned above.

On the other hand, the same study reported that a $90 \%$ indolene $/ 10 \%$-ethanol blend showed definite improvements over pure indolene in tailpipe hydrocarbon and carbon monoxide emissions, nitrogen oxides emissions equal to the summer-grade gasoline, and a slight increase of evaporative emissions relative to the pure summer-grade gasoline.

EPA and the Department of Energy have conducted a cooperative gasohol testing program to obtain and evaluate environmental impact data. On the basis of these tests, EPA concluded that the addition of $10 \%$ ethanol to gasoline [2]:

- slightly decreases hydrocarbon emissions;

- significantly decreases carbon monoxide emissions;

- slightly increases nitrogen oxides emissions; and

- substantially increases evaporative hydrocarbon emissions.

On December 16, 1978, EPA approved use of gasohol under Section 211(f)(3) of the Clean Air Act of 1977 and found that there was no significant environmental risk associated with gasohol's continued use [3]. Furthermore, new emissions control systems, such as the "threeway catalyst with exhaust oxygen sensors for carburetion feedback for air-fuel control," have been shown to be equally effective using either gasoline or gasohol [3].

In summary, the results to date have been generally favorable with respect to the use of gasohol in automobiles. However, in a recent technical memorandum, the Office of Technology Assessment of the Congress of the United States stated that the "mixture of observed emissions reductions and increases, and the lack of extensive and controlled emissions testing, does not justify a strong value judgment about the environmental effect of gasohol used in the general automobile population (although the majority of analysts have concluded that the net effect is unlikely to be significant)" [4]. 


\section{REFERENCES}

1. Jackson, B. R. "Testimony at DOE Hearings on Alcohol Fuels." U.S. Environmental Protection Agency; December 6, 1978.

2. Characterization Report: Analysis of Gasohol Fleet Data to Characterize the Impact of Gasohol on Tailpipe and Evaporative Emissions. U.S. Environmental Protection Agency, Technical Support Branch, Mobile Source Enforcement Division, December 1978.
3. Allsup, J. R.; Eccleston, P. B. "Ethanol/Gasoline Blends as Automotive Fuels." Alcohol Fuels Technology, 3rd International Symposium; Asilomar, CA; 1979.

4. Office of Technology Assessment. Gasohol-A Technical Memorandum. September 1979, 69 p. Available from Superintendent of Documents, U.S. Government Printing Office, Stock No. 052-003-00706-1. [P48] 


\section{APPENDIX D}

\section{Reference Information}

- Conversion Factors

- Properties of Ethanol, Gasoline, and Water

- Water, Protein, and Carbohydrate Content of Selected Farm Products

- Typical Analysis of Distillers' Dried Grain Solids-Corn

- Energy Content for Feed

- Percent Sugar and Starch in Grains

- Comparison of Raw Materials for Ethanol Production

- Comparative Energy Balances for Ethanol Production 


\section{CONVERSION FACTORS}

1 gallon water $=8.33$ pounds $\left(\right.$ at $\left.60^{\circ} \mathrm{F}\right)=0.134$ cubic foot $=128$ fluid ounces $=4$ quarts $=8$ pints $=3.785$ liters

1 gallon of ethanol weighs 6.6 pounds

1 barrel of crude oil $=42$ gallons

$1 \mathrm{Btu}=252$ calories $=$ heat required to raise $1 \mathrm{lb}$ of water 1 degree Fahrenheit $\left({ }^{\circ} \mathrm{F}\right)$.

1 bushel of corn $=56$ pounds

1 calorie $=.00397 \mathrm{Btu}=$ heat required to raise 1 gram of water 1 degree Centigrade $\left({ }^{\circ} \mathrm{C}\right)$

1 U.S. liquid gallon $=4$ quarts $=231$ cubic inches $=3.78$ liters

8 gallons $=1$ bushel of corn

1 liter $=1.057$ U.S. liquid quarts

1 fluid ounce $=30$ milliliters

1 pound $=453.6$ grams

1 cubic foot $=7.48$ liquid gallons $=62.36$ pounds $\mathrm{H}_{2} \mathrm{O}\left(\right.$ at $60^{\circ} \mathrm{F}$ )

1 acre $=43,560$ square feet $=4,840$ square yards

To convert from ${ }^{\circ} \mathrm{F}$ to ${ }^{\circ} \mathrm{C}$, subtract 32 and then multiply by $\%$.

To convert from ${ }^{\circ} \mathrm{C}$ to ${ }^{\circ} \mathrm{F}$, multiply by $\% / s$ and then add 32 . 
PROPERTIES OF ETHANOL, GASOLINE AND WATER

\begin{tabular}{|c|c|c|c|}
\hline CHEMICAL PROPERTIES & Gasoline & Ethanol & Water \\
\hline $\begin{array}{l}\text { Formula } \\
\text { Molecular Weight } \\
\text { \%Carbon (by weight) } \\
\text { \%Hydrogen (by weight) } \\
\text { \%Oxygen (by weight) } \\
\text { C/H ratio } \\
\text { Stoichiometric Air-to-Fuel Ratio }\end{array}$ & $\begin{array}{c}\mathrm{C}_{4}-\mathrm{C}_{12} \\
\text { varies } \\
85-88 \\
12-15 \\
\text { indefinite } \\
5.6-7.4 \\
14.2-15.1\end{array}$ & $\begin{array}{c}\mathrm{CH}_{3} \mathrm{CH}_{2} \mathrm{OH} \\
46.1 \\
52.1 \\
13.1 \\
34.7 \\
4.0 \\
9.0\end{array}$ & $\begin{array}{c}\mathrm{H}_{2} \mathrm{O} \\
18.015\end{array}$ \\
\hline PHYSICAL PROPERTIES & Gasoline & Ethanol & Water \\
\hline $\begin{array}{l}\text { Specific Gravity } \\
\text { Liquid Density } \mathrm{lb} / \mathrm{ft}^{3} \\
\mathrm{lb} / \text { gal } \\
\text { psi at } 100^{\circ} \mathrm{F}(\text { Reid) } \\
\text { psi at } 77^{\circ} \mathrm{F} \\
\text { Boiling Point }\left({ }^{\circ} \mathrm{F}\right) \\
\text { Freezing Point }\left({ }^{\circ} \mathrm{F}\right) \\
\text { Solubility in Water } \\
\text { Water in } \\
\left.\text { Surface Tension (dyne } / \mathrm{cm}^{2}\right) \\
\text { Dielectric Constant } \\
\text { Viscosity at } 68^{\circ} \mathrm{F}(\mathrm{cp}) \\
\text { Specific Resistivity }\end{array}$ & $\begin{array}{c}0.70-0.78 \\
43.6 \text { approx. } \\
5.8-6.5 \\
7-15 \\
0.3 \text { approx. } \\
80-440 \\
-70 \text { approx. } \\
240 \text { ppm } \\
88 \text { ppm }\end{array}$ & $\begin{array}{c}0.794 \\
49.3 \\
6.59 \\
2.5 \\
0.85 \\
173 \\
-173 \\
\text { infinite } \\
\text { infinite } \\
23 \\
24.3 \\
1.17 \\
0.3 \times 10^{6}\end{array}$ & $\begin{array}{r}54.9 \\
1.0\end{array}$ \\
\hline THERMAL PROPERTIES & Gasoline & Ethanol & Water \\
\hline $\begin{array}{l}\text { Lower Heating Value } \\
\text { Btu/lb } \\
\text { Btu/gal }\end{array}$ & $\begin{array}{c}18,900 \text { (avg) } \\
115,400 \text { (avg) }\end{array}$ & $\begin{array}{r}11,500 \\
76,152\end{array}$ & \\
\hline $\begin{array}{l}\text { Higher Heating Value } \\
\text { Btu/lb at } 68^{\circ} \mathrm{F} \\
\text { Btu/gal }\end{array}$ & $\begin{array}{c}20,260 \\
124,800\end{array}$ & $\begin{array}{l}12,800 \\
84,400\end{array}$ & \\
\hline $\begin{array}{l}\text { Heat of Vaporization } \\
\text { Btu/lb } \\
\text { Btu/gal }\end{array}$ & $\begin{array}{l}142 \\
873\end{array}$ & $\begin{array}{c}361 \\
2,379\end{array}$ & $\begin{array}{c}940 \\
7,802\end{array}$ \\
\hline $\begin{array}{l}\text { Octane Ratings } \\
\text { Research } \\
\text { Pump (Ron + Mon) } / 2\end{array}$ & $\begin{array}{c}91-105 \\
86-90\end{array}$ & $\begin{array}{c}106-108 \\
98-100\end{array}$ & \\
\hline $\begin{array}{l}\text { Flammability Limits } \\
(\% \text { by volume in air }) \\
\text { Specific Heat }\end{array}$ & $1.4-7.6$ & $4.3-19.0$ & \\
\hline $\begin{array}{l}\left(\mathrm{Btu} / \mathrm{lb}-{ }^{\circ} \mathrm{F}\right) \\
\text { Autoignition Temperature }\left({ }^{\circ} \mathrm{F}\right) \\
\text { Flash Point }\left({ }^{\circ} \mathrm{F}\right)\end{array}$ & $\begin{array}{c}0.48 \\
430-500 \\
-50\end{array}$ & $\begin{array}{c}0.60 \\
685 \\
70\end{array}$ & 1.0 \\
\hline $\begin{array}{l}\text { Coefficient of Thermal } \\
\text { Expansion at } 60^{\circ} \mathrm{F} \text { and } 1 \text { atm }\end{array}$ & 0.0006 & 0.00112 & 0.00 \\
\hline
\end{tabular}


WATER, PROTEIN, AND CARBOHYDRATE

CONTENT OF SELECTED FARM PRODUCTS

\begin{tabular}{|c|c|c|c|c|c|c|c|}
\hline Crop & $\%$ Water & \%Protein & $\begin{array}{l}\overline{7} 0 \text { Carbo- } \\
\text { hydrate }\end{array}$ & Crop & $\%$ Water & $\%$ Protein & $\begin{array}{r}\% \text { Carbo- } \\
\text { hydrate }\end{array}$ \\
\hline Apples, raw & 84.4 & 0.2 & 14.5 & Muskmelons & 91.2 & 0.7 & 7.5 \\
\hline Apricots, raw & 85.3 & 1.0 & 12.8 & Mustard greens & 89.5 & 3.0 & 5.6 \\
\hline Artichokes, French & 85.5 & 2.9 & 10.6 & Okra & 88.9 & 2.4 & 7.6 \\
\hline Artichokes, & & & & Onions, dry & 89.1 & 1.5 & 8.7 \\
\hline Jerusalem & 79.8 & 2.3 & 16.7 & Oranges & 86.0 & 1.0 & 12.2 \\
\hline Asparagus, raw & 91.7 & 2.5 & 5.0 & Parsnips & 79.1 & 1.7 & 17.5 \\
\hline Beans, lima, dry & 10.3 & 20.4 & 64.0 & Peaches & 89.1 & 0.6 & 9.7 \\
\hline Beans, white & 10.9 & 22.3 & 61.3 & Peanuts & 5.6 & 26.0 & 18.6 \\
\hline Beans, red & 10.4 & 22.5 & 61.9 & Pears & 83.2 & 0.7 & 15.3 \\
\hline Beans, pinto & 8.3 & 22.9 & 63.7 & Peas, edible pod & 83.3 & 3.4 & 12.0 \\
\hline Beets, red & 87.3 & 1.6 & 9.9 & Peas, split & 9.3 & 1.0 & 62.7 \\
\hline Beet greens & 90.9 & 2.2 & 4.6 & Peppers, hot chili & 74.3 & 3.7 & 18.1 \\
\hline Blackberries & 84.5 & 1.2 & 12.9 & Peppers, sweet & 93.4 & 1.2 & 4.8 \\
\hline Blueberries & 83.2 & 0.7 & 15.3 & Persimmons & 78.6 & 0.7 & 19.7 \\
\hline Boysenberries & 86.8 & 1.2 & 11.4 & Plums, Damson & 81.1 & 0.5 & 17.8 \\
\hline Broccoli & 89.1 & 3.6 & 5.9 & Poke shoots & 91.6 & 2.6 & 3.1 \\
\hline Brussels sprouts & 85.2 & 4.9 & 8.3 & Popcorn & 9.8 & 11.9 & 72.1 \\
\hline Buckwheat & 11.0 & 11.7 & 72.9 & Potatoes, raw & 79.8 & 2.1 & 17.1 \\
\hline Cabbage & 92.4 & 1.3 & 5.4 & Pumpkin & 91.6 & 1.0 & 6.5 \\
\hline Carrots & 8.2 & 1.1 & 9.7 & Quinces & 83.8 & 0.4 & 15.3 \\
\hline Cauliflower & 91.0 & 2.7 & 5.2 & Radishes & 94.5 & 1.0 & 3.6 \\
\hline Celery & 94.1 & 0.9 & 3.9 & Raspberries & 84.2 & 1.2 & 13.6 \\
\hline Cherries, sour & 83.7 & 1.2 & 14.3 & Rhubarb & 94.8 & 0.6 & 3.7 \\
\hline Cherries, sweet & 80.4 & 1.3 & 17.4 & Rice, brown & 12.0 & 7.5 & 77.4 \\
\hline Collards & 85.3 & 4.8 & 7.5 & Rice, white & 12.0 & 6.7 & 80.4 \\
\hline Corn, field & 13.8 & 8.9 & 72.2 & Rutabagas & 87.0 & 1.1 & 11.0 \\
\hline Corn, sweet & 72.7 & 3.5 & 22.1 & Rye & 11.0 & 12.1 & 73.4 \\
\hline Cowpeas & 10.5 & 22.8 & 61.7 & Salsify & 77.6 & 2.9 & 18.0 \\
\hline Cowpeas, undried & 66.8 & 9.0 & 21.8 & Soybeans, dry & 10.0 & 34.1 & 33.5 \\
\hline Crabapples & 81.1 & 0.4 & 17.8 & Spinach & 90.7 & 3.2 & 4.3 \\
\hline Cranberries & 87.9 & 0.4 & 10.8 & Squash, summer & 94.0 & 1.1 & 4.2 \\
\hline Cucumbers & 95.1 & 0.9 & 3.4 & Squash, winter & 85.1 & 1.4 & 12.4 \\
\hline Dandelion greens & 85.6 & 2.7 & 9.2 & Strawberries & 89.9 & 0.7 & 8.4 \\
\hline Dates & 22.5 & 2.2 & 72.9 & Sweet potatoes & 70.6 & 1.7 & 26.3 \\
\hline Dock, sheep sorrel & 90.9 & 2.1 & 5.6 & Tomatoes & 93.5 & 1.1 & 4.7 \\
\hline Figs & 77.5 & 1.2 & 20.3 & Turnips & 91.5 & 1.0 & 6.6 \\
\hline Garlic cloves & 61.3 & 6.2 & 30.8 & Turnip greens & 90.3 & 3.0 & 5.0 \\
\hline Grapefruit pulp & 88.4 & 0.5 & 10.6 & Watermelon & 92.6 & 0.5 & 6.4 \\
\hline Grapes, American & 81.6 & 1.3 & 15.7 & Wheat, HRS & 13.0 & 14.0 & 69.1 \\
\hline Lamb's-quarters & 84.3 & 4.2 & 7.3 & Wheat, HRW & 12.5 & 12.3 & 71.7 \\
\hline Lemons, whole & 87.4 & 1.2 & 10.7 & Wheat, SRW & 14.0 & 10.2 & 72.1 \\
\hline Lentils & 11.1 & 24.7 & 60.1 & Wheat, white & 11.5 & 9.4 & 75.4 \\
\hline Milk, cow & 87.4 & 3.5 & 4.9 & Wheat, durum & 13.0 & 12.7 & 70.1 \\
\hline Milk, goat & 87.5 & 3.2 & 4.6 & Whey & 93.1 & 0.9 & 5.1 \\
\hline Millet & 11.8 & 9.9 & 72.9 & Yams & 73.5 & 2.1 & 23.2 \\
\hline
\end{tabular}

Source: Handbook of the Nutritional Contents of Foods, USDA. 
TYPICAL ANALYSIS OF DISTILLERS' DRIED GRAIN SOLIDS-CORN

\begin{tabular}{lccc}
\hline & $\begin{array}{c}\text { Distillers' } \\
\text { Dried Grains } \\
(\%)\end{array}$ & $\begin{array}{c}\text { Distillers' } \\
\text { Dried Solubles } \\
(\%)\end{array}$ & $\begin{array}{c}\text { Distillers' Dried } \\
\text { Grains with Solubles } \\
\text { (\%) }\end{array}$ \\
\hline Moisture & 7.5 & 4.5 & 9.0 \\
Protein & 27.0 & 28.5 & 27.0 \\
Lot & 7.6 & 9.0 & 8.0 \\
Fiber & 12.8 & 4.0 & 8.5 \\
Ash & 2.0 & 7.0 & 4.5 \\
Amino Acids & & & \\
Lysine & & & 0.6 \\
Methionine & 0.6 & 0.95 & 0.6 \\
Cystine & 0.5 & 0.5 & 0.4 \\
Histidine & 0.2 & 0.4 & 0.6 \\
Arginine & 0.6 & 0.63 & 1.0 \\
Aspartic Acid & 1.1 & 1.15 & 1.7 \\
Threonine & 1.68 & 1.9 & 0.95 \\
Serinine & 0.9 & 0.98 & 1.0 \\
Glutamic Acid & 1.0 & 1.25 & 4.2 \\
Proline & 4.0 & 6.0 & 2.8 \\
Glycine & 2.6 & 2.9 & 1.0 \\
Alanine & 1.0 & 1.2 & 1.9 \\
Valine & 2.0 & 1.75 & 1.3 \\
Isoleucine & 1.3 & 1.39 & 1.0 \\
Leucine & 1.0 & 1.25 & 2.7 \\
Tyrosine & 3.0 & 2.6 & 0.8 \\
Phenylalanine & 0.8 & 0.95 & 1.2 \\
Tryptophan & 1.2 & 1.3 & 0.2 \\
(1) & 0.2 & 0.3 & \\
\hline (1) & & & \\
\hline
\end{tabular}

ENERGY CONTENT FOR FEED

$\begin{array}{ccc}\text { Distillers' } & \text { Distillers' } & \text { Distillers' Dried } \\ \text { Dried Grains } & \text { Dried Solubles } & \text { Grains with Solubles }\end{array}$

For Cattle:

Total digestible nutrients

Megacalories per kilogram

For Poultry:

Megacalories per kilogram

For Swine:

Megacalories per kilogram
83

2.19

2.0

2.98

80

2.32

2.75

1.84
2.62

82

2.3

3.39

Source: Feed Formulation, Distillers Feed Research Council, 1435 Enquirer Building, Cincinnati, Ohio 45202. 
PERCENT SUGAR AND STARCH IN GRAINS

\begin{tabular}{lcc}
\hline Grain & \%Sugar & \%Starch \\
\hline Barley & 2.5 & 64.6 \\
Corn & 1.8 & 72.0 \\
Grain sorghum & 1.4 & 70.2 \\
Oats & 1.6 & 44.5 \\
Rye & 4.5 & 64.0 \\
Wheat & & 63.8
\end{tabular}

Source: Composition of Cereal Grains and Forages, National Academy of Sciences publication.
COMPARISON OF RAW MATERIALS

FOR ETHANOL PRODUCTION

\begin{tabular}{|c|c|c|c|}
\hline Raw Material & $\begin{array}{c}\text { Gal } \\
\text { Ethanol }\end{array}$ & $\begin{array}{c}\text { lb } \\
\text { Protein } \\
\text { Yield }\end{array}$ & $\begin{array}{c}\text { \%Protein } \\
\text { dry }\end{array}$ \\
\hline Corn & $2.6 / \mathrm{bu}$ & $18 / \mathrm{bu}$ & $29-30$ \\
\hline Wheat & $2.6 / \mathrm{bu}$ & $20.7 / \mathrm{bu}$ & 36 \\
\hline Grain sorghum & $2.6 / \mathrm{bu}$ & $16.8 / \mathrm{bu}$ & $29-30$ \\
\hline Average starch grains & $2.5 / \mathrm{bu}$ & $17.5 / \mathrm{bu}$ & 27.5 \\
\hline $\begin{array}{l}\text { Potatoes(75\% Moist) } \\
\text { 12-14 }\end{array}$ & $1.4 / \mathrm{cwt}$ & $14.8 / \mathrm{cwt}$ & 10 \\
\hline Sugar beets & $20.3 /$ ton & $26.4 /$ ton & 20 \\
\hline Sugar cane & $17 /$ ton & -- & -- \\
\hline $\begin{array}{l}\text { Sugar beet molasses } \\
(50 \% \text { sugar })\end{array}$ & $0.35 / \mathrm{gal}$ & - & -- \\
\hline $\begin{array}{l}\text { Sugar cane molasses } \\
(55 \% \text { sugar })\end{array}$ & $0.4 / \mathrm{gal}$ & -- & -- \\
\hline
\end{tabular}

Source: National Gasohol Commission.

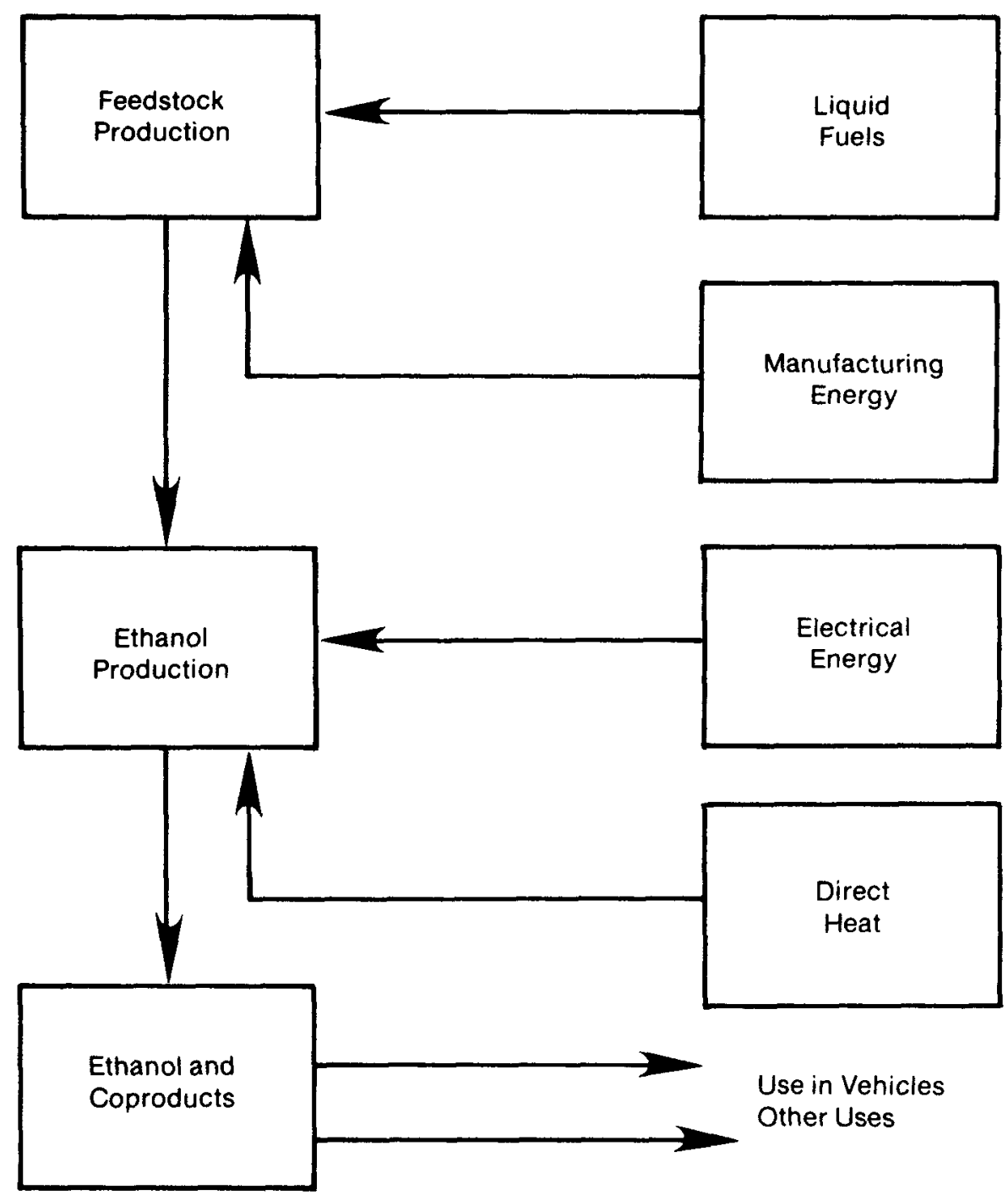

Figure D-1. Ethanol Production System Block Diagram 
Energy balances are a confusing and controversial subject. The sources of the confusion are varied but most stem from differences in opinion regarding what must be included for consideration and the proper approach to use. One of the principal sources of confusion is the type of energy balance being investigated in a given case. Some energy balance studies compare the total energy contents of the products and coproducts with the fossil energy consumed in their production. Other studies compare the amount of crude petroleum energy required to produce a given amount of petroleum substitute. Whatever types of energy are compared, an energy balance study has the objective to compare the energy input to a system with the energy output of the system. If the energy input is greater than the energy output, the energy balance is said to be negative; conversly, if the energy output of the system is greater than the energy input to the system, the energy balance is said to be positive. The causes of disparity among the various studies include differences in assumptions and reference technologies, and ambiguities in defining the boundaries of the given system under consideration.

Consider the ethanol production system shown in Figure D-1. Energy inputs to the system include the liquid fuel and manufacturing energy required to produce the feedstocks and the electrical and heat energy required to convert the feedstocks into ethanol. Note that the solar energy input is not included. Energy output of the system is in the form of ethanol which can be used in vehicles and other applications and other coproducts. To illustrate how differences in opinion among various studies can arise, consider the ethanol energy balance studies of Scheller and Mohr [1] and Reilly [2]. For 1 bushel of corn, the two studies calculate similar values for the total nonrenewable energy inputs as follows:

\section{REFERENCES}

1. Scheller, W., Mohr B. "Net Energy Balance for Ethanol Production." Presented at the 171st National Meeting of the American Chemical Society, New York, April 7, 1976.

2. Reilly, P.J. "Economics and Energy Requirements for Ethanol Production." Department of
ENERGY BALANCES

(Basis: 1 Bushel Corn)

\begin{tabular}{|c|c|c|}
\hline Energy Inputs & Scheller \& Mohr & Reilly \\
\hline Agricultural Energy & $119,000 \mathrm{Btu}$ & $135,000 \mathrm{Btu}$ \\
\hline $\begin{array}{l}\text { Direct on-farm } \\
\text { Fertilizer and } \\
\text { chemicals } \\
\text { Transport }\end{array}$ & & \\
\hline Ethanol Process Energy & $370,000 \mathrm{Btu}$ & $368,000 \mathrm{Btu}$ \\
\hline $\begin{array}{l}\text { Cooking and } \\
\text { fermentation }\end{array}$ & 64,000 & \\
\hline $\begin{array}{l}\text { Distilling and } \\
\text { centrifuging }\end{array}$ & 105,000 & \\
\hline Dehydration & 37,000 & \\
\hline Evaporation of stillage & 113,000 & \\
\hline Drying of stillage & 51,000 & \\
\hline TOTAL ENERGY INPUT & T $489,000 \mathrm{Btu}$ & $503,000 \mathrm{Btu}$ \\
\hline
\end{tabular}

From similar values of energy input, Scheller and Mohr proceed to calculate a positive energy balance, while Reilly calculates a negative energy balance. Reilly considers the outputs to be 2.6 gallons of ethanol, with a total (lower) heating value of about 191,000 Btu, and the stillage coproduct which can be given an energy credit of about 49,000 Btu [3]. Subtracting the energy input of $503,000 \mathrm{Btu}$ from the total of energy output of $240,000 \mathrm{Btu}$, Reilly obtains a negative energy balance of $260,000 \mathrm{Btu}$. However, Scheller and Mohr include, as an additional coproduct, the heat content of $75 \%$ of the corn stover to be used as energy input into the ethanol production process. This amounts to an additional energy output of about 322,000 Btu. Thus, Scheller and Mohr would calculate a total energy output of 562,000 Btu and achieve a positive energy balance of about 73,000 Btu for each bushel of corn processed into ethanol.
Chemical and Nuclear Engineering, lowa State University; January 1978.

3. Chambers, R.S., Herendeen, R.A., Joyce, J.J., and Penner, P.S. “Gasohol: Does It or Doesn't It Produce Positive Net Energy?" Science, Volume 206 (no. 4420): November 16, 1979, pp. 789-795. 


\author{
APPENDIX E \\ Resource People and \\ Organizations \\ - Associations and Organizations \\ - Colleges \\ - Component Manufacturers \\ - Consultants for Fuel From Farms \\ - Cooperative Extension Service \\ - Engineering Firms \\ - Enzyme Producers \\ - Ethanol Producers \\ - Molecular Sieve Manufacturers \\ - On-Farm Demonstration or Operating Plants \\ - Plant Packages \\ - Plant Plans \\ - State Alcohol Fuels Contacts
}

\title{
NOTICE
}

The following list of resource people and organizations is provided for your information. Neither DOE nor SERI recommend or vouch for these sources. We would appreciate receiving additions or revisions to this information. 


\section{ASSOCIATIONS AND ORGANIZATIONS}

Agriculture Council of America 1625 Eye St. N.W. Suite 708 Washington, DC 20006 202/466-3100

Alcohol-Alternative Fuel Institute 9400 Wisconsin Ave. Bethesda, MD 20014

American Agriculture Foundation

308 Second Street, SE

Washington, DC 20003

202/544-5750

American Agricultural Movement

308 Second Street, SE

Washington, DC 20003

202/544-5750

American Farm Bureau

Federation

225 Touhy Avenue

Park Ridge, IL 60068

312/399-5850

American Soybean Association

P.O. Box 27300

St. Louis, MO 63141

Beef Industry Council

National Livestock and Meat Board

444 N. Michigan Avenue

Chicago, IL 60611

$312 / 467-5520$

The Bio-Energy Council 1625 Eye Street, NW Suite 825A Washington, DC 20006 202/822-5656

Brewers Grain Institute 1754 K Street, NW Washington, DC 20006

Center for Renewable Resources 1001 Connecticut Ave., NW

Suite 510

Washington, DC 20036

Citizens Energy Project 1413 "K" Street NW 8th Floor Washington, DC 20005
Corn Development Commission

Route 2

Holdrege, NE 68949

Distillers Feed Research Council 208 Air Park Drive

P.O. Box 75153

Cincinnati, $\mathrm{OH} 45202$

606/371-1360

Domestic Technology

International

P.O. Box 2043

Evergreen, CO 80439

303/674-1597

The Fertilizer Institute 1015 18th Street NW

Washington, DC 20036

202/466-2700

The Grain Terminal Association

1667 Snelling Avenue N

P.O. Box 43594

St. Paul, MN 55164

612/646-9433

The Grange

Route 2, Box 154

Waterloo, NE 68069

402/359-5604

International Biomass Institute 1522 K Street, NW, Suite 600

Washington, D.C. 20005

202/783-1133

Iowa Corn Promotion Board

402 West Towers

1200 35th Street

West Des Moines, IA 50265

515/225-9242

Iowa Development Commission 250 Jewett Building

Des Moines, IA 50309

515/281-5360

National Alcohol Fuel Producers Association

1760 Reston Avenue

Reston, VA 22090

703/471-1611

National Association of Wheat Growers

1030 15th Street, NW, Suite 1030

Washington, DC 20005

202/466-8630
National Cattlemen's Association 1001 Lincoln Street

P.O. Box 569

Denver, CO 80203

303/861-1904

National Center for Appropriate Technology

P.O. Box 3838

Butte, MT 59701

406/494-4577

National Corn Growers Association

815 Office Park Road Suite 201

West Des Moines, IA 50265

515/225-8840

National Farmers Organization 720 Davis Avenue

Corning, IA 50841

515/322-3131

National Grange

1616 H Street, NW

Washington, DC 20006

202/628-3507

National Livestock Producers Association

307 Livestock Exchange Bldg.

Denver, CO 80216

303/623-2098

National Milk Producers

Federation

30 "F" Street, NW

Washington, DC 20001

202/393-8151

National Oil Jobbers Council 1707 H Street, NW 11th Floor Washington, DC 20006 202/331-1198

National Pork Producers Council 4715 Grande Avenue

Des Moines, IA 50312

515/277-6419

Nebraska Agricultural Products Industrial Utilization Committee P.O. Box 94831

Lincoln, NE 68509

402/471-2941 
Pork Industry Group

National Livestock and

Meat Boavd

444 N. Michigan Avenue

Chicago, IL 60611

Red River Valley Potato

Growers Association

Box 31

East Grand Forks, MN 56721

218/773-3633

Red River Valley Sugarbeet

Growers Association

1701 West View Drive

West Acres Office Park

Fargo, ND 58102

$701 / 282-0694$

Small Farm Energy Project

P.O. Box 736

Hartington, NE 68739

402/254-6893

Solar Energy Research Institute 1617 Cole Boulevard

Golden, CO 80401

303/231-1207

U.S. Beet Sugar Association

1156 15th Street, NW

Washington, DC 20005

202/296-4820

U.S. Feed Grains Council

1030 15th Street, NW, Suite 540

Washington, DC 20005

202/659-1640

The Wheat Growers

Route \#1, Box 27

Hemingford, NE 69438

308/487-3794

The WIFE Organization

Osceola, NE 68651

\section{COLLEGES}

(To Verify Course Offerings, Contact College)
Alabama
Livingston University
Livingston, AL 35470
Contact: Wayne F. Canis
205/652-9661 Ext. 245

Talladega College

627 West Battle Street

Talladega, AL 35160

Contact: Richard A. Morrison

205/362-8800

Wallace State Community

College

P.O. Box 250 A

Hanceville, AL 35077

Contact: Rayburn Williams

205/352-6403 Ext. 34

Arizona

Central Arizona College

Woodruff at Overfield Road

Coolige, AZ 85228

Contact: John Palmer

602/723-4141 Ext. 221

Central Arizona College

P.O. Box 97

Winkleman, AZ 85292

Contact: Glen F. Johnson

602/356-7864

College of Ganado

Ganado, AZ 86505

Contact: Jefferson R. Snider

602/755-3442 Ext. 30

\section{Arkansas}

Mississippi County Community College

Mid-South Energy Project

Box 1109

Blytheville, AR 72315

Contact: Christopher M.

Benson

501/762-1020 Ext. 40

North Arkansas Community

College

Pioneer Ridge

Harrison, AR 72601

Contact:

501/743-3000 Ext. 60

\section{California}

Antioch University

650 Pine Street

San Francisco, CA 94108

Contact: Brant Ingram

415/956-1688 Ext. 215
Cabrillo Community College

6500 Soquel Drive

Aptos, CA 95003

Contact: Richard Merrill

408/425-6481

California State Polytechnical University at Pomona

Pomona, CA 91768

Contact: John R. Biddle

714/598-0239

California State University at Hayward

Hayward, CA 94598

Contact: Esther Railton

451/881-3016 Ext. 3027

College of Siskiyous

800 College Avenue

Weed, CA 96094

Contact: William R. Kinkade

916/938-4463 Ext. 262

College of The Redwoods

Eureka, CA 95501

Contact: David Mills

707/443-8411 Ext. 424

East Los Angeles College

1301 Brooklyn Avenue

Monterey Park, CA 91754

Contact: Robert A. Stevenson

213/265-8855

Glendale Community College

1500 North Verdugo Road

Glendale, CA 91208

Contact: Dave Davenport

213/240-1000 Ext. 312

Indian Valley Colleges

1800 Ignacio Boulevard

Novato, CA 94947

Contact: Don Marin

415/883-2211 Ext. 200

Lake Tahoe Community College

2659 Lake Tahoe Boulevard

P.O. Box 14445

South Lake Tahoe, CA 95702

Contact: Dave Bainbridge

916/541-4660 Ext. 30

Modesto Jr. College

Modesto, CA 95350

Contact: Ron Alves

209/526-2000 Ext. 311 
Saddleback Community

College District

28000 Marquerite Parkway

Mission Viejo, CA 92692

Contact: John Batok

714/831-4819

San Joaquin Delta College

5151 Pacific Avenue

Stockton, CA 95207

Contact: Gary Blomgren

209/478-2011 Ext. 322

Stanford University

Stanford, CA 94305

Contact: Channing Robertson

415/497-4906

University of California at Davis

Davis, CA 95616

Contact: Paul Craig

916/752-0360

University of California at

San Diego

La Jolla, CA 92093

714/452-4706

Victor Valley College 58422 Bear Valley Road

Victorville, CA 92392

Contact: Kermit E. Irby

714/245-4271 Ext. 238

West Hills Community College 300 Cherry Lane

Coalinga, CA 93210

Contact: Robert Gibson

209/935-0801 Ext. 225

\section{Colorado}

Colorado State University

Fort Collins, CO 80523

Contact: S. Karaki

303/491-8617

Lamar Community College

2401 South Main

Lamar, CO 81052

Contact: Bill Henderson

303/336-2248

Mesa College

Box 2647

Grand Junction, CO 81502

Contact: Woodrow Ramsey

303/248-1476
Pikes Peak Community College

5675 South Academy Blvd.

Colorado Springs, CO 80911

Contact: Robert J. Earle

303/576-7711 Ext. 217

University of Colorado at Boulder

Boulder, CO 80309

Contact: Dennis R. Holloway

303/492-7497

Connecticut

Central Connecticut State College

1615 Stanley Street

New Britain, CT 06050

Contact: Thattil J. Devassy

203/827-7280

Fairfield University

Fairfield, CT 06430

Contact: Victor Newton

203/255-5411 Ext. 2564

Delware

Delaware Tech. and Community

College, Terry Campus

1832 North Dupont Parkway

Dover, DE 19901

Contact: Bob Adams

302/678-5401

\section{District of Columbia}

George Washington University

725 23rd Street, NW

Washington, DC 20052

Contact: W. Jackson

202/676-6749

\section{Florida}

Brevard Community College

1519 Clearlake Road

Cocoa, FL 32922

Contact: Philip Stokes

305/632-1111 Ext. 407

Broward Community College 1000 Coconut Creek Boulevard

Pompano Beach, FL 33063

Contact: Ulmer

305/972-9100 Ext. 2460

Florida International University

Miami, FL 33199

Contact: John H. Parker

305/522-2605
Florida State University

Tallahassee, FL 32306

Contact: R. H. Davis

904/644-2867

Saint Augustine Technical Center Collins Avenue at Delmonte Dr. St. Augustine, FL 32084

Contact: Ken Todd

904/824-4401 Ext. 78

Stetson University

Deland, FL 32720

Contact: E.C. Coolidge

904/734-4121 Ext. 244

University of North Florida

4567 St. Johns Bluff Road

Jacksonville, FL 32216

Contact: Ray Bowman

\section{Georgia}

Georgia Institute of Technology Atlanta, GA 30332

Contact: S. M. Jeter

404/894-3351

University of Georgia

Athens, GA 30602

Contact: B. Derrell McLendon 404/549-7527

Idaho

College of Southern Idaho

315 Falls Avenue West

Twin Falls, ID 83301

Contact: James Taylor

208/733-9554

Idaho State University

Box 8088

Pocatello, ID 83209

Contact: L. E. Corey

208/236-3975

University of Idaho

Moscow, ID 83843

Contact: James M. Cassetto

208/885-6492

\section{Illinois}

Chicago State University 95 95th Street and King Drive Chicago, IL 60628

Contact: D. W. Appenbrink 312/995-2339 
Eureka College

300 College Avenue

Eureka, IL 61520

Contact: R. J. Eichenberger

309/467-3721 Ext. 241

Illinois Wesleyan University

210 East University Street

Bloomington, IL 61701

Contact: Gary Kessler

309/556-3004

Kankakee Community College

Box 888

Kankakee, IL 60901

Contact: Kris Mathers

815/944-5385

Lake Land Community College

South Route 45

Matoon, IL 61938

Contact: Robert D. Webb

217/235-3131

Lincoln Land Community College

Springfield, IL 62708

Contact: Robert Poorman

217/786-2200

Loyola University of Chicago

820 North Michigan Avenue

Chicago, IL 60611

Contact: Raymond W. Nackoney

312/670-3000 Ext. 759

Roosevelt University

430 South Michigan

Chicago, IL 60605

Contact: M. Goran

312/341-3738

Southern Illinois University at

Carbondale

Carbondale, IL 62901

Contact: Richard E. Archer

618/453-5761 Ext. 32

University of Illinois at Urbana-

Champaign

Urbana, IL 61801

Contact: Gene C. Shove

217/333-6762

Western Illinois University

Macomb, IL 61455

Contact: John Shaver

309/298-1258
Wheaton College

Wheaton, IL 60187

Contact: J. H. Kraakevik

312/682-5007

\section{Indiana}

Indiana State University

Terre Haute, IN 47809

Contact: William G. Turner

812/232-6311 Ext. 2193

Indiana Vocational Technical

College at Muncie

4100 Cowan Road

Muncie, IN 47302

Contact: Jerry Bunch

317/289-2291 Ext. 33

Purdue University

West Lafayette, IN 47907

Contact: G. H. Krockover

317/493-9526

Tri-State University

Angola, IN 46703

Contact: Henry Tucker

219/665-3141 Ext. 253

Vincennes University

Vincennes, IN 47591

Contact: Daryle Riegle

812/885-4197

lowa

Des Moines Area Community College

2006 South Ankeny Boulevard

Ankeny, IA 50021

Contact: Gordon N. Rowe

515/964-6266

Eastern Iowa Community College

2804 Eastern Avenue

Davenport, IA 52803

Contact: Robert Illingsworth $319 / 242-6841$

Iowa Central Community College 330 Avenue $M$

Fort Dodge, IA 50501

Contact: James C. Royce

515/576-7201 Ext. 148
Marshall Town Community

College

3700 South Center

Marshalltown, IA 50158

Contact: Dennis Kethenbeutel

515/752-7106 Ext. 45

Northwest Iowa Technical College

Highway 18 West

Sheldon, IA 51201

Contact: Larry Sturdevant

712/324-2587 Ext. 78

Scott Community College

Belmont Road

Bettendorf, IA 52722

Contact: Myron Hummel

319/359-7531 Ext. 259

University of Dubuque

2050 University Avenue

Dubuque, IA 52001

Contact: David B. Straley

319/589-3142

University of Iowa

Iowa City, IA 52242

Contact: Karl Lonngren

319/353-3696

\section{Kansas}

Colby Community College

1255 South Range

Colby, KS 67701

Contact: Gene Ostmeyer

913/462-3984

Dodge City Community College

U.S. 50 Bypass and 14th Avenue

Dodge City, KS 67801

Contact: Ronald G. Albrecht

316/225-1321 Ext. 239

\section{Kentucky}

Paducah Community College

Box 1380

Paducah, KY 42001

Contact: Donald Clemons

$502 / 442-6131$

University of Louisville

Louisville, KY 40292

Contact: Dan Ochs

502/588-6591 
Louisiana

Louisiana State University and $A$ and $M$ College

Baton Rouge, LA 70803

Contact: Clayton Callihan 504/388-1426

Nicholls State University

P.O. Box 2031

Thibodaux, LA 70301

Contact: Carey Flowers

504/446-8111 Ext. 301

\section{Maryland}

Cecil Community College 1000 North East Road North East, MD 21901 Contact: William Charlton 301/287-6060 Ext. 251

Harford Community College 401 Thomas Run Road Bel Air, MD 21014 Contact: Dale Rhodes $301 / 836-4173$

\section{Maryland}

Montgomery College 51 Mannakee Street Rockville, MD 20850 Contact: William Davis 301/279-5232

United States Naval Academy Annapolis, MD 21402 Contact: Chih Wu 301/267-3186

University of Maryland, Eastern Shore

Princess, MD 21853

Contact: Gian Gupta

301/651-2200 Ext. 327

\section{Massachusetts}

Bentley College Waltham, MA 02154

Contact: B. Aghassi

617/891-2236

Clark University 450 Main

Worchester, MA 01610

Contact: Albert Gottlieb 617/793-7439
Fitchburg State College

160 Pearl Street

Fitchburg, MA 01420

Contact: Erling Lanson

617/345-2151 Ext. 184

Holyoke Community College 303 Homestead Avenue

Holyoke, MA 01040

Contact: Andrew Ellis

413/538-7000 Ext. 430

North Adams State College

Church Street

North Adams, MA 01247

Contact: W. Seeley

413/664-4511 Ext. 457

Springfield Tech. and Community College One Armory Square Springfield, MA 01105 Contact: Robert Geidz 413/781-6470

Worcester State College 486 Chandler Street Worcester, MA 01602 Contact: Daniel E. Dick 617/752-7700 Ext. 136

\section{Michigan}

Central Michigan University

Mt. Pleasant, MI 48859

Contact: Louis Ecker

517/774-3996

Delta College

Markinaw Road

University Center, MI 48710

Contact: Paul Koblas

517/686-9256

Glen Oaks Community College

Route 1 Shimmel Road

Centreville, MI 49032

Contact: Wayne Moss

616/467-9945 Ext. 217

Jackson Community College

Jackson, MI 49201

Contact: V. A. Hanson

517/787-0800 Ext. 172p

Jordan College

1460 Laughlin Street

Grand Rapids, MI 49504

Contact: Alan O. Martin

616/453-5417
Michigan State University

East Lansing, MI 48824

Contact: A. M. Dhanak

$517 / 355-5160$

Mott Community College 1401 East Court Street

Flint, MI 48503

Contact: Charles Roched 313/762-0237

Northern Michigan University Presque Isle Avenue 410 B Cohodas Adm. Center Marquette, MI 49855

Contact: Richard V. Allenstein 906/227-2911

Saint Clair County Community College

323 Erie Street

Port Huron, MI 48060

Contact: Phil Zochowski

313/984-3881 Ext. 288

Wayne State University

5050 Cass

Detroit, MI 48202

Contact: Trilochan Singh

313/577-3885

Lakewood Community College White Bear Lake, MN 55110

Contact: Robert Wischmann

612/770-1331 Ext. 111

Redwind Energy Education Center

Highway 16 and 19

Red Wing, MN 55066

Contact: Pat Enz

612/388-3594 Ext. 2

Saint Cloud State University

College of Industry

Department of Industrial Education

Saint Cloud, MN 56301

Contact: Anthony Schwaller 612/255-2118

Southwest State University Marshall, MN 56258

Contact: Richard Spencer 507/537-7217 
University of Minnesota at

Minneapolis-St. Paul

Dept. of Mechanical Engineering

111 Church St., SE

Minneapolis, MN 55455

Contact: R. J. Goldstein

612/373-3302

University of Minnesota

Technical College at Crookston

Crookston, MN 56716

Contact: Kent Freberg

218/281-6510 Ext. 265

\section{Mississippi}

NW Mississippi Jr. College.

Highway 51

North Senatobia, MS 38668

Contact: William Oakley

$601 / 562-5262$

University of Mississippi

University, MS 38677

Contact: John A. Fox

$601 / 232-7219$

University of Southern

Mississippi

Southern Station

Hattiesburg, MS 39401

Contact: Charles R. Brent

601/266-7212

Wood Junior College

P.O. Drawer C

Mathiston, MS 39752

Contact: Barbara Crawford

601/263-5352

\section{Missouri}

Crowder College

Neosho, MO 64850

Contact: Art Boyt

$417 / 451-4700$

Drury College

900 North Benton Avenue

Springfield, MO 65802

Contact: Howard Hufford

$417 / 887-4894$

Saint Louis Community College

at Forest Park

5600 Oakland Avenue

Saint Louis, MO 63110

Contact: Paul D. Nelson

314/644-9285
Southeast Missouri State

University

Cape Girardeau, MO 63701

Contact: John E. Tansil

314/651-2157

State Fairground Community College

Sedalia, MO 65301

Contact: Marvin Fielding

816/826-7100, Ext. 60

\section{Montana}

Montana College of Mineral Science Technology

Butte, MT 59701

Contact: Richard Alexander

406/792-8321 Ext. 328

Nebraska

Grand Island Education Center, CICCA

3134 West Highway 34

Grand Island, NE 68801

Contact: Marion C. Kinkade

308/384-5220 Ext. 270

Peru State College

Peru, NE 68421

Contact: Daryl Long

402/872-3815 Ext. 214

South East Community College

Milford, NE 68405

Contact: Dean Roll

402/761-2131

New Hampshire

Dartmouth College

Hanover, NH 03755

Contact: A. E. Converse

603/646-2606

New Hampshire Vocational

Technical College, Manchester

1066 Front Street

Manchester, NH 03102

Contact: David Magnon

\section{New Jersey}

Bergen Community College

400 Paramus Road

Paramus, NJ 07652

Contact: Neil Ender

201/447-1500 Ext. 300
Kean College

Morris Avenue

Union, NJ 07083

Contact: Joseph Clinton

201/527-2342

Rider College

P.O. Box 6400

Lawrenceville, NJ 08638

Contact: Gerald Witt

609/896-5091

\section{New Mexico}

Navajo Community College

Box 580

Shiprock, NM 87420

Contact: Raymond Housh

505/268-5291

\section{New York}

Broome Community College

Binghamton, NY 13902

Contact: Norm Herbert

$607 / 772-5078$

Columbia University, Main Division

New York, NY 10027

Contact: Harry Gregor

212/280-4716

Cornell University

B-7 Day Hall

Ithaca, NY 14853

Contact: Albert George

607/256-7540

Genesee Community College

One College Road

Batavia, NY 14020

Contact: Ray Chaya

716/343-0055 Ext. 228

New York University

32 Washington Place, Room 42

New York, NY 10003

Contact: Marshall S. Hahn

212/598-3356

Onondaga County Community College

Syracuse, NY 13215

Contact: Andreas Paloumpis

315/469-7741 
Pratt Institute

215 Ryerson Street

Brooklyn, NY 11205

Contact: Brent M. Peter

212/636-3650

Rensselaer Polytechnic Institute

Troy, NY 12181

Contact: Frederick Bordt

518/270-6543

State University of New York at Fredonia

Fredonia, NY 14063

Contact: J. J. Connelly

716/673-3305

State University of New York, Agricultural

State University of New York, Agricultural and

Technical College

Canton, NY 13617

Contact: Carson A. Emhof

315/386-7313

Westchester Community College

75 Grasslands Road

Valhalla, NY 10595

Contact: Diana Lee

914/347-6914

\section{North Carolina}

Appalachian State University

101 Sanford Hall

Boone, NC 28608

Contact: Karl C. Mamola

704/262-3090

Caldwell Community College and

Technical Institute

1000 Hickory Boulevard

Hudson, NC 28638

Contact: David Monroe

704/728-4323 Ext. 239

Martin Community College

Kehukee Park Road

Williamston, NC 27892

Contact: Geoffrey Balkam

919/792-1521 Ext. 249

Pitt Community College

Box Drawer 7007

Greenville, NC 27834

Contact: Mareus King

919/756-3130 Ext. 274
Technical College of Alamance

P.O. Box 623

Haw River, NC 27258

Contact: David M. Payne

919/578-2002 Ext. 29

Vance-Granville Community College

P.O. Box 917

Henderson, NC 27536

Contact: Daniel W. Guin

919/492-2061

Western Carolina University

Cullowhee, NC 28723

Contact: Don Wood

704/227-7397

North Dakota State School of Science

Wahpeton, ND 58075

Contact: Claire T. Blikre

701/671-2221

North Dakota

University of North Dakota

Grand Forks, ND 58202

Contact: W. A. Dando

$701 / 777-4588$

Ohio

Bowling Green State University Bowling Green, $\mathrm{OH} 43403$

Contact: A. J. PaLumbo

419/372-2436

Cleveland State University

24th Street and Euclid Avenue

Cleveland, $\mathrm{OH} 44115$

Contact: Rama S. R. Govla

216/687-2567

Miami University

High Street

Exford, OH 45056

Contact: Fuller Moore

513/529-5811

University of Akron

Buchtel Avenue

Akron, OH 44325

Contact: Jim L. Jackson

216/657-2815

Wittenberg University

Springfield, $\mathrm{OH} 45501$

Contact: Nelson Sartoris

$513 / 327-7432$

\section{Oklahoma}

Panhandle State University

Box 430

Goodwell, OK 73939

Contact: Gene Reeves

405/742-2121

\section{Oregon}

Eastern Oregon State College 8th and $K$ Streets

LaGrande, OR 97850

Contact: Paul Stephas

503/963-2171 Ext. 310

\section{Pennsylvania}

King's College

River Street

Wilkes-Barre, PA 18711

Contact: J. Rakowski

717/824-9931 Ext. 237

LeHigh County Community College

2370 Main Street

Schnecksville, PA 18078

Contact: J. Robert Walker

215/799-2121 Ext. 1500

Mansfield State College

Mansfield, PA 16933

Contact: George Mullen

$717 / 662-4275$

\section{South Carolina}

Chesterfield-Marlboro Technical College

P.O. Drawer 928

Cheraw, SC 29520

Contact: Donald R. Smith

803/537-5286

Horry Georgetown Technical College

Highway 501 East

Conway, SC 29526

Contact: Wade Harper

803/347-3186 Ext. 261 


\author{
South Dakota \\ Ogalala Sioux Community \\ College \\ Box 439 \\ Pine Ridge, SD 57700 \\ Contact: Roberta Barbalace \\ 606/867-5110
}

Northern State College

Aberdeen, SD 57401

Contact: Terry Richardson

605/622-2571

South Dakota State University

Brookings, SD 57007

Contact: Paul Middaugh

605/688-4116

University of South Dakota, Main Campus

Vermillion, SD 57069

Contact: Robert W. Jones

605/677-5649

\section{Tennessee}

State Technical Institute at

Knoxville

3435 Division Street,

P.O. Box 19802

Knoxville, TN 37919

Contact: Dwight Magnuson

$615 / 637-4262$

\section{Texas}

East Field College

3737 Matley Drive

Mesquite, TX 75150

Contact: W. Tim Hughes

214/756-3208

Grayson County Junior College

Denison, TX 75020

Contact: Clifford Wood

214/465-6030 Ext. 227

Navarro Jr. College

Box 1170

Corsicana, TX 75110

Contact: Darrell Raines

214/874-6501

Richland College

12800 Abrams Road

Dallas, TX 75243

Contact: J. H. Daugherty

214/746-4585
Texas A \& I University

Kingsville, TX 78363

Contact: Lionel D. Hewett

512/959-2618

Texas Technical University

Lubbock, TX 79409

Contact: Steven R. Beck

$806 / 742-3553$

University of Texas at Dallas

P.O. Box 688

Richardson, TX 75080

Contact: Ervin J. Fenyves

214/690-2971

Utah

University of Utah

Salt Lake City, UT 84112

Contact: R. F. Boehm

801/581-6441

Vermont

Castleton State College

Castleton, VT 05735

Contact: J. V. Freeman

802/468-5611 Ext. 201

University of Vermont

Burlington, VT 05404

Contact: Grant Wells

802/656-2000

\section{Virginia}

James Madison University

Harrisonburg, VA 22807

Contact: Kent Moore

703/433-6338

Old Dominion University

Box 6173 Hampton Blvd.

Norfolk, VA 23508

Contact: Gary R. Crossman

804/440-3766

Radford University

Radford, VA 24142

Contact: Franklin M. Jones

703/731-5145

Virginia Polytechnic Institute and

State University

Blacksburg, VA 24061

Contact: David H. Vaughan

703/961-5038
Washington

Skagit Valley College

2405 College Way

Mount Vernon, WA 98273

Contact: Douglas N. Campbell

206/428-1195

The Evergreen State College

Olympia, WA 98505

Contact: Rob Knapp

206/866-6679

Washington State University

Box 708

Chehalis, WA 98532

Contact: Larry Gueck

206/748-9121, Ext. 212

University of Washington

Seattle, WA 98195

Contact: James S. Bechtel

206/543-2730

Whatcam Community College

Northwest Road

Bellingham, WA 98225

Contact: Douglas N. Campbell

206/384-1541

\section{West Virginia}

University of Charleston

2300 MacCorkle Avenue, SE

Charleston, WV 25304

Contact: Jesse Spencer

304/346-9471 Ext. 226

West Virginia University

Morgantown, WV 26506

Contact: Paul W. DeVore

304/392-3803

\section{Wisconsin}

District One Technical Institute

Eau Claire, WI 54701

Contact: Thomas A. Dougherty

715/836-2828

Marquette University

1515 West Wisconsin Avenue

Milwaukee, WI 53233

Contact: S. V. Jaskolski

414/224-6820 
University of Wisconsin at

River Falls

River Falls, WI 54022

Contact: C. M. Jones

715/425-3950 Ext. 3985

University of Wisconsin at

Whitewater

800 West Main Street

Whitewater, WI 53190

Contact: Carl W. Shinners

414/472-1075

\section{Wyoming}

Eastern Wyoming College 3200 West C

Torrinton, WY 82240

Contact: Charles Rogers

307/532-7111

University of Wyoming

Laramie, WY 82071

Contact: V. G. Sindt

307/766-6381

\section{Virgin Islands}

College of the Virgin Islands

St. Thomas, VI 00801

Contact: Michael Canoy

\section{COMPONENT}

MANUFACTURERS

A. O. Smith

P.O. Box 29

Kankakee, IL 60901

815/933-8241

Ace Pump Corporation

1650 Channel Avenue

Memphis, TN 38113

901/948-8514

Acem International Equipment and Supply Co., Inc.

P.O. Box 6097

Spartanburg, SC 29304

Ad-Pro Industries, Inc.

3110 Southwest Freeway,

Suite 130

Houston, TX 77098.

$713 / 523-4441$

Ag-Bag Corporation

P.O. Box 418

Astoria, OR 97103

503/325-2488
Agri-Fuel

P.O. Box 26581

Denver, CO 80226

303/989-3343

Agri-Fuel Corp.

200 Market Building

Suite 961

Portland, OR 97201

502/233-6660

Agri-Stills of North America 3550 Great Northern Avenue Springfield, IL 62707

217/787-4233

Agrihol, Inc.

Box 18

Rosholt, SD 57260

605/537-4252

Agro-City Incorporated

Route 1, Box 861

Cedar Hill, TX 75104

214/296-2401

Agrodyne

P.O. Box 934

Idaho Falls, ID 83401

208/524-1000

Agrohol Systems Incorporated

6120 Earle Brown Drive

Minneapolis, MN 55430

$612 / 560-4282$

Aidco Maine Corp.

Orr's Island, ME 04066

207/833-6700

Alco-Fuels, Inc.

5118 Valley Road

Fairfield, AL 35054

205/787-3835

Alcogas, Inc.

5200 South Quebec

Suite 201

Englewood, CO 80111

303/572-9300, 770-9667

Alcohol Fuel Works

8549 Sunset Avenue

Fair Oaks, CA 95628

916/961-2896, 988-7569

Alcohol Plant Supply Company

P.O. Box 248

Sherwood, OR 97140

503/244-3230
Alcohol Power Consultant

Rural Route

Linden, IA 50146

515/744-2086

Alcohol Production Engineering Company

7201 West Vickery Street

Fort Worth, TX 76116

$817 / 731-4121$

Alcohol Technology, Inc.

P.O. Box 1489

Rockdale, TX 76567

512/446-6777

Alcomotive, Inc.

101 South Cleveland

Farmersville, IL 62533

217/227-3227

Alltech, Inc.

271 Gold rush Road

Lexington, KY 40503

606/276-3414

Alpha Tank and Metals Mfg. Co. 5001 South 38th Street

St. Louis, MO 83116

314/481-6790

Alternate Energy Association of the Ozarks

1200 South Maryland

Springfield, MO 65807

417/869-8930, 623-4289

Alternative Fuels, Inc.

2880 Southwest 4th Avenue

Ontario, OR 97914

503/881-1317

Amber Laboratoraies

6101 North Teutonia Avenue

Milwaukee, WI 53209

$414 / 462-3700$

American Agri-Fuels

Corporation

1006 Grand Avenue, 10th Floor

Suite 1010

Kansas City, MO 64106

816/221-0070

American Alloy Steel, Inc.

Dept. TR

2070 Steel Drive

Tucker, GA 30084

404/934-1681 
American Homegrown Fuel Company

864-B Haight Street

San Francisco, CA 94117

415/621-6338

American Lewa, Inc.

11 Mercer Road

Natick, MA 01760

617/653-0229

Ametek

2300 West Marshall Drive

Grand Prairie, TX 75201

214/647-2626

Anheuser-Busch, Inc., Yeast

Products Research

72 Pestalozzi Street

St. Louis, MO 63118

314/577-2000

Applied Technologies, Inc., 722 East South Street

Hastings, NE 68901

$402 / 463-0521$

Archer Daniels Midland 1350 Waconia Avenue, SW Cedar Rapids, IA 52406 319/398-0600

Arlon Industries, Inc.

P.O. Box 347

Sheldon, IA 51201

Arrow Tank Co., Inc.

16 Barnett Street

Buffalo, NY 14215

Astro Metallurgical Corporation

3225 Lincoln Way West

Wooster, OH 44691

216/264-8639

Atec Energy Corporation 1916 Old Middlefield Way

Mt. View, CA 94043

415/961-6500

Automatic Equipment

Manufacturing Company

P.O. Box P

Pender, NE 68047

402/385-3051

Automation Products, Inc. 3030 Max Roy Street

Houston, TX 77008

713/869-0361
ACR Process Corporation

602 East Green Street

Champaign, IL 61820

217/351-7510

ARI Industries, Inc.

9000 King Street

Franklin Park, IL 60131

312/671-0511

Barber-Colman Company

1300 Rock Street

Rockford, IL 61101

815/877-0241

Behlen Manufacturing Company

P.O. Box 569

Columbus, NE 68601

402/564-3111

Bell and Gossett

8200 North Austin Avenue

Morton Grove, IL 60053

312/966-3700

Beloit Corporation

Dalton, MA 01226

413/443-5621

Best Welding and Fabrication

Service, Inc.

Route L, Box 6A

Lockport, LA 70374

504/693-8656

Biocon (U.S.), Inc.

261 Midland

Lexington, KY 40507

606/254-0517

Blue Bell Equipment Company 3110 Maple Drive, NE

Atlanta, GA 30305

404/237-9678

Bohler Brothers of America, Inc. 1625 West Belt North

Houston, TX 77043

$713 / 465-8376$

Brown Fintube Company

P.O. Box 2739

Tulsa, OK 74101

918/584-2621

C. J. Wennberg, Inc.

1260 Winchester Parkway, Suite 209

Smyrna, GA 30080

404/433-1765
Caldwell Tanks, Inc.

4000 Tower Road

Louisville, KY 40219

502/964-3361

Cellulose Catalyst Company 1714 Gervais Avenue

North St. Paul, MN 55109

612/777-8545

Central Fabricators, Inc.

408-418 Poplar Street

Cincinnati, OH 45214

513/621-1240

Chem-Pro Equipment

Corporation

27 Daniel Road

Fairfield, NJ 07006

201/575-1924

Chemapec, Inc.

230 Crossways Park Drive

Woodbury, NY 11797

516/364-2100

Chief Industries, Inc.

West Highway 30

Grand Island, NE 68801

308/382-8820

Circle Bin Sales, Inc.

Rural Route 1

New Market, IA 51646

712/585-3430

Clary Corporation

917 Parkway Dr.;

Grand Prairie, TX 75051

214/647-4156

Coaltech, Inc.

P.O. Box 1602

York, PA 17405

$717 / 767-6717$

Compost Making Enzymes

R.R. 1, Box 114

Harton, KS 66439

913/486-3302

Conameter Corporation

9 Democrat Way

Gibbsboro, NJ 08026

609/783-7675

Craisner, Inc.

P.O. Box 94662

Schaumburg, IL 60193

312/830-0060 
Cross Manufacturing, Inc.

204 West Simpson

Pratt, KS 67124

316/672-7484

CCI Industries

27 West 990 Industrial Road

Barrington, IL 60010

312/381-7441

$\mathrm{D}$ and $\mathrm{N}$ Distillers

Route 2, Box 41

Breman, AL 35033

205/287-1134

Damrow Co.

196 Western Avenue

Fond du Lac, WI 54935

414/922-1500

De Laval Separators

350 Dutchess Turnpike

Poughkeepsie, NY 12602

914/452-1000

Doerr Metal Products

320 East sixth

Larned, KS 67550

316/285-2174

Double "A" Quality Products Co.

P.O. Box 1107, Highway 65 South

Albert Lea, MN 56007

Double "L" Mfg., Inc.

P.O. Box 533

American Falls, ID 83211

208/226-5592

Dwyer Instruments, Inc.

Jct. Ind. 212 and U.S. 12

Michigan City, IN 46360

219/872-9141

DCI

600 North 54th Avenue

St. Cloud, MN 56301

$612 / 252-8200$

Easy Engineering, Inc.

3353 Larimer Street

Denver, CO 80205

303/893-8936

Eaton Metal Products Company 4800 York Street

Denver, CO 80216

303/825-7204
Economy Alcohol Fuel Supplies

4853 Joyce Drive

Dayton, $\mathrm{OH} 45439$

$513 / 299-4283$

Elmer G. Carlson and Associates

3624 Leavenworth Street

Omaha, NE 68105

402/345-3090

Elwood Energy, Inc.

P.O. Box 321

Plainfield, IL 60544

815/436-7463

Energy Complexes, Inc.

4200 South Louis, Suite 303

Sioux Falls, SD 57106

605/331-2555

Energy Independence

Corporation

P.O. Box 56

Montrose, MN 55363

612/675-3131

Energy Restoration, Inc.

1201 J Street, Suite 101

Lincoln, NE 68508

402/475-9237

Enterprise Steelfat, Inc.

115 West 7 th Avenue

Oshkosh, WI 54901

414/235-1250

Ernst Gage Co.

250 South Livingston Avenue

Livingston, NJ 07039

201/992-1400

Ethylene Corporation

7401 Phillips Hwy.

Jacksonville, FL 32216

904/731-8290

Extech International Corporation

114 State Street

Boston, MA 02109

617/227-7090

EMCO Wheaton, Inc.

Chamberlain Blvd.

Conneaut, $\mathrm{OH} 44030$

216/599-8151

Fanco, Inc.

317 East Cotton Street

Longview, TX 75606

$713 / 757-8120$
Fisher Scientific Company

711 Forbes Avenue

Pittsburgh, PA 15219

412/562-8300

Flow Technology, Inc.

4250 East Broadway Road Phoenix, AZ 85040

602/268-8776

Fuels Development and

Manufacturing, Inc.

418 South 12th

Caldwell, ID 83605

208/459-1215, 459-1245

G. B. Fermentation Industries, Inc.

One North Broadway

Des Plaines, IL 60016

312/827-9700

Gaston County Sales and

Service Corporation

P.O. Box 308

Stanley, NC 28164

704/263-4765

Georgia-Pacific

P.O. Box 1236

Bellingham, WA 98225

$503 / 222-5561$

Glitsch, Inc.

P.O. Box 226227

Dallas, TX 75266

214/631-3841

Gorman-Rupp Company

15601 19th Place West

Sand Springs, OK 74063

918/245-9555

Granco-Clark, Inc.

7298 North Storey Road

Belding, MI 48809

616/794-2600

Hamilton Tank Company

1520 Bender Avenue

Hamilton, $\mathrm{OH} 45011$

513/863-2062

Harrison and Ellis Corporation

P.O. Box 528

Cairo, GA 31728

912/377-4482 
Harwil Corporation

1548C 17th Street

Santa Monica, CA 30404

213/829-2310

Homak, Inc.

P.O. box 3242

Abilene, TX 79604

915/673-4015

Honeywell

1700 West Highway 36

Roseville, MN 55113

612/378-4178

Hot Energy Shoppe
490 West 300 South
Provo, UT 84601
$801 / 377-8130$

Hydro-Thermal Corporation 1263 North 70th Street

Milwaukee, WI 53213

414/476-7711

Independent Fuels Company

741 Merus Court

Fenton, MO 63026

314/343-0508

Industrial Boiler Company, Inc.

221 Law Street

Thomasville, GA 31792

912/226-3024

Industrial Fiberglas, Inc.

3065 West 2100

Salt Lake City, UT 84119

801/972-6658

Industrial Innovators, Inc.

P.O. Box 387

Ashford, AL 36312

205/899-3314

Ingersoll-Rand

P.O. Box 668

Hastings, NE 68901

402/463-6821

Ingersoll-Rand Air Center

5805 East 39th Avenue

Denver, CO 80207

303/399-1585

Insta-Pro

10301 Dennis Drive

Des Moines, IA 50322

515/276-4524
International Fuel Systems

P.O. Box 7232

Overland Park, KS 66207

913/341-8211

International Stills, Inc.

P.O. Box 240

Lake City, MN 55041

612/345-5368

Ionics, Inc.

P.O. Box 99

Bridgeville, PA 15017

412/343-1040

$\mathrm{J}$ and $\mathrm{M}$ Distillers

Route 2, Box 151

Maynard, MN 56260

612/367-2905

J. E. Stabley

2361 Druck Valley Road

York, PA 17402

$717 / 755-4190$

Jacobson Machine Works, Inc.

2445 Nevada Avenue, N

Minneapolis, MN 55429

$612 / 544-3781$

Jay Bee Manufacturing, Inc.

P.O. Box 986

Tyler, TX 75701

214/597-9343

Jaybee Associates, Inc.

2315 Bob Wallace Avenue

Suite 102

Huntsville, AL 35805

205/533-1021

John's Stills

6878 Kent Drive

Baker, LA 70714

504/654-3126

Jones and Hunts, Inc.

21 Pheasant Run Road

Orwigsburg, PA 17361

717/366-1035

K B K Industries, Inc.

East Highway 96

Rush Center, KS 67575

913/372-4331

Kar-Ad Manufacturing Company 1626 South Greenwood

Park Ridge, IL 60068

312/823-2419
Kargard Industries 2121 Cleveland Avenue

Marinette, WI 54143

715/735-9311

$L$ and $A$ Engineering and Equipment, Inc.

4124 South Soderquist Road

Turlock, CA 95380

209/632-3191

Larry Goad and Company, Inc.

260 Old State Road

Ellsville, MO 63011

314/394-6334

Lasker Boiler and Engineering Corporation

3201 South Wolcott Avenue

Chicago, IL 60608

312/523-3700

Lipton Steel and Metal

Products, Inc.

458 South Street

Pittsfield, MA 01201

413/499-1661

Liquid Control Corporation

7576 Freedom Avenue

North Canton, OH 44720

216/494-1313

Louisiana Milling Company

P.O. Box 15903

Baton Rouge, LA 70895

504/275-9741

Lucas engineering, Inc.

4205 Fox Street

Denver, CO 80216

303/458-7460

$M$ and W Gear Company

Route 47 South

South Gibson City, IL 60936 217/784-4261

M-E-C Company

Box 330

Neodesha, KS 66757

316/325-2673

Mandil Corporation Colorado Technical Center 12687 West Cedar Drive

Lakewood, CO 80229

303/989-7155 
Manning and Lewis Engineering Company

675 Rahway Avenue

Union, NJ 07083

201/687-2400

Marlin Car Care, Inc.

P.O. Box 1009

Marlin, TX 76661

817/883-3491

Mason Street Fabricating

Company, Inc.

1645 North Railroad Avenue

Decatur, IL 62525

217/424-2611

Maurice A. Knight Company

P.O. Box 109

Akron, OH 44309

216/724-1277

McKee Engineers and

Constructors

10 South Riverside Plaza

Chicago, IL 60606

$312 / 454-3810$

Mead Instrument Corporation One Day Lane

Riverdale, NJ 07457

201/835-5988

Metal Equipment Company

P.O. Box 153

Savannah, GA 31402

912/236-3378

Micro Motion, Inc.

7070 Winchester Circle

Boulder, CO 80301

$303 / 530-0530$

Micro-Tec Laboratories, Inc.

Route 2, Box 19

Logan, IA 51546

$712 / 644-2193$

Middle State Manufacturing, Inc.

P.O. Box 788

Columbus, NE 68601

402/564-1411

Midwest Energy Company, Inc. 700 North Lake Street, Suite 200 Mundelein, IL 60060

312/949-6360
Midwest Solvents Co., Inc.

1300 Main Street

Atchison, KS 66002

Miles Laboratories

P.O. Box 932

Elkhart, IN 46515

219/262-7176

Modern Welding Company, Inc.

2880 New Hartford Road

Owensboro, KY 42301

$502 / 685-4404$

Modular Fuel Systems

2348 FM 1960 West

Houston, TX 77068

$713 / 537-6155$

MRC Energy System

Rural Route 2, Box 399

Plymouth, IN 46563

219/784-8500

Nabal, Inc.

P.O. Box 82842

Lincoln, NE 68501

402/474-2120

National Tank and Manufacturing Co., Inc.

8201 Santa Fe Avenue

Huntington Park, CA 90255

213/583-1841

National Tank and Pipe

Company

10037 Southeast Mather Road

Clackamas, OR 97015

503/656-1991

New Brunswick Scientific

Co., Inc.

44 Talmadge Road

Edison, NJ 08817

201/287-1200

Niro Atomizer, Inc.

9165 Rumsey Road

Columbia, MD 21045

301/997-8700

Norton Company

P.O. Box 350

Akron, OH 44309

216/798-9240
Novo Laboratories, Inc.

59 Danbury Road

Wilton, CT 06897

203/762-2401

Oklahol, Inc.

Box 32671

Oklahoma City, OK 73123

405/722-5956

Olin Corporation

Shamrock Street

East Alton, IL 62024

618/258-2000

Oscar Krenz, Inc.

750 Potter Street

Berkeley, CA 94710

415/845-1400

Owens-Corning Fiberglas

Corporation

Fiberglas Tower

Toledo, OH 43659

419/248-9000

Pak-Tronics, Inc.

4044 North Rockwell Avenue

Chicago, IL 60618

312/478-8585

Palmer Manufacturing and Tank, Inc.

P.O. Box 1195, West Highway 50

Garden City, KS 67846

316/275-7461

Energy Systems, Inc.

423 North University Avenue

Little Rock, AR 72205

501/664-3985

Peabody Tec Tank

South Industrial Park

Parsons, KS 67357

316/421-0200

Plyboard Corporation

P.O. Box 498

Brownsville, OR 97327

503/466-5177

Poly Cal Plastics, Inc.

1250 South Wilson Way, No. 3

Stockton, CA 95205

209/948-9675

Pott Industries, Inc.

611 East Marceau Street

St. Louis, MO 63111

$314 / 638-4000$ 
Premier Malt Products, Inc.

1037 West McKinley Avenue

Milwaukee, WI 53201

$309 / 682-5411,414 / 347-7300$

Process Equipment Corporation

500 Reed Street

Belding, MI 48809

616/794-1230

Pufahl Enterprises, Ltd.

RR 2, Box 99

Milbank, SD 57252

$605 / 432-4169$

PEDCo International, Inc.

11499 Chester Road

Cincinnati, $\mathrm{OH} 45246$

513/782-4500

\section{R. B. Industries \\ P.O. Box 182 \\ Riverdale, MI 48877 \\ 517/833-7584 \\ Rad Tanks and Welding \\ Co., Inc. \\ 2614 North Main SE \\ Hubbard, $\mathrm{OH} 44425$ \\ 216/534-1184}

Raymond Control Systems

315 Kirk Road

St. Charles, IL 60174

312/293-0090

Reinke Manufactuaring

Company, Inc.

P.O. Box 566

Deshler, NE 68340

402/365-7251

Richmond Engineering Company, Inc.

P.O. Box 25189

Richmond, VA 23260

904/644-2611

Rochelle Energy Development, Inc.

Box 356

Rochelle, IL 61068

$815 / 562-7372$

Rohm and Haas Company

Independence Mall West

Philadelphia, PA 19105

215/592-3000
Rovac Pump and Supply Co.

Troiano Industrial Park

188 Moody Road

Enfield, CT 06082

203/668-7290

Sargent-Welch Scientific Company

7300 North Linder Avenue

Skokie, IL 60077

312/676-0172

Schmitt Energy Systems

Rural Route 2

Hawkeye, IA 52147

319/427-3479, 913/462-7531

Seven Energy Corporation

11901 West Cedar Avenue

Lakewood, CO 80226

303/989-777

Shur Stills

1607 Southeast Spokane Street

Portland, OR 97202

503/231-1130

Silver Engineering Works, Inc.

3309 Blake Street

Denver, CO 80205

303/623-0211

Sisterville Tank Works, Inc.

1942 McCoy Street

Sisterville, WV 26175

304/652-3011

Solar Energy Innovations

Corporation

54-45 44th Street

Maspeth, NY 11378

212/361-9038

Solar fuels International, Inc.

P.O. Box 311

Springfield, OR 97477

503/746-8821

Solargizer International, Inc. 2000 West 98th Street

Bloomington, MN 55431

612/888-0018

Solstice Designs, Inc.

Box 2043

Evergreen, CO 80439

303/674-1597
Stord Bartz Americas, Inc.

1 North Broadway

White Plains, NY 10601

914/949-8588

Sunquest, Inc.

2601 Northwest 74th Place

Gainesville, FL 32601

904/375-0406

Sybron Corporation

P.O. Box 365

Rochester, NY 14602

SWECO, Inc.

6033 East Bandini Boulevard

Los Angeles, CA 90051

213/726-1177

Terry G. Spragg and Associates

201 Ocean Drive

Manhattan Beach, CA 90266

213/374-0471

The Bishopric Products

Company

4413 Kings Run Drive

Cincinnati, $\mathrm{OH} 45232$

$513 / 641-0500$

The Duriron Company, Inc.

Box 1145

Dayton, $\mathrm{OH} 45401$

$513 / 226-4000$

The John T. Cody Corporation

4116 Dr. Greaves Road

Grandview, MO 64030

816/966-3500

The Revenoor, Inc.

P.O. Box 185

La Center, WA 98629

206/263-2200

The Virtis Company

Box V4, Route 208

Gardiner, NY 12525

914/255-5000

The World Energy Co.

Route 5, Box 251

Carthage, MO 64836

Thermax, Inc.

3 Pleasant Street

South Dartmouth, MA 02748

617/999-1231 
Tomco Division C.S.P., Inc. 30520 Lakeland Boulevard Willowick, $\mathrm{OH} 44094$

216/944-9000

Tomco Systems Equipment Company

Rosebud Road, Route 2

Loganville, GA 30249

404/979-8000

Tri-Star Corporation

Rural Route 3, Illini Street

Vandalia, IL 62471

618/283-1666

U. S. Alcohol Corporation 6565 Carpenter Street

Marlette, MI 48453

517/635-3484

Union Pump Company

6914 Hillpoint

Parker, CO 80134

303/841-3092

United Electric Controls

Company

85 School Street

Watertown, MA 02172

617/926-1000

United International, Inc.

P.O. Box 11

Buena Vista, GA 31803

912/649-7444

Universal Food Corporation

433 East Michigan Street

Milwaukee, WI 53201

414/271-6755

Vara International, Inc.

Gulf and Western Plaza

1201 19th Place

Vero Beach, FL 32960

305/567-1320

Vendome Copper and Brass

Works, Inc.

North Shelby Street

Louisville, KY 40202

502/587-1930

Victory Still, Inc.

3317 Tait Terrace

Norfolk, VA 23513

804/855-7110
Vulcan Cincinnati, Inc.

2900 Vernon Place

Cincinnati, OH 45219

513/281-2800

Warner Fiberglass Products

P.O. Box 31

Belding, MI809

616/794-1130

Wenger Alko-Vap System

904 Oakdale

Holland, MI 49422

616/399-2436

Wenger Manufacturing, Inc.

714 Main Street

Sabetha, KS 66534

913/284-2133

Werner and Pfleiderer

Corporation

663 East Crescent Avenue

Ramsey, NJ 07446

201/327-6300

Williams and Davis Boilers, Inc.

P.O. Box AF

Hutchins, TX 75141

214/225-2356

Winbco Tank Company

1200 East Main Street

Ottumwa, IA 52501

515/683-1855

World Wide Construction

Service, Inc.

P.O. Box 8126

Wichita, KS 67208

316/942-0101

WAAS, Inc.

P.O. Box 100

Adamsville, AL 35005

205/787-3835

WOODCO Enterprises

3300 Buckeye Road

Suite 857

Atlanta, GA 30341

404/455-1610

Youngstown Steel Tank

Company P.O. Box 268

Youngstown, $\mathrm{OH} 44501$

$216 / 74304121$
3 T Engineering, Inc.

P.O. Box 80

Arentzville, IL 62611

217/997-2188

CONSULTANTS FOR

FUEL FROM FARMS

FIRST EDITION

Bartlesville Energy

Technology Center

Bartlesville, OK

Contact: Jerry Allsup

918/336-4268

Battelle Columbus Laboratories

505 King Avenue

Columbus, $\mathrm{OH} 43201$

Contact: Billy Allen

614/424-6424

Center for Biology of Natural Systems

Washington University

St. Louis, MO

Contact: David Freedman

314/889-5317

EG\&G Idaho, Inc.

P.O. Box 1625

Idaho Falls, ID 83415

Contact: Dan Larue

208/526-0509

Energy, Inc.

P.O. Box 736

Idaho Falls, ID 83415

Contact: Don LaRue

208/526-0509

Energy, Inc.

P.O. Box 736

Idaho Falls, ID 83401

Contact: Steve Winston

208/524-1000

Environmental Group

RD \#3

Quakertown, PA 18951

Contacts: Jack Hershey

Bob Meskunas

215/536-8243

Galusha, Higgins and Galusha

P.O. Box 751

Glascow, MT 59230

Contact: Jim Smrcka

406/228-9391 
William S. Hedrick

844 Clarkson

Denver, CO 80218

303/832-1407

Pincas Jawetz

Independent Consultant on

Energy Policy

425 East 72nd Street

New York NY 10021

212/535-2734

TRW Energy Systems Group

8301 Greensboro Drive

McLean, VA 22102

Contacts: V. Daniel Hunt

Mani Balasubramaniam

Harlan L. Watson

Warren Standley

703/734-6554

\section{COOPERATIVE EXTENSION SERVICE}

\author{
Alabama \\ Cooperative Extension Service \\ Auburn University \\ Auburn, AL 36849 \\ 205/826-4000
}

Alabama A\&M University

1890 Program

P.O. Box 54

Normal, AL 35762

205/859-7342

Tuskegee Institute

1890 Program

109 Extension Building

Tuskegee Institute, AL 36088

205/727-8807

\begin{abstract}
Alaska
Cooperative Extension Service

University of Alaska

Fairbanks, AK 99701

907/479-7246
\end{abstract}

Arizona

Cooperative Extension Service University of Arizona

College of Agriculture

Tucson, AZ 85721

602/626-0111
Arkansas

Cooperative Extension Service

University of Arkansas

1201 McAlmont

P.O. Box 391

Little Rock, AR 72203

501/376-6301

California

Cooperative Extension Service

University of California

2200 University Avenue

Berkeley, CA 94720

415/642-9300

\section{Colorado}

Cooperative Extension Service Colorado State University

Fort Collins, CO 80523

303/491-1101

\section{Connecticut}

Cooperative Extension Service

University of Connecticut

College of Agriculture and Natural Resources

Storrs, CT 06268

203/486-2000

\section{Delaware}

Cooperative Extension Service

University of Delaware

College of Agricultural Sciences

Newark, DE 19711

302/738-2504

District of Columbia

D.C. Cooperative Extension Service

Univ. of the District of Columbia 1331 H Street, NW

Washington, DC 20005

202/727-2016

\section{Florida}

Cooperative Extension Service

University of Florida

Institute of Food and Agricultural Sciences

Gainesville, FL 32611

904/392-1761

\section{Georgia}

Cooperative Extension Service

University of Georgia

College of Agriculture

Athens, GA 30602

$404 / 542-3824$

\section{Hawaii}

Cooperative Extension Service

University of Hawaii at Manoa

Honolulu, HI 96822

808/948-8397

Idaho

Cooperative Extension Service

University of Idaho

College of Agriculture

Moscow, ID 83843

208/885-6639

Illinois

Cooperative Extension Service

University of Illinois

College of Agriculture

Mumford Hall

1301 West Gregory Drive

Urbana, IL 61801

217/333-1000

Indiana

Cooperative Extension Service

Purdue University

West Lafayette, IN 47907

317/749-8111

Iowa

Cooperative Extension Service

Iowa State University

Ames, IA 50011

515/294-4111

\section{Kansas}

Cooperative Extension Service

Kansas State University

Umberger Hall

Manhattan, KS 66506

913/532-5820 


\section{Kentucky}

Cooperative Extension Service

University of Kentucky

College of Agriculture

Lexington, KY 40506

$606 / 258-9000$

\section{Louisiana}

Cooperative Extension Service

Knapp Hall

Louisiana State University

University Station

Baton Rouge, LA 70803

504/388-4141

\section{Maine}

Cooperative Extension Service

University of Maine

Winslow Hall

Orono, ME 04469

207/581-2211

\section{Maryland}

Cooperative Extension Service

University of Maryland

Symons Hall

College Park, MD 20742

301/454-0100

\section{Massachusetts}

Cooperative Extension Service University of Massachusetts

Amherst, MA 01003

413/545-2766

\section{Michigan}

Cooperative Extension Service Michigan State University

113 Agriculture Hall

East Lansing, MI 48824

517/355-1855

\section{Minnesota}

Agricultural Extension Service University of Minnesota

St. Pual, MN 55108

612/373-1243

\section{New Jersey}

Cooperative Extension Service

Cook College

Rutgers - The State University

New Brunswick, NJ 08903

201/932-9306

\section{New Mexico}

Cooperative Extension Service

New Mexico State University

Box 3AE

Las Cruces, NM 88003

505/646-1806

\section{New York}

Cooperative Extension

Cornell University

Ithaca, NY 14853

607/256-2117.

\section{North Carolina}

Agricultural Extension Service

N.C. State University

P.O. Box 5157

Raleigh, NC 27650

919/737-2812

AT\&T State University

P.O. Box 21928

Greensboro, NC 27420

919/379-7956

\section{North Dakota}

Cooperative Extension Service North Dakota State University Fargo, ND 58105

701/237-8944

\section{Ohio}

Cooperative Extension Service Ohio State University

2120 Fyffe Road

Columbus, $\mathrm{OH} 43210$

614/422-6181
Mississippi

Cooperative Extension Service Mississippi State University

P.O. Box 5446

Mississippi State, MS 39762

601/325-3036

\section{Missouri}

Cooperative Extension Service

University of Missouri

Columbia, MO 65211

314/882-7754

Lincoln University of Missouri Jefferson City, MO 65101

314/751-2325

\section{Montana}

Cooperative Extension Service Montana State University

Bozeman, MT 59715

406/994-3402

\author{
Nebraska \\ Nebraska Cooperative Extension \\ Service \\ Division of Institute of \\ Agriculture and Natural \\ Resources \\ Agricultural Hall \\ Lincoln, NE 68583 \\ 402/472-7211
}

\section{Nevada}

Cooperative Extension Service

University of Nevada

College of Agriculture

Reno, NV 89557

702/784-6611

\section{New Hampshire}

Cooperative Extension Service

College of Life Sciences and

Agriculture

Taylor Hall - University of

New Hampshire

Durham, NJ 03824

603/862-1520 
Oklahoma

Oklahoma Cooperative

Extension Service

Oklahoma State University

139 Agricultural Hall

Stillwater, OK 74078

405/624-5400

Langston Coop Extension

P.O. Box 779

Langston, OK 73050

\section{Oregon}

Extension Service

Oregon State University

Corvallis, OR 97331

503/754-2713

Pennsylvania

Cooperative Extension Service

The Pennsylvania State Univ.

323 Agri. Admin. Building

University Park, PA 16802

814/863-0331

\section{Rhode Island \\ Cooperative Extension \\ University of Rhode Island \\ Kingston, RI 02881 \\ 401/792-2476}

\section{South Carolina}

Cooperative Extension Service 107 Barre Hall

Clemson University

Clemson, SC 29631

803/656-3311

\section{South Dakota}

Cooperative Extension Service South Dakota State University College of Agriculture

Box 2207

Brookings, SD 57007

$605 / 688-4147$
Agricultural Extension Service University of Tennessee

Institute of Agriculture

P.O. Box 1071

Knoxville, TN 37901

615/974-7114

\section{Texas}

Agricultural Extension Service Texas A\&M University College Station, TX 77843 713/845-6411

\section{Utah}

Cooperation Extension Service Utah State University Logan, UT 84322

$801 / 750-2194$

Vermont

Cooperative Extension Service

University of Vermont

Burlington, VA 05405

802/656-2990

\section{Virginia}

Cooperative Extension Service Burruss Hall

Virginia Polytechnic Institute and State University

Blacksburg, VA 24061

703/951-6705

Virginia State University

Cooperative Extension Programs

Box 540

Virginia State University

Petersburg, VA 23803

804/520-6421

\section{Washington}

Cooperative Extension Service Washington State University

College of Agriculture

Pullman, WA 99164

509/335-2511

\section{West Virginia}

Cooperative Extension Service Center for Extension and

Continuing Education

West Virginia University

Morgantown, WV 26506

304/293-5691

\section{Wisconsin}

Cooperative Extension Service Univ. of Wisconsin-Extension 432 North Lake Street Madison, WI 53706 $608 / 262-9510$

\section{Wyoming}

Agricultural Extension Service University Station

Box 3354

Laramie, WY 82071

307/766-6363

\section{Puerto Rico}

Cooperative Extension Service College of Agriculture University of Puerto Rico Mayaguez, PR 00708 809/833-7000

\section{Land Grant Colleges}

University of Guam

UOG Station

Mangilao, Guam 96913

734-2177

College of Virgin lslands

St. Thomas, Virgin Islands 00801 809/774-1252 
ENGINEERING FIRMS

ACR Process Corporation 808 South Lincoln, \#14

Irbana, IL 61801

217/384-8003

A. G. McKee Association 10 South Riverside Plaza 12th Floor

Chicago, IL 60606

312/454-3685

Alltech, Inc.

271 Goldrush Rd.

Lexington, KY 40503

606/276-3414

Alternative Energy, Ltd.

650 Pine Street

Colby, KS 6770I

913/462-7531

Bartlesville Energy

Technology Center

Bartlesville, OK 74003

918/336-4268

Bechtel Corporation

50 Beale Street

15th Floor, Room B15

San Francisco, CA 94119

415/768-2971

Bohler/Vogelbusch 1625 West Belt North

Houston, Tx 77043

713/465-3373

C\&I Girdler Co.

1721 South 7th Street

P.O. Box 32940

Louisville, KY 40234

502/637-8701

Center for Biology of

Natural Systems

Washington University

St. Louis, MO 63130

314/889-5317

Chamapec, Inc.

230 Crossways Park Drive

Woodbury, NY 11797

516/364-2100
Development Planning and

Research Associates

200 Research Drive

P.O. Box 727

Manhattan, KS 66502

913/539-3565

Day \& Zimmerman, Inc. 1818 Market Street

Philadelphia, PA 19103

215/299-8193

Honeywell, Inc.

Corp. Tech. Center

10701 Lyndale Avenue South

Bloomington, MN 55420

612/887-4477

Hydrocarbon Research, Inc. 134 Franklin Corner Rd.

P.O. Box 6047

Lawrenceville, NJ 08648

609/896-1300

I. E. Associates

3704 11th Avenue South

Minneapolis, MN 55407

612/825-9451p

Raphael Katzen Assoc.

1050 Delta Avenue

Cincinnati, $\mathrm{OH} 45208$

513/871-7500

A. G. McKee Corporation 10 South Riverside Plaza

Chicago, IL 60606

312/454-3685

PEDCo International, Inc. 11499 Chester Rd.

Cincinnati, OH 45246

$513 / 782-4717$

Power Engineering Co.

1313 S.W. 27th Avenue

Miami, FL 33145

Seven Energy Corporation

3760 Vance

Wheat Ridge, CO030

303/989-7777
Stone \& Webster Engineering Corporation

One Penn Plaza

New York, NY 10001

212/760-2000

3-T Engineers

Arenzville, IL 62611

217/997-2188

Vulcan Cincinnati, Inc. 2900 Vernon Plaza Cincinnati, OH 45219

$513 / 281-2800$

\section{ENZYME AND YEAST PRODUCERS}

Altech, Inc.

271 Goldrush Road

Lexington, KY 40503

606/276-3414

Anheuser-Busch, Inc. 721 Pestalozzi Street

St. Louis, MO 63118

314/577-2000

Aquaterra Biochemicals Corporation

Dept. TMEN

Box 496

Lancaster, Tx 75146

214/227-6960

Alco-Zyme Supply

Box 79

Halecenter, TX 79041

806/839-2273

Biocon, Inc.

261 Midland Avenue

Lexington, KY 40507

606/254-0517

Chamapec, Inc.

230 Crossways Park Drive

Woodbury, NY 11797

Contact: Rene Loser

$516 / 364 / 2100$ 
Enzyme Development

Corporation

210 Plaza

New York, NY 10001

Contact: Randy Ross

212/736-1580

Fermco Biochemicals, Inc.

2638 Delton Lane

Elk Grove Village, IL 60007

312/595-3131

G. B. Fermentation Industry, Inc.

One North Broadway

Des Plaines, IL 60061

312/827-9700

Norbert Haverkamp

Compost Making Enzymes

Rural Route 1, Box 114

Horton, KS 66439

913/486-3302

Miles Laboratoraies, Inc.

Enzyme Products Division

P.O. Box 932

Elkhart, IN 56515

219/564-8111

National Laboratories

Development Center

Pollution Abatement Division

U.S. Army

Natick, MA 01760

Contact: Leo A. Spano

617/653-2914

Novo Laboratory, Inc.

59 Danbury Road

Wilton, CT 06897

203/762-2401

Rohm \& Haas

Independence Mall West

Philadelphia, PA 19105

Contact: Bob Broadbent

215/592-2517

Schwarz Service International Ltd.

230 Washington Street

Mt. Vernon, NY 10551

Contact: Mr. Aberdein

914/664-1 100

Scientific Products co.

1120 Clay

North Kansas City, MO 64116

806/221-2533
Red Star Yeast

Fermentation Products Division

Universal Foods Corporation

433 East Michigan Street

Milwaukee, WI 53201

414/271-6755

Red Star Yeast

Fermentation Products Division

Universal Foods Corporation 433 East Michigan St.

Milwaukee, WI 53201

414/271-6755

\section{ETHANOL PRODUCERS/ DISTRIBUTORS}

Almarc

2700 Lively Boulevard

Elk Grove, IL 60007

312/766-2906

American Gasohol Refiners

P.O. Box 18767

Wichita, KS 67218

216/683-3812

Amoco Production Company

P.O. Box 5340a

Chicago, IL 60680

312/856-222

APCO Oil Corporation

Houston Natural Gas Building

Houston, TX 77002

$713 / 658-0610$

Archer Daniels Midland

Company

Box 1470

Decatur, IL 62525

217/424-5700

Encore Energy Resources, Incorporated

11951 Mitchell Road,

Mitchell Island

Richmond, British Columbia

604/327-8394

Exxon Corporation

Exxon Research and

Engineering

Public Relations

P.O. Box 639

Linden, NJ 07036
Georgia Pacific Company

Bellingham Division

P.O. Box 1236

Beilingham, WA 98225

206/733-4410

Grain Processing Corporation

Muscatine, IA 52761

918/264-4211

Hiram Walker

31275 Northwestern Highway

Farmington Hills

Detroit, MI 48018

Marcam Industries

527 North Easton Road

Glenside, PA 19038

215/885-5400

Midwest Solvents Company

1300 Main Street

Atchison, KS 66002

913/367-1480

Milbrew, Incorporated

330 South Mill Street

Juneau, WI 53039

414/462-3700

Mode, Ronald C.

Box 682

Glen Alpine, NC 28628

704/584-1432

Publicker Industries

777 W. Putnam Avenue

Greenwich, CT 06830

203/531-4500

Quaternoin Chemical Industries

72026 Livingston Street

Oakland, CA 94604

Contact: Louis Nagel

415/535-2311

Sigmor Corporation

P.O. Box 20267

San Antonio, TX 78220

512/223-2631

Syncorp

Rt. 1, Box 301

Roberta, GA 31078

912/836-3136

Texaco, Inc.

135 East 42nd Street

New York, NY 10017

212/953-6000 
TIPCO

9000 N. Pioneer Rd.

Peoria, IL 61614

309/692-6543

United States Gasohol Corp.

P.O. Box N

Lockeford, CA 95237

209/727-5511

White Flame Fuels

P.O. Box 1516

Van Buren, AR 72956

501/474-5258

Worum Chemical Company

2130 Kasoto Avenue

St. Paul, MN 55108

Contact: Mr. Ritt

612/645-9224

\section{MOLECULAR SIEVE MANUFACTURERS}

Applied Techologies, Inc.

P.O. box 296

Hastings, NE 68901

Contact: M. W. (Bill) Locatis

402/463-0521

Coast Engineering Laboratory

13510 South Normandie

Gardena, CA 90249

213/532-7400

Farrier Industries, Inc.

Baltimore Division

4211 Shannon Drive

Baltimore, MD 21213

301/483-2300

Frontier Industrial Controls

Corporation

2695 Alcott Street

Denver, Colorado 80211

Contact: James W. Tatman

303/534-5065

Gas Drying, Inc.

P.O. Box D1

Wharton, NJ 07885

201/361-2212

Grace, W. R., \& Company

Davison Chemical Division

Charles and Baltimore Streets

Baltimore, MD 21202

301/727-3900
Henderson Engineering, Inc.

701 Factory Road

Addison, IL 60101

312/543-9150

Kahn and Company

885 Wells Road

Wethersfield, CT 06109

203/529-8643

Kemp, C. M., Mfg. Company 490 Baltimore-Annapolis Blvd.

Glen Burnie, MD 21061

301/761-5100

Norton Company

P.O. Box 350

Akron, OH 44309

216/673-5860

Union Carbide Corporation

Molecular Sieve Department

Linde Division

Two Greenway Plaza East

Houston, TX 77046

$713 / 840-5930$

\section{ON-FARM}

\section{OPERATING PLANTS}

Don Cook

2380 Coutny Road $18 \mathrm{~N}$

Craig, CO 81625

303/824-6746

(Operational in 1 month)

Don Kriley

RD2, Box 2243

Harrisville, PA 16038

412/735-4489

David Gahimer

7-H Corporation

Terre Haute, IN 47803

812/877-1511 Ext. 227

Luke Staengel

Floud Agricultural Energy

Co-op.

Floyd, VA 24091

703/745-3131

Dan Williams

1514 Bennet Road

Mount Vernon, WA 98273

206/466-3973

(Operational in 2 months)
Terry Edvalson

Oregon State College

8th and K Street

LaGrande, OR 97850

503/963-2171

Frank Tilley

Conklin Associated Marketing

Services

P.O. Box 492

Marshalltown, IA 50158

515/752-6895

Jerry Harper

7600 West $4000 \mathrm{~N}$

Corinne, UT 84307

801/723-2987

Dean Roll

Southeast Community College

Milford, NE 68857

402/761-2131

Jim Jackson

Aquarius Solar Products, Inc.

Kuna, ID 83634

208/376-3172

(Operational in 2 months)

Jamie Jacobsen

Box 845

Paonia, CO 81428

$303 / 527-4322$

Howard Baumgartner

Unlimited Energy, Inc.

R.R. 4

Decatur, IN 46733

219/824-1353

(Operational in 2 months)

Max Pickerill

Colby Community College

Colby, KS 67701

913/462-3984 Ext. 230

Noel Reid

Ephrata, WA 98823

509/787-2098

Norbert Haverkamp

Nature's Way, Inc.

R.R. 1, Box 114

Horton, KS 66439

913/486-3302 
Cliff Friedrich

Miner Agricultural Research

Institute

Route 191, Ridge Road,

Chazy, NY 12921

518/846-7121

Dennis Knobelock

Route 1

Muscoutah, IL 62258

618/566-4135

Charles Minter

15444 Miller Road

Richwood, OH 43344

614/943-3405

Floyd Hoff

Box 162

Dalton, MN 56324

218/589-8444

\section{PLANT PLANS}

Goosen's EtOH Fuel Book

Still Plans

The Harvester Press

P.O. Box 1669

Hendersonville, NC 28793

704/692-4809

Makin' It On the Farm

American Agriculture News

P.O. Box 100

Iredell, TX 76649

$817 / 364-2474$

Mother Earth News

P.O. Box 70

Hendersonville, NC 28739

704/693-0211

Solstice Designs, Inc.

Box 2043

Evergreen, CO 80439

303/674-1597

STATE ALCOHOL FUELS CONTACTS

Alabama

Leonard McGann

Alabama Solar Energy Center

P.O. Box 1247

Huntsville, AL 35607
Alaska

Ken Ulz

Kobuk

P.O. Box 1599

Fairbanks, AK 99707

Arizona

Dan Shein

Arizona Energy Office

$1700 \mathrm{~W}$. Washington

Phoenix, AZ 85007

602/255-3632

Arkansas

Jodie Marler

Arkansas Department of Energy

960 Plaza West

Little Rock, AR 72205

\section{California}

Peter Ward

Fuels Specialist

California Energy Commission

Development Division

111 Howell Avenue

Sacramento, CA 95825

916/920-6031

\section{Colorado}

Bob Merten

Colorado Gasohol Promotion

Committee

Department of Agriculture

1525 Sherman Street, 4th Floor

Denver, CO 80203

303/866-3218

\section{Connecticut}

R. C. Hoerning

85 Roosevelt Boulevard

Enfield, CT 06082

203/677-4631

\section{Florida}

Halen Vermeers

160 SW, 17th Court \#7

Miami, FL 33135

305/642-3994
Georgia

Michael K. Harsh

510 Houston Street

Montezuma, GA 31603

\section{Idaho}

Ralph Woodmansee

Chairman, Gasohol Prom. Com.

325 Ron Glyn

Idaho Falls, ID 83401

208/523-6970

Illinois

John Lehmann

Illinois Department of Agriculture

Emerson Building

State Fairgrounds

Springfield, IL 62706

Iowa

Roger Etrheim

Iowa Corn Promotion Board

$200 \mathrm{~W}$. Towers

1200 35th Street

W. Des Moines, IA 50265

515/255-9242

Tom Perason

Iowa Department of Commerce

250 Jewett Building

Des Moines, IA 50309

Kansas

Dean Shelor

Route 1

Mineola, KA 67865

Kentucky

Bruce Sauer

Kentucky Center for Energy Research

P.O. Box 118888

Lexington, KY 40578

$606 / 252-5535$

\section{Louisiana}

Toni Morrison

1102 6th Street

New Orleans, LA 70115 
Maine

Nancy Holmes

Office of Energy Resources

55 Capital Street

Augusta, ME 04330

\section{Maryland}

Dick Merritt

9400 Wisc. Avenue

Bethesda, MD 20014

\section{Michigan}

Vincent Parris

Michigan Department of Agriculture

Marketing/International Trade Division

P.O. Box 30017

Lansing, MI 49809

517/373-1054

\section{Minnesota}

Glenn Kiecker

Minnesota Alcohol Fuel Assn.

5641 Newton Avenue S

Minneapolis, MN 55419

$612 / 348-7897$

\section{Mississippi}

Billie Davis

Rt. 3, Box 510

Laurel, MS 39440

$601 / 425-4428$

\section{Missouri}

Don Varney

Division of Energy

P.O. Box 176

Jefferson City, MO 65102

314/751-3332

\section{Montana}

Georgia Brensdal

Energy Division

State of Montana

Department of National

Resources and Conservation

32 South Ewing

Helena, MT 59601

406/449-4624
Nebraska

Ohio

Todd Sneller, Adm.

Nebraska Grain Alcohol

Program

Ag Products Industrial Utility

Commission

3rd Floor, Box 94831

301 Centennial Mall South

Lincoln, NE 68509

402/471-2941

\section{New Mexico}

Lee Tilman

New Mexico Alcohol Fuels Association

c/o Lee Tilman

Eastern Plains Council of Governments

Curry County Courthouse

Clovis, NM 88101

505/762-7714, 763-5591

New York

Eugene White 257 Middle County Road

Smithtown, NY 11787

516/724-5300

\section{North Carolina}

John Manuel

Energy Division

Department of Commerce

P.O. Box 25249

Raleigh, NC 27611

919/733-4493

\section{North Dakota}

Dean McIlroy

North Dakota Ag Products

Utilization Committee

6th Floor

Capitol Building

Bismarck, ND 58505

701/224-2232

Ag Products Industrial Utilization Committee 701/224-2232
Jack Hill

Ohio Farm Bureau

P.O. Box 479

Columbus, OH 47215

614/461-6211

Oregon

Tom Winn

Oregon Department of

Agriculture

635 Capital NE

Salem, OR 97310

Pennsylvania

Joseph M. Barron

Chief Executive Officer

Pennsylvania Gasohol

Association

Reynolds-Ward Building

606 Island Avenue

McKees Rocks, PA 15136

South Carolina

Bob Kinard

SCN Center

Suite 1130

Columbus, SC 29201

803/758-7502

\section{South Dakota}

Verne Brakke

Office of Energy Policy

Capital Lake Plaza

Pierre, SD 57501

605/773-3603

Texas

Robert V. Avant, Jr.

Texas Energy and National

Resources Advisory Council

200 E. 18th Room 511

Austin, TX 78701

512/475-5588

Utah

Jim Byrne

Utah Energy Office

231 East 400 Street

Salt Lake City, UT 84111 
Vermont

Dick Cambio

Vermont Energy Office

State Office Building

Montpelier, VT 05602

\section{Virginia}

Irl Smith

Alcohol Fuel/Gasohol Project Coordinator

Department of Agriculture and Consumer Service

203 North Gov Street

Richmond, VA 23219

803/786-3519
Washington

Robert Sarvis

Edmond Community College 200068 Avenue W

Lynwood, WA 98036

206/771-1524

Bob Michaelson

Director of Department of Agriculture

406 General Administration Building

Olympia, WA 98504

206/753-5050

West Virginia

Clifford L. Manley

Glenville, WV 26351

304/3642-8997
Wisconsin

George Plaza

Biomass Analyst

Division of State Energy

1010 S. Webster Street

Madison, WI 53702

608/266-0985

\section{Wyoming}

Butch Keadle

Fuel Allocation Specialist Energy Conservation Office Capitol Hill Office Building 25th and Pioneer Cheyenne, WY 80002 307/777-7284 


\section{APPENDIX F}

\section{Bibliography}

- General

- Government 'Reports \& Magazines

- Conversion

- Coproducts

- Design

- Distillation

- Economics

- Energy Balance

- Environmental Considerations

- Feedstocks

- Fermentation

- Hardware-Equipment

- Regulatory

- Transportation Use 


\section{GENERAL}

\section{Introductory}

Alcohol Car Conversion. Al Rutan; Minneapolis, MN: Rutan Publishing; 1980; 47 p. \$5.00. Available from: Rutan Publishing, Box 3585, Minneapolis, MN 55403.

Alcohol Distiller's Manual for Gasohol and Spirits. Roberto De Rasor; San Antonio, TX: Dona Carolina Distillers; 1980; 202 p. \$12.50. Available from: Dona Carolina Distillers, Box 13189, San Antonio, TX 78213.

Auto Fuels of the 1980's. Jack Frazier; Indian Mills, WV: Solar Age Press; 1978; 71 p. \$4.55. Available from: Citizens Energy Projects, 1110 6th Street., NW., Suite 300, Washington, DC 20001.

Brown's Alcohol Motor Fuel Cookbook. Michael H. Brown; Cornville, AZ: Desert Publications; 1979; 140 p. \$12.00. Available from: Desert Publications, Star Rte., Box 1935, Cornville, AZ 86325.

Ethanol Production and Utilization for Fuel. Lincoln, NE: Cooperative Extension Service, Institute of Agriculture and Natural Resources, University of Nebraska; October $1979 ; 83$ p. $\$ 2.00$. Available from: Extension Publication Service, Agricultural Engineering Annex, University of Nebraska, Lincoln, NE 68583.

Ethanol Fuels: Use, Production, and Economics. A Product of the Solar Energy Information Data Bank, Solar Energy Research Institute, Golden, CO; May 1981. Report No. SERI/SP-751-1018.

Ethyl Alcohol Production and Use as a Motor Fuel. J. K. Paul; Park Ridge, NJ: Noyes Data Corp.; Chemical Technology Review, no. 144; 1979; 354 p. \$48.00. Available from: Noyes Data Corp., Mill Rd. at Grand Ave., Park Ridge, NJ 07656.

Gasohol. Ken Bossong and Maureen Paskin; Washington, DC: Citizens Energy Project; Report Series, no. 24; Spring 1978; 7 p. \$1.50. Available from: Citizens Energy Project, 1110 6th St., NW., Washington, DC 20001.

Gasohol for Energy Production. Nicholas P. Cheremisinoff; Ann Arbor, MI: Ann Arbor Science; Energy Technology Series; $1979 ; 140$ p. \$14.95. Available from: Ann Arbor Science, Box 1425, Ann Arbor, MI 48106.

Individual and Group Gasohol-Alcohol Fuel Production and Usage. B. W. Kirby; Columbia, SC: B. W. Kirby Co.; 1979; 70 p. $\$ 10.00$. Available from: Energy Economy Digest, 3615 Verner St., Columbia, SC 29204.

A Learning Guide for Alcohol Fuel Production. Colby, KS: Colby Community College; July 1979; 348 p. \$45.00. Available from: National Alcohol Fuel Producers Association, 1700 South 24th St., Lincoln, NE 68502.
Makin' it on the Farm: Alcohol Fuel is the Road to Independence. Micki Nellis; Iredell, TX: American Agriculture News; $1979 ; 88$ p. $\$ 4.00$. Available from: American Agriculture News, Box 100, Iredell, TX 76649.

Making Alcohol Fuel - Recipe and Procedure. Lance Crombie; Minneapolis, MN: Rutan Publishing; revised, 1979; 111 p. \$8.00. Available from: Rutan Publishing, Box 3585, Minneapolis, MN 55403

Making Fuel in Your Back Yard. Jack Bradley; Wenatchee, WA: Biomass Resources; 1979; 63 p. \$10.95. Available from: Biomass Resources, Box 2912, Wenatchee, WA 98801.

Manual for the Home and Farm Production of Alcohol Fuel. Stephen W. Mathewson; Las Banos, CA: J. A. Diaz Publications; 2nd ed.; 1980; 208p. \$12.95. Available from: J. A. Diaz Publications, Box 709, Las Banos, CA 93635 .

Methanol and Other Ways Around the Gas Pump. John W. Lincoln; Charlotte, VT: Garden Way Press; 1976; 134 p. \$5.95. Available from: Garden Way Press, Ferry Rd., Charlotte, VT 05445. Revised edition to be published under title: Driving Without Gas; July 1980 $\$ 8.95$.

Methanol Technology and Application in Motor Fuels. J. K. Paul; Park Ridge, NJ: Noyes Data Corp., Chemical Technology Review, vol. 114; 1978; 85 p. \$54.00. Available from: Noyes Data Corp., Mill Rd. at Grande Ave., Park Ridge, NJ 07656.

Net Energy Analysis of Alcohol Fuels. D. M. Jenkins; T. A. McClure; T. S. Reddy; Washington, DC: American Petroleum Institute; API Publication no. 4312; November $1979 ; 39$ p. \$3.00. Available from: American Petroleum Institute, 2101 L St., NW., Washington, DC 20037.

Science of Ethanol Production. A. J. Benesi; 1981, 187p.; Eastern Oregon State College, Le Grande, OR 97850.

Solar Alcohol: The Fuel Revolution. Michael Wells Mandeville; Seattle, WAS: Ambix; 2nd ed.; 1980; 127 p. \$10.00. Available from: Ambix, 1223 North Northgate Way, Seattle, WA 98133. Presents a complete briefing on the alcohol biofuel potential.

\section{Government Reports and Publications}

Agricultural Sector Impacts of Making Ethanol from Grain. Donald Hertzmark; Golden, CO: Solar Energy Research Institute; March 1980; Report no. SERI/TR352-554; 64 p. \$5.25. Available from: NTIS*.

Biomass-Based Alcohol Fuels: The Near Term Potential for Use with Gasoline. W. Park; E. Price; D. Salo; 
McLean, VA: MITRE Corp. Prepared for the U.S. Department of Energy; August 1978; Report no. HCP/T4101-3; 74 p. \$6.00. Available from: NTIS*.

Comparative Automotive Engine Operation When Fueled with Ethanol and Methanol. E. E. Ecklund; Santa Clara, CA: Santa Clara Univ.; Coral Gables, FL: Miami Univ. Prepared for the U.S. Department of Energy; May 1978; Report no. HCP/W1737-01; 59 p. \$7.00. Available from: NTIS*.

Denaturants for Ethanol/Gasoline Blends. Mueller Associates, Inc. Prepared for the U.S. Department of Energy; April 1978; Report no. HCP/M2098-01; 16 p. $\$ 5.00$. Available from: NTIS*.

Ethanol/Gasoline Blends as Automotive Fuel. J. R. Allsup; D. B. Eccleston; Bartlesville, OK: Bartlesville Energy Technology Center, U.S. Department of Energy; May 1979; Report no. BETC/RI-79/2; 13 p. $\$ 5.00$. Available from: NTIS*.

Fuel Alcohol: An Energy Alternative for the 1980s. Final Report - U.S. National Alcohol Fuels Commission, Washington, DC; $1981 ; 151$ p. $\$ 4.25$. Stock no. 052-00300792-4. Available from: U.S. Superintendent of Documents, Washington, DC 20402.

Fuel from Farms - A Guide to Small-Scale Ethanol Production. Golden, CO: Solar Energy Research Institute; 1980; Report no. SERI/SP-451-519; 157 p. \$4.50. Available from: NTIS*.

Fuels from Sugar Crops: Systems Study for Sugar Cane, Sweet Sorghum, and Sugar Beets. Richard A. Nathan; Oak Ridge, TN: Technical Information Center, U.S. Department of Energy; 1978; Report no. TID-22781; 137 p. \$6.50. Available from: NTIS*.

Gasohol: A Technical Memorandum. Washington, DC: Office of Technology Assessment; September 1979; Report no. PB80-105885; 89 p. $\$ 8.00$. Available from: NTIS*.

Small-Scale Fuel Alcohol Production. Development Planning and Research Associates, Inc.; Manhattan, KS. Prepared for the U.S. Department of Agriculture; Washington, DC; March 1980.

Status of Alcohol Fuels Utilization - Technology for Highway Transporation. Mueller Associates, Inc. Prepared for the U.S. Department of Energy; June 1978; Report no. HCP-M2923-01; 144 p. $\$ 10.00$. Available from: NTIS*.

Energy Research for the Farm: An Overview. Agricultural Bulletin Number 447; U.S.D.A. Publication Request and Distribution, Extension Service, 6007 South Bldg., Washington, DC, 20250.

\section{Magazines}

Ag Energy. Weekly, $\$ 78 /$ year, $\$ 2$ for single copies, back copies available on request. Available from Miller Publishing Co., P.O. Box 9498, Minneapolis, MN 55440, 612/374-5200.

Alcohol Fuels Industry Report. \$495/year. Available from: Information Resources, Inc., 1413 Cedar Avenue, McLean, VA 22101, 703/734-0077.

Alcohol Fuels Process R/D Newsletter. Semi-annual, no charge. Available from: Document Distribution Service, Solar Energy Research Institute, Building 18,

Alcohol Fuels Process $R / D$ Newsletter. Semi-annual, no charge. Available from: Document Distribution Service, Solar Energy Research Institute, Building 15, First floor, 1617 Cole Blvd., Golden, CO 80401, 303/231-1158. (Formerly Biomass Refining Newsletter; formerly Fuels from Biomass Fermentation Newsletter.)

Alcohol Week; an Exclusive Report on Alcohol Fuels and Feedstocks. Weekly, \$295/year. Available from: Inside Washington Publishers, P.O. Box 7167, Ben Franklin Station, Washington, DC 20004. Toll-free $800 / 424-9068$, or $202 / 347-3976$.

American Agriculture News. Weekly, \$15/year. Available from: Alden and Micki Nellis, P.O. Box 100, Iredell, TX 76649, 817/364-2474.

ADM Gasohol News. Monthly. Available to ADM customers from Archer Daniels Midland Co., 1350 Waconia Ave., SW., Cedar Rapids, IA 52406. Toll-free 800/553-8411.

Bioenergy Bulletin. Bi-monthly, no charge. Available from: Pacific Northwest Bioconversion Energy Task Force, U.S. Department of Energy, Region 10, 1992 Federal Building, 915 Second Ave., Seattle, WA 98174, 206/442-1842.

Biomass Digest. Monthly, \$87/year. Available from: Technical Insights, Inc., P.O. Box 1304, Fort Lee, NJ 07024, 201/944-6204.

Biotimes. Bi-monthly, \$15/year, Available from: The International Biomass Institute, 1000 Vermont Ave., NW., Suite 209, Washington, DC 20005.

Earth Energy. Monthly, \$10/year (associate membership, \$15; active membership, \$75; includes other publications and benefits). Available from: National Alcohol Fuel Producers Association, 1760 Reston Ave., Suite 102, Reston, VA 22090, 703/471-1611.

Farm Energy. Monthly. Free to members of Iowa Corn Growers Association, \$20/year for lowa farmers, \$25/ 
year to others. Available from: Iowa Corn Producers Association, 200 West Towers, 1200 35th Street, West Des Moines, IA 50265, 515/225-9242.

Gasohol...Key to Renewable Fuel. Monthly. Available from: Colorado Gasohol Promotion Committee, 1525 Sherman Street, Fourth Floor, Denver, CO 80203 , 303/866-3218.

Gasohol U.S.A. Monthly, \$13/year. Availble from: Gasohol U.S.A., P.O. Box 9547, Kansas City, MO 64133, 816/737-0064.

Illinois Alcohol Fuel News. Bi-monthly, \$12/year. Available from: Illinois Alcohol Fuels Assn., Fifth and Stanford Streets, Springfield, IL 62703.

Mother Earth News. Bi-monthly, \$15/year. Available from: Mother Earth News, P.O. Box 70, Hendersonville, NC $28739,704 / 693-0211$.

Washington Gasohol Commission Newsletter. Monthly; to members of the Washington Gasohol Commission. Available from: The Commission, 103 12th Ave., SW., Suite P, Ephrata, WA 98823, 509/754-3463.

\section{CO PRODUCTS}

"About CO2", Gasohol USA, Vol. 2 (no. 1), January 1980, pp. 15-17.

Distillers Feeds, Distillers Feed Research Council, Cincinnati, OH 45202.

Hertzmark, D. and Gould, B. Solar Energy Research Institute, Golden, CO. "Market for Ethanol Feed Joint Products", Report SERI/RR-352-357, October 1979, 84 p. Available from: NTIS*, $\$ 9.00$ printed copy, $\$ 3.00$ microfiche.

Kienholz, E. W., Colorado State University, Fort Collins, CO. "Use of Grain Alcohol By-Products in Colorado" Gasohol USA, Vol. 2 (no. 3), March 1980, 34 p.

Winston, S. J., Energy Incorporated, "Stillage Treatment Technologies," October 1979, 20 p.

Winston, S. J. Energy Incorporated, "Current Stateof-the-Art Stillage Use and Disposal," October 1979, $30 \mathrm{p}$.

\section{DESIGN}

Chambers, R. S. ACR Process Corporation, Urbana, IL, "The Small Fuel-Alcohol Distillery: General Description and Economic Feasibility Workbook," 1979, 21 pages. Available from: ACR Process Corporation, 808 S. Lincoln Ave., Urbana, IL 61801. (free)
Katzen, Raphael Associates, "Grain Motor Fuel Alcohol Technical and Economic Assessment Study," Report no. HCP/J6639-01, June 1979, 341 p. Available from: NTIS*, $\$ 12.00$ paper copy, $\$ 3.00$ microfiche.

Office of Alcohol Fuels. Department of Energy. "Design Report: Small-Scale Fuel Alcohol Plant," December 1980, 3 volumes, Report no. IDO-10088. Available from: NTIS*, $\$ 25.00$.

\section{DISTILLATION}

"Applications of Molecular Sieve Technology," Gasohol USA, vol. 3, no. 6, pp. 10-12, June 1981.

Eakin, D. E., et al., "Evaluation of Ethanol/Water Separation Process," vol. 3, no. 9, pp. 13-18, 32, September 1981.

Glassett, J. and Rankin, J., "Distillation Tower," Gasohol USA, vol. 3, no. 9, pp. 8-10, September 1980.

King, C. J., Separation Processes, McGraw-Hill, NY, 1971.

Tassios, D. P., ed., Extractive and Azeotropic Distillation, Advances in Chemistry, Number 115, American Chemical Society, Washington, DC, 1972.

\section{ECONOMICS}

Biosynthetics, Inc., "Fuel Alcohol Limited Partnership," Gasohol USA, vol. 3, no. 3, pp. 14-18, 31, March 1981.

Hertzmark, D., et. al., "Economic Feasibility of Agricultural Alcohol Production within a Biomass system," American Journal of Agricultural Economics, vol. 62, no. 5, pp. 965-971, December 1980.

Jantzen, D. and McKinnon, T., Solar Energy Research Institute, "Preliminary Energy Balance and Economics of a Farm-Scale Ethanol Plant," SERI/RR-624-669, May 1980. Available from: NTIS*, $\$ .00$ paper copy, $\$ 3.00$ microfiche.

Prebluda, H. J. and Williams, R., Jr., "Perspectives on the Economic Analysis of Ethanol Production from Biomass." 177th National Meeting of the American Chemical Society, Honolulu, HI, March 1979, pp. 481-487.

Scheller, W. A. "Gasohol, Ethanol, and Energy." Gasohol USA, vol. 2, no. 7, pp. 14-18, 36, July 1980.

\section{ENERGY BALANCE}

Bare, G., "Net Energy Analysis," Gasohol USA, vol. 3, no. 9, pp. 10-12, September 1981. 
Jenkins, D. M., et. al. "Net Energy Analysis of Alcohol Fuels," API Publication no. 4312, American Petroleum Institute, 2101 L St., NW., Washington, DC 20037, November 1979. \$3.00.

Chambers, R. S., et. al., "Gasohol: Does It or Doesn't It Produce Positive Net Energy," Science, vol. 208 p. 789, November 16, 1979.

Ladisch, M. R.; Dyck, K., "Dehydration of Ethanol: New Approach Gives Positive Energy Balance," Science, vol. 205 (no. 31), August 3, 1979, pp. 898-900.

\section{ENVIRONMENTAL CONSIDERATIONS}

Fogde, Co., "Handling and Care of Gasohol," Gasohol $U S A$, vol. 2, no. 9, pp. 16-18, September 1980.

"Safety Standards in Fuel Alcohol Production," Gasohol $U S A$, vol. 2, no. 5, pp. 10-11, May 1980.

Mandia, J. W. and Powers, T. J., III, "Seminar Proceedings Environmental Evaluation 'Gasohol' Production and Health." October 1979, Environmental Protection Agency, Kansas City, MO, 32 p.

"Safety Standards in Fuel Alcohol Production," Gasohol USA, vol. 2, no. 5, pp. 10-11, May 1980.

\section{FEEDSTOCKS}

"Biomass Research in Idaho," Gasohol USA, vol. 2, no. 1, pp. 28-29, 35, January 1980.

Bower, R. C., "Alcohol from Artichokes," Outdoor Indiana December 1980 - January 1981, pp. 12-13, December 1980.

Jackson, D. R. and Arthur, M.F., "Alcohol Crop for the U.S.; Sweet Sorghum," Gasohol USA, vol. 2, no. 3, pp. 26-27, 32-33, March 1980.

Lukens, T., "Jerusalem Artichoke," Gasohol USA, vol. 3, no. 5, pp. 20-21, May 1981.

Lyons, T. P. "Technical Aspects of Alcohol Production II," Gasohol USA, vol. 2, no. 11, pp. 7-11, November 1980.

Lyons, T. P. and Cunningham, J. D., "Fuel Alcohol from Whey," American Dairy Review, vol. 42, no. 11, pp. 42A42E, November 1980.

Sachs, R. M. "Crop Feedstocks for Fuel Alcohol Production," California Agriculture, vol. 34, no. 6, pp. 11-14, June 1980.

\section{FERMENTATION}

"Continuous Fermentation Comes of Age," Gasohol $U S A$, vol. 2, no. 4, pp. 8-10, April 1980.

Fermentation Guide for Common Grains: A Step-byStep Procedure for Small-Scale Ethanol Fuel Production, SERI, June 1981. Available from: the Superintendent of Documents, U.S. Government Printing Office, Washington, DC 20402. Stock no. 061-0000055306, \$3.00.

Fermentation Guide for Potatoes: A Step-by-Step Procedure for Small-Scale Ethanol Fuel Production, SERI, September 1981. Available from: the Superintendent of Documents, U.S. Government Printing Office, Washington, DC 20402. Stock no. 061-000-00560-9, \$3.00.

Lyons, T. P., "Technical Aspects of Fuel Alcohol Production, Part III," Gasohol USA, vol. 3, no. 1, pp. 6-8, 10, January 1981.

Kolot, F. B., "Ethanol, Advantages, Limitations, and Economics," Gasohol USA, vol. 2, no. 6, pp. 6-7, 45, June 1980.

\section{HARDWARE - EQUIPMENT}

Clyde, R. A., "New Ceramic Column Packing for Gasohol Production," Proceedings Bio-Energy '80 World Congress and Exposition, Atlanta, GA, 1980, The Bio-Energy Council, Washington, DC.

Glassett, J. and Rankin, J., "Simplifying Tower Equipment and Controls," Gasohol USA, vol. 2, no. 12, pp. 10-11, December 1980.

Lukchis, G. M., “Adsorption Systems: Part I. Design by Mass-Transfer-Zone Concept," Chemical Engineering, June 11, 1973, pp. 111-116.

Lukchis, G. M., “Adsorption Systems: Part III, Adsorbent Regeneration," Chemical Engineering, August 6, 1973, pp. 83-90.

Morgan, C. R. and Herbst, N. R., "Agitator Design in Fuel Alcohol Production," Gasohol USA, vol. 3, no. 3, pp. 20-22, March 1981.

\section{REGULATORY}

Foster, C. D., “Legal Aspects of Gasohol Production for Fuel," Biomass Alcohol for California. Proceedings: Potential for the 1980's, University of California, Davis, CA, January 1980, pp. 42-43. 
Bureau of Alcohol, Tobacco, and Firearms, Alcohol Fuel Plants, Information Brochure, ATF P5000.4, July 1980 .

Bureau of Alcohol, Tobacco, and Firearms, Distilled Spirits for Fuel Use, Informational Brochure, ATF P 5000.5, July 1980.

\section{TRANSPORTATION USE}

"Adapting Ethanol Fuels to Diesel Engines," Gasohol $U S A$, vol. 3, no. 8, pp. 12-15, 37, August 1981.

"Alternative Fuels," Society of Automotive Engineers, Inc., Warrendale, PA SAE Special Publication, SP-480, February 1981, $260 \mathrm{pp}$.

Davison, R. R. and Harris, W. B., "Converting Vehicles to Neat Alcohol," Alcohol USA, vol. 3, no. 2, pp. 10-12, February 1981.

Kampen, W. H., "Engines Run Well on Alcohols, Hydrocarbon Processing, vol. 59, no. 2, pp. 72-75, February 1980.

Keller, J. L., “Alcohols as Motor Fuel?,” Hydrocarbon Processing, vol. 58, no. 5, pp. 127-138, May 1979.

Kirik, M., "Conversion of Engines to Run on Fuel Alcohol," Alcohol USA, vol. 3, no. 6, pp. 17-20, 42, June 1981.

Knapp, Connie L., Alcohol-Gasoline Blends as Vehicular Fleet Fuels; Summaries of Blended Fuel Usage by 26 Vehicular Fleets, SERI, September 1981. Available from: the Superintendent of Documents, U.S. Government Printing Office, Washington, DC 20402. Stock no. 061-000-00558-7, \$3.75.

Use of Alcohol and Gasoline in Farm Engines, Rutan Publishing, Minneapolis, MN, 100 pp., 1980.

* National Technical Information Service (NTIS) U.S. Department of Commerce 5785 Port Royal Road Springfield, VA 22161 


\section{APPENDIX G}

\section{Glossary}


ACID HYDROLYSIS: decomposition or alteration of a chemical substance by acid.

ACIDITY: the measure of how many hydrogen ions a solution contains.

AFLATOXIN: the substance produced by some strains of the fungus Aspergillus Flavus; a potent carcinogen; a persistent contaminant of corn that renders crops unsalable.

ALCOHOL: the family name of a group of organic chemical compounds composed of carbon, hydrogen, and oxygen; a series of molecules that vary in chain length and are composed of a hydrocarbon plus a hydroxyl group, $\mathrm{CH}_{3}-\left(\mathrm{CH}_{2}\right) \mathrm{n}-\mathrm{OH}$; includes methanol, ethanol, isopropyl alcohol, and others.

ALDEHYDES: any of a class of highly reactive organic chemical compounds obtained by oxidation of primary alcohols, characterized by the common group $\mathrm{CHO}$, and used in the manufacture of resins, dyes, and organic acids.

ALKALI: soluble mineral salt of a low density, low melting point, highly reactive metal; characteristically "basic" in nature.

ALPHA-AMYLASE - AMYLASE: enzyme which converts starch into sugars.

AMBIENT: the prevalent surrounding conditions usually expressed as functions of temperature, pressure, and humidity.

AMINO ACIDS: the naturally-occurring, nitrogencontaining building blocks of protein.

AMYLODEXTRINS: see Dextrins.

ANAEROBIC DIGESTION: without air; a type of bacterial degradation of organic matter that occurs only in the absence of air (oxygen).

ANHYDROUS: a compound that does not contain water either absorbed on its surface or as water of crystallization.

ATMOSPHERIC PRESSURE: pressure of the air (and atmosphere surrounding us) which changes from day to day; it averages 14.7 psia.

AZEOTROPE: the chemical term for two liquids that, at a certain concentration, boil at the same temperature; alcohol and water cannot be separated further than 194.4 proof because at this concentration, alcohol and water form an azeotrope and vaporize together.
AZEOTROPIC DISTILLATION: distillation in which a substance is added to the mixture to be separated in order to form an azeotropic mixture with one or more of the components of the original mixture; the azeotrope formed will have a boiling point different from the boiling point of the original mixture which will allow separation to occur.

BALLING HYDROMETER OR BRIX HYDROMETER: a triple-scale wine hydrometer designed to record the specific gravity of a solution containing sugar.

BARREL: a liquid measure equal to 42 American gallons or about 306 pounds; one barrel equals 5.6 cubic feet or 0.159 cubic meters; for crude oil, one barrel is about 0.136 metric tons, 0.134 long tons, and 0.150 short tons.

BASIC HYDROLYSIS: decomposition or alteration of a chemical substance by alkali (basic) solution.

BATCH FERMENTATION: fermentation conducted from start to finish in a single vessel.

BATF: Bureau of Alcohol, Tobacco, and Firearms; under the U.S. Department of Treasury. Responsible for the issuance of permits, both experimental and commercial, for the production of alcohol.

BEER: the product of fermentation by microorganisms; the fermented mash, which contains about $11-12 \%$ alcohol; usually refers to the alcohol solution remaining after yeast fermentation of sugars.

BEER STILL: the stripping section of a distillation column for concentrating ethanol.

BEER WELL: the surge tank used for storing beer prior to distillation.

BETA - AMYLASE: see Amylase.

BIOMASS: plant material, includes cellulose carbohydrates, ligniferous constituents, etc.

BOILING POINT: the temperature at which the transition from the liquid to the gaseous phase occurs in a pure substance at fixed pressure.

BRITISH THERMAL UNIT (Btu): the amount of heat required to raise the temperature of one pound of water one degree Fahrenheit under stated conditions of pressure and temperature (equal to 252 calories, 778 foot-pounds, 1,055 joules, and 0.293 watt-hours); it is the standard unit for measuring quantity of heat energy. 
BULK DENSITY: the mass (weight) of a material divided by the actual volume it displaces as a whole substance expressed in $\mathrm{lb} / \mathrm{ft}^{3} ; \mathrm{kg} / \mathrm{m}^{3}$; etc.

CALORIE: the amount of heat required to raise one gram of water one degree centigrade.

CARBOHYDRATE: a chemical term describing compounds made up of carbon, hydrogen, and oxygen; includes all starches and sugars.

CARBON DIOXIDE: a gas produced as a by-product of fermentation; chemical formula is $\mathrm{CO}_{2}$.

CASSAVA: a starchy root crop used for tapioca; can be grown on marginal croplands along the southern coast of the United States.

CELL RECYCLE: the process of separating yeast from fully fermented beer and returning it to ferment a new mash; can be done with clear worts in either batch or continuous operations.

CELLULASE: an enzyme capable of splitting cellulose.

CELLULOSE: the main polysaccharide in living plants forms the skeletal structure of the plant cell wall; can be hydrolyzed to glucose.

CELSIUS (Centigrade): a temperature scale commonly used in the sciences; at sea level, water freezes at $0^{\circ} \mathrm{C}$ and boils at $100^{\circ} \mathrm{C}$.

CENTRIFUGE: a rotating device for separating liquids of different specific gravities or for separating suspended colloidal particles according to particlesize fractions by centrifical force.

CHLOROPLAST: a small portion of a plant cell which contains the light-absorbing pigment chlorophyll, and converts light energy to chemical energy.

COLUMN: vertical, cylindrical vessel used to increase the degree of separation of liquid mixtures by distillation or extraction.

COMPOUND: a chemical term denoting a combination of two or more distinct elements.

CONCENTRATION: ratio of mass or volume of solute present in a solution to the amount of solvent.

CONDENSER: a heat-transfer device that reduces a thermodynamic fluid from its vapor phase to its liquid phase.

CONTINUOUS FERMENTATION: a steady-state fermentation system that operates without interrup- tion; each stage of fermentation occurs in a separate section of the fermenter, and flow rates are set to correspond with required residence times.

COOKER: a tank or vessel designed to cook a liquid or extract or digest solids in suspension; the cooker usually contains a source of heat; and is fitted with an agitator.

COPRODUCTS: the resulting substances and materials that accompany the production of ethanol by fermentation process.

DDGS: see Distiller Dried Grains with Solubles.

DEHYDRATION: the removal of $95 \%$ or more of the water from any substance by exposure to high temperature or chemical action.

DENATURANT: a substance that makes ethanol unfit for human consumption.

DENATURE: the process of adding a substance to ethyl alcohol to make it unfit for human consumption; the denaturing agent may be gasoline or other substances specified by the Bureau of Alcohol, Tobacco, and Firearms.

DEPARTMENT OF ENERGY: in October 1977, the Department of Energy (DOE) was created to consolidate the multitude of energy-oriented government programs and agencies; the Department carries out its mission through a unified organization that coordinates and manages energy conservation, supply development, information collection and analysis, regulation, research, development, and demonstration.

DESICCANT: a substance having an affinity for water; used for drying purposes.

DEWATERING: to remove the free water from a solid substance.

DEXTRINS: a polymer of glucose which is intermediate in complexity between starch and maltose formed by hydrolysis of starches.

DEXTROSE: the same as glucose.

DISACCHARIDES: the class of compound sugars which yield two monosaccharide units upon hydrolysis; examples are sucrose, mannose, and lactose.

DISPERSION: the distribution of finely divided particles in a medium.

DISTILLATE: that portion of a liquid which is removed as a vapor and condensed during a distillation process. 
DISTILLATION: the process of separating the components of a mixture by differences in boiling point; a vapor is formed from the liquid by heating the liquid in a vessel and successively collecting and condensing the vapors into liquids.

DISTILLERS DRIED GRAINS (DDG): the dried distillers grains by-product of the grain fermentation process which may be used as a high-protein $(28 \%)$ animal feed. (See distillers grains.)

DISTILLERS DRIED GRAINS WITH SOLUBLES (DDGS): a grain mixture obtained by mixing distillers dried grains and distillers dried solubles.

DISTILLERS DRIED SOLUBLES (DDS): a mixture of water-soluble oils and hydrocarbons obtained by condensing the thin stillage fraction of the solids obtained from fermentation and distillation processes.

DISTILLERS FEEDS: primary fermentation products resulting from the fermentation of cereal grains by the yeast Saccharomyces cerevisiae.

DISTILLERS GRAIN: the nonfermentable portion of a grain mash comprised of protein, unconverted carbohydrates and sugars, and inert material.

ENRICHMENT: the increase of the more volatile component in the condensate of each successive stage above the feed plate.

ENSILAGE: immature green forage crops and grains which are preserved by alcohol formed by an anaerobic fermentation process.

ENZYMES: the group of catalytic proteins that are produced by living microorganisms; enzymes mediate and promote the chemical processes of life without themselves being altered or destroyed.

ETHANOL: $\mathrm{C}_{2} \mathrm{H}_{5} \mathrm{OH}$; the alcohol product of fermentation that is used in alcohol beverages and for industrial purposes; chemical formula blended with gasoline to make gasohol; also known as ethyl alcohol or grain alcohol.

ETHYL ALCOHOL: also known as ethanol or grain alcohol; see Ethanol.

EVAPORATION: conversion of a liquid to the vapor state by the addition of latent heat of vaporization.

FACULTATIVE (ANAEROBE): a microorganism that grows equally well under aerobic and anaerobic conditions.

FAHRENHEIT SCALE: a temperature scale in which the boiling point of water is $212^{\circ}$ and its freezing point $32^{\circ}$; to convert ${ }^{\circ} \mathrm{F}$ to ${ }^{\circ} \mathrm{C}$, subtract 32 , multiply by 5 , and divide the product by 9 (at sea level).

FEED PLATE: the theoretical position in a distillation column above which enrichment occurs and below which stripping occurs.

FEEDSTOCK: the base raw material that is the source of sugar for fermentation.

FERMENTABLE SUGAR: sugar (usually glucose) derived from starch and cellulose that can be converted to ethanol (also known as reducing sugar or monosaccharide).

FERMENTATION: a microorganically mediated enzymatic transformation of organic substances, especially carbohydrates, generally accompanied by the evolution of a gas.

FERMENTATION ETHANOL: ethyl alcohol produced from the enzymatic transformation of organic substances.

FLASH HEATING: very rapid heating of material by exposure of small fractions to temperature and using high flow rates.

FLASH POINT: the temperature at which a combustible liquid will ignite when a flame is introduced; anhydrous ethanol will flash at $51^{\circ} \mathrm{F}, 90$-proof ethanol will flash at $78^{\circ} \mathrm{F}$.

FLOCCULATION: the aggregation of fine suspended particles to form floating clusters or clumps.

FOSSIL FUEL: any naturally occurring fuel of an organic nature such as coal, crude oil, or natural gas.

FRACTIONAL DISTILLATION: a process of separating alcohol and water (or other mixtures).

FRUCTOSE: a fermentable monosaccharide (simple) sugar of chemical formula $\mathrm{C}_{6} \mathrm{H}_{12} \mathrm{O}_{6}$. Fructose and glucose are optical isomers; that is, their chemical structures are the same but their geometric configurations are mirror images of one another.

FUSEL OIL: a clear, colorless, poisonous liquid mixture of alcohols obtained as a byproduct of grain fermentation; generally amyl, isoamyl, propyl, isopropyl, butyl, isobutyl alcohols and acetic and lactic acids.

GASOHOL (Gasahol): registered trade names for a blend of $90 \%$ unleaded gasoline with $10 \%$ fermentation ethanol. 
GASOLINE: a volatile, flammable liquid obtained from petroleum that has a boiling range of approximately $29^{\circ}-216^{\circ} \mathrm{C}$ and is used as fuel for sparkignition internal combustion engines.

GELATINIZATION: the rupture of starch granules by temperature which forms a gel of soluble starch and dextrins.

GLUCOSE: a monosaccharide; occurs free or combined and is the most common sugar; chemical formula $\mathrm{C}_{6} \mathrm{H}_{12} \mathrm{O}_{6}$.

GLUCOSIDASE: an enzyme that hydrolyzes any polymer of glucose monomers (glucoside). Specific glucosidases must be used to hydrolyze specific glucosides; e.g., B-glucosidases are used to hydrolyze cellulose; $\alpha$-glucosidases are used to hydrolyze starch.

GRAIN ALCOHOL: see Ethanol.

HEAT EXCHANGER: a device that transfers heat from one fluid (liquid or gas) to another, or to the environment.

HEAT OF CONDENSATION: the same as the heat of vaporization, except that the heat is given up as the vapor condenses to a liquid at its boiling point.

HEAT OF VAPORIZATION: the heat input required to change a unit mass of liquid at its boiling point (water at $212^{\circ} \mathrm{F}$ ) to a vapor at the same temperature $\left(212^{\circ} \mathrm{F}\right)$.

HEATING VALUE: the amount of heat obtainable from a fuel and expressed, for example, in Btu/lb.

HEXOSE: any of various simple sugars that have six carbon atoms per molecule.

HYDRATED: chemically combined with water.

HYDROCARBON: a chemical compound containing hydrogen, oxygen, and carbon.

HYDROLYSIS: the decomposition or alteration of a polymeric substance by chemically adding a water molecule to the monomeric unit at the point of bonding.

HYDROMETER: a long-stemmed glass tube with a weighted bottom; it floats at different levels depending on the relative weight (specific gravity) of the liquid; the specific gravity of other information is read where the calibrated stem emerges from the liquid.

INDOLENE: a chemical used in comparative tests of automotive fuels.
INOCULUM: a small amount of bacteria produced from a pure culture which is used to start a new culture.

INULIN: a polymeric carbohydrate comprised of fructose monomers found in the roots of many plants, particularly Jerusalem artichokes.

LACTIC ACID: $\mathrm{C}_{3} \mathrm{H}_{6} \mathrm{O}_{3}$, the acid formed from milk sugar (lactose) and produced as a result of fermentation of carbohydrates by bacteria called Lactobaccilus.

LACTOSE: a white crystalline disaccharide made from whey and used in pharmaceuticals, infant foods, bakery products, and confections; also called "milk sugar", $\mathrm{C}_{12} \mathrm{H}_{22} \mathrm{O}_{11}$.

LEADED GASOLINE: gasoline containing tetraethyllead to raise octane value.

LIGNIFIED CELLULOSE: cellulose polymer wrapped in a polymeric sheath extremely resistant to hydrolysis because of the strength of its linkages called lignin.

LINKAGE: the bond or chemical connection between constituents of a polymeric molecule.

LIQUEFACTION: the change in the phase of a substance to the liquid state; in the case of fermentation, the conversion of water-insoluble carbohydrate to water-soluble carbohydrate.

MALT: barley softened by steeping in water, allowed to germinate, and used especially in brewing and distilling.

MASH: a mixture of grain and other ingredients with water to prepare wort for brewing operations.

MEAL: a granular substance produced by grinding.

MEMBRANE: a polymer sheet capable of separating liquid solutions.

METHANOL: a light volatile, flammable, poisonous, liquid alcohol, $\mathrm{CH}_{3} \mathrm{OH}$, formed in the destructive distillation of wood or made synthetically and used especially as a fuel, a solvent, an antifreeze, or a denaturant for ethyl alcohol, and in the synthesis of other chemicals; methanol can be used as fuel for motor vehicles; also known as methyl alcohol or wood alcohol.

METHYL ALCOHOL: also known as methanol or wood alcohol; see Methanol. 
MOLECULAR SEIVE: a column which separates molecules by selective adsorption of molecules on the basis of size.

MOLECULE: the chemical term for the smallest particle of matter that is the same chemically as the whole mass.

MONOMER: a simple molecule which is capable of combining with a number of like or unlike molecules to form a polymer.

MONOSACCHARIDES: see Fermentable Sugar.

OCTANE NUMBER: a rating which indicates the tendency to knock when a fuel is used in a standard internal combustion engine under standard conditions.

OSMOTIC PRESSURE: pressure required to prevent passage of a solvent across a membrane which separates solutions of different concentrations.

OSMOPHYLLIC: organisms which prosper in solutions with high osmotic pressure.

PACKED DISTILLATION COLUMN: a column or tube constructed such that a packing of ceramics, steel, copper, or fiberglass-type material.

pH: a term used to describe the free hydrogen ion concentration of a system; a solution of pH 0 to 7 is acid; $\mathrm{pH}$ of 7 is neutral; $\mathrm{pH}$ over 7 to 14 is alkaline.

PLATE DISTILLATION COLUMN (Sieve tray column): a distillation column constructed with perforated plates or screens.

POLYMER: a substance made of molecules comprised of long chains or cross-linked simple molecules.

POUNDS PER SQUARE INCH ABSOLUTE (psia): the measurement of pressure referred to a complete vacuum or 0 pressure.

POUNDS PER SQUARE INCH GUAGE (psig): expressed as a quantity measured from above atmospheric pressure.

POUND OF STEAM: one pound (mass) of water in the vapor phase not to be confused with the steam pressure which is expressed in pounds per square inch.

PRACTICAL YIELD: the amount of product that can actually be derived under normal operating conditions; i.e., the amount of sugar that normally can be obtained from a given amount of starch or the amount of alcohol that normally can be obtained is usually less than theoretical yield.

PROOF: a measure of ethanol content; 1 percent equals 2 proof.

PROOF GALLON: a U.S. gallon of liquid which is $50 \%$ ethyl alcohol by volume; also one tax gallon.

PROTEIN: any of a class of high molecular weight polymer compounds comprised of a variety of amino acids joined by a peptide linkage.

PYROLYSIS: the breaking apart of complex molecules into simpler units by heating in the absence of sufficient quantities of oxygen.

QUAD: one quadrillion $\left(10^{15}\right.$ or $\left.1,000,000,000,000,000\right)$ Btu's (British thermal units).

RECTIFICATION: with regard to distillation, the selective increase of the concentration of the lower volatile component in a mixture by successive evaporation and condensation.

RECTIFYING COLUMN: the portion of a distillation column above the feed tray in which rising vapor is enriched by interaction with a countercurrent falling stream of condensed vapor.

REFLUX: that part of the product stream that may be returned to the process to assist in giving increased conversion or recovery.

RELATIVE DENSITY: see Specific Gravity.

RENEWABLE RESOURCES: renewable energy; resources that can be replaced after use through natural means; example: solar energy, wind energy, energy from growing plants.

ROAD OCTANE: a numerical value for automotive anti-knock properties of a gasoline; determined by operating a car over a stretch of level road.

SACCHARIFY: to hydrolyze a complex carbohydrate into a simpler soluble fermentable sugar, such as glucose or maltose.

SACCHAROMYCES: a class of single-cell yeasts which selectively consume simple sugars.

SCRUBBING EQUIPMENT: equipment for countercurrent liquid-vapor contact of flue gases to remove chemical contaminants and particulates.

SETTLING TIME: in a controlled system, the time re- 
quired for entrained or colloidal material to separate from the liquid.

SIGHT GAUGE: a clear calibrated cylinder through which liquid level can be observed and measured.

SIMPLE SUGARS: see Fermentable Sugars.

SOLAR ENERGY RESEARCH INSTITUTE (SERI): the Solar Energy Research Development and Demonstration Act of 1974 called for the establishment of SERI, whose general mission is to support DOE's solar energy program and foster the widespread use of all aspects of solar technology, including direct solar conversion (photovoltaics), solar heating and cooling, solar thermal power generation, wind conversion, ocean thermal conversion, and biomass conversion.

SPECIFIC GRAVITY: the ratio of the mass of a solid or liquid to the mass of an equal volume of distilled water at $4^{\circ} \mathrm{C}$.

SPENT GRAINS: the nonfermentable solids remaining after fermentation of a grain mash.

STARCH: a carbohydrate polymer comprised of glucose monomers linked together by a glycosidic bond and organized in repeating units; starch is found in most plants and is a principal energy storage product of photosynthesis; starch hydrolyzes to several forms of dextrin and glucose.

STILL: an apparatus for distilling liquids, particularly alcohols; it consists of a vessel in which the liquid is vaporized by heat, and a cooling device in which the vapor is condensed.

STILLAGE: the nonfermentable residue from the fermentation of a mash to produce alcohol.

STOVER: the dried stalks and leaves of a crop remaining after the grain has been harvested.
STRIPPING SECTION: the section of a distillation column below the feed in which the condensate is progressively decreased in the fraction of more volatile component by stripping.

SUCROSE: a crystalline disaccharide carbohydrate found in many plants, mainly sugar cane, sugar beets, and maple trees; $\mathrm{C}_{12} \mathrm{H}_{22} \mathrm{O}_{11}$.

THERMOPHYLLIC: capable of growing and surviving at high temperatures.

THIN STILLAGE: the water-soluble fraction of a fermented mash plus the mashing water.

VACUUM DISTILLATION: the separation of two or more liquids under reduced vapor pressure; reduces the boiling points of the liquids being separated.

VAPORIZE: to change from a liquid or a solid to a vapor, as in heating water to steam.

VAPOR PRESSURE: the pressure at any given temperature of a vapor in equilibrium with its liquid or solid form.

WHOLE STILLAGE: the undried "bottoms" from the beer well comprised of nonfermentable solids, distillers solubles, and the mashing water.

WOOD ALCOHOL: see Methanol.

WORT: the liquid remaining from a brewing mash preparation following the filtration of fermentable beer.

YEAST: single-cell microorganisms (fungi) that produce alcohol and $\mathrm{CO}_{2}$ under anaerobic conditions and acetic acid and $\mathrm{CO}_{2}$ under aerobic conditions; the microorganism that is capable of changing sugar to alcohol by fermentation.

ZYMOSIS: see Fermentation. 


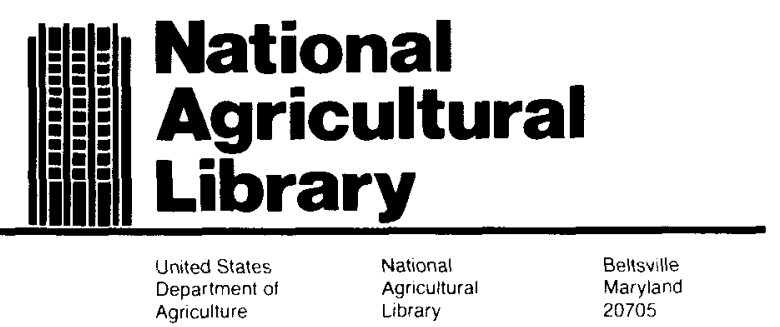

